University of Rhode Island

DigitalCommons@URI

Open Access Dissertations

1992

\title{
Infared Spectral Measurement of Space Shuttle Glow
}

Mark Ahmadjian

University of Rhode Island

Follow this and additional works at: https://digitalcommons.uri.edu/oa_diss

\section{Recommended Citation}

Ahmadjian, Mark, "Infared Spectral Measurement of Space Shuttle Glow" (1992). Open Access

Dissertations. Paper 517.

https://digitalcommons.uri.edu/oa_diss/517

This Dissertation is brought to you for free and open access by DigitalCommons@URI. It has been accepted for inclusion in Open Access Dissertations by an authorized administrator of DigitalCommons@URI. For more information, please contact digitalcommons@etal.uri.edu. 
INFRARED SPECTRAL MEASUREMENT OF

SPACE SHUTTLE GLOW

BY

MARK AHMADJIAN

A DISSERTATION SUBMITTED IN PARTIAL FULFILLMENT OF THE REQUIREMENTS FOR THE DEGREE OF DOCTOR OF PHILOSOPHY

IN

CHEMISTRY

UNIVERSITY OF RHODE ISLAND

1992 


\section{ABSTRACT}

Infrared spectral measurements of the space shuttle glow were successfully conducted during the STS-39 space shuttle mission. Analysis indicates that $\mathrm{NO}, \mathrm{NO}^{+}, \mathrm{OH}$, and co are among the molecules associated with the infrared glow phenomenon. During orbiter thruster firings the glow intensities in the infrared are enhanced by factors of $10 x$ to $100 x$ with significant changes in spectral distribution.

These measurements were obtained with the spacecraft

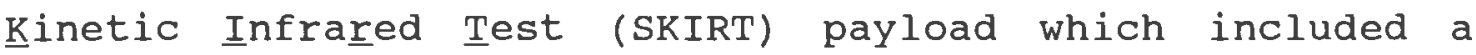
cryogenic infrared circular variable filter (CVF) spectrometer $(0.6 \mu \mathrm{m}$ to $5.4 \mu \mathrm{m})$ and a number of infrared, visible, and ultraviolet radiometers $(0.2 \mu \mathrm{m}$ to $5.4 \mu \mathrm{m}$ and $9.9 \mu \mathrm{m}$ to $10.4 \mu \mathrm{m})$. In addition, glow measurements were unsuccessfully attempted with the cryogenic Infrared Radiance Instrumentation for shuttle (CIRRIS-1A) with its $2.5 \mu \mathrm{m}$ to $25 \mu \mathrm{m}$ Fourier transform interferometer.

SKIRT CVF obtained over 14,000 spectra of quiescent shuttle glow, thruster enhanced shuttle glow, upper atmosphere airglow, aurora, orbiter environment, and deep space non-glow backgrounds during its eight day mission. The SKIRT radiometers operated almost continuously throughout the mission to provide a detailed history of the IR/VIS/UV optical environment associated with the operation of large spacecraft structures in low earth orbit. This dissertation will primarily address those measurements conducted by the 
SKIRT spectrometer as they relate to space shuttle glow in the infrared.

The STS-39 Space Shuttle Discovery was launched from the NASA Kennedy Space Center on 28 April 1991 into a 57 degree inclination circular orbit at an altitude of $260 \mathrm{~km}$. 
This research was conducted primarily at the optical Environment Division, Geophysics Directorate (formerly Air Force Geophysics Laboratory), Phillips Laboratory, Air Force systems Command, U.S. Air Force, Hanscom Air Force Base, Massachusetts. Space shuttle experiment payload ground operations and flight operations were conducted at NASA Goddard space Flight center in Greenbelt, Maryland; NASA Kennedy space Center and Cape Canaveral Air Force station in Cape Canaveral, Florida; NASA Johnson space center in Houston, Texas; and on board the STS-39 space shuttle Discovery while in orbit around the Earth.

Engineering contractual support was provided by the Space Dynamics Laboratory of Utah State University in Logan, Utah, Space systems Engineering Inc. in Logan, Utah, and Physical Sciences Inc. in Andover, Massachusetts under U.S. Air Force Contracts F19628-88-C-0069 and F19628-81-C-0123. NASA in house technical support was funded by the Laboratory for Extraterrestrial Physics at NASA Goddard space Flight Center. Flight operations and sensor calibration support were provided by Space and Environment Technology Center of The Aerospace Corporation at Los Angeles Air Force Base, Los Angeles, California under U.S. Air Force Contract F04701-88C-0089. Integration and flight operations support were provided by the NASA Goddard space Flight center Hitchhiker 
office with funding provided by the Air Force systems Command HQ Space Systems Division's Space Test Program.

specific acknowledgements are given to Dr. Carl Rice of The Aerospace Corporation and Dr. Micheal Mumma of NASA Goddard space Flight Center who provided support in all areas of the SKIRT program; Brent Dix, Gary Frodsham, John Frodsham and Robert olsen of Space Systems Engineering Inc. for fabrication, testing, integration, and flight operations of the SKIRT CVF spectrometer assembly; Dr. Allan steed and Jim Ulwick of Utah state University for their contractual support; Dr. David Green, Dana Trembley, and George Sacco of Physical Sciences Inc. for the fabrication, qualification, and flight operations of the SKIRT GLOS radiometer assemblies; Jack Griffin and Russ steeves of the Aerospace Engineering Division of the Phillips Laboratory for their engineering reviews of the SKIRT designs; Col Alan Blackburn, Dr. William Blumberg, Dr. R. Earl Good, Dr. Duane Paulsen, Marion Peko, Dr. Stephan Price, Robert Raistrick, Dr. A.J. Ratkowski, Francis Robert, and Dr. Ramesh Sharma of the Phillips Laboratory Geophysics Directorate for their overall support; Chuck Chidekel, Girard Durback, Ted Goldsmith, and Debbie Knapp of NASA GSFC for integration and flight operations; Rick Agardy of The Aerospace Corporation for his planning of the most complex payload timeline yet flown by a space shuttle; Dr. Ray Russell of The Aerospace Corporation for calibration and flight operations support; 
Vic Gehr of Omitron for pre-flight and real time on orbit planning; Sue Sheffield of Rockwell International for ensuring we were correctly plugged into the orbiter; Maj $\mathrm{G}$. Scott Yeakel of the U.S. Air Force (assigned to the U.S. Department of state) for his flight operations support; Dr. Randall Murphy of Research Sciences Corporation (formerly my supervisor at the Air Force Gephysical Laboratory) who suggested this investigation for my Doctoral Dissertation; Dr. A.T. Stair, Jr. of the U.S. Air Force scientific Advisory Board (formerly Chief Scientist at the Air Force Geophysical Laboratory) who was my mentor when I first started out as a USAF 2Lt; Rebecca Healey of YAP Analytics for generating atmospheric radiances codes to help interpret the SKIRT data; Dr. Russell Armstrong of Mission Research Corporation for providing spectra of excited molecules from previous rocket missions; Nelson Bonito of RADEX for generating orbiter ephemeris and ancillary data; the STS-39 flight crew Capt Micheal L. Coats, USN (Commander), Ltcol Blaine Hammand, Jr., USAF (Pilot), Gregory J. Harbaugh (MS), Richard J. Hieb (MS), Don McMonagle (MS), and especially Col Guion S. Bluford, USAF (MS), and LtCol Charles Lacy Veach, ANG, (MS); and the hundreds of U.S. Air Force, NASA, and contractor support personnel around the world.

I give special acknowledgement to Dr. Donald Jennings of NASA Goddard space Flight center. We demonstrated how the Department of Defense and NASA can combine resources to 
conduct a space experiment even though we have different agency charters.

I thank my Committee: Dr. Phyllis R. Brown, Dr. Ken R. Force, Dr. Joeseph G. Turcotte, and Dr. Mason P. Wilson, Jr. and my Department Chairman, Dr. James L. Fasching, and Deans, Dr. Robert B. Turcotte and Dr. Vincent C. Rose for allowing me to conduct this research at U.S. Air Force and NASA laboratories.

Finally, I thank my Major Professor and a best friend, Dr. Chris w. Brown. I took my first undergraduate P. Chem course from him in 1970, did undergraduate research under him in 1972-73, had my first publication with him in 1973, was one of his Research Associates from 1973-80, had him as my Major Professor for the Masters Degree in 1987, and have been with him out on the high seas and all over the country. We have applied analytical infrared spectroscopy to the oceans, land, air, and now to the edge of our planet's atmosphere. It has been a series of exciting adventures and a wonderful association. 


\section{Preface}

This work was conducted under the auspices of the United States Air Force, Department of Defense, United states of America. The performing organization is the Optical Environment Division, Geophysics Directorate, Phillips Laboratory, Air Force systems Command, U.S. Air Force, Hanscom AFB, Massachusetts. The In House Work Unit is 30540119 Spacecraft Kinetic Infrared Test (SKIRT). The Work Unit Manager and Task Scientist is Mark Ahmadjian.

The contents of this Ph.D. Dissertation "Infrared Spectral Measurement of space shuttle Glow" have received security reviews by U.S. Air Force Public Affairs at the Phillips Laboratory Geophysics Directorate, HQ Electronic Systems Division, HQ Space systems Division, and by the Strategic Defense Initiative Organization Public Affairs. It is unclassified and cleared for public release under the following clearance numbers:

$\begin{array}{ll}\text { ESD } 89-875 & \text { ESD } 91-1755 \\ \text { ESD } 89-1732 & \text { HQ SSD/PAS } 10317 \\ \text { ESD } 90-1623 & \text { HQ SSD/PAS } 10822 \\ \text { ESD } 90-1881 & \\ \text { ESD } 91-1139 & \\ \text { ESD } 91-1307 & \\ \text { ESD } 91-1308 & \\ \text { ESD } 91-1568 & \end{array}$


Page

List of Tables........................... $x$

List of figures........................... xi

Introduction.............................. 1

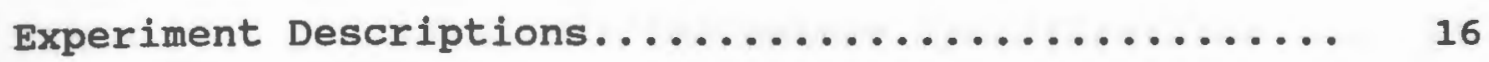

Ground operations....................... 42

Flight operations.......................... 48

Results and Discussion...................... 58

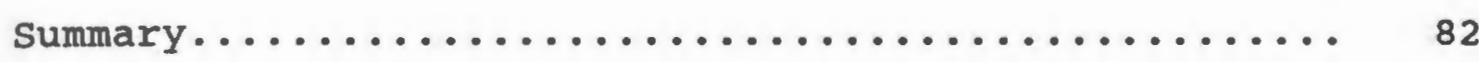

References............................... 83

Appendices.............................. 87

Bibliography.............................. 153 
List of Tables

Page

Table 1.

Number Densities of Neutral Atmospheric

Species at $260 \mathrm{Km}$ Altitude.......... 6

Table 2.

SKIRT CVF/Radiometer Specifications.....20 
List of Figures

Page

Figure 1.

Figure 2 .

Figure 3 .

Figure 4 .

Figure 5 .

Figure 6 .

Figure 7 .

Figure 8 .

Figure 9 .

Figure 10.

Figure 11.

Figure 12.

Figure 13.

Figure 14 .

Figure 15.

Figure 16.

Figure 17.

Figure 18.

Figure 19.

Figure 20.

Figure 21.

Figure 22 .

Figure 23.
Photograph of Space Shuttle Glow....... 2 Concentration of Atmosphere Neutrals.... 3 Concentration of Daytime Positive Ions... 4 Concentration of Nighttime Positive Ions. 5 Laboratory Glow Data Compared with

Shuttle Glow Measurements.......... 11

STs-39 Configuration............ 17

SKIRT/Hitchhiker Configuration........ 18

SKIRT CVF Optical Head............ 21

SKIRT CVF Payload Configuration....... 23

SKIRT CVF/GAS Can............... 24

SKIRT GLOS Payload Configuration...... 27

SKIRT GLOS Exploded View........... 28

SKIRT GLOS Infrared Module Configuration 29

SKIRT GLOS UV/VIS Module........... 30

SKIRT GLOS Power/Telemetry Interfaces... 31

SKIRT GLOS Filters............. 32

CIRRIS-1A Payload.............. 37

Payload in Cargo Bay............. 43

Cryogen Fill schematic............ 45

Cryogen Freeze Schematic.......... 46

Discovery on Launch Pad........... 48

Discovery on Orbit............. 49

Hitchhiker Telemetry Link......... 50 
Figure 24 .

NASA JSC Console.............. 52

Figure 25.

CIRRIS-1A Drawing................ 55

Figure 26.

Shuttle Glow Spectrum - Quiescent..... 58

Figure 27.

Shuttle Glow Spectrum - Enhanced...... 60

Figure 28 .

Earthlimb Airglow................ 62

Figure 29.

Quiescent/Thruster/Earthlimb Compared... 63

Figure 30.

Comparison to No................ 64

Figure 31 .

Comparison to $\mathrm{H}_{2} \mathrm{O} \ldots \ldots \ldots \ldots \ldots \ldots \ldots$

Figure 32 .

Comparison to No and Not........... 34

Figure 33 .

Day Glow/Night Glow............... 68

Figure 34 .

Glow vs Ram Angle.............. 70

Figure 35 .

$5.3 \mu \mathrm{m}$ vs Ram Angle............... 71

Figure 36 .

$2.9,4.5$, and $5.3 \mu \mathrm{m}$ vs Ram Angle..... 72

Figure 37 .

SKIRT GLOS Signal During NO Release.... 74

Figure 38 .

No Decay......................... 75

Figure 39.

Photograph of No Release.......... 76

Figure 40.

NO Release Compared to Laboratory...... 78

Figure 41 .

Ground Based Fast o source......... 79 
space shuttle and spacecraft observations show that vehicles in low earth orbits produce a glow effect above surfaces oriented into the direction of motion ${ }^{1,2}$. The first positive confirmation of this glow phenomenon occurred during post-flight data reduction and analysis of visible photographs from space shuttle mission STS $-3^{3}$ in March of 1982 (Figure 1) with subsequent confirmation on other shuttle flights ${ }^{4}$. STS-3 represents the first unambiguous glow observation and confirmed a number of earlier glow type related observations on satellites that can be traced back to the 1977 Atmosphere Explorer Satellite program5,6.

Based on these orbital observations and earth based laboratory experiments the glow is known to be caused by the interaction of low earth orbit spacecraft, travelling at approximately $8 \mathrm{~km} / \mathrm{sec}$, with high altitude ambient atmosphere.

Figure 2 is a plot of atmospheric neutral species concentration as a function of altitude. Figures 3 and 4 are plots of daytime and nighttime positive ion concentrations as a function of altitude. Specific number densities $\left(\mathrm{m}^{-3}\right)$ of the predominant trace neutral species for a $260 \mathrm{~km}$ orbit as listed in the U.S. Standard Atmosphere, 1976 are presented in Table 1. As can be seen atomic oxygen has the highest concentration followed by molecular nitrogen. 


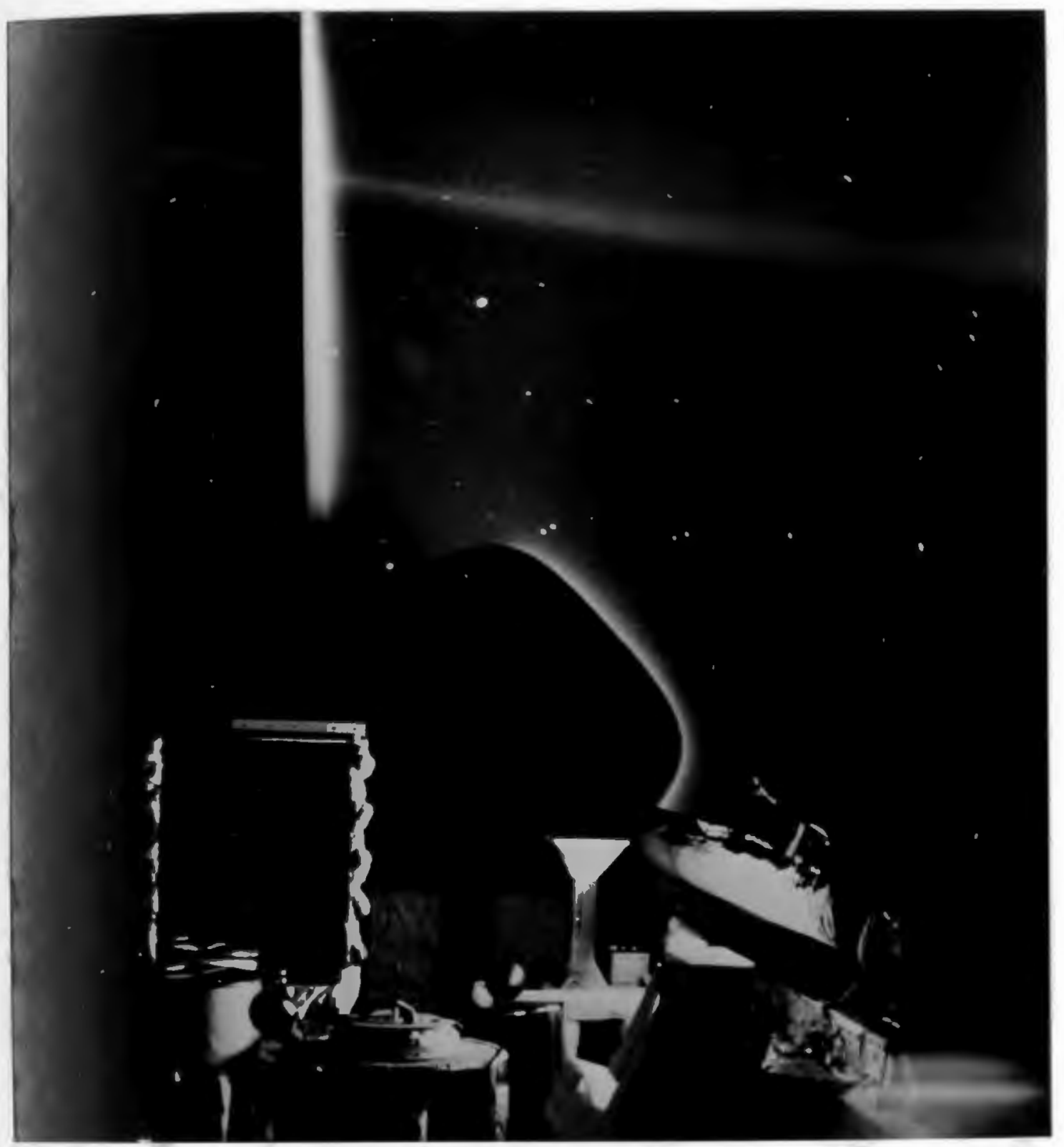

Figure 1. Photograph of space shuttle glow taken from the aft flight deck during STs-3 in 1982. The shuttle was flying such that its port wing was into the velocity vector and the ambient earth atmosphere was impacting the vertical stabilizer and OMS pod. A visible glow is seen above those areas exposed to ram. 
ATMOSPHERIC COMPOSITION

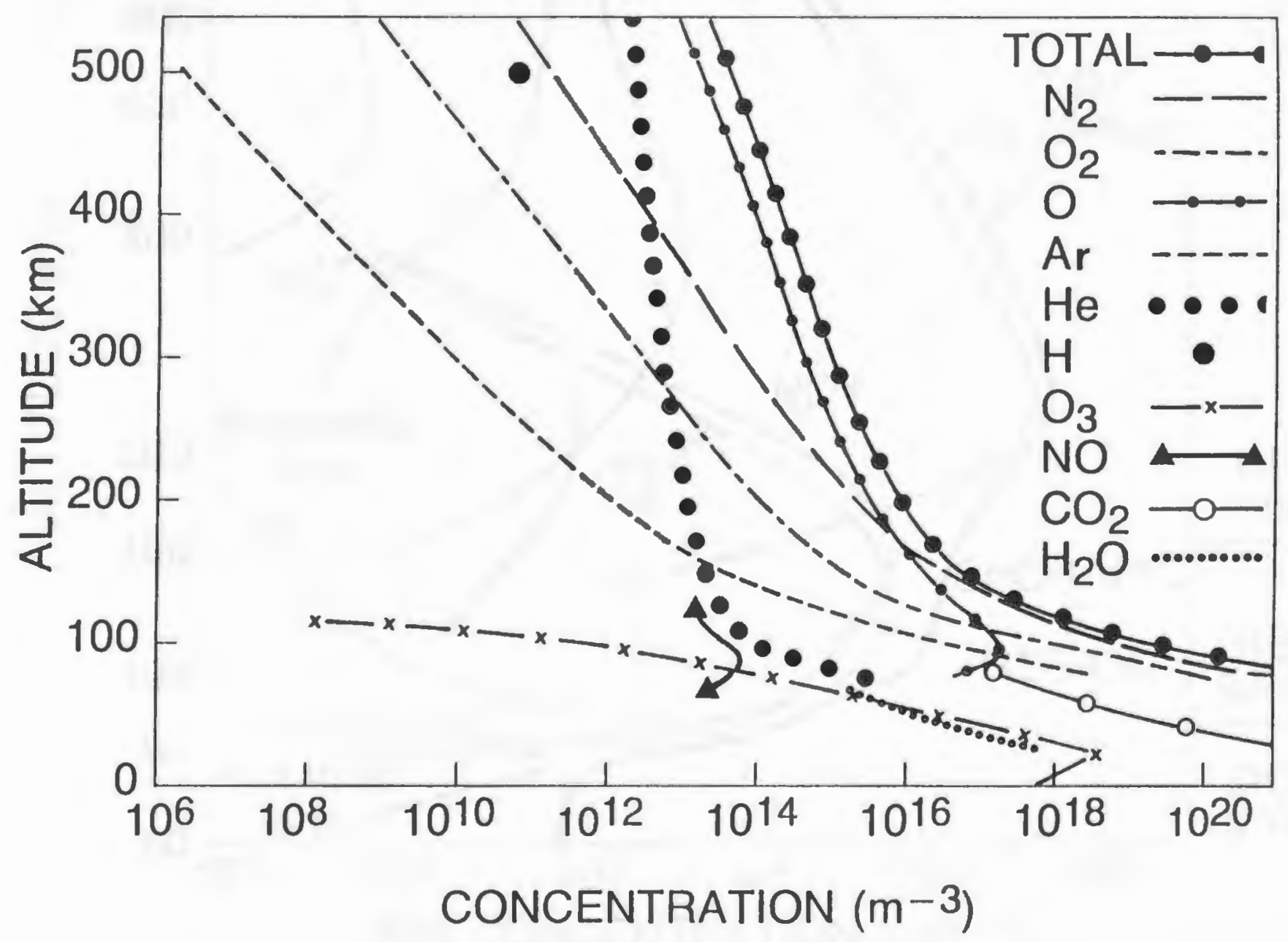

Figure 2. Atmospheric Composition (Neutrals) 


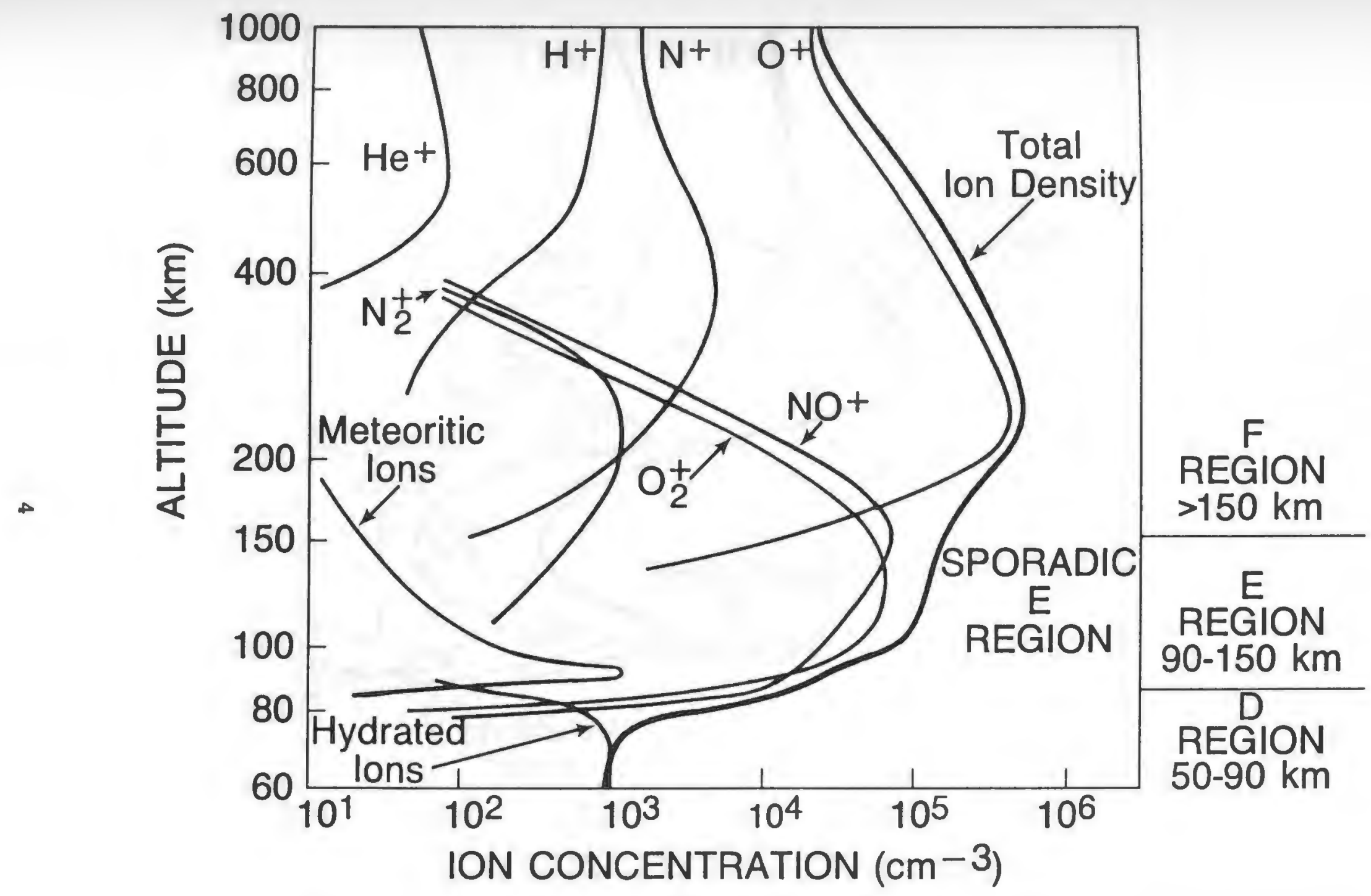

Figure 3. Daytime Atmospheric Positive Ion Composition 


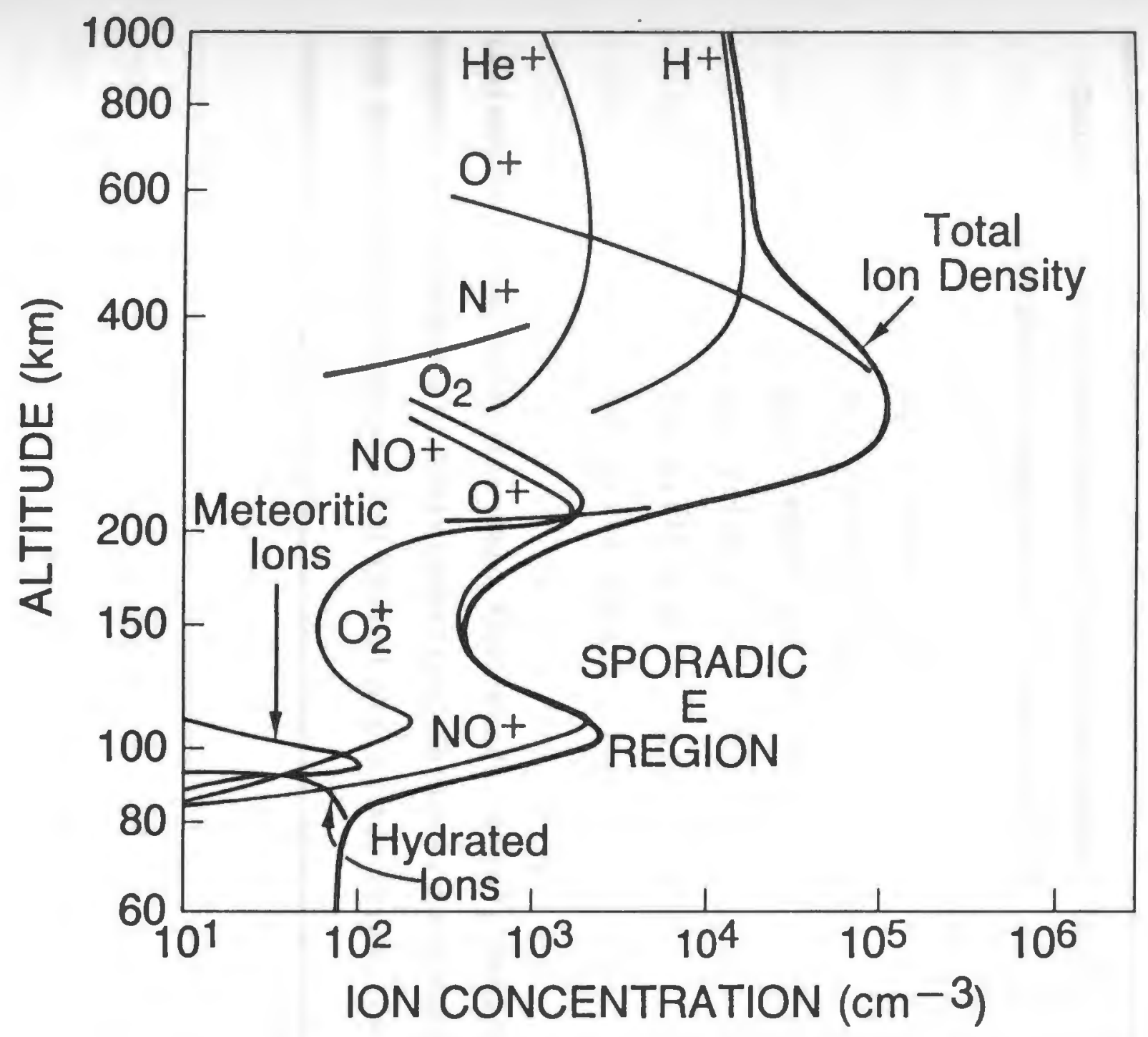

Figure 4. Nighttime Atmospheric Positive Ion Composition 
Table 1. Number Densities $\left(M^{3}\right)$ of Predominant Neutral

\section{Atmospheric Species at $260 \mathrm{~km}$ Altitude}

$$
\begin{aligned}
& \mathrm{O}_{1}: 1.143 \times 10^{15} \\
& \mathrm{O}_{2}: 1.700 \times 10^{13} \\
& \mathrm{~N}_{2}: 3.459 \times 10^{14} \\
& \mathrm{Ar}: 9.658 \times 10^{10} \\
& \mathrm{H}_{1}: 1.167 \times 10^{11} \\
& \mathrm{He}: 9.196 \times 10^{12}
\end{aligned}
$$

(Referenced from "U.S. Standard Atmosphere, 1976", National Oceanic and Atmospheric Administration, National Aeronautics and Space Administration, and United States Air Force, 1976) 
The concentrations of neutrals and ions vary not only as a function of altitude and day/night, but also with geographic latitude and longitude, geomagnetic conditions, solar activity, and solar cycle. In most atmospheric radiance computer models it is necessary to specify these conditions when plotting an altitude radiance profile. In one of the U.S. Air Force computer codes, input parameters such as model atmosphere (1976 standard for example), molecular emitters, solar zenith angle, day/night, latitude, and $k_{p}$ must be specified.

The U.S. Air Force, NASA, NOAA, and other agencies and research groups spend enormous amounts of resources developing atmospheric computer models and conducting analytical measurements from ground based telescopes and radars, aircraft, balloons, rockets, space shuttles, and satellites to update and validate those models. Thus, the concentrations shown in Figures 2,3 , and 4 and Table 1 are representative and are not exact numbers for the specific times, altitude, and solar conditions which existed within the STS -39 orbital environment.

Although the spacecraft glow has been detected on both space shuttles and satellites, the available orbital and laboratory data have been limited for a number of reasons. The execution of an orbital space experiment is a very difficult, long lead, and costly effort; much more so in the aftermath of the space shuttle challenger destruction. In 
regards to earth based laboratory experiments the nonavallability of fast atomic oxygen sources, until recently, prevented ground based studies of atomic oxygen impacting material surfaces at orbital velocities. The realization, by NASA, that atomic oxygen erosion of critical spacecraft surfaces, such as those associated with space station Freedom, has provided the impetus and funding for ground based investigations with the emphasis on material effects. Another deficiency is that the lack of high spectral resolution orbital spacecraft measurement data prevents validation of ground based measurements.

In 1987, as part of its Department of Defense responsibilities for the design and operation of United states military spacecraft, the U.S. Air Force Geophysics Laboratory, allocated funding for on-orbit glow experiments. The purpose was to determine the impact and uses of glow on and for operational space defense assets in the infrared, visible, and ultraviolet regions of the electromagnetic spectrum. Areas of interest include, and are not limited to, infrared, visible, and ultraviolet glow intensities and spectral distribution as a function of spacecraft materials, spacecraft surface temperatures, vehicle attitude, orbital altitude, day/night atmospheric composition, addition of atmospheric and non-atmospheric pre-cursers into the reaction area, determination of glow mechanisms for both gas phase and surface mediated reactions, lifetimes of 
electronically and vibrationally excited states, and other pertinent investigations in support of various applications.

The specific objective of this Ph.D. Dissertation, conducted as a part of the U.S. Air Force's overall Investigation, and as a cooperative effort by the University of Rhode Island, U.S. Air Force, Strategic Defense Initiative Organization, and the National Aeronautics and space Administration (NASA), was to obtain the first infrared spectral measurement of space shuttle glow.

The initial step was to conduct an extensive search of the available civilian and government scientific, engineering, intelligence, and contractual literature and data bases to provide guidance in the experiment objectives, design, and operation.

In the visible spectral region, photographic and hand held spectrophotometer observations from the aft flight decks of space shuttles provided the most extensive data base. Photographs show the glow is most intense from shuttle surfaces which are oriented into the direction of motion and exposed to the impacting ambient atmosphere. Analysis of these visible glows show a measurable orange colored glow extending approximately $20 \mathrm{~cm}$ above ram exposed surfaces and that the intensities decrease with increasing distances from the surfaces. Spectrophotometer measurements, conducted from inside the shuttle crew compartments looking out at ram exposed surfaces, show a spectral continuum from 
approximately $400 \mathrm{~nm}$ to $680 \mathrm{~nm}$ at $3.4 \mathrm{~nm}$ resolution (Figure 5). This data is limited to the visible spectral region by the optical transmission characteristics of the shuttle aft flight deck windows. The source of this glow is thought to be electronically excited nitrogen dioxide $\left(\mathrm{NO}_{2}{ }^{*}\right)$ created by the impact of atmospheric oxygen with nitric oxide (NO) on shuttle surfaces facing the velocity vector ${ }^{8}$. Shuttle crews have also documented an intensity increase in the glow when the orbiter attitude control thruster are fired. These firings are known to generate a number of combustion products which are then part of the ambient orbiter environment for varying time periods. Presumably, these species, when produced near ram exposed surfaces provide a greater than normal amount of glow reaction precursors which in turn leads to a greater amount of reaction with the ambient atmosphere and in turn generates a stronger glow signal. This hypothesis was confirmed by a gas release experiment which also flew on the STS-39 mission and will be addressed as part of the results and discussion.

In the case of low earth orbit satellites, filtered photometers on board Atmosphere Explorers have detected excess radiances under certain orbital altitudes and spacecraft attitudes. Highly vibrationally excited hydroxyl molecules (OH), created by the reaction of spacecraft materials with atomic oxygen, has been proposed as the source of this glow ${ }^{10}$. Also, an ultraviolet glow has been 


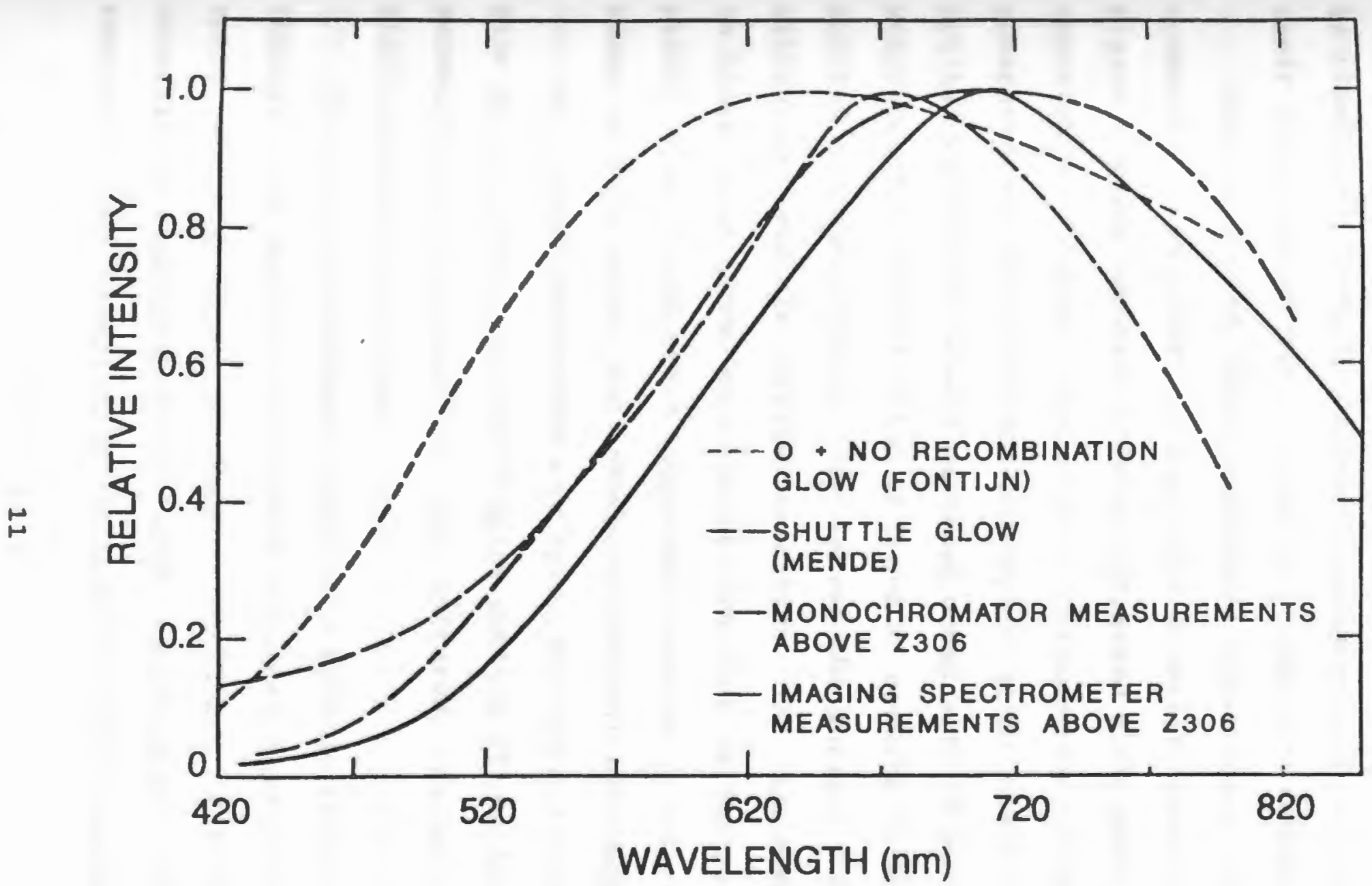

Figure 5. Laboratory glow data compared to shuttle observed glow, 2,6,7,8,9 
observed by a spectrometer on the $53 / 4$ satellite which is consistent with electronically excited nitrogen $\left(\mathrm{N}_{2}\right)$.

Based on these shuttle and satellite observations, it is likely that several different processes are occurring onorbit and there is not a single glow reaction mechanism.

Several ground based laboratory experiments have been conducted in an effort to duplicate on-orbit observations ${ }^{9}$. Figure 5 shows laboratory data contrasted with shuttle glow observations. The laboratory luminescence data were generated by directing pulsed oxygen atoms travelling at orbital velocities toward surfaces doped with No molecules. Heterogeneous recombination of $\mathrm{O}$ and No results in $\mathrm{NO}_{2}{ }^{*}$. The excited nitrogen dioxide then leaves the surface and emits ultraviolet/visible (UV/VIS) radiation. The sample surfaces in these experiments were coated with 2306 telescope baffle paint. The ground based experiments are on going, and are being used to verify and understand orbital measurements.

No orbital measurements of space shuttle and spacecraft glow prior to the 1991 STS-39 space shuttle flight have been successfully conducted in the infrared region of the electromagnetic spectrum.

The STS-39 experiment, Spacecraft Kinetic Infrared Test (SKIRT), was designed to obtain infrared measurements of space shuttle glow (including ancillary visible and ultraviolet measurements) with sufficient spectral resolution and sensitivity to identify emitting species. 
other STS-39 payloads including the cryogenic Infrared Radiance Instrumentation for shuttle (CIRRIS-1A) and the Infrared Background signature survey/Ärizona Imaging spectrometer (IBSS/AIS) experiments were also configured to look at glow. In addition, ultraviolet glow measurements were planned by the U.S. Navy's Far UV Cameras and UVLIMB experiment.

SKIRT, CIRRIS-1A, and the many other experiments on this manifest were launched on 28 April 1991 on board the STS-39 Space Shuttle Discovery (OV-103) into a $260 \mathrm{~km}$ altitude orbit at an inclination of 57 degrees for an eight day mission.

SKIRT successfully obtained on orbit measurements of space shuttle glow at infrared wavelengths $(0.6 \mu \mathrm{m}$ to 5.4 $\mu \mathrm{m})$. Analysis shows spectral band structure consistent with that of $\mathrm{NO}, \mathrm{NO}^{+}, \mathrm{OH}$, and $\mathrm{CO}$. In addition, enhancement of the glow intensity and changes in its spectral signature are evident during thruster firings.

CIRRIS-1A and IBSS did not measure any noticeable glow emissions for reasons which will be discussed.

Ultraviolet measurements were successfully conducted by AIS, Far UV, and UVLIMB, however, the data analysis results have not yet been released.

Photographs taken by the crew during a nitric oxide gas release show an enhanced visible glow effect above the shuttle surfaces and these results will be briefly discussed 
in relation to the SKIRT measurements.

SKIRT also operated during "non-glow" times to measure the in situ orbiter environment in support of the atmospheric measurements conducted by CIRRIS-1A ${ }^{11}$.

It has long been debated within the NASA, U.S. Air Force, and Strategic Defense Initiative organization (SDIO) space community whether space shuttle environments, or those of any large maneuvering spacecraft, are suitable for cryogenic infrared sensors ${ }^{12}$. Arguments have been made that water and carbon dioxide leaking from the crew compartment, maneuvering thruster by products, flash evaporators, water dumps, and outgasssing molecules from shuttle tiles and spacecraft surfaces would form and maintain a gaseous and particulate contamination cloud around the vehicle. The gaseous contamination would attenuate incoming optical radiation as well as self radiate into the on board sensor's field of view. The particles would scatter solar light and thermally radiate into the field of views. These are in addition to the optical contamination associated with glow. Because all of these events produce infrared radiation and thermally condensible matter, there were serious concerns expressed in attempting to fly cryogenic infrared sensors sensitive to very low signal intensities as well as having exposed sensor components such as telescope baffles and mirrors (at temperatures of approximately $12 \mathrm{~K}$ ) exposed to this environment. Analysis of SKIRT data taken when the 
orbiter environment was constrained to be as benign as possible (no thruster firings, water dumps, or vehicle vibrations), demonstrate that space shuttle contamination levels are acceptable for sensitive cryogenic infrared sensors operating from the shuttle cargo bay.

This dissertation describes the mission objectives, payloads, ground operations, flight operations, and experimental results. 
Figure 6 shows the STS-39 cargo bay configuration. SKIRT and other Hitchhiker payloads occupied the forward part of the cargo bay, IBSS/AIS the center, and the CIRRIS$1 \mathrm{~A}$ and associated secondary experiments were in the aft section.

\section{SKIRT}

SKIRT consisted of two separate payloads, designated as SKIRT CVF (ćircular Variable Filter) and SKIRT GLOS (Gaseous Luminosity/optical surfaces). Together with other experiments, avionics, and payload support structures (Figure 7) the payload was designated as STP-1 on the STS-39 manifest.

SKIRT CVF features an infrared circular variable filter spectrometer and a long wavelength infrared radiometer, both sharing common collecting optics and cooled with solid nitrogen. The spectrometer (using an In: Sb detector) covers the wavelength region from $0.6 \mu \mathrm{m}$ to $5.4 \mu \mathrm{m}$ at $2 \%$ to $3 \%$ spectral resolution and completes a spectral scan in five seconds. The radiometer has a $\mathrm{Hg}: \mathrm{Cd}: \mathrm{Te}$ detector and samples a single wavelength interval (9.9 $\mu \mathrm{m}$ to $10.4 \mu \mathrm{m}$ ) which is an atmospheric transmission "window" for infrared sensors. The detectors and optics are cooled to approximately $57 \mathrm{~K}$. An aperture cover is opened during on-orbit measurement times 


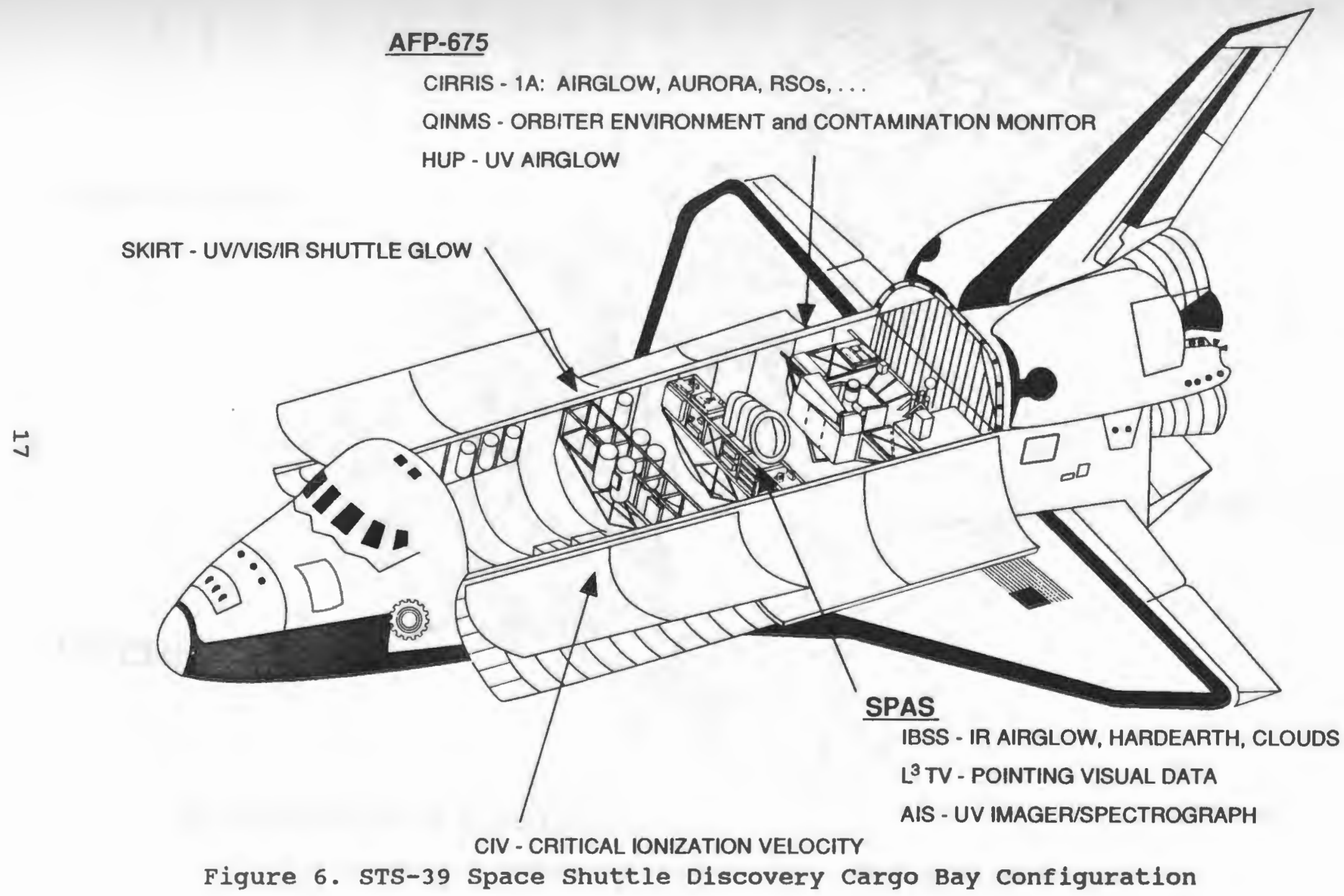




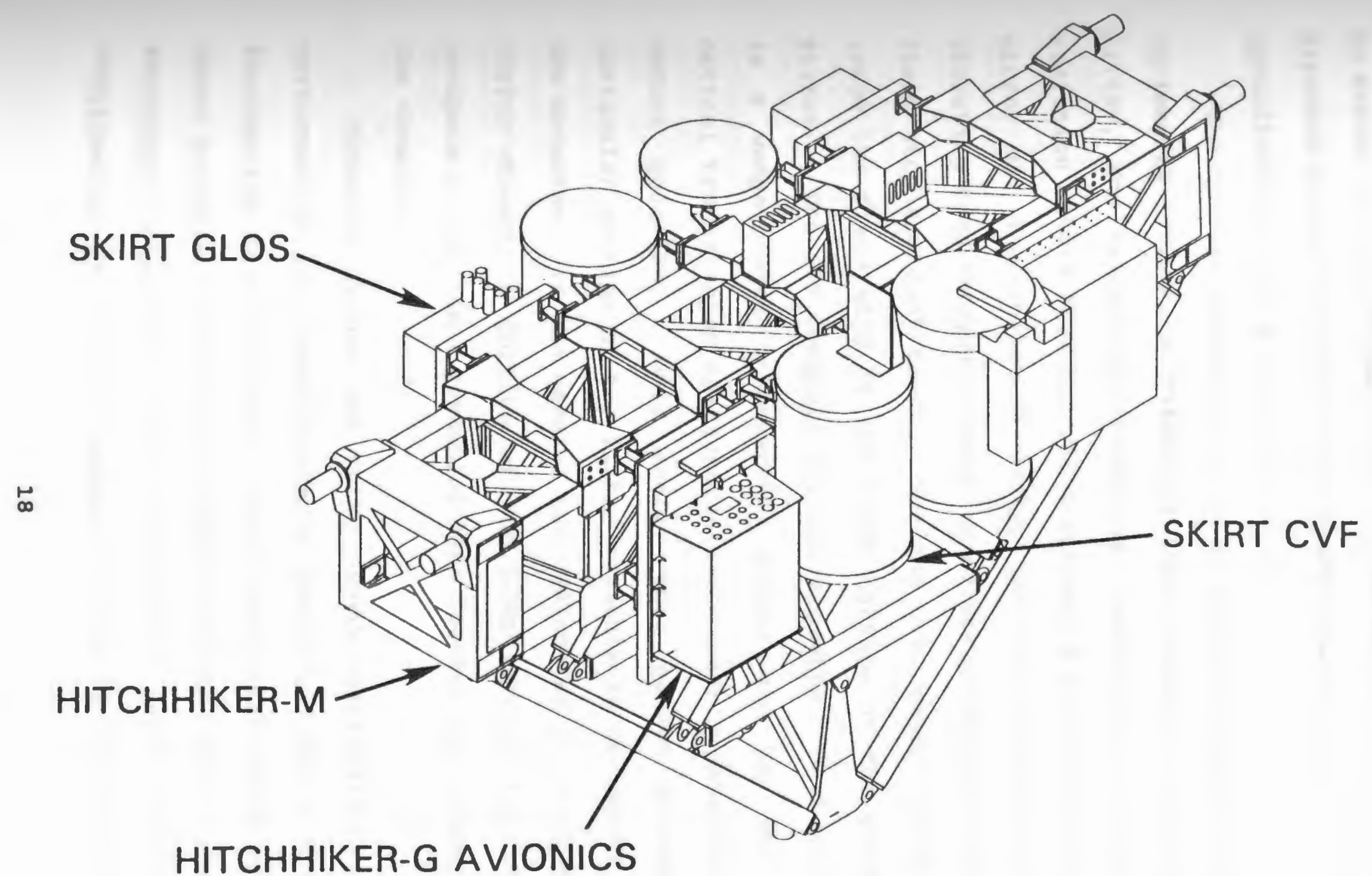

Figure 7. STS-39 SKIRT/Hitchhiker STP-1 Payload configuration 
to expose the $2 \times 2$ degree field of view along a line of sight directed perpendicularly to the shuttle cargo bay ( $-\mathrm{Z}$ axis). specifications are given in Table 2.

The optical assembly (Figure 8) includes collecting and re-imaging optics, a vibrating reed chopper, a rotating filter, and detector/pre-amplifier assemblies. Incoming radiation enters from the right through a baffled tube onto mirror M1. The collected energy is then chopped by the vibrating reed chopper located immediately behind the first field stop and sent to M2. For the CVF, relay optics reimage the field stop at the first surface of the rotating filter. The CVF consists of four segments. Each segment is a wedge-coated interference filter and has spectral optical transmission characteristics linearly dependent on radial position. only energy that passes through a particular section of the filter segments is re-imaged onto the detector. In the case of the radiometer, a right-angle mirror diverts a portion of the beam through the narrow bandpass filter and a germanium lens focuses the energy onto the detector.

Extended source and point source calibrations were performed at the manufacturer's facility (Space systems Engineering Inc. in Logan, Utah) with assistance by the Space Dynamics Laboratory of Utah state University and the Aerospace corporation. The calibration report is titled "Engineering Calibration summary for the NS-9D shuttle 
Table 2. SKIRT CVF/Radiometer specifications

Spectrometer

Wavelength Range

Spectral Resolution

Detector

NESR $(60 \mathrm{~K}, 5 \mathrm{um}, 17 \mathrm{~Hz}$ )

scan Time

Field-of-View

Aperture Size

optical Transmission

operating Temperature

Instrument Power

Heater Power

Radiometer

Spectral Bandwidth

Detector

NER ( $60 \mathrm{~K}, 11 \mathrm{um}, 17 \mathrm{~Hz}$ )

Field-of-View

Aperture Size

optical Transmission

Operating Temperature

Instrument Power

Heater Power

Dewar

Cryogen

Pumping Method

trold Time
$0.6 \mu \mathrm{m}$ to $5.4 \mathrm{um}$

$2 \%$ Nominal

In: $\mathrm{Sb}$

$1.3 \times 10^{-10} \mathrm{~W} / \mathrm{cm}^{2} \mathrm{sr} \mu \mathrm{m}$

$5 \mathrm{sec}$

$2 \times 2$ degrees (Full)

$1.52 \mathrm{~cm}$ (Diameter)

$>0.4$

$<60 \mathrm{~K}$

30 Watts

30 Watts

$9.9 \mu \mathrm{m}$ to $10.4 \mu \mathrm{m}$

$\mathrm{Hg}: \mathrm{Cd}: \mathrm{Te}$

$9 \times 10^{-9} \mathrm{~W} / \mathrm{cm}^{2} \mathrm{sr}$

$2 \times 2$ degrees (Full)

$1.52 \mathrm{~cm}$ (Diameter)

$>0.4$

$<60 \mathrm{~K}$

30 Watts

30 Watts

$\mathrm{N}_{2}$ solid

Vent to Ambient

5 Days Pre-Flight

60 Days on-Orbit (Closed) 


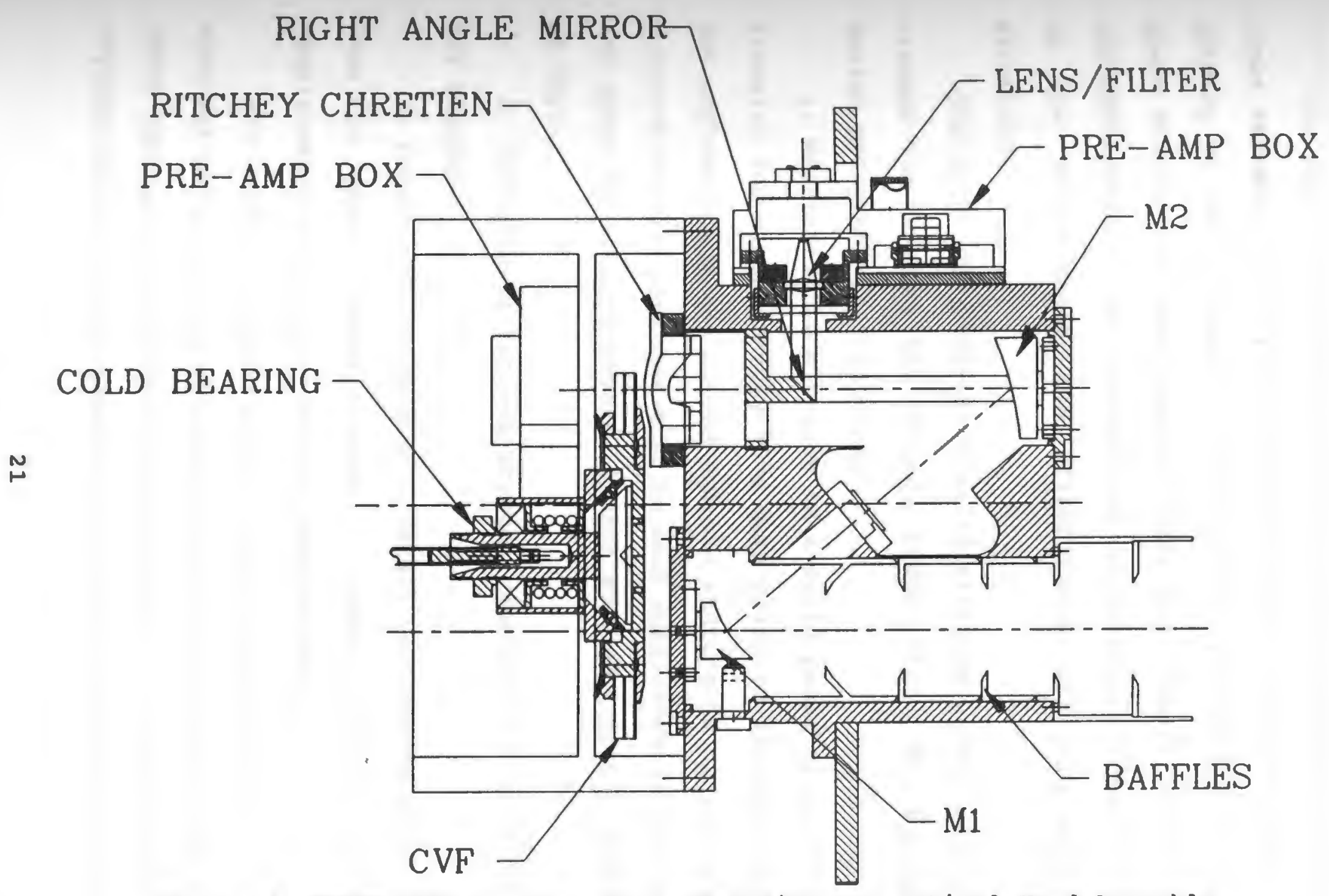

Figure 8. SKIRT CVF Spectrometer and Radiometer Optical Head Assembly 
Rinetic Infrared Test (SKIRT) ${ }^{13}$.

The SKIRT CVF also has a dewar/cryogen system, aperture cover assembly, glow plate, and avionics. Figure 9 is a drawing of the payload. This assembly is mounted into a space shuttle Get Away special (GAS) can (Figure 10) which has been adapted for a mechanical and electrical interface to the Hitchhiker-M and Hitchhiker-G payload support structure.

The SKIRT CVF dewar uses solid nitrogen as the working cryogen for cooling the optical components. The thermal design provides the following:

1) Maintains the nitrogen in a solid phase after final freezing for approximately five days prior to launch. Once the payload doors are closed and the shuttle is placed into a launch status, payloads must be self sufficient in cryogen and power to survive several launch attempts over a number of days.

2) Provides sufficient cryogen capacity for an eightday mission.

3) Ensures the cryogen will safely vent in the event of loss of dewar jacket vacuum. space shuttle safety requirements are primary design considerations.

The dewar encloses a 38.6 liter cryogen tank filled with $94 \%$ void fraction aluminum foam (to ensure good thermal paths between the cryogen and tank wall). The effective cryogen volume is approximately 36 liters. Surrounding the 


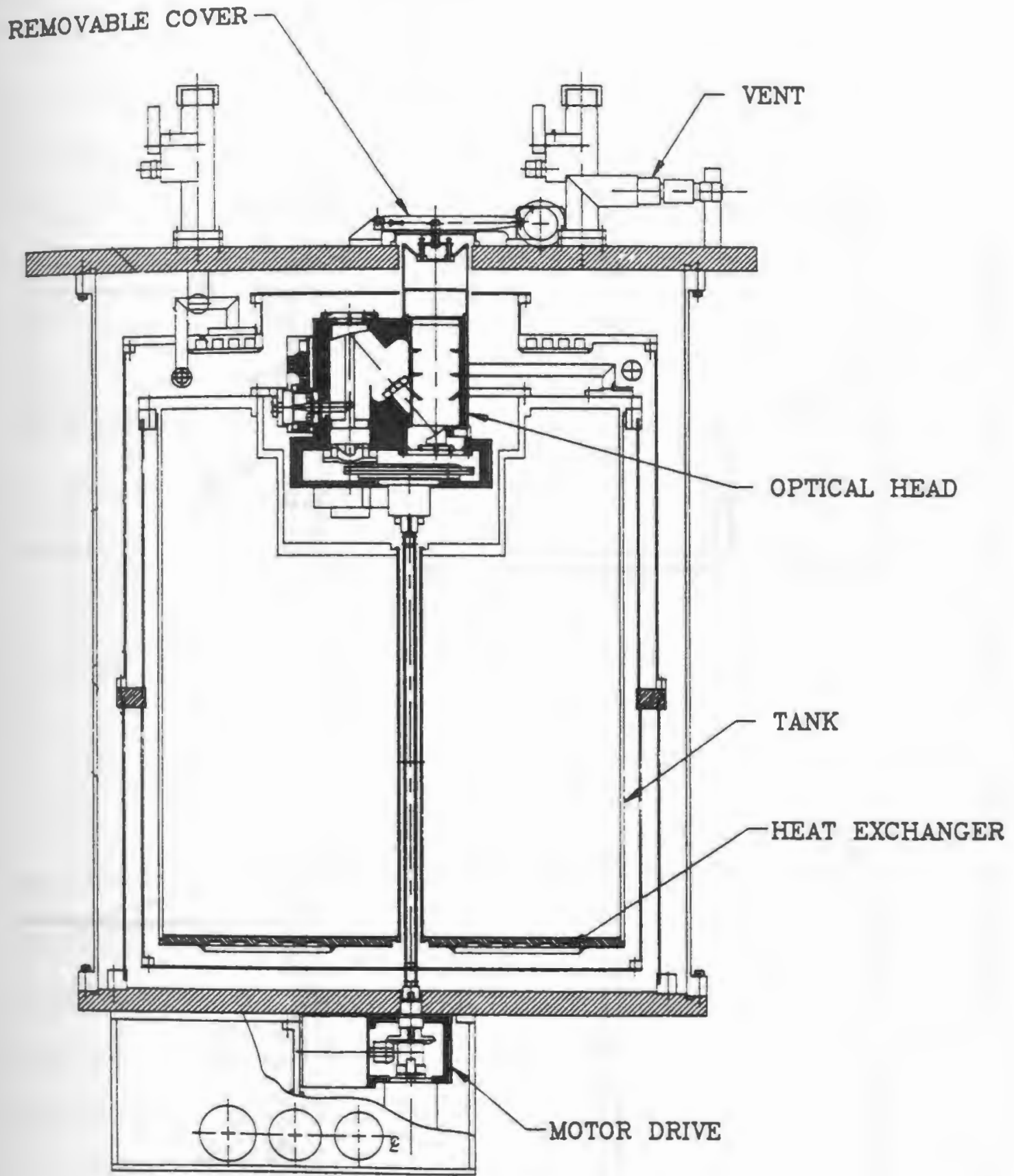

Figure 9. SKIRT CVF payload configuration. This assembly fits into a NASA Get Away Special (GAS) can modified for a Hitchhiker mechanical and electrical interface. 

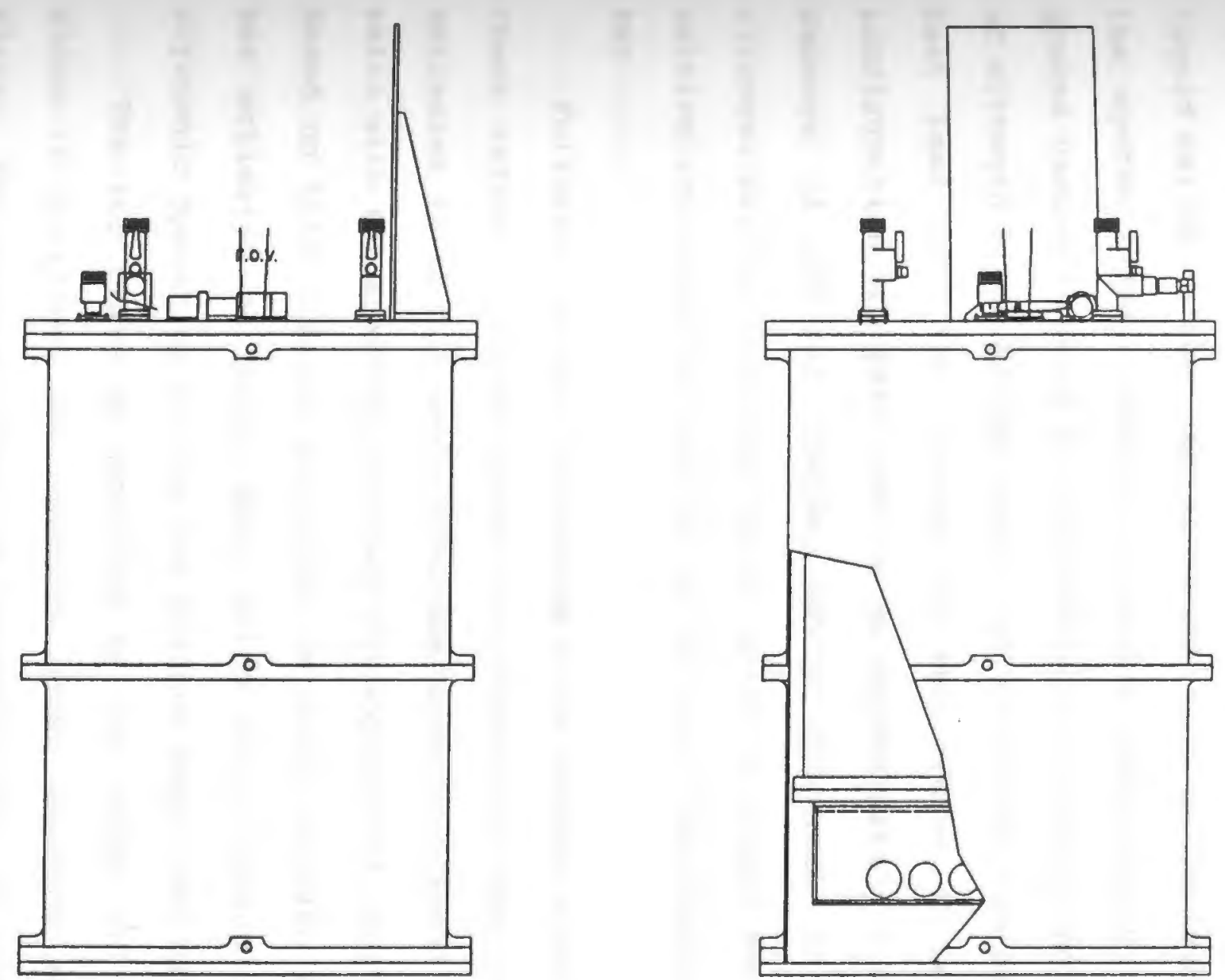

Figure 10. Hitchhiker Canister with SKIRT CVF Experiment 
tank is a radiation shield wrapped with multi-layer insulation.

Prior to launch the system is filled with liquid nitrogen and then frozen to approximately $30 \mathrm{~K}$ by flowing liquid helium through heat exchanger coils. The pressure of the system after freezing is below atmospheric. Since ground vacuum venting is not provided, there is no venting of nitrogen vapor during launch pad hold time. The parasitic heat load into the cryogen on the ground in a launch configuration was predicted to be approximately 1.8 watts. Because of orbiter system safety concerns, the solid nitrogen was sufficiently cooled prior to launch to prevent melting and possible venting $\mathrm{N}_{2}$ gas into the shuttle cargo bay.

Following launch, the system vents through a mechanical check valve. Once in orbit the parasitic heat load was estimated to be 1.3 watts with the aperture closed and 2.1 watts with the aperture open and the experiment operational. Based on this thermal analysis, on orbit cryogen lifetime was estimated at sixty days which would ensure uniform cryogenic operation during the planned eight day mission.

The top plate is provided by the SKIRT CVF payload since it contained the aperture cover assembly and glow plate. The aperture cover is commanded open by the ground via s-band telemetry for on-orbit operations. Otherwise it remains closed to prevent contamination of the cryogenic 
optics from orbiter activities such as thruster firings, water dumps, and other events which produce condensible gaseous products around the vehicle. The glow plate is aluminum painted with a standard telescope baffle paint, Chemglaze 2306, which from previous experiments ${ }^{14}$ is known to provide an intense visible glow when exposed to ram. The plate is mounted just outside the sensor's $2 \times 2$ degree fieldof-view in order to provide a known surface glow source for the experiment and has sensors to monitor the plate temperature. The bottom cover is provided by NASA and provides connections from the SKIRT avionics box to the Hitchhiker avionics for power as well as real time commanding and telemetry data down-link. All SKIRT CVF data are sent via Ku-band telemetry to the NASA Goddard space Flight center for real time processing and display.

The SKIRT GLOS sensors (Figures 11, 12, 13, 14, and 15) were designed for radiometric measurements in the infrared, visible, and ultraviolet wavelength regions. The design philosophy for the infrared modules was that they would be backup payloads to the SKIRT infrared CVF spectrometer. The SKIRT CVF, with a never before flown solid nitrogen cooling system, a stepper motor driven filter wheel mechanism, and a motor driven aperture cover which had to operate in microgravity, high vacuum, and in a broad temperature range environment, was considered high risk. The SKIRT GLOS, with previously shuttle flight qualified cryocoolers and solid 


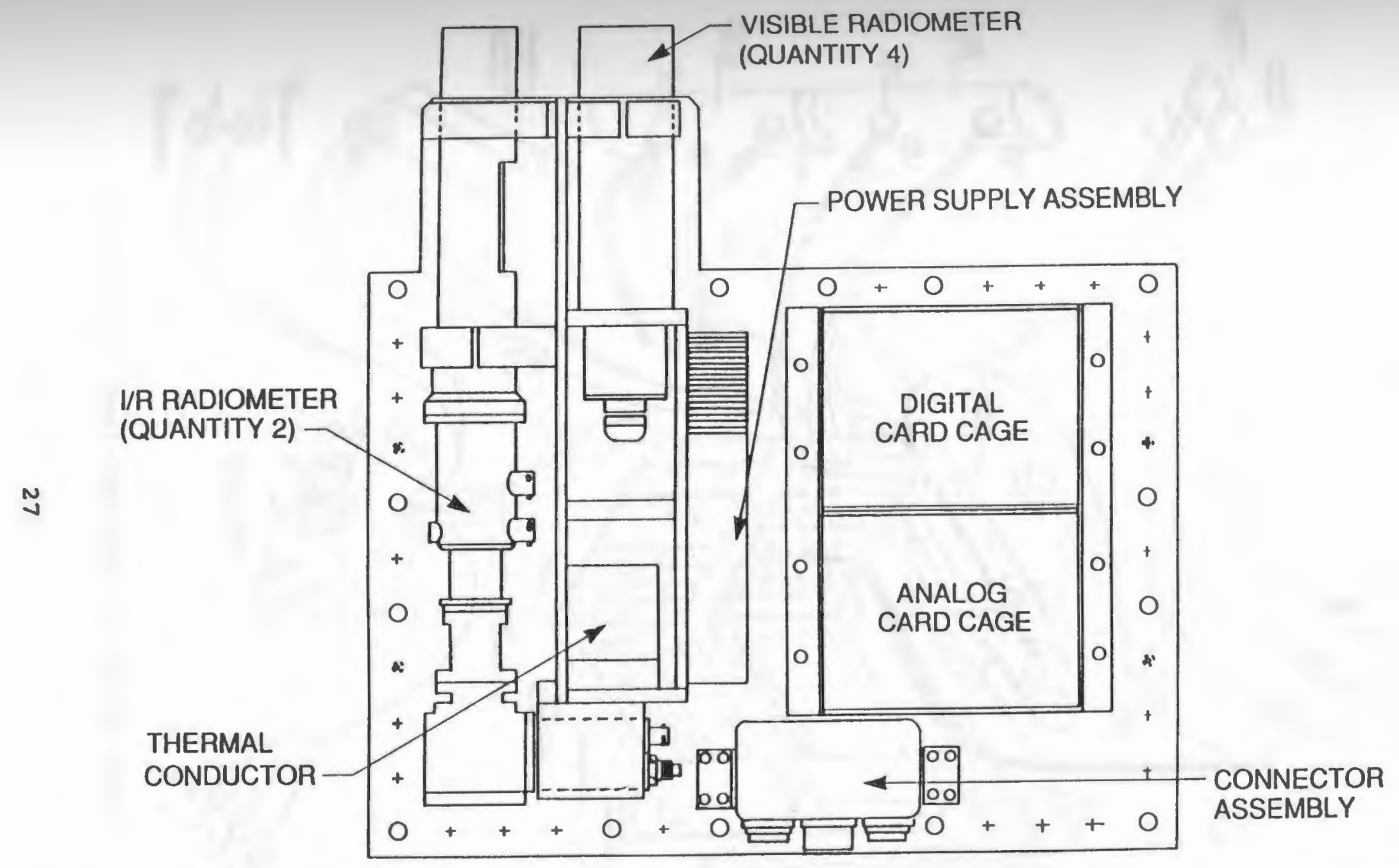

Figure 11. SKIRT GLOS with payload cover removed showing mechanical configuration of UV/VIS/IR modules and avionics. This assembly mounts to the Hitchhiker-M payload support structure with an electrical interface to the Hitchhiker-G avionics. 


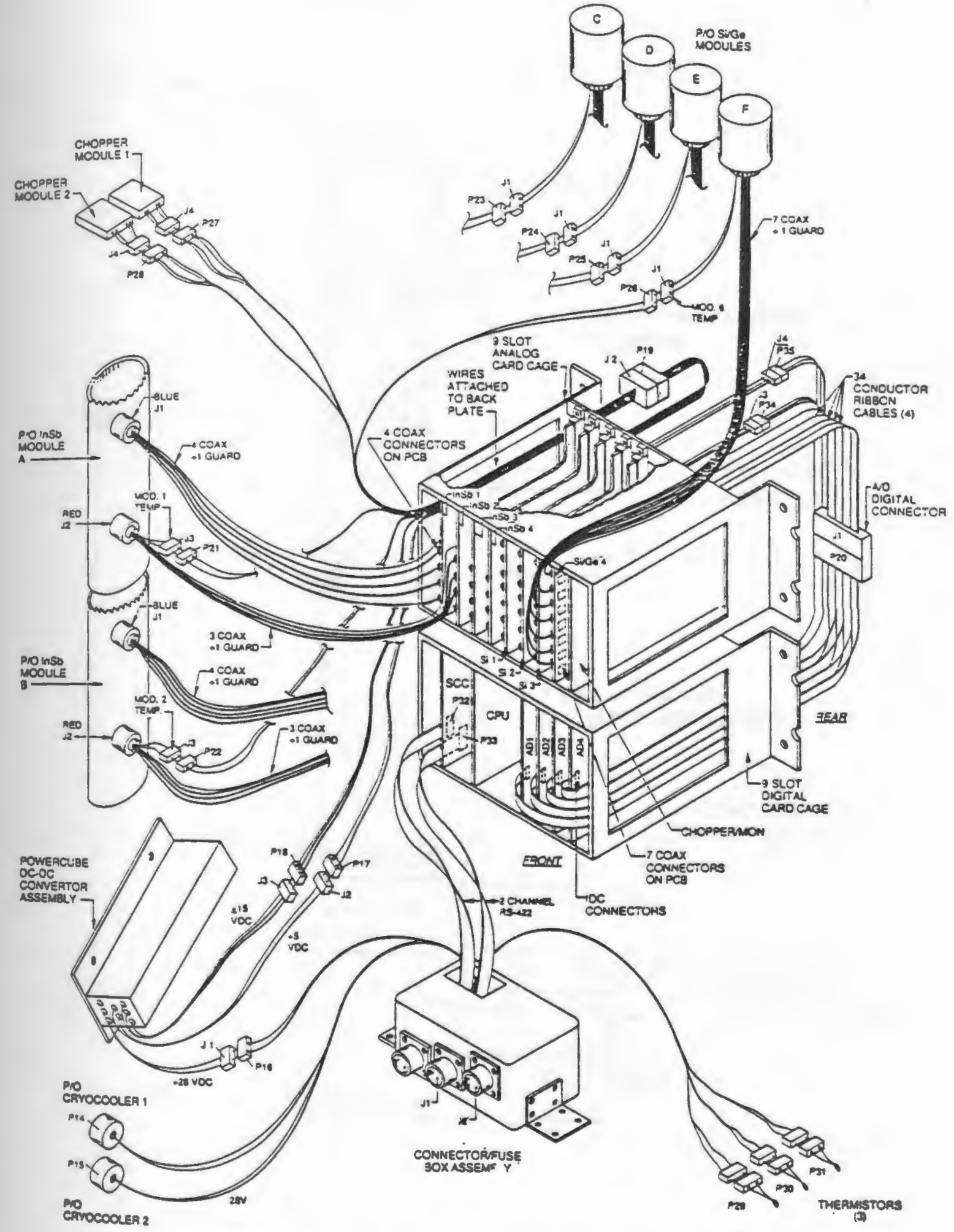

Figure 12. Exploded view of SKIRT GLOS 


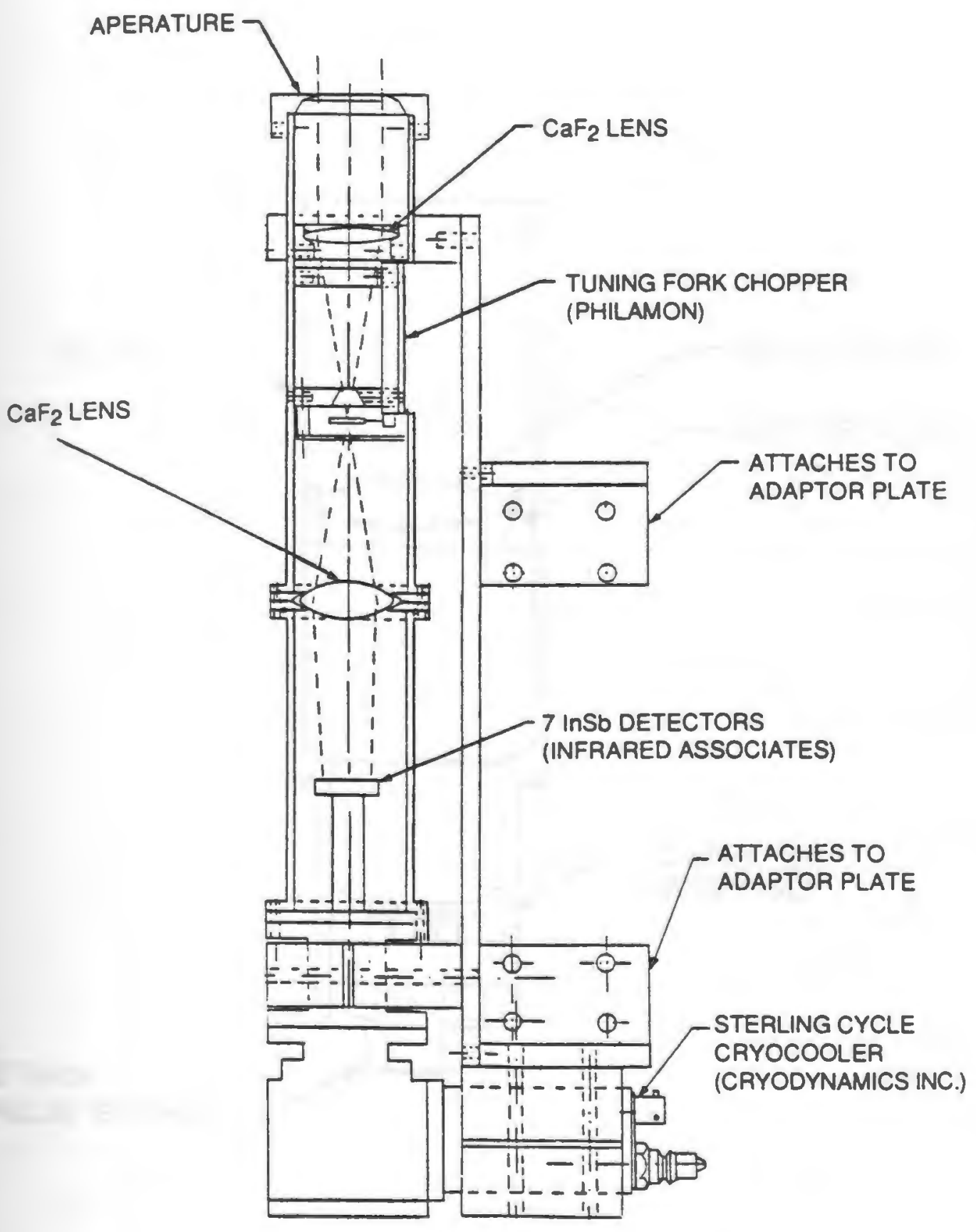

Figure 13. SKIRT GLOS IR Module (1 of 2) 


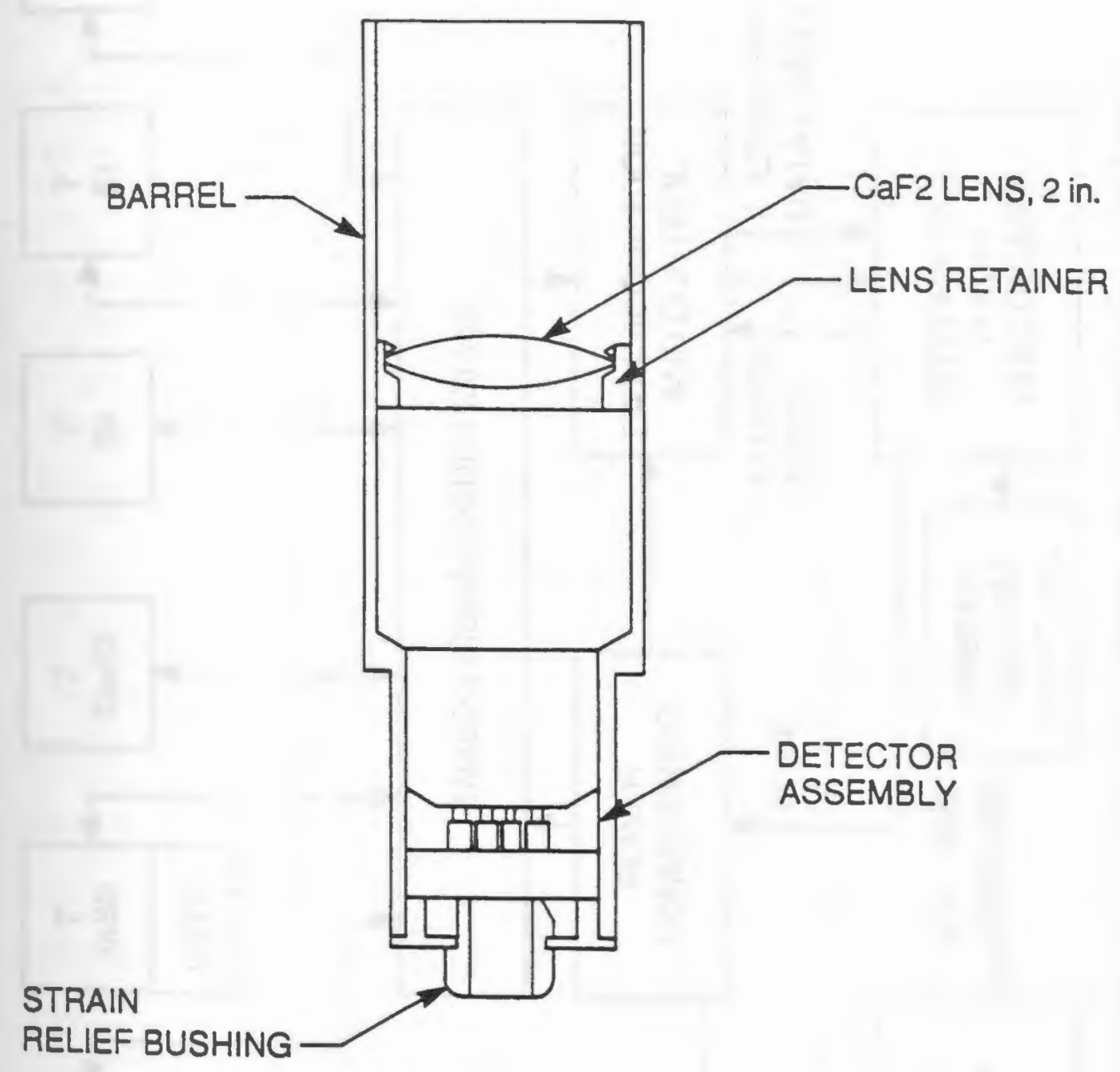

Figure 14. SKIRT GLOS UV/VIS Module ( 1 of 4) 


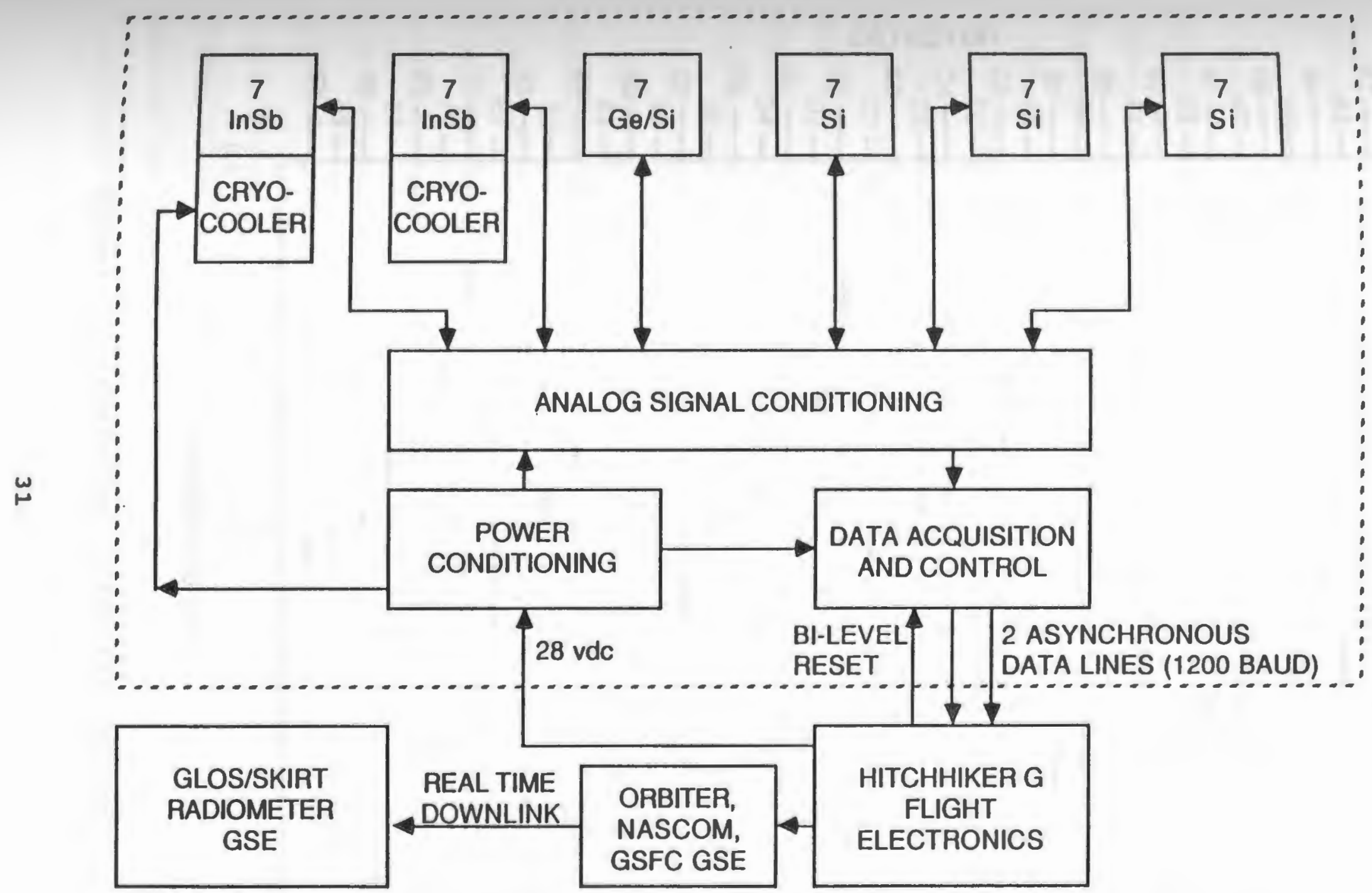

Figure 15. SKIRT GLOS Power and Telemetry Interfaces 


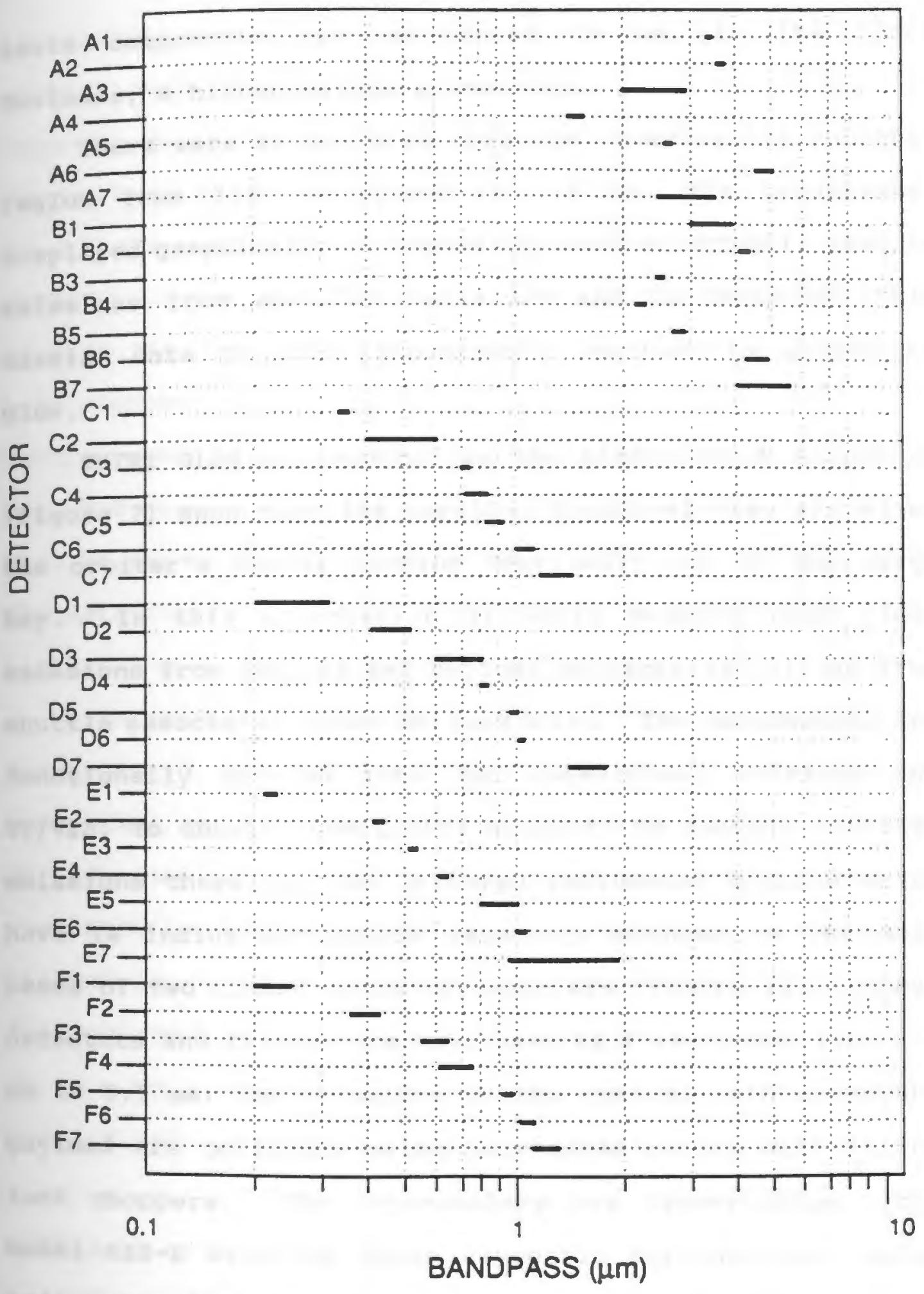

Figure 16. SKIRT GLOS filter band passes 
state components was considered to be, in the space business, a higher reliable assembly.

There were 42 filtered channels covering the spectral region from 2000 Angstroms to $5.4 \mu \mathrm{m}$. The bandpasses, displayed graphically in Figure 16, were selected to isolate emissions from specific radiators and to correlate this mission data to other experiments involved in spacecraft glow.

SKIRT GLOS was mounted on the Hitchhiker-M structure (Figure 7) such that its parallel fields-of-view are along the orbiter's z-axis looking vertically out of the cargo bay. In this orientation it would measure near field emissions from orbiter and payload surfaces as well as from shuttle associated gases and particles. The radiometers are functionally grouped into two categories, infrared and UV/VIS. To obtain sensitivity adequate to measure infrared emissions there are two infrared radiometer modules which have 14 indium antimonide detectors mounted on the cold heads of two closed cycle cryo-coolers (Figure 13). These detectors and filters are held near $80 \mathrm{~K}$ and cover from 1.5 $\mu \mathrm{m}$ to $5.3 \mu \mathrm{m}$. The emissions in the optical path above the payload are collected using telescoped optics with tuning fork choppers. The cryo-coolers are cryodynamics, Inc. Model M15-R stirling cycle cryogenic refrigerators using helium as the working gas. Because of the expected inability to efficiently dissipate thermal energy from the 
refrigerators while in the orbiter cargo bay, the infrared modules were not planned to be operated continuously, but were to be commanded on/off by ground command as upper temperature limits on the hardware warranted.

There are four UV/VIS modules using silicon and germanium detectors (Figure 14). To study transient events, such as thruster firings, eight of the radiometer channels were sampled every 0.1 second. This time scale is comparable to thruster duration and near field residence times of thruster generated products. On board micro-processors were used to A/D sample the data, sequence, format, and configure the data for real time Hitchhiker-G s-band telemetry downlink to the ground (Figure 15).

Electrical power was supplied by the orbiter via the Hitchhiker-G avionics which also provided real time commanding and telemetry down-link to the ground. Because of this real time communication link with the payload, we were able to modify pre-flight planned measurements. This allowed us to optimize our data collection opportunities based on analysis of real time calibrated spectra generated at the Payload operations Control center at NASA Goddard Space Flight Center.

\section{CIRRIS-1A}

The CIRRIS-1A was a U.S. Air Force, Defense Nuclear Agency, and Strategic Defense Initiative experiment designed 
to obtain simultaneous infrared spectral and spatial maasurements of airglow, aurora, and targets of opportunity. CIRRIS-1A was originally manifested for a West coast launch in 1986, however, with the space shuttle challenger destruction all flight operations associated with the National Space Transportation System were indefinitely suspended. The CIRRIS-1A was eventually remanifested for a 1991 launch. During this interim period, as the U.S. Air Force became concerned about spacecraft glow on low earth orbit systems, CIRRIS-1A flight operations and associated timeline activities were modified to include a shuttle glow measurement.

The primary sensors consist of a Michelson interferometer (Fourier Transform - Infrared; FTIR) for high resolution spectral measurements and a dual focal plane radiometer with selectable bandpass filters for spatial/clutter measurements in the $2.5 \mu \mathrm{m}$ to $25 \mu \mathrm{m}$ wavelength region. The interferometer and radiometers share the collection optics of a high off-axis-rejection telescope for simultaneous spectral and spatial measurements within the same field of view. The sensor optics and telescope were cooled to liquid helium temperatures, $12 \mathrm{~K}$, to allow measurements of emissions from weak infrared sources in the 60 to $150 \mathrm{~km}$ altitude atmosphere.

The CIRRIS-1A sensor is mounted into a two axis gimbal system that rotates the sensor in the orbiter pitch and roll 
axis (Figure 17). It was commanded by the shuttle crew from an aft flight deck command and monitor panel.

The CIRRIS-1A interferometer has a $1 \mathrm{~cm}^{-1}$ spectral resolution capability, compared to the SKIRT CVF $20 \mathrm{~cm}^{-1}$ resolution, and offered the prospect of actually measuring the rotational line structure associated with the vibrational band structure. This would have provided the definite measurement of shuttle glow emissions.

At $5 \mu \mathrm{m}$ the sensitivity of CIRRIS-1A \#2 interferometer detector is approximately $8 \times 10^{-9} \mathrm{~W} / \mathrm{cm}^{2} \mathrm{sr} \mu \mathrm{m}$. The sensitivity of the SKIRT CVF at $5 \mu \mathrm{m}$ is $1.3 \times 10^{-10} \mathrm{~W} / \mathrm{cm}^{2} \mathrm{sr}$ $\mu \mathrm{m}$. CIRRIS-1A with its As:Si detectors was designed for maximum sensitivity in the LWIR and not the SWIR region which overlaps the SKIRT CVF wavelength coverage. As can be seen, SKIRT CVF is more sensitive in the SWIR by more than a factor of $10 x$ for near field extended source emissions than the CIRRIS-1A.

Even though CIRRIS-1A was never designed for shuttle glow measurements we decided to modify on orbit operations to attempt a glow measurement. Unfortunately, the gimbal system did not have sufficient pitch capability to point the sensor in the vicinity of the orbiter vertical stabilizer and OMS pods where we knew intense glow emissions occurred when these surfaces were exposed to ram. In addition, because of primary mirror cleanliness considerations we could not point the telescope aperture into the ram 
direction. The only other option was to maneuver the shuttle remote manipulator system (RMS), the arm, into the vicinity of the sensor and attempt to measure the glow off of a small section of the RMS while it was exposed to ram. Further details will be described in the flight operations section. 


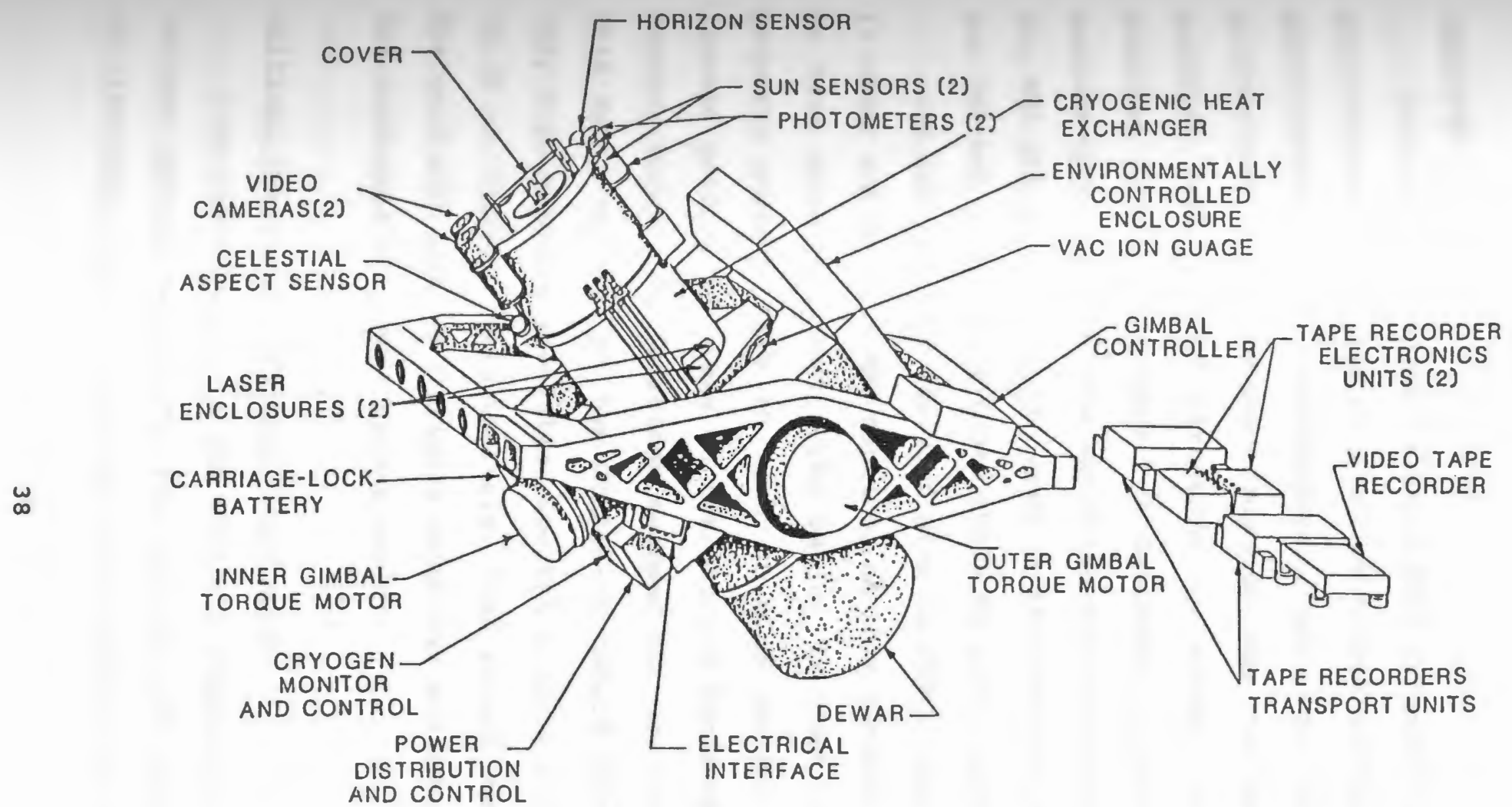

Figure 17. STS-39 CIRRIS-1A Payload 


\section{IBSS/AIS}

This set of instruments was a SDIO sponsored experiment and consisted primarily of a helium cooled grating infrared epectrometer, a UV spectrometer, and low light level televisions. Its primary mission was to measure the spectral and spatial structure of rocket firings and chemical releases in space. A secondary objective was to measure space shuttle glow while the payload was attached to the RMS and pointed by the crew at the vertical stabilizer and OMS pod areas while those surfaces were exposed to ram. AIS successfully measured glow in the UV and this data is under analysis. IBSS appears, at this present time, not to have measured glow. The belief is that it was not properly pointed into an area of glow emission and was instead pointed so close to the shuttle surfaces that the orbiter black body emissions swamped out any glow signal. This data, as well as the CIRRIS-1A, would have provided very high spectral resolution spectra of glow in the $2.5 \mu \mathrm{m}$ to $25 \mu \mathrm{m}$ region. Unfortunately, this sensor also was not designed with glow as a primary objective and like CIRRIS-1A was conducted on a best effort basis.

\section{Pitical Ionization Velocity Experiment}

Also associated with the IBSS/AIS experiment was a gas release payload, mounted on the forward port cargo bay sill of Discovery, which discharged small amounts of gases into 
space to test a critical ionization velocity theory. Associated with the gas release payload were UV/VIS radiometers and low light level televisions to measure the effect of gas releases in low earth orbit at velocities of $8 \mathrm{~km} / \mathrm{second}$. One of these gases was nitric oxide and the results of that gas release will be discussed further in the results and discussion section.

\section{Vass spectrometer}

A secondary experiment which flew with the CIRRIS-1A was a neutral/ion quadrapole mass spectrometer. It was planned to operate continuously on orbit to provide a qualitative and quantitative measurement of neutral and ionized species as a function of MET and attitude. Many of the SKIRT CVF measurements were designed to operate simultaneously with the mass spectrometer such that both instruments would be in a optimum glow attitude. The mass spectrometer was mounted in the cargo bay parallel to the starboard wing and pointed 15 degrees up in roll. The SKIRT CVF was designed such that its glow plate and surface area would be exposed to maximum ram when the orbiter was flying starboard wing into the velocity vector with the SKIRT CVF field of view looking toward deep space. Thus, at these times the SKIRT CVF would be in its most intense glow attitude while the mass spectrometer would be looking directly into the ram. Unfortunately, the tape recorders 
which the mass spectrometer were to record on failed and no useful mass spectrometer data to support this investigation was obtained. 
Ground operations are those processes concerned with the delivery, final testing, qualification, integration into the shuttle cargo bay, and pre-launch servicing of the payload prior to cargo bay close out. This section will deal only with the SKIRT payload.

SKIRT CVF and GLOS underwent stringent NASA safety reviews to preclude any possibility of personnel injury, structural failure, electrical short, cryogen blow down, or in-bay operations which would jeopardize the mission and/or cause catastrophic failure to the vehicle and loss of life of the crew or support personnel.

Six major safety reviews were conducted. Ground safety was performed at NASA Kennedy space center (KSC) under the auspices of a NASA-USAF Safety Review Team (SRT). Flight safety was conducted at NASA Johnson Space Center with a slightly different SRT. The reviews were designated as Phase $0 / 1,2$, and 3. At the Phase 3 Review all SRT, experiment principal investigators, and program managers signed off on safety certifications stating that they had meet all NASA Space Transportation System (STS) requirements through analysis and testing.

Safety documents are thousands of pages in content and are not included in this Dissertation $15,16,17,18,19,20$.

Payload qualifications included shake and vibration, 
lectromagnetic interference, electromagnetic compatibility, and thermal/vacuum testing of the payload standing alone and integrated into the Hitchhiker payload support structure. In addition, extensive computer modelling for thermal and mechanical structural analysis were conducted by the NASA GSFC Hitchhiker Program office. Again, these documents are not included as part of this Dissertation, but are available from the appropriate U.S. Air Force and NASA offices.

Upon completion of final testings and calibrations the SKIRT payloads were delivered to NASA GSFC for mechanical and electrical integration into the Hitchhiker-M and Hitchhiker-G payload support system. Final testing and payload compatibilities were performed and any necessary modifications completed.

During this time SKIRT ground support equipment (GSE) were interfaced to the NASA GSFC computers. Testing, modifications, and mission rehearsals were conducted on a regular and continual basis up to launch.

The entire STP-1 payload was then transported to the NASA Kennedy spaceflight center (KSC) launch facility for integration into the Space shuttle Discovery cargo bay. Figure 18 is a photograph of the SKIRT payload mounted in the Discovery's cargo bay surrounded by ground support personnel (author is standing in back row fourth from left). Final ground processing commenced at L-144 hours. Liquid nitrogen was flowed into the SKIRT CVF until the 


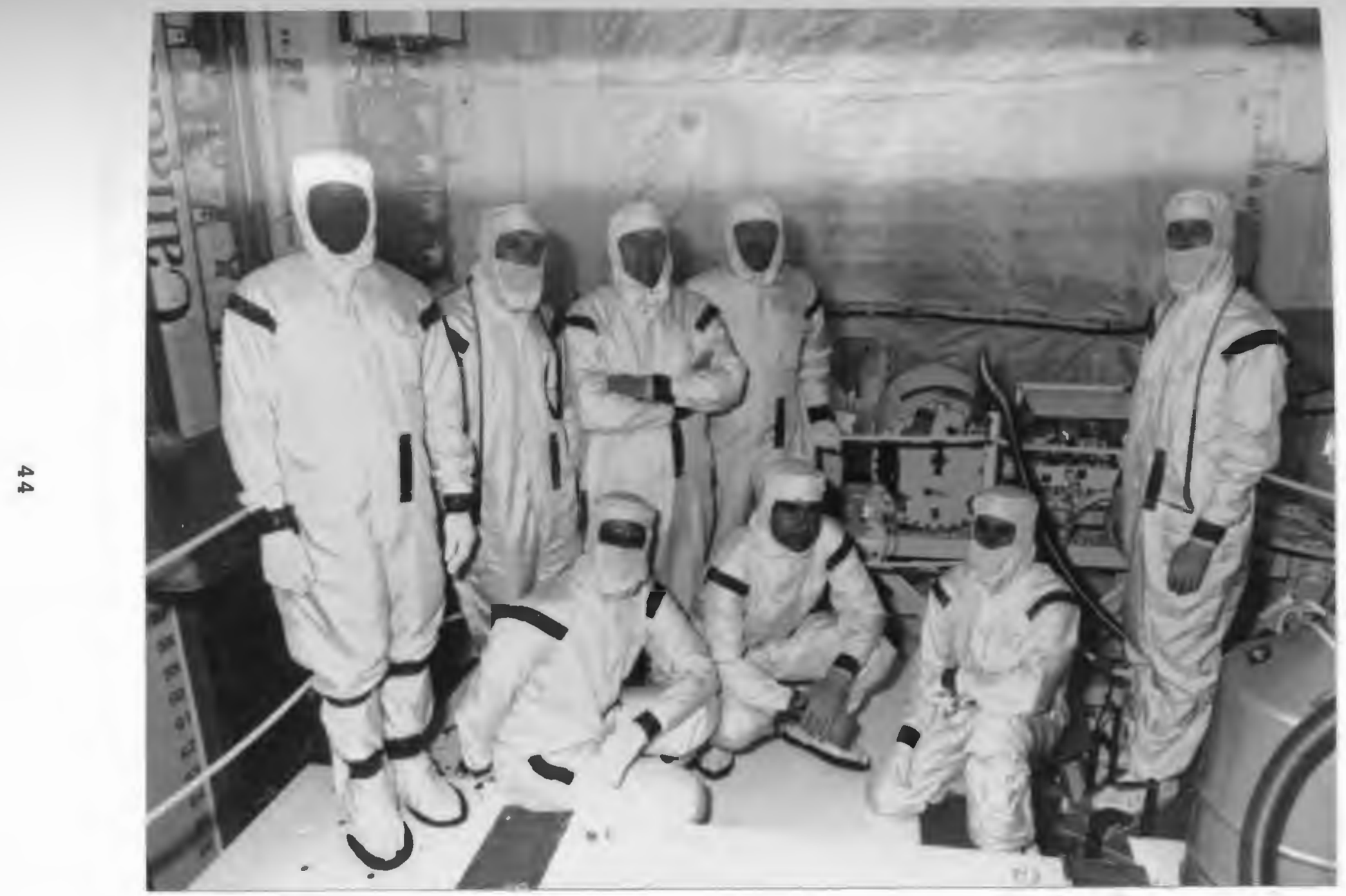

Figure 18. SKIRT Payload and Support Personnel in Discovery Cargo Bay 
sensor was cold and filled (Figure 19). Helium was then flowed through heat exchanger coils on the SKIRT CVF dewar to freeze the nitrogen (Figure 20). At L-72 hours all valves were configured for launch and red tag covers removed from SKIRT CVF and GLOS. All ground support equipment (GSE) and personnel were removed from the cargo bay area, the cargo bay doors closed, and the rotating service structure at Launch Complex 39 moved into a launch configuration.

SKIRT GSE were transported from the launch pad area to NASA GSFC to act as backup flight operations GSE for commanding and recording data from the payloads. 


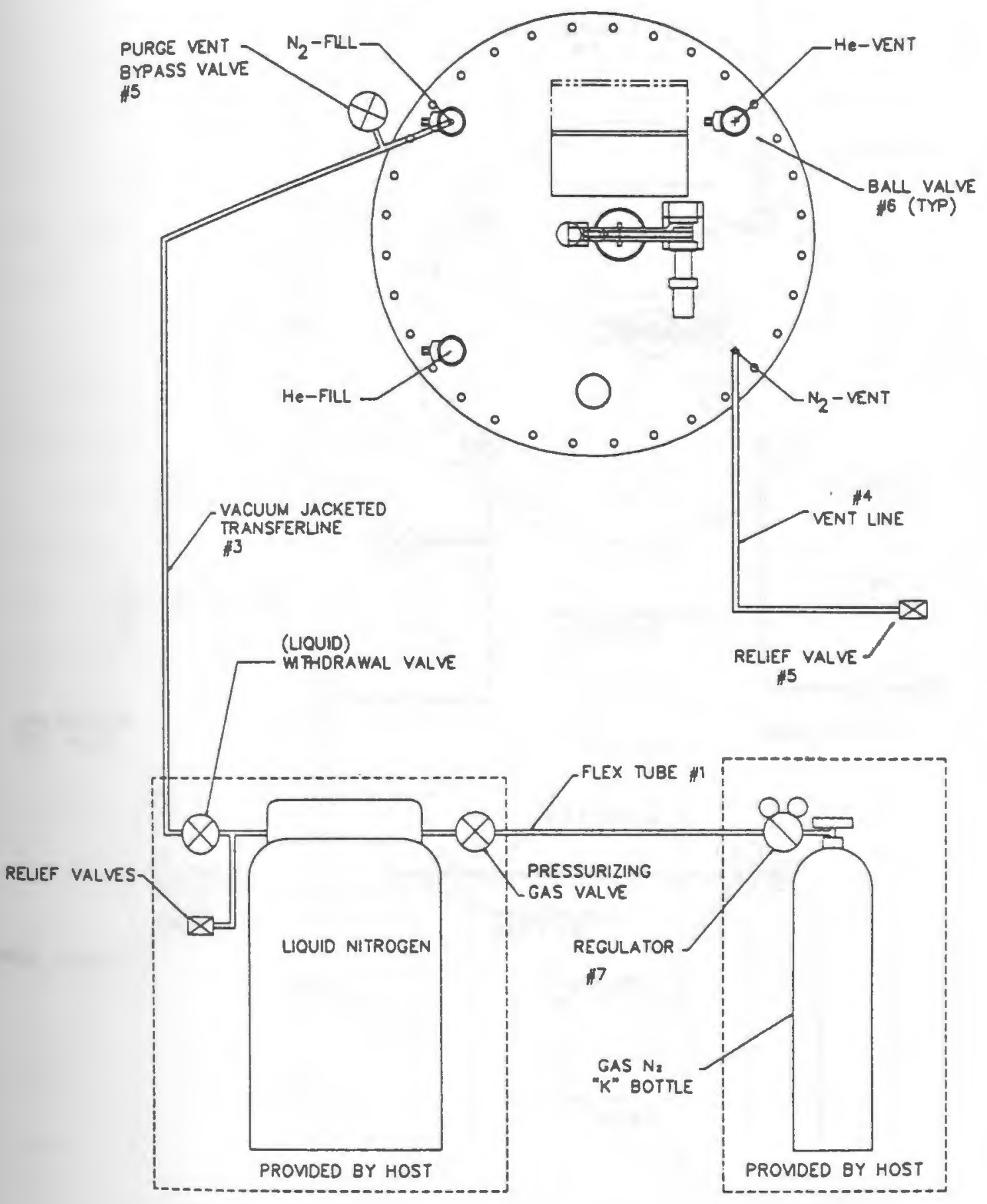

Figure 19. Liquid nitrogen fill schematic. 


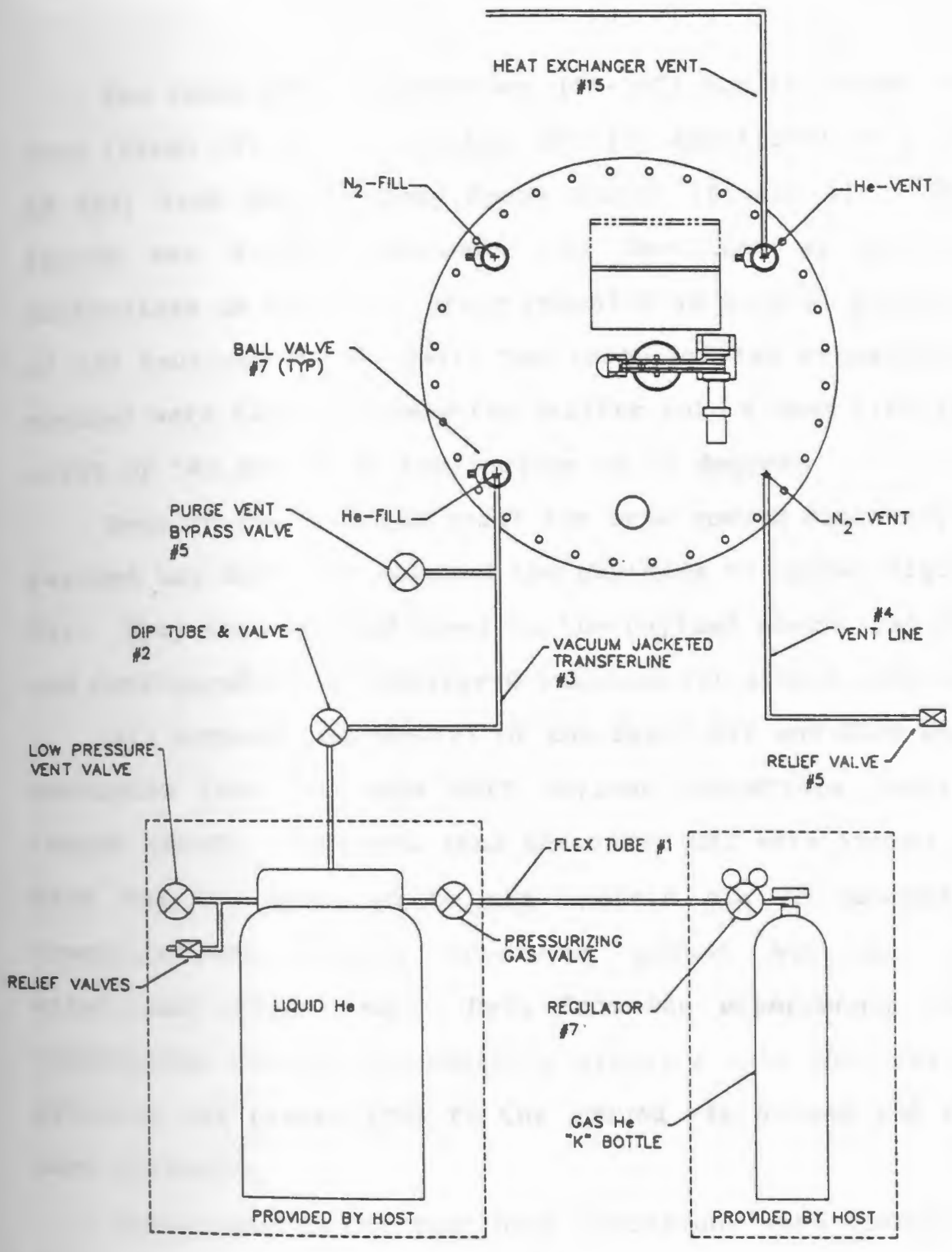

Figure 20. Heat exchanger transfer schematic 
Flight operations

The Space Shuttle Discovery $(\mathrm{OV}-103)$ and its seven man crew lifted off at 118:11:33:14 GMT (28 April 1991 at 07:33 AM EDT) from NASA Kennedy Space Center (Figure 21). The launch was without incident and described by mission controllers as nominal. After reaching an initial altitude of 133 nautical miles ( $\mathrm{nmi}$ ), the large orbital maneuvering engines were fired to place the orbiter into a near circular orbit of $140 \mathrm{nmi}$ at an inclination of 57 degrees.

Once in the required orbit the crew opened Discovery's payload bay doors and exposed the payloads to space (Figure 22). They then enabled power to the payload electrical bus and configured the Hitchhiker-G avionics for ground control.

All command and control of the SKIRT CVF and GLOS were conducted from the NASA GSFC Payload Operations Control Center (POCC). Commands from the SKIRT GSE were routed to NASA GSE and uplinked to the shuttle via an extensive communications network involving ground stations and satellites (Figure 23). Data from the experiments were transmitted via the Hitchhiker-G avionics into the orbiter avionics and transmitted to the ground via s-band and $\mathrm{Ku}-$ band telemetry.

Continuous twenty four hour operations were conducted during the eight day mission. A SKIRT CVF team headed up by Dr. Donald Jennings of NASA GSFC and a SKIRT GLOS team 


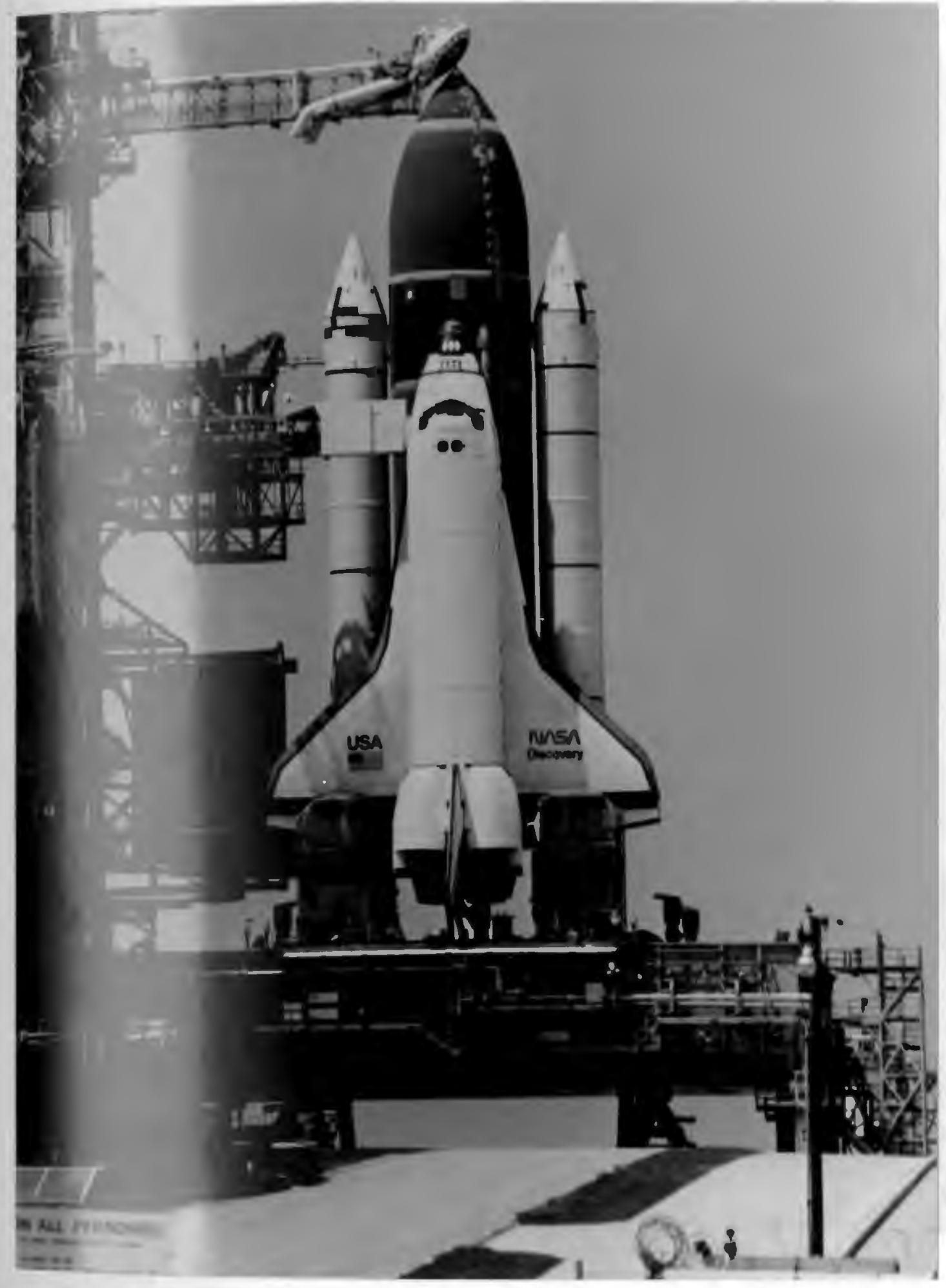

Figure 21. STS-39 Space Shuttle Discovery on Launch Pad 


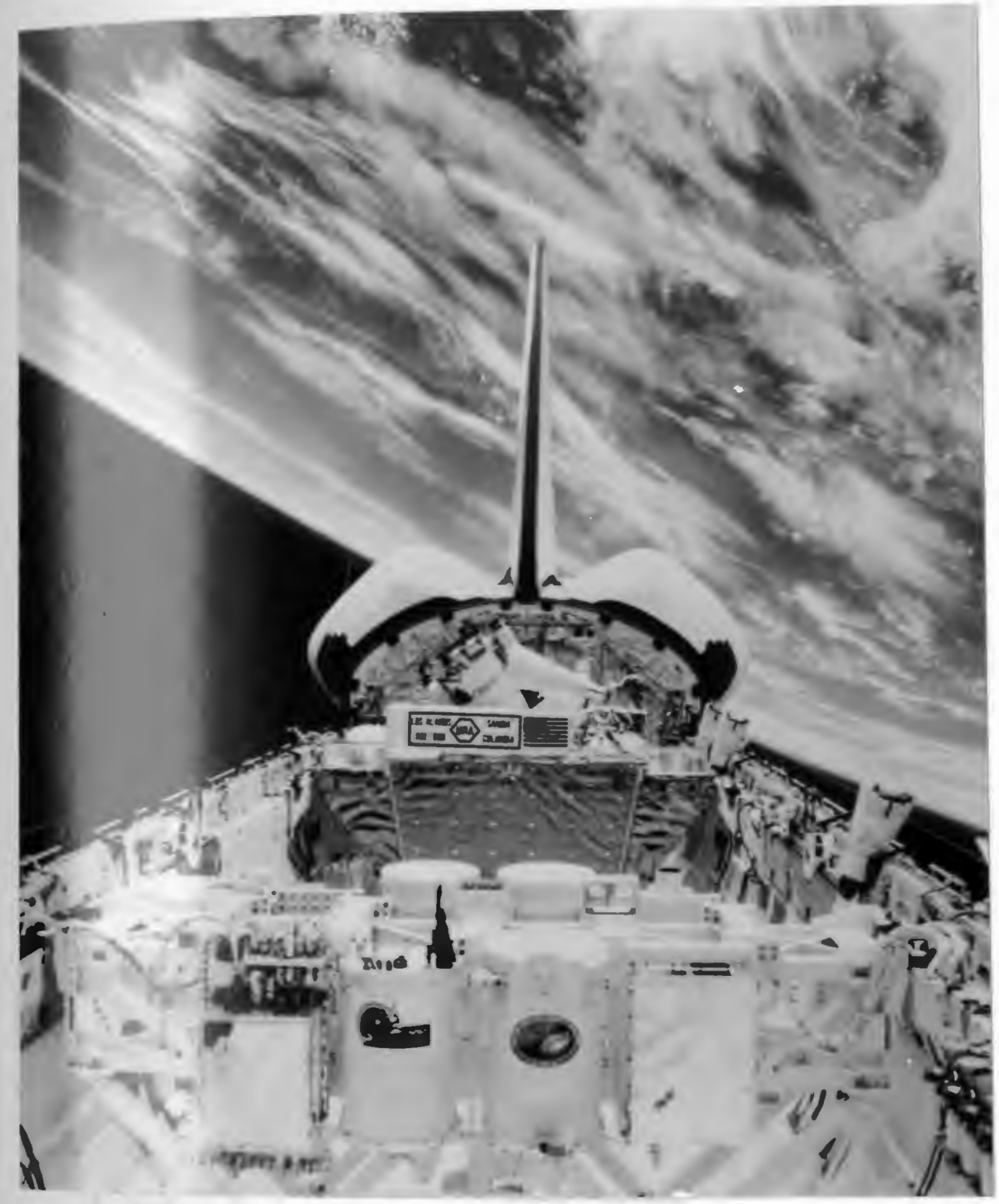

Figure 22. STS-39 Cargo Bay 


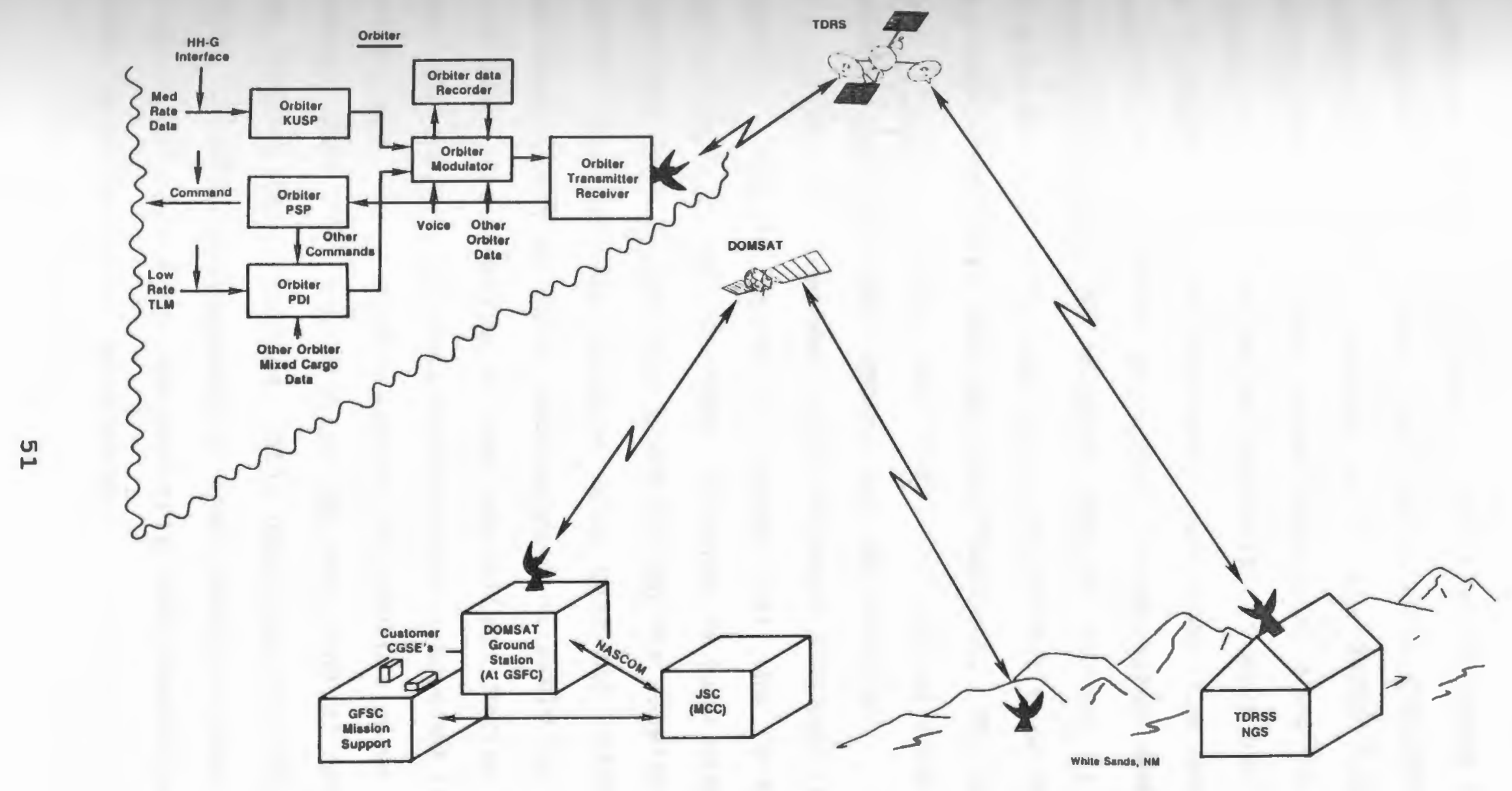

Figure 23. Hitchhiker Telemetry Link 
headed up by Dr. David Green of Physical Sciences Inc, were divided into a two shift operation with approximately five members per shift. In addition to the SKIRT teams there were personnel dedicated to the Hitchhiker-M and Hitchhiker$G$ under the direction of Ted Goldsmith of NASA GSFC as well as hundreds of other personnel all over the world. My position was as SKIRT Principal Investigator and Program Manager at NASA JSC Mission Control Center in Houston (Figure 24). In addition, I was one of two team chiefs and Principal Investigators for the CIRRIS-1A. My call signs were "Houston SKIRT PI" and "CIRRIS PI" on the communication networks between NASA Centers and the shuttle.

SKIRT was commanded on at Mission Elapsed Time (MET) 00/02:56 (Day 00, hour 02, minute 56) and continued to operate through MET 07:22:00. A number of glow measurements were conducted at specific times during the mission when the orbiter attitude was oriented such that the SKIRT payload and surrounding surfaces were exposed directly to ram, away from ram, and looking at the earthlimb. During non-glow related times, other measurements were conducted throughout the flight. Over 14,000 spectra of shuttle glow, airglow, aurora (IBC III), calibration objects, and of the orbiter environment were recorded. This data provides not only the first infrared measurement of space shuttle glow, but also a detailed record of the on-orbit environment associated with large spacecraft structures. 


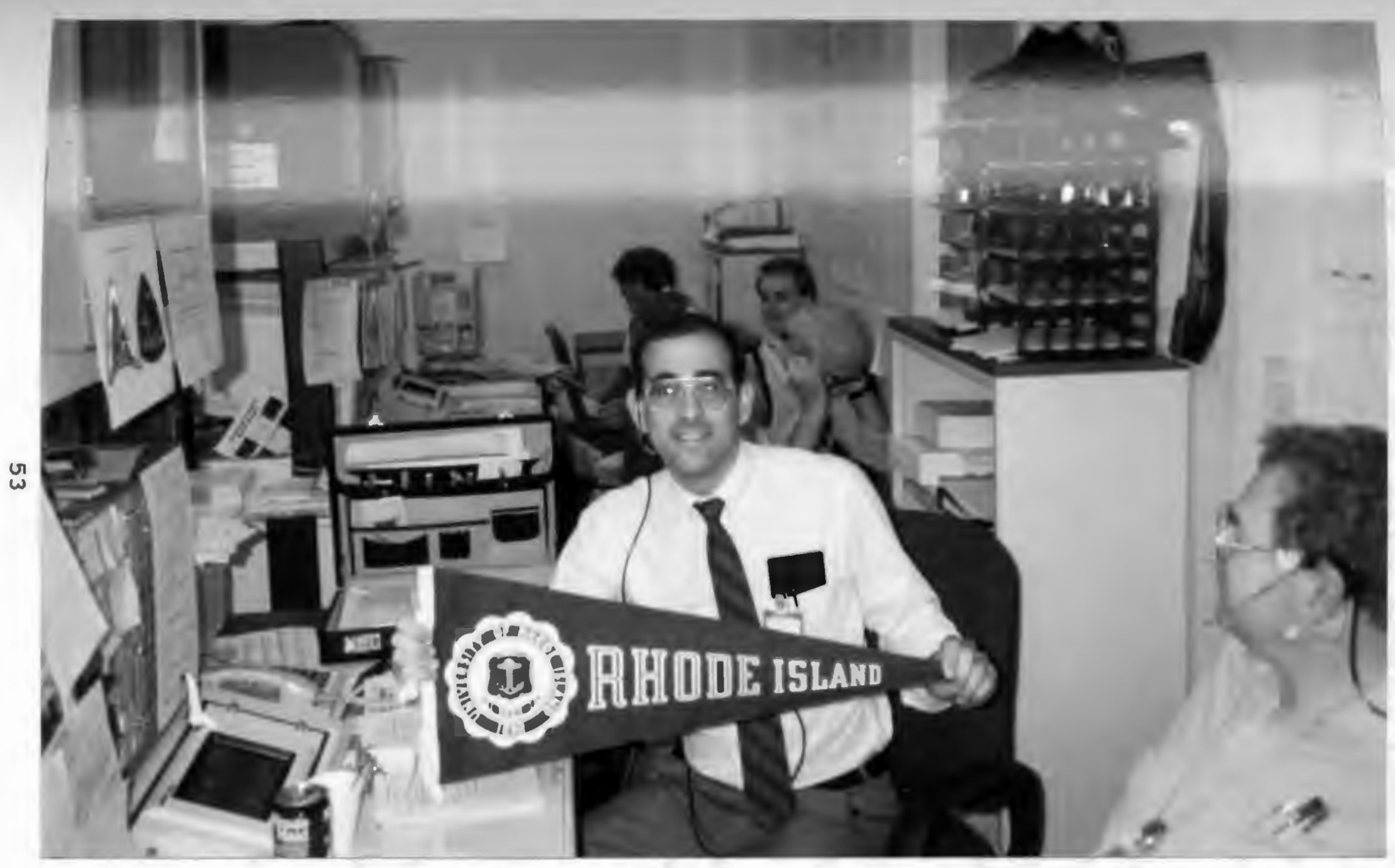

Figure 24. On Console at Mission Control, NASA JSC, Houston, TX 28 April 1991 - 6 May 1991 
SKIRT CVF operated only during specific times during the mission. Appendix I contains the STS-39 planned and as flown timelines. Constraints included: 1 - Availability of ku-band telemetry down-link. Since the CVF spectrometer required a high data bandwidth, all CVF data were sent down on the high speed Ku-band link. This necessitated being able to point the shuttle $\mathrm{Ku}$-band transmitter/radar antenna at one of two available Tracking and Data Relay Satellites (TDRS) for downlink to the White Sands Missile Range (WSMR) receivers with subsequent retransmission to the NASA GSFC POCC. 2 - other payloads on STS -39 also required the Kuband antenna and time had to be allocated between experiments. 3 - Because of the cryogenic nature of the SKIRT CVF primary mirror the aperture cover was not opened during orbiter contamination producing events such as water dumps to prevent condensible matter contaminating the cold sensor optics. Sun avoidance and other constraints also determined payload operations.

All SKIRT data were recorded on disks and real time data analysis was conducted off line as time permitted. Because of the real time data down-link the SKIRT team was one of the few investigators who knew in real time that their experiment was working and successfully obtaining the sought after data. Appendix II list the SKIRT CVF data sets collected along with brief comments by the on-shift NASA GSFC POCC team chief. 
SKIRT GLOS operated almost continuously throughout the mission with sun avoidance the primary concern. The preflight thermal concern on the mechanical coolers was not a significant problem as the orbiter maintained a fairly cold attitude.

Because of the higher priority earthlimb objectives the CIRRIS-1A glow measurement, designated as PC61, was conducted as one of the final CIRRIS-1A measurements and there was only one opportunity allowed in the timeline. This was an intensive crew operations involving not only the CIRRIS-1A payload specialist, but also a mission specialist to position the RMS and a pilot to maneuver the orbiter (Appendix IV is the crew checklist for this operation).

Considerations and constraints were many for this one chance opportunity to obtain a 2.5 to $25 \mu \mathrm{m}$ glow measurement at $1 \mathrm{~cm}^{-1}$ resolution. To maximize the purity of the shuttle glow observation the measurement was conducted in umbra to prevent direct and scattered solar radiation from entering the CIRRIS-1A telescope. To prevent earthshine and earthlimb radiation from entering the telescope the CIRRISIA was pointed to deep space. The cargo bay lights were turned off. The RMS was positioned relative to the 0,0 CIRRIS-1A gimbal position (looking straight up out of the cargo bay) such that it was two meters above the aperture and one meter to port (Figure 25). The orbiter was flown such that the starboard wing was into the velocity vector 


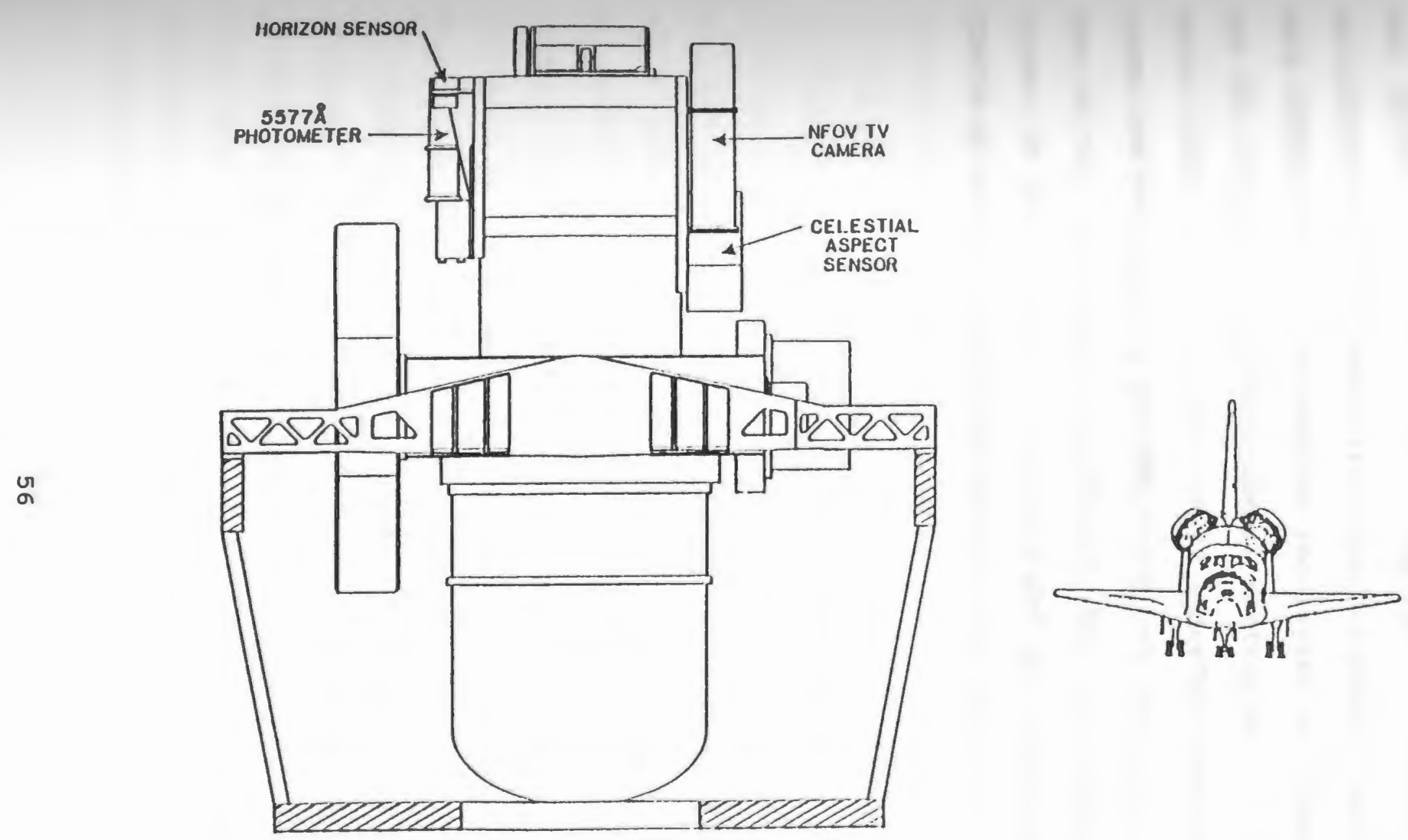

Figure 25. CIRRIS-1A as seen from the aft flight deck. The RMS was positioned one meter to the port side of the CIRRIS-1A FOV center line and two meters above the telescope aperture cover. 
and the RMS surface closest to the CIRRIS-1A field of view was exposed to ram. All maneuvering thrusters and entamination events were inhibited to prevent mirror and data contamination. The payload specialist was directed to use the CIRRIS-1A joystick gimbal controller to roll the sensor toward the RMS until the \#2 interferometer detector signal was saturated by the RMS black body emission. He was then to roll the sensor to starboard until the signal was no longer in saturation. It was hoped at this point the CIRRIS-1A would be measuring glow of the RMS. 
Results and Discussion

This section addresses the SKIRT CVF data for cuiescent glow, thruster enhanced glow, atmospheric emissions, comparison to synthetic spectra, day/night variations, and ram angle dependance. SKIRT GLOS results will be shown for a nitric oxide gas release. A brief discussion of the CIRRIS-1A and IBSS results at measuring glow will also be included.

Figure 26 is a spectrum of daytime space shuttle glow measured when the orbiter was flying bay to ram in a vehicle attitude such that the SKIRT CVF sensor field of view was between 3 to 40 degrees from the velocity vector (sensor pointing into ram while looking above the horizon). This spectrum was generated from twenty nine stacked spectra which were recorded during a time interval of MET 06/16:16:11 through MET 06/16:18:39 (local time 1304 hours through 1345 hours). These scans were acquired after piscovery had been on orbit for over 160 hours. The orbiter surfaces (top and bottom) had been heated by the sun during the first day on orbit to bake out water and other adsorbed molecules. By the time these data were collected, outgassing from external surfaces is believed to have been minimized. Prior to and during this measurement time all thruster firings, water dumps, flash evaporators, and other ontamination generating activities were suppressed. Thus, 


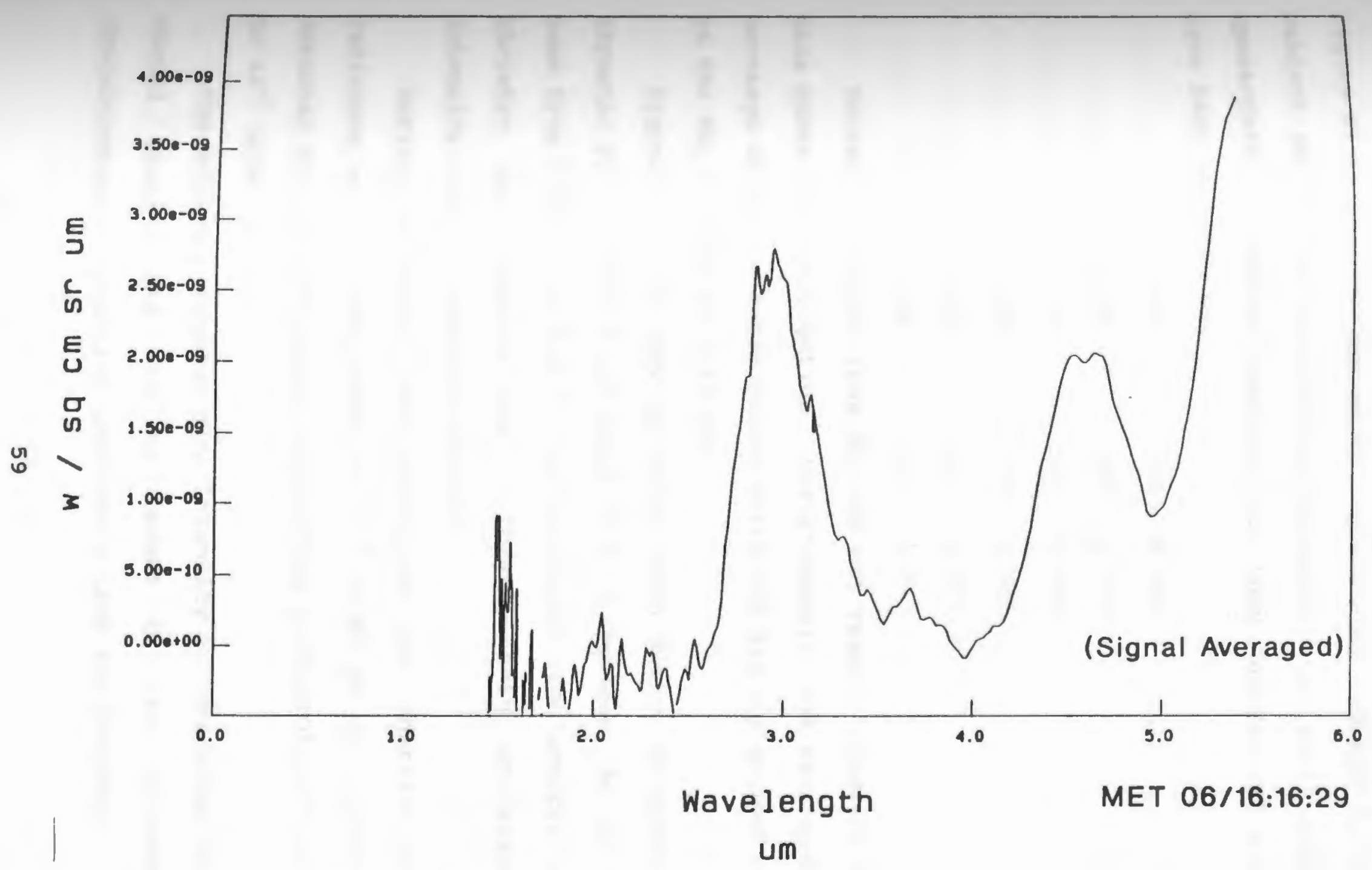

Figure 26. Quiescent Space Shuttle Glow Spectrum 
Figure 26 is representative of the radiance induced by the ambient environment surrounding quiescent low earth orbit pacecraft. Emission features for this "quiescent" glow have been assigned as:

\begin{tabular}{|c|c|c|c|}
\hline 5.3 & $\mu \mathrm{m}$ & NO & $\Delta$ \\
\hline 2.7 & $\mu \mathrm{m}$ & NO & $\Delta$ \\
\hline 4.3 & $\mu \mathrm{m}$ & $\mathrm{NO}^{+}$ & $\Delta$ \\
\hline 2.8 & $\mu \mathrm{m}$ & $\mathrm{OH}$ & $\Delta$ \\
\hline 1.4 & $\mu \mathrm{m}$ & $\mathrm{OH}$ & $\Delta$ \\
\hline 4.6 & $\mu \mathrm{m}$ & $\mathrm{CO}$ & $\Delta$ \\
\hline
\end{tabular}

Emission features from $\mathrm{NO}_{2}$ are not readily apparent at this phase of investigation. Unfortunately, the wavelength coverage of the nitrogen cooled SKIRT CVF did not extend out to the $\mathrm{NO}_{2} \mathrm{v}_{3}$ band at $6.17 \mu \mathrm{m}$.

Figure 27 is a glow spectrum taken during an orbiter thruster firing with a ram angle of 24.6 degrees. As can be seen from Figures 26 and 27 , the quiescent glow spectra and thruster glow spectra are different, both in signal intensity, and in spectral content.

During quiescent ram conditions the shuttle glow radiances are on the order of $10^{-9} \mathrm{w} / \mathrm{cm}^{2}$ sr $\mu \mathrm{m}$. During thruster firings the signal intensities increased up to $10^{-8}$ to $10^{-7} \mathrm{w} / \mathrm{cm}^{2} \mathrm{sr} \mu \mathrm{m}$.

The enhanced thruster glow intensity is consistent with visual observations and is caused by the increased concentration of reaction precursors from the thruster 


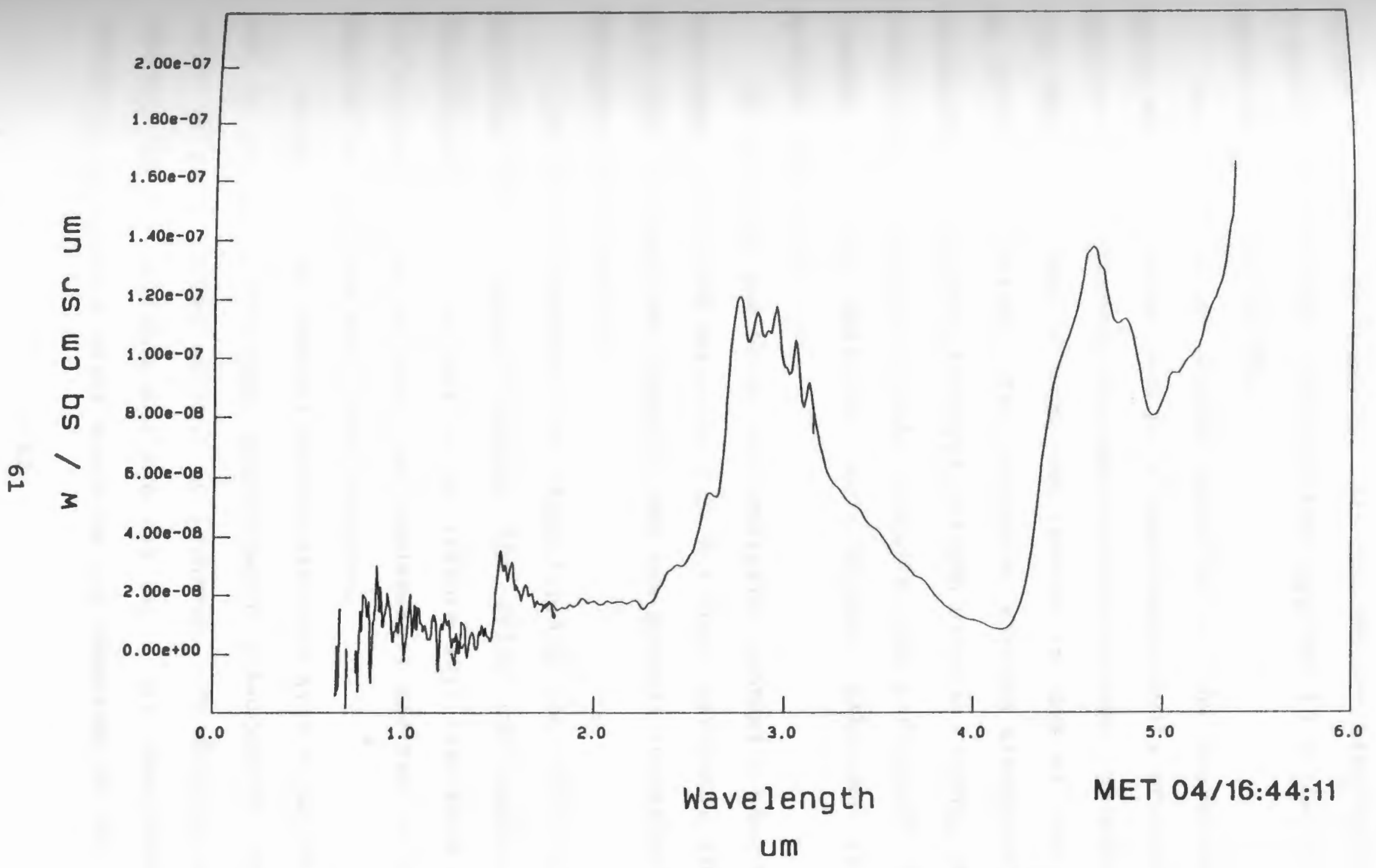

Figure 27. Thruster Enhanced Shuttle Glow Spectrum 
exhaust available for reaction with the ambient atmospheric 0 and $\mathrm{N}_{2}$. The thruster glow spectrum appears to contain at least $\mathrm{NO}, \mathrm{NO}^{+}, \mathrm{OH}$, and $\mathrm{CO}$.

Figure 28 is an airglow spectrum of the earthlimb, taken when the orbiter was in a nose down gravity gradient attitude with thrusters and contamination events inhibited (the SKIRT CVF field of view was looking in wake at the 77 $\mathrm{km}$ altitude earthlimb). This spectrum, showing atmospheric emissions from oxygen, hydroxyl, carbon dioxide, ozone, and nitric oxide, provides a well characterized reference ${ }^{21}$ to compare with the quiescent and thruster enhanced glow spectra (Figure 29).

To assist in the SKIRT data analysis, synthetic spectra have been calculated using the U.S. Air Force strategic High Altitude Radiance Code (SHARC) ${ }^{22}$ and the seuroral Attmospheric Radiance code (AARC) ${ }^{23}$.

A synthetic spectrum for vibrationally excited No was generated that closely matches the SKIRT CVF spectral distribution at $2.7 \mu \mathrm{m}$ and $5.3 \mu \mathrm{m}$ (Figure 30). The band at $5.3 \mu \mathrm{m}$ is assigned to the $\Delta \mathrm{v}=1$ fundamental and the $2.7 \mu \mathrm{m}$ band is assigned to the $\Delta \mathrm{v}=2$ overtone.

In the $2.7 \mu \mathrm{m}$ spectral region water is also a radiator and it is known from mass spectrometer measurements that water is part of the shuttle environment. To distinguish between the NO overtone and the $\mathrm{H}_{2} \mathrm{O}\left(\mathrm{v}_{1}+\mathrm{v}_{2}\right)$ combination bands an atmospheric water spectrum was compared to the 


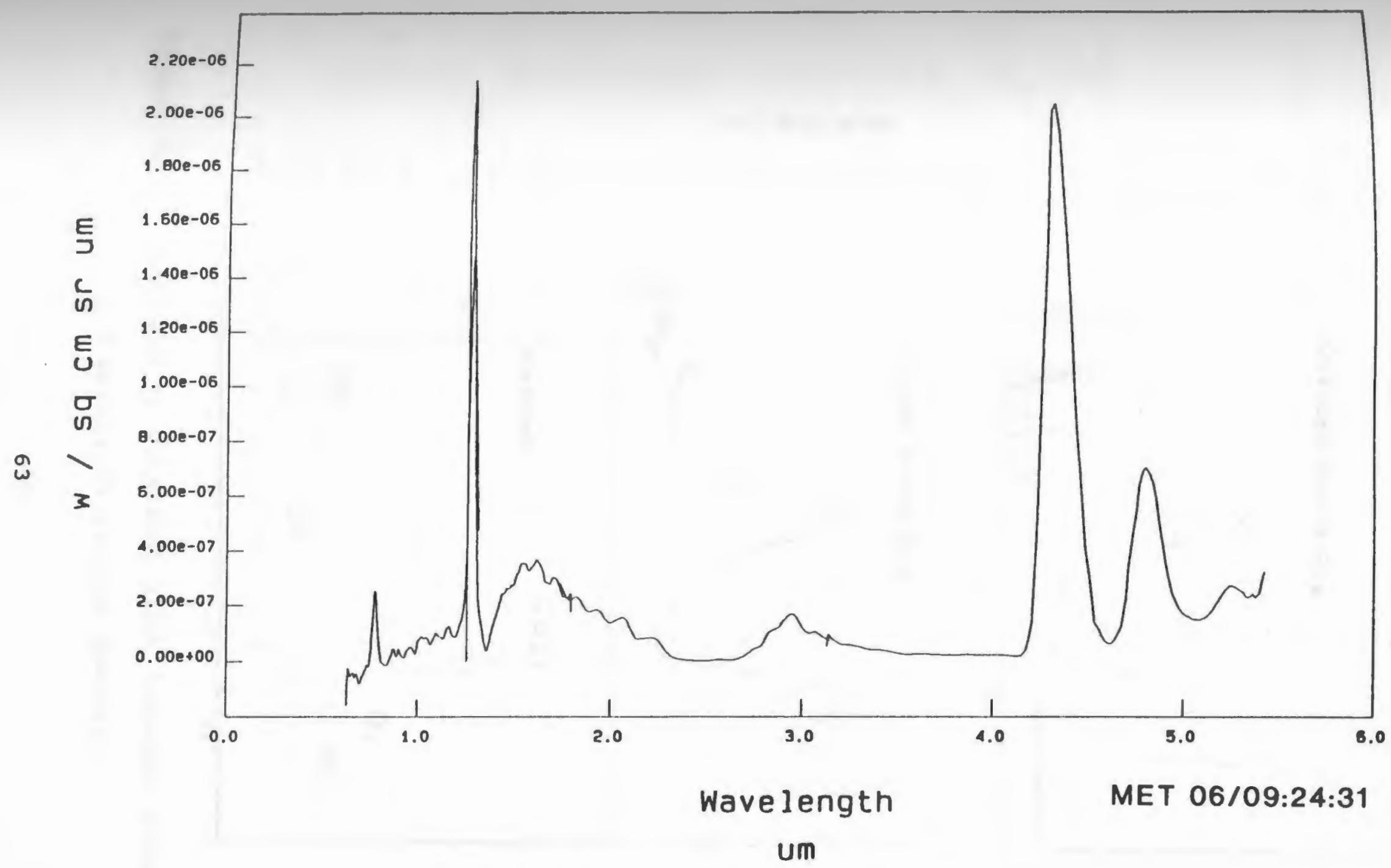

Figure 28. Earthlimb Airglow Spectrum 


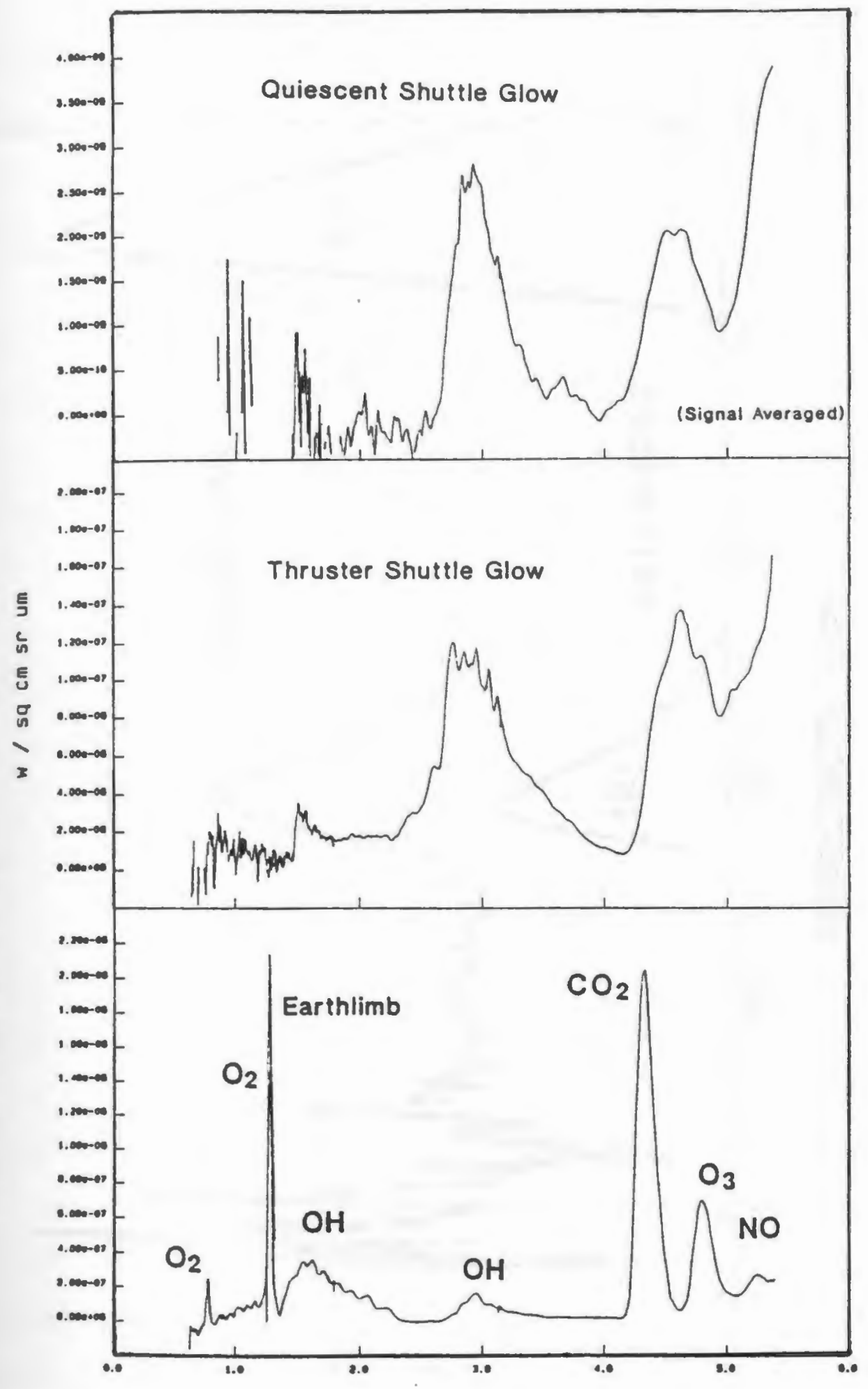

Figure 29. Comparison of quiescent glow, thruster enhanced glow, and earthlimb airglow spectra. 


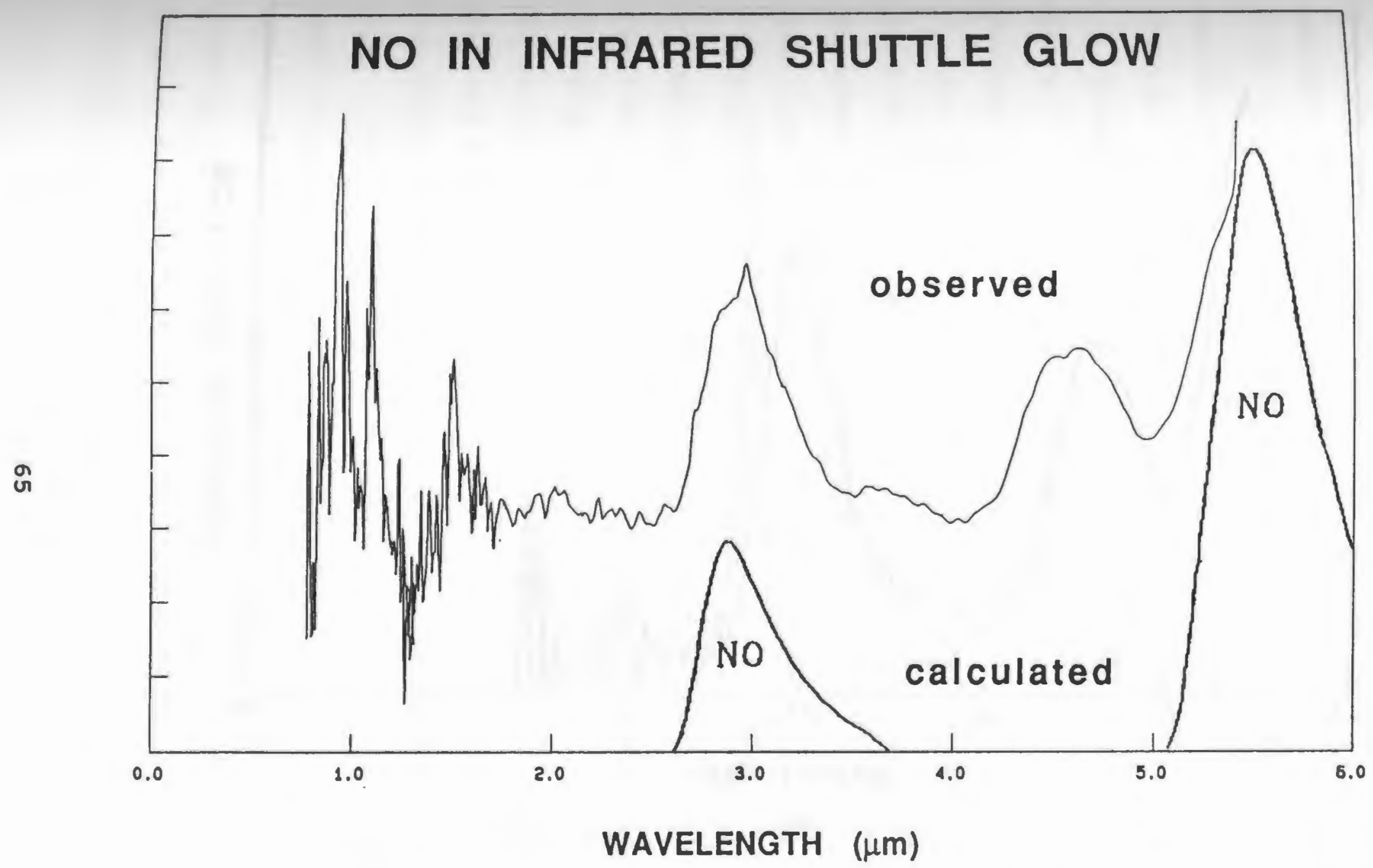

Figure 30. Comparison of Nitric oxide Fundamental and overtone Bands to Quiescent Shuttle Glow Emissions 


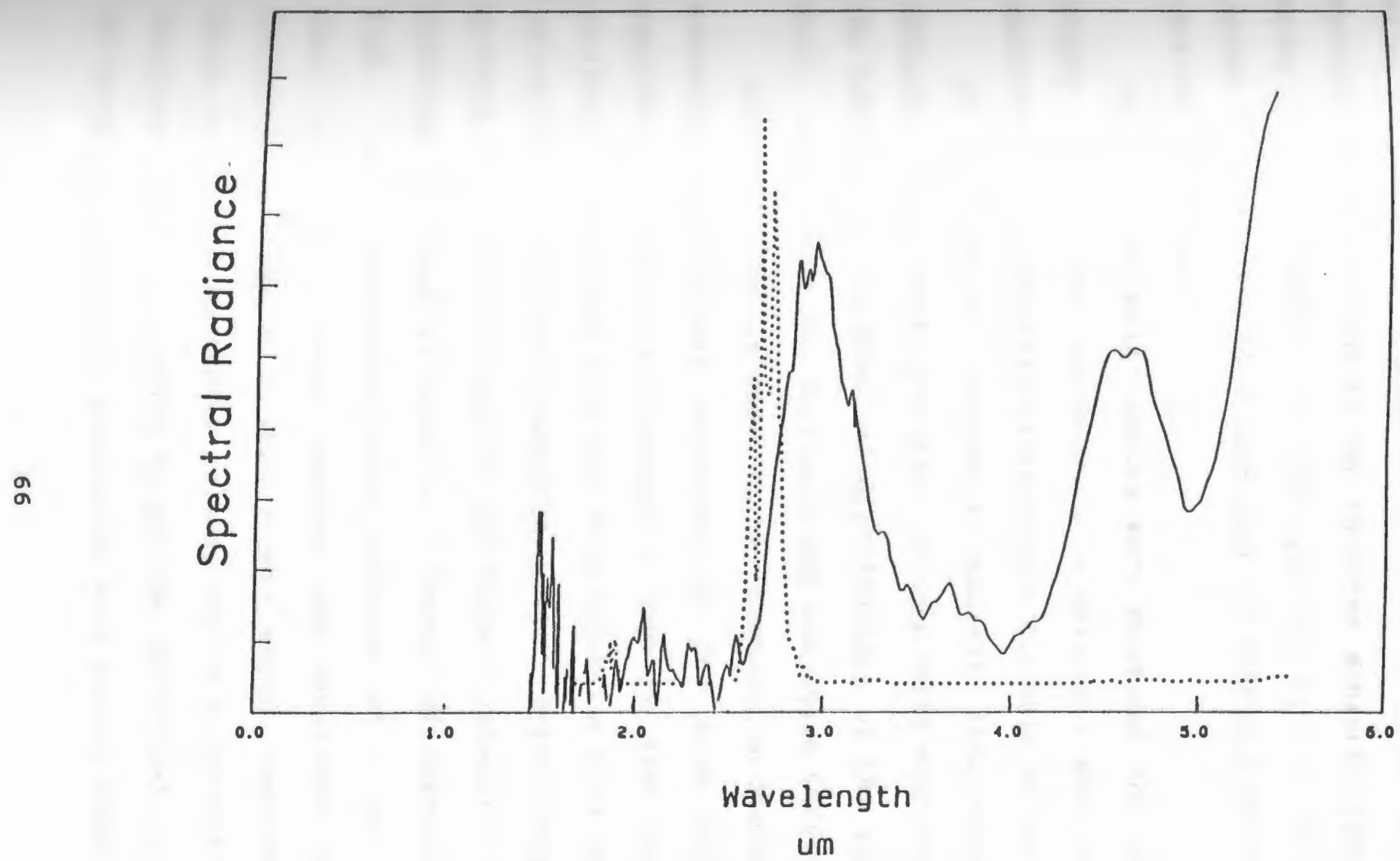

Figure 31. Comparison of SWIR water spectrum to quiescent shuttle glow spectrum. Dotted line is $\mathrm{H}_{2} \mathrm{O}$ at $20 \mathrm{~cm}^{-1}$ spectral resolution. 
quiescent shuttle glow data (Figure 31 ). The peak of the water band is blue shifted relative to the glow emission. However, when compared to the thruster enhanced glow data there is some overlap in this spectral region and water cannot be ruled out as a component of infrared glow under certain conditions.

similar synthetic spectra were produced for $\mathrm{NO}^{+}$and Figure 32 shows the comparison of a quiescent shuttle glow spectrum to the spectral distribution for both NO and $\mathrm{NO}^{+}$.

In addition to changes in shuttle glow caused by thruster firings there are other factors which may influence the intensities and spectral distributions of the infrared glow. Among these are day/night and ram angle variations.

since the glow is known to be dependent on atmospheric composition a diurnal variation in the glow would be expected. Figure 33 compares a daytime glow spectrum (06/16:16; local time $1300 \mathrm{hrs})$ to a nighttime glow spectrum (07/18:19; local time 2340-0100 hrs). Even though the spectral features are similar the overall intensity of the nighttime spectrum is down by a factor of approximately 2.5x. Both measurements were conducted at a ten degree angle from ram. These results are consistent with a nighttime decrease of 0 when atomic oxygen combines with ozone to produce molecular oxygen, and to a decrease in $0^{+}$ (Figures 3 and 4 ) relative to daytime concentrations. The on-orbit observation is consistent with ground based 


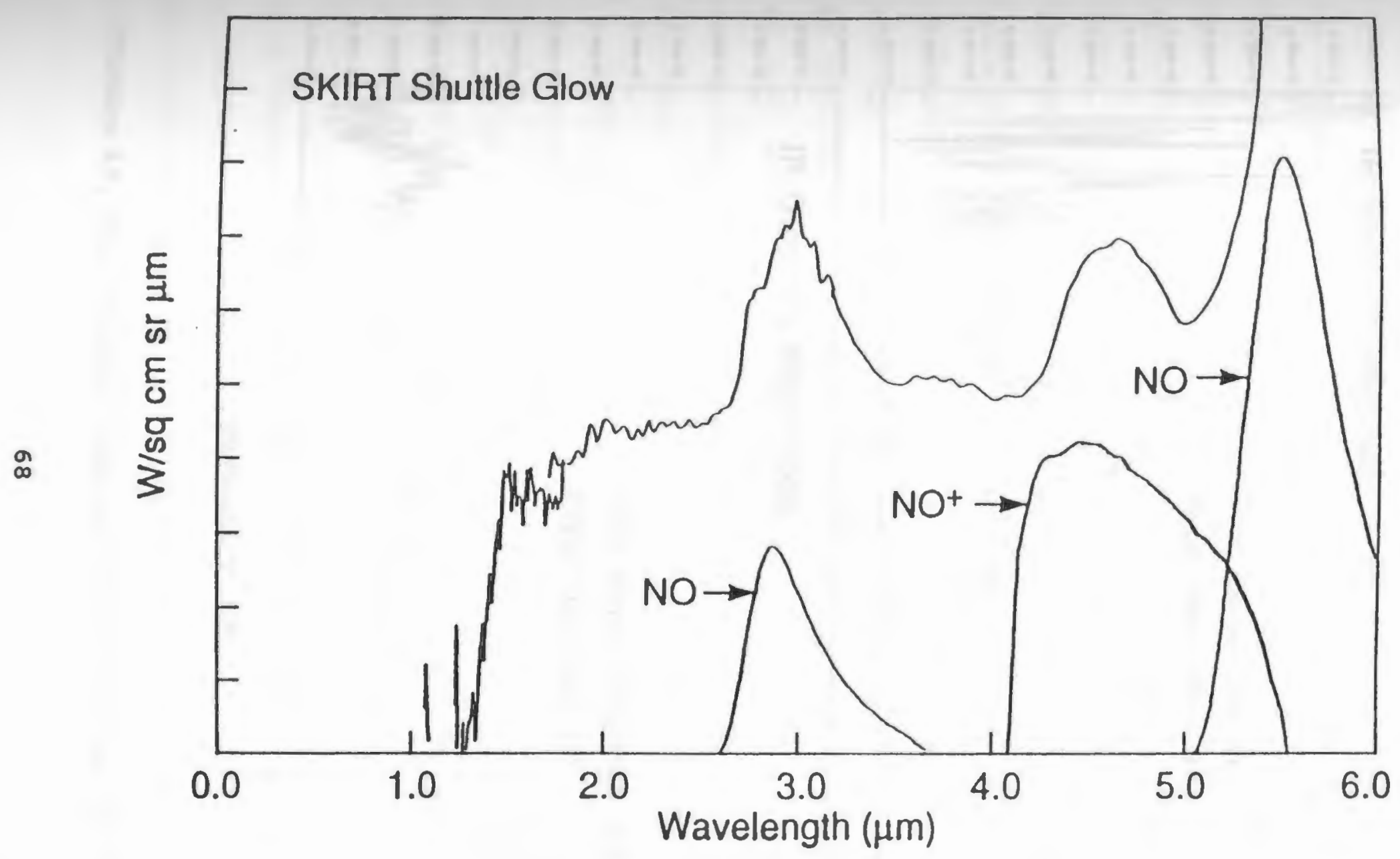

Figure 32. Comparison of $\mathrm{NO}$ and $\mathrm{NO}^{+}$to quiescent shuttle glow. 


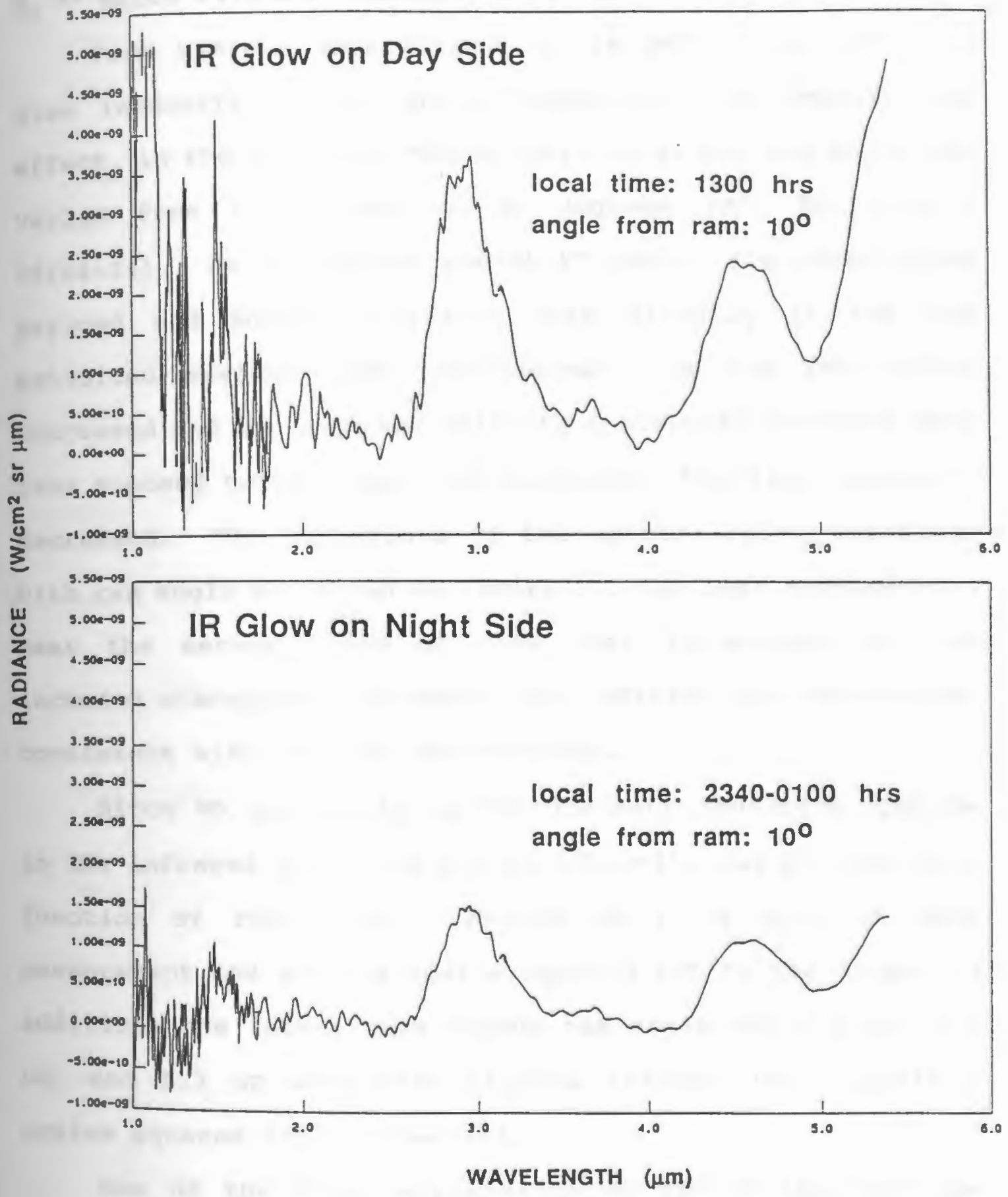

Figure 33. Day Shuttle Glow vs Night Shuttle Glow 25 
laboratory experiments involving fast 0 and $0^{+}$reacting with $\mathrm{N}_{2}{ }^{24}$ which will be discussed later in this section.

From visible observations it is well known that the glow intensity is ram angle dependent. To measure the effect, in the infrared, the shuttle cargo bay ram angle was varied from 11 degrees to 90 degrees (MET 06/18:09 06/18:24). At 11 degrees the SKIRT sensor and surrounding payload and shuttle surfaces were directly in ram and exhibited maximum glow intensities. As the ram angles Increased and the $8 \mathrm{~km} / \mathrm{sec}$ velocity spacecraft surfaces were less exposed to the impacting atmosphere the glow intensity decreased. The variations of the spectral glow emissions with ram angle are shown in Figure 34 . The less surface area near the sensor field of view that is exposed to the incoming atmosphere the weaker the infrared glow emissions; consistent with visible observations.

Since NO appears to be the dominant radiating species in the infrared glow, its $5.3 \mu \mathrm{m}$ intensity was plotted as a function of ram angle. Figure 35 is a plot of this measurement and shows a cosine squared fit to the data. In addition, the intensities versus ram angle for $2.9 \mu \mathrm{m}, 4.5$ $\mu \mathrm{m}$, and $5.3 \mu \mathrm{m}$ were also plotted (Figure 36). Again a cosine squared $f$ it is observed.

One of the other experiments on STS-39 involved the controlled releases of four gases (nitric oxide, xenon, neon, and carbon dioxide. During the No gas release the 


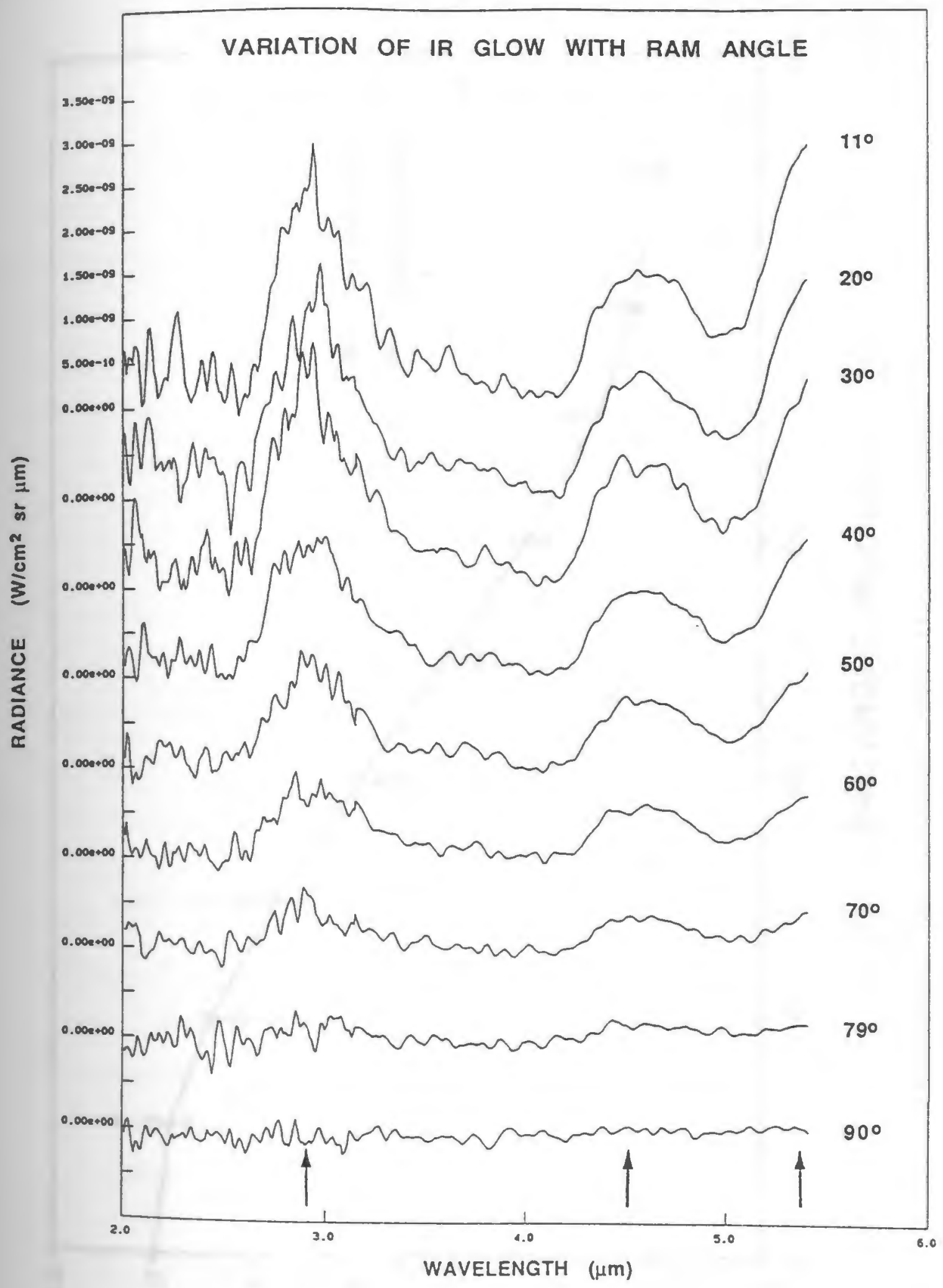

Figure 34. Variation of Glow Spectra with Ram Angle 25 


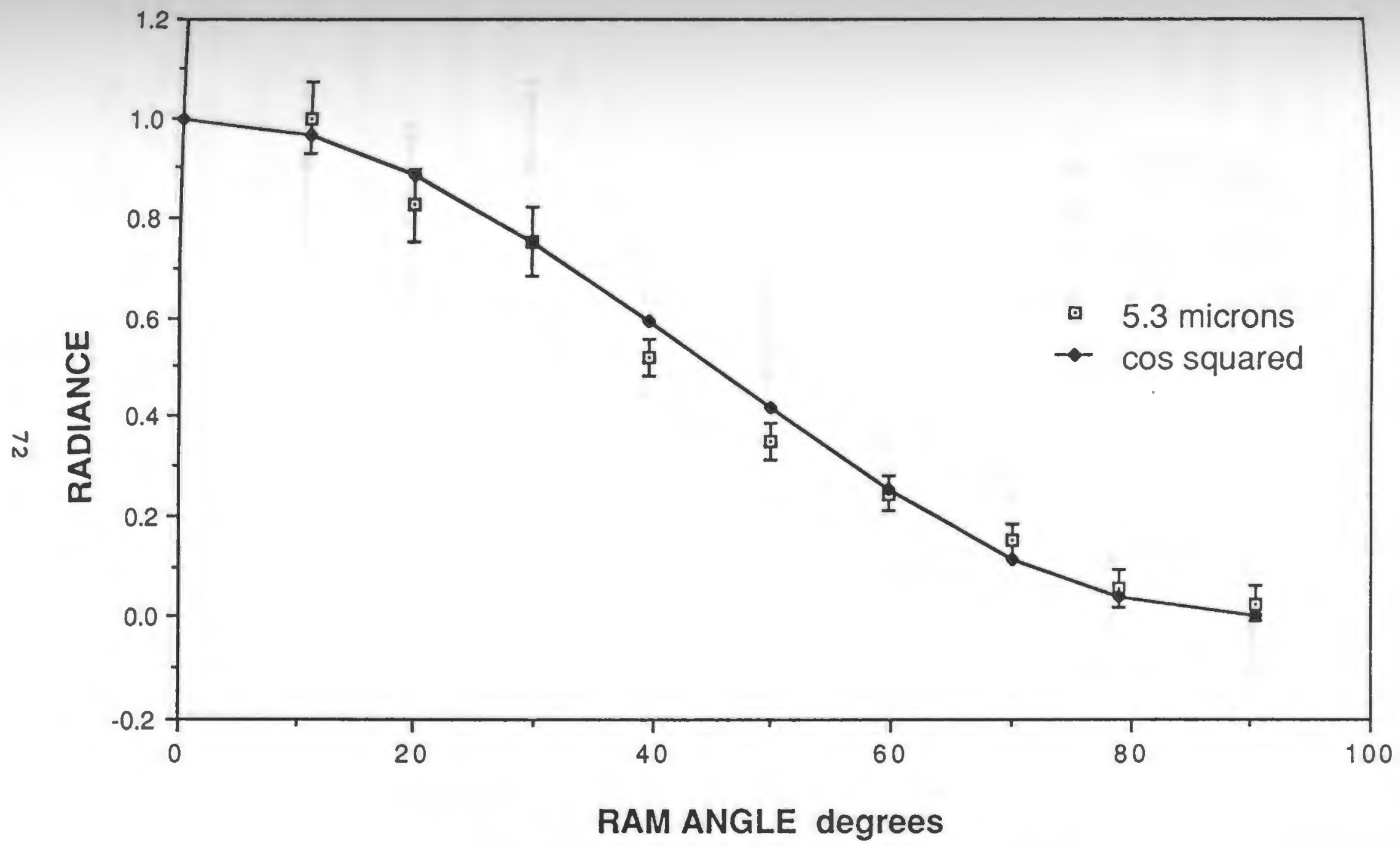

Figure 35. $5.3 \mu \mathrm{m}$ Glow Intensity vs Ram Angle 


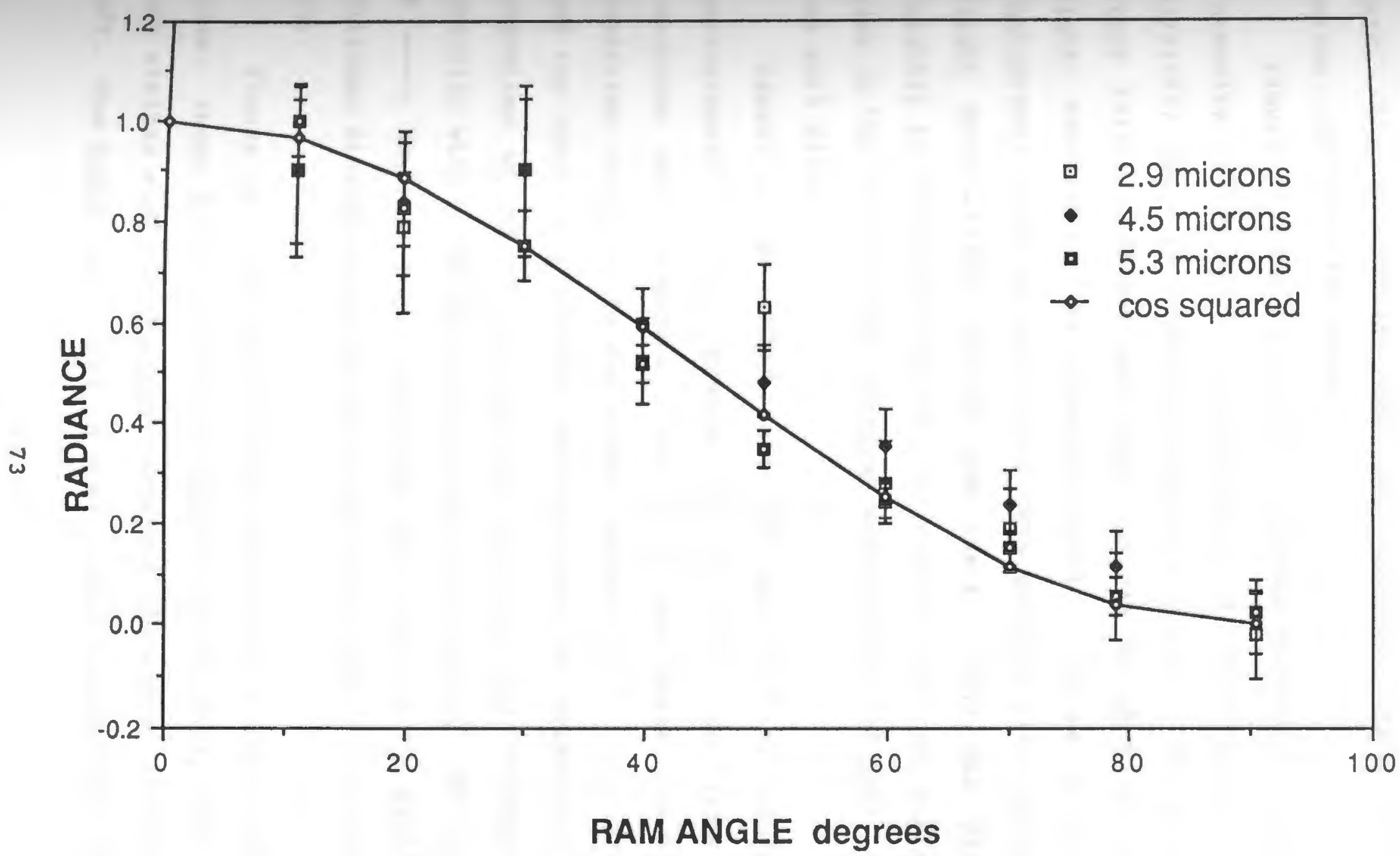

Figure 36. $2.9 \mu \mathrm{m}, 4.5 \mu \mathrm{m}$, and $5.5 \mu \mathrm{m}$ Glow Intensities vs Ram Angle. ${ }^{25}$ 
SKIRT GLOS radiometers obtained excellent data prior, during, and after the event.

Figure 37 is a plot of the visible radiometer signal intensity versus time. At the start of the release (MET $03 / 23: 25$ ) there is a rapid increase in signal. The signal stays fairly constant and when the gas is shut off the signal returns to its baseline level. Figure 38 is a photograph, taken by one of the crew members from the aft flight deck window, during the event. The gas glows brightly in the cargo bay and also creates a bright surface glow on the orbiter rear vertical stabilizer, oms pods, and top port wing.

Based on the SKIRT data and analysis of visible photographs $26,27,28$ it appears that at least two types of reactions are occuring. One is a gas phase reaction involving nitric oxide and atomic oxygen ( $\mathrm{NO}+\mathrm{O}-\rightarrow \mathrm{NO}_{2}{ }^{*}$ ) and the other is a surface mediated reaction caused by the migration of NO to the vehicle surfaces and subsequent reaction with incoming atomic oxygen to form $\mathrm{NO}_{2}{ }^{*}$ ( $\mathrm{NO}+\mathrm{O}+$ $\mathrm{M}--->\mathrm{NO}_{2}{ }^{*}$ ). Both reactions are followed by excited nitrogen dioxide going to its ground state $\left(\mathrm{NO}_{2}{ }^{*}---->\mathrm{NO}_{2}+\right.$ hv).

Figure 38 is a plot of the radiometer signal versus time. There are two different slopes in the decay time of the visible radiometer signal once the gas supply is turned off. The rapid decay time is most likely associated with 


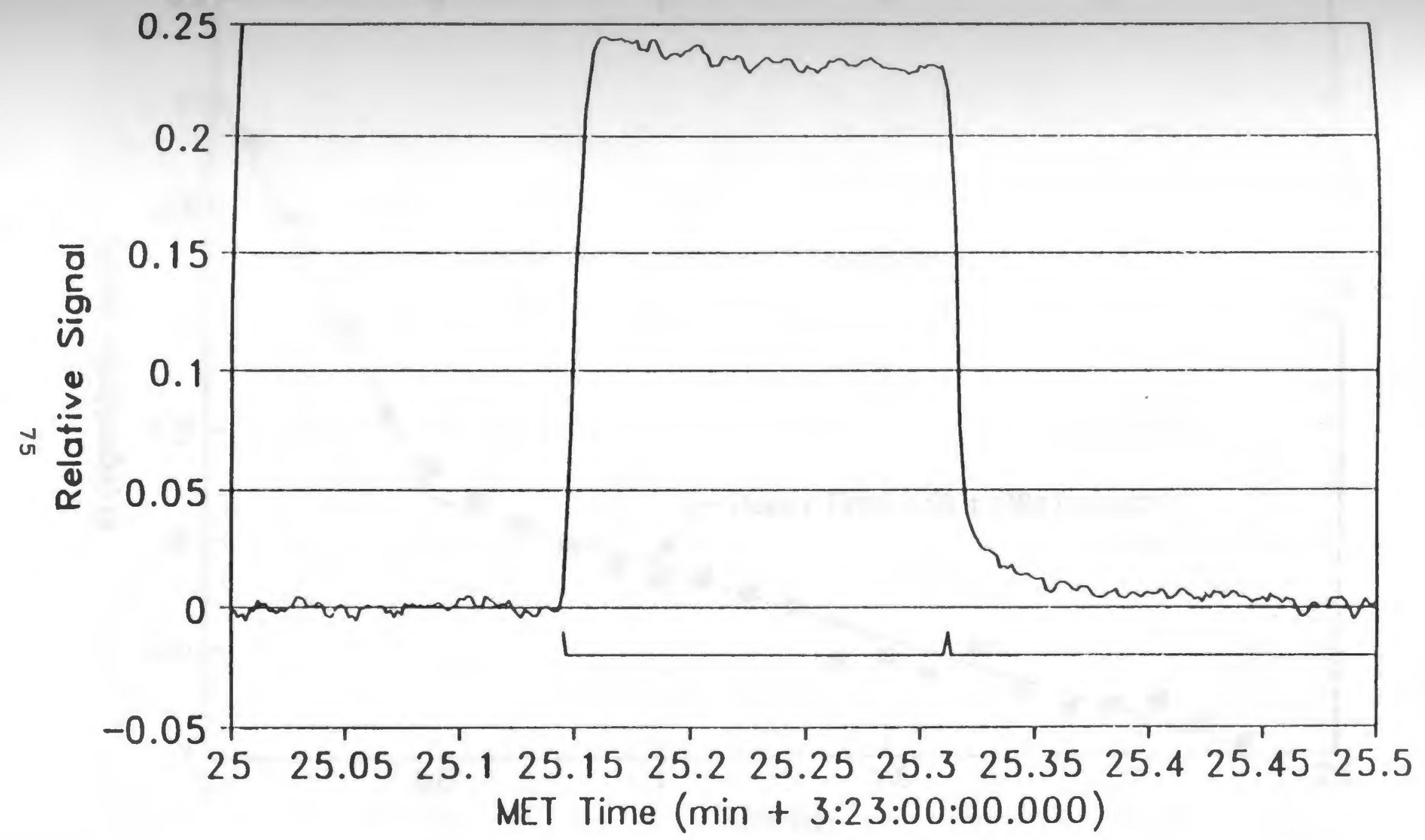

Figure 37. SKIRT GLOS Visible Radiometer Signals During No Gas Release 28 


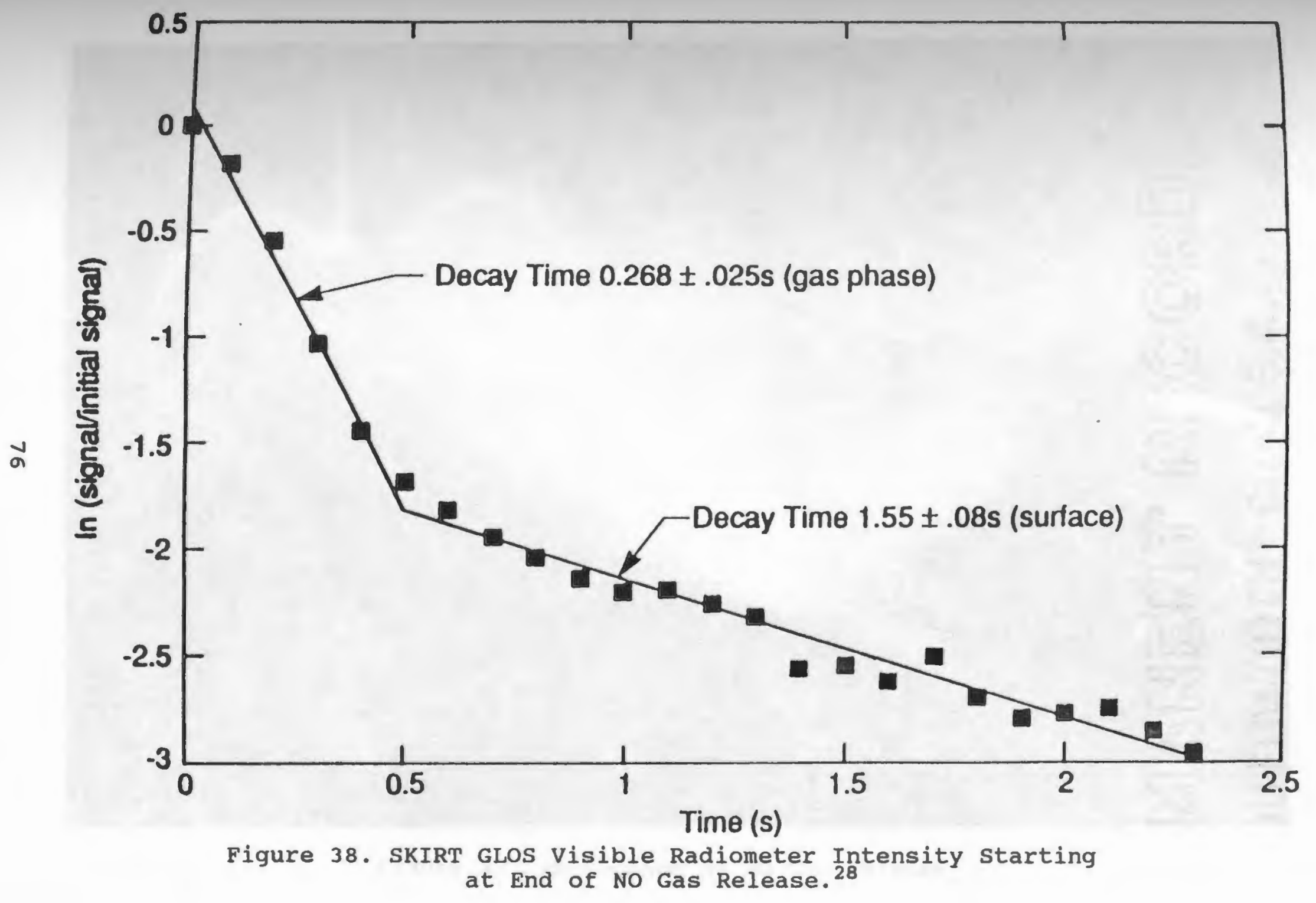




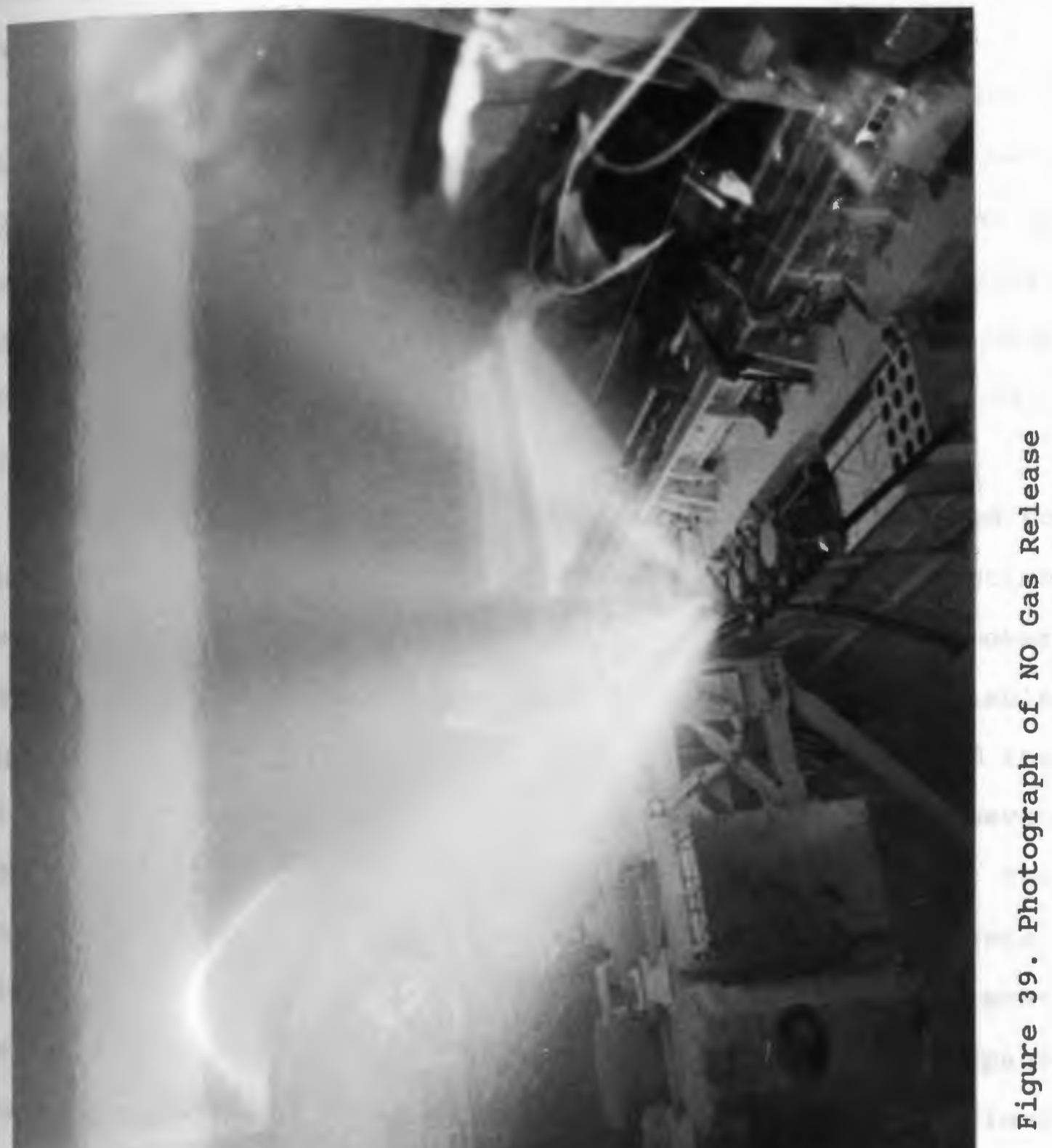


the gas phase reaction while the slower decay time is associated with the surface mediated reaction.

The attempt to measure shuttle glow with the CIRRIS-1A was not successful. The interferometer did not have sufficent sensitivity to see quiescent glow as produced by the small section of the RMS exposed to ram. Had the column density within the CIRRIS-1A field of view been greater then the glow might have been measured with the sensor's $1 \mathrm{~cm}^{-1}$ spectral resolution capability.

Ground based laboratory measurements are being used to extend the SKIRT data to understanding glow reaction mechanisms. Advantages of non-orbiting experiments over shuttle cargo bay payloads are exact control over variable parameters, ability to repeat and change conditions, and the luxury of conducting measurements over a greater than seven day time period. A major disadvantage, however, is the uncertainty of accurately duplicating orbital conditions. To obtain the maximum possible scientific results, almost all space related research involves both ground and space based experimentation. For SKIRT we are looking at previous ground based data and are conducting additional givestigations based on the orbital data.

Figure 40 is a plot of fourteen of the SKIRT GLOS radiometer channels during the No gas release compared to a previously measured laboratory spectrum ${ }^{29}$ for $\mathrm{NO}+0+\mathrm{M}$. There is a good correlation between the visible and near 


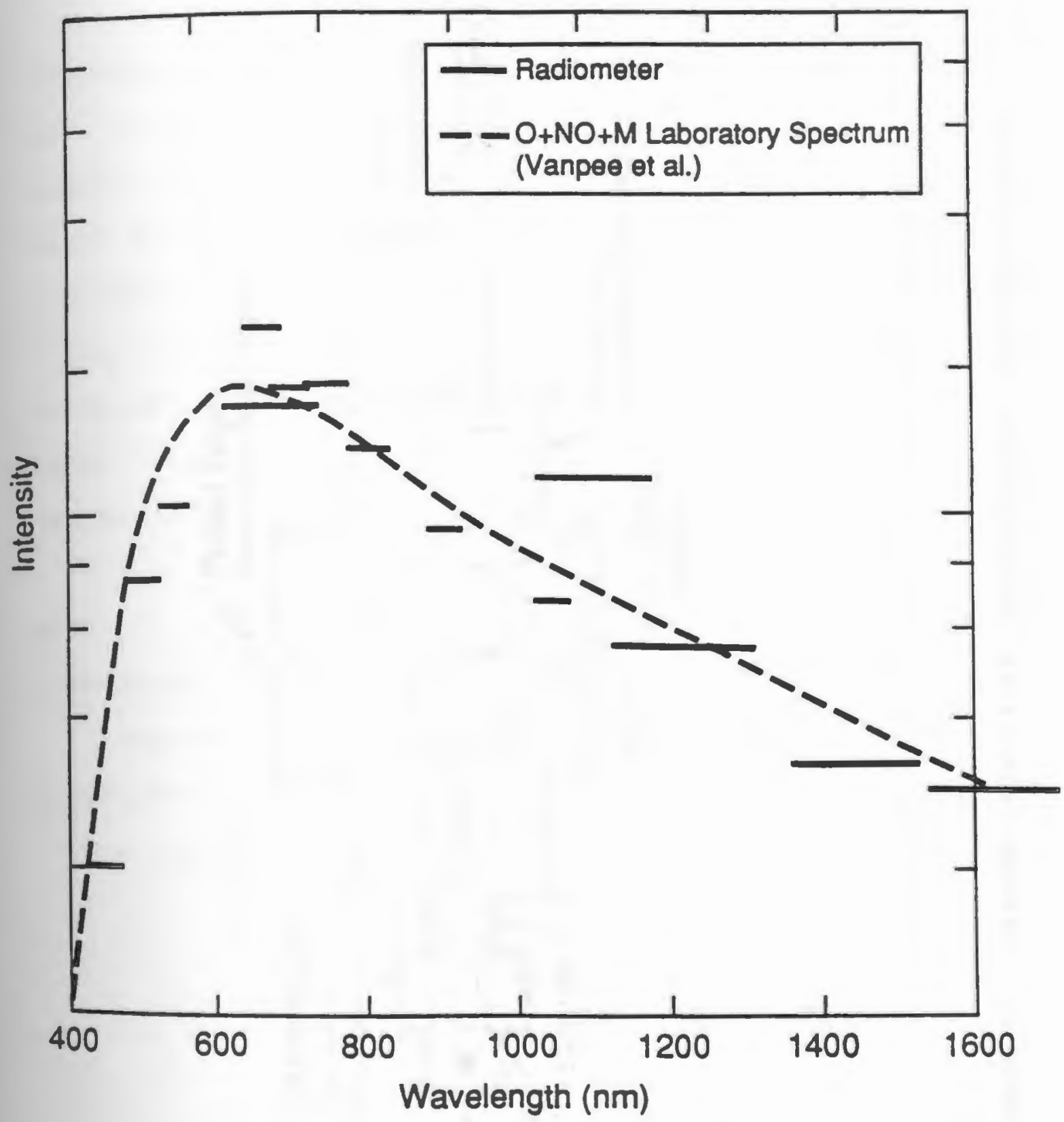

Figure 40. SKIRT GLOS nitric oxide gas release measurement compared to ground based laboratory data. ${ }^{28}$ 


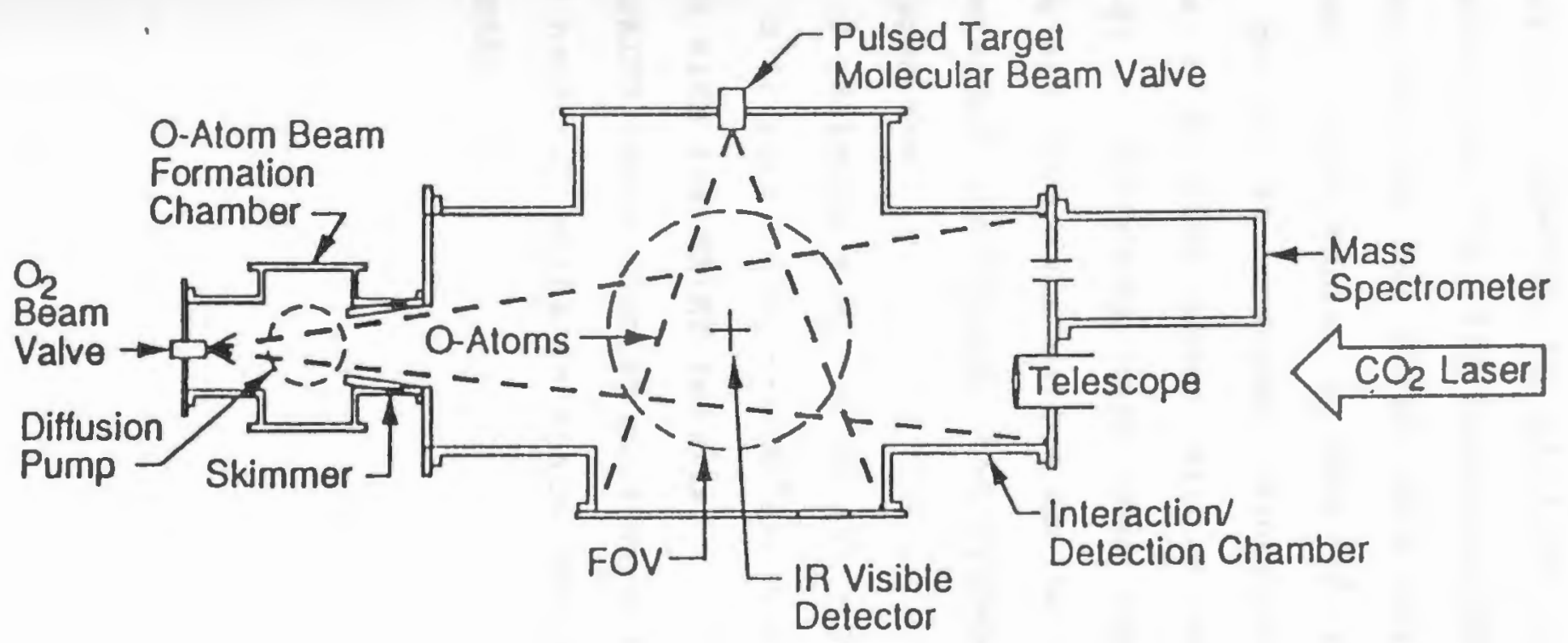

Figure 41. Ground based fast atomic oxygen reaction chamber. 
infrared radiometer on-orbit measurements to this laboratory data.

Laboratory experiments of fast oxygen atom/nitrogen uteractions under U.S. Air Force and NASA sponsorship are also being used in the SKIRT data analysis ${ }^{26}$. In these ground based experiments, a beam of atomic oxygen (with trace $\mathrm{O}^{+}$) moving at selected velocities of 8 to $12 \mathrm{~km} / \mathrm{s}$ intersects a $\mathrm{N}_{2}$ flow under single collision conditions (Figure 41). Radiances have been observed in the same bandpasses and intensity ratios as the SKIRT orbital data. Under laboratory conditions, the processes giving rise to the emissions are:

$$
O(8 \mathrm{~km} / \mathrm{s})+\mathrm{N}_{2} \rightarrow \mathrm{NO}(\mathrm{V})+\mathrm{N}
$$

and

$$
\mathrm{O}^{+}(8 \mathrm{~km} / \mathrm{s})+\mathrm{N}_{2} \rightarrow->\mathrm{NO}^{+}(\mathrm{V})+\mathrm{N}
$$

consistent with the SKIRT results.

The SKIRT space shuttle glow experiment travelled over $3,475,000$ nautical miles in space and completed 134 orbits of the earth. 
The SKIRT payloads on board the STS-39 space shuttle Discovery obtained the first infrared spectra of space shuttle glow. Analysis shows $\mathrm{NO}, \mathrm{NO}^{+}, \mathrm{OH}$, and $\mathrm{CO}$ to be components of the infrared glow. During thruster firings there are 10- to 100-fold enhancements in the infrared glow radiance intensities, as well as changes in the observed apectral distribution. Visible measurements obtained during a NO gas release show emissions from $\mathrm{NO}_{2}{ }^{*}$. The SKIRT orbital data are consistent with experimental results from other space observations and ground based measurements. 
1 Green, B.D., "Review of the Vehicle Glow", Shuttle ironment and operations II conference, American Institute of Seronautics and Astronautic Report AIAA-85-6095CP, 1985.

2 Garrett, H.B., Chutjian, A., and Gabriel, S., "Space vehicle Glow and its Impact on spacecraft systems," J. spacecraft, 25, 321, 1988.

3 Banks, P.M., P.R. Williamson, and W.J. Raitt, "Space Shuttle Glow Observations", Geophys. Res. Lett., 10, 118 , 1983.

4 Mende, S.B. and G.R. Swenson, "Vehicle Glow Measurements on the Space Shuttle", Second Workshop on spacecraft Glow, NASA Conference Publication-2391, pp.1-45, 1985.

5 Torr, M.R., Hays, P.B., and Kennedy, B.C., "Intercalibration of Airglow observatories with the Atmosphere Explorer Satellite," Planet. Space Sci., 25, pp. 173-184, 1977.

6 Fontijn, A., Meyer, C.B., and Schiff, H.I., "Absolute Quantum Yield Measurement of the NO-O Reaction and its Use as a standard for Chemiliminescent Reactions," Journal of chemical Physics, Vol. 40, pp. 64-70, 1964.

7 Paulsen, D.E., Sheridan, W.F., and Huffman, R.E., "Thermal and Recombination Emsission of $\mathrm{NO}_{2}$, Journal of Chemical Physics, Vol.53, p.647, 1970.

8 Swenson, G.R., Mende, S.B., clifton, K.S., "Ram Vehicle Glow spectrum:Implication of $\mathrm{NO}_{2}$ Recombination continuum," myrical Research Letters, Vol. 12, No. 2, pp. 97-100, 
1985.

9 caledonia, G.E., Holtzclaw, K.W., Green, B.D., Krech, R.H., Leone, A., and Swenson, G.R, "Laboratory Investigation of shuttle Glow Mechanisms," Geophys. Res. Lett. In Press.

10 Yee, J.H. and Abreu, V.J.; "Optical contamination on the Atmosphere Explorer-E Satellite," Spacecraft Contamination mvironment, Proceedings of SPIE-The International society for Optical Engineers, 338, pp. 120-128, 1982.

11 Ahmadjian, M., J.O. Wise, R.M. Nadile, B. Bartshci, "CIRRIS-1A space Shuttle Experiment," Journal of spacecraft and Rockets, Vol. 27, No. 6, 669-674, 1990.

12 Ahmadjian, M., E.R. Huppi, T. Conley, and K. Baker, "Cryogenic IR Measurements on Board the space shuttle," SPIE Technical Symposium East 1981, SPIE Conference Proceedings, washington, D.C., April 20-24, 1981.

13 Jensen, G.L., "Engineering Calibration Summary for the NS9D Shuttle Kinetic Infrared Test (SKIRT), Space systems mineering, Inc, Technical Report 013-CA-0100, Space Systems Engineering, Inc., December 7, 1989.

14 Swenson, G.R., A. Leone, K.W. Holtzclaw, and G.E. Caledonia, "spatial and spectral characterization of Laboratory Shuttle Glow simulations, J. Geophys. Res., In Press, 1991.

$15,16,17,18,19,20$ NASA Goddard spaceflight center, "STS-39 Space Test Program (STP)-1 Phase '0/1' '02' '03' 'Flight Safety' and 'Ground Safety' Data Review Package", NASA berd space Flight center, Hitchhiker and small payloads Program office, Greenbelt, MD, 1989 - 1990. 
21 Jursa, A.S., "Handbook of Geophysics and the space unvironment", Air Force Geophysics Laboratory, Air Force systems Command, United States Air Force, Hanscom AFB, MA 1985 .

22 Sharma, R.D., A.J. Ratkowski, R.I. Sundberg, J.W. Duff, L.S. Bernstein, P.K. Acharya, J.H. Gruninger, D.C. Robertson, R.J. Healey, "Description of SHARC, The Strategic High-Altitude Radiance Code", Geophysics Laboratory (AFSC), GL-TR-89-0229, Hanscom AFB, MA, 1989.

23 winick, J.R., R.H. Picard, R.A. Joseph, R.D. Sharma, P.P. Wintersteiner, "An Infrared Radiance Code for the Auroral Thermosphere (AARC)", Air Force Geophysics Laboratory (AFSC), AFGL-TR-87-0334, Hanscom AFB, MA, 1987.

24 Upschulte, B.L., Oakes, D.B., Caledonia, G.E., and Blumberg, W.A.M., "Infrared Emissions Arising from the Reactions of Fast $\mathrm{O} / \mathrm{O}^{+}$with $\mathrm{N}_{2}, "$ Geophysical Research Letters, In Press, 1992.

25 Ahmadjian, M., Jennings, D.E., Mumma, M.J., Espanak, F., Rice, C.J., Russell, R.W., Green, B.D., and Brown, C.W., "Infrared Spectral Identification of Space shuttle Glow," 42 Fall Meeting of The American Geophysical Union, San Fransisco, CA, December 9-13, 1991.

26 Ahmadjian, M., Jennings, D., Mumma, M., Rice, C., Green, D., Oakes, D., Malonson, M., Fraser, M., Gauthier, M., and Gelb, A., "Infrared space Shuttle Glow Measurements from STS-39; Laboratory Measurements of Vehicle Glow Arising from Gas Doped Surface", 1992 Meeting of the IRSIS Specialty on Targets, Backgrounds, and Discrimination, Naval Iraining Center, Orlando, FL, January 28-30, 1992. 
27 viereck, R.A., Murad, E., Green, B.D., Joshi, P., Pike, C.P., Hieb, R., and Harbaugh, G., "Origin of the shuttle Glow," Nature, Vol.354, Nov 7, 1991.

28 upschulte, B.L., Caledonia, G.E., Green, B.D., Ahmadjian, M., and Blumberg, W.A.M., "Mechanisms Responsible for Interaction Radiances Surrounding STS-39 Based on SKIRT/GLOS Data," 1991 Fall Meeting of The American Geophysical Union, San Fransisco, CA, December 9-13, 1991.

29 Vanpee, M., Hill, K.D., and Kineyko, W.R., "Absolute Rate constant Measurement for the Radiative Combination of Atomic oxygen with Nitric oxide," Journal of Cemical Physics, Vol. 72 , No. 20, 1980. 
STS-39 was a complex mission to plan and execute. This appendix shows one version of an experiment flight timeline. In combination with other data sets, these were used to fly the mission and in post-flight data reduction and analysis are used to reconstruct on-orbit activities related to payload data acquisition. The first timeline is the preflight plan and the second is the as flown mission. Numerous and constant changes were made real time to optimize data collection and to work around malfunctions and contingencies. These documents were generated and maintained by Rick Agardy of The Aerospace Corporation who acted as one of the interfaces between the experimenter flight operations team and NASA JSC flight operations team. 


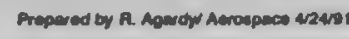

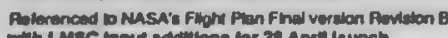

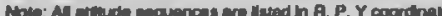

AFP 675 Timeline for a Flight Plan of Launch on 28 Apri1 11:01 GMT 16:01 CST)
Legend:

Waler Dump - Crow Hand-Over -

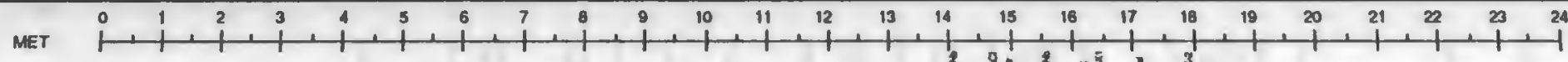

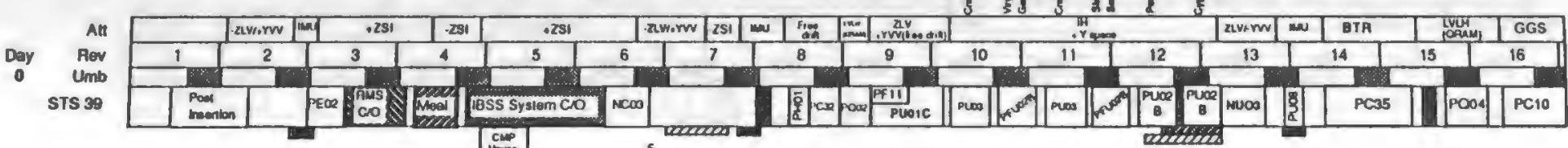
s 11

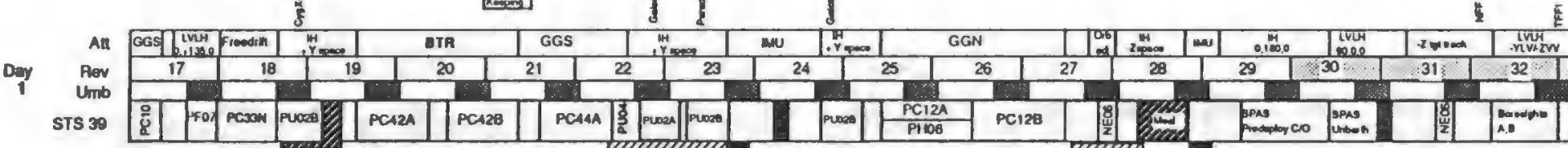

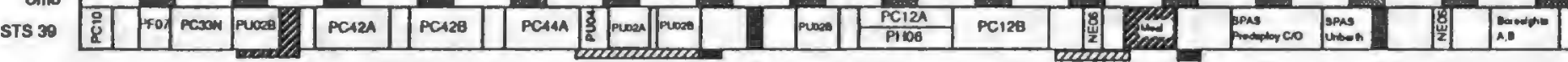

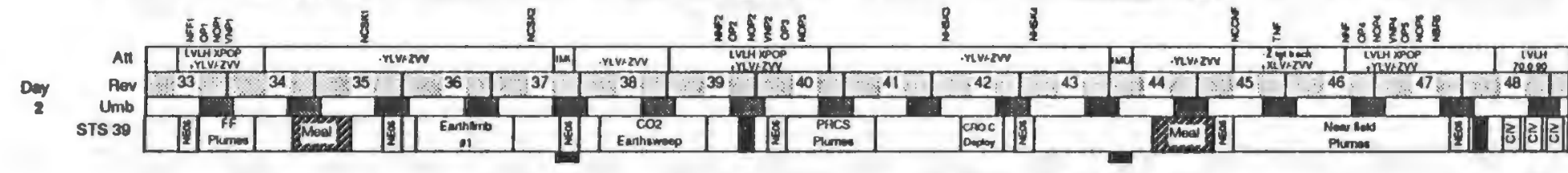

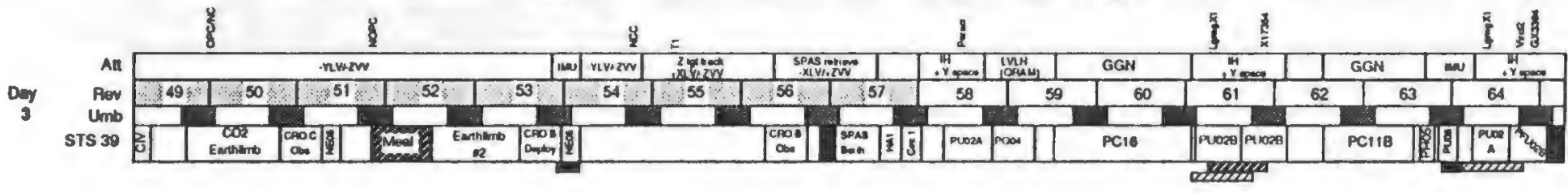

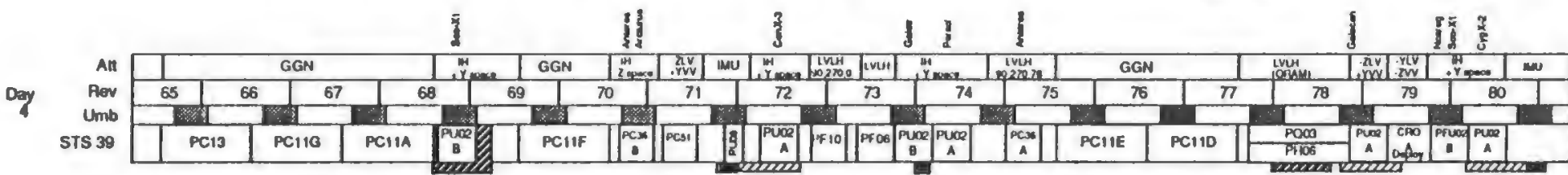

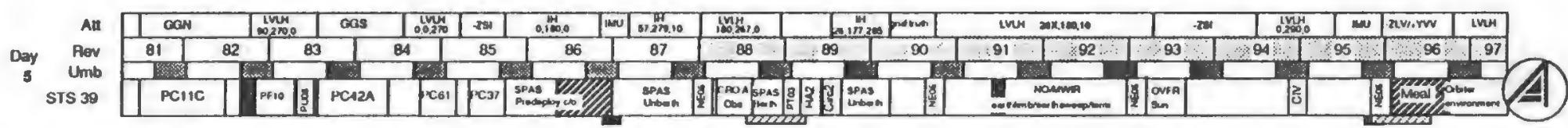




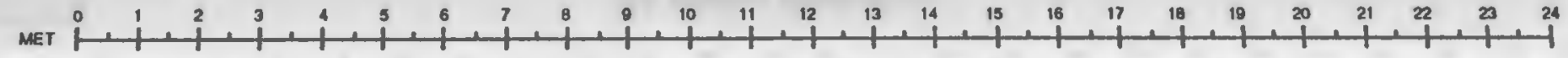

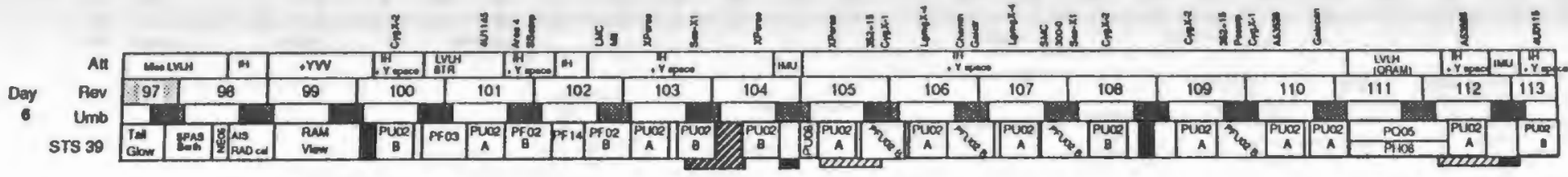

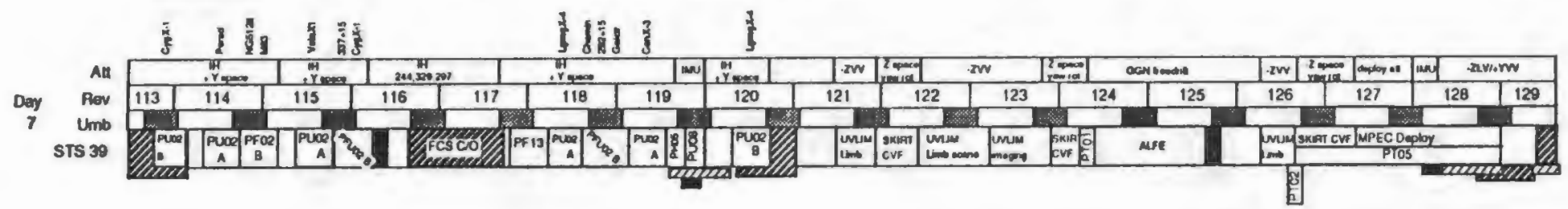

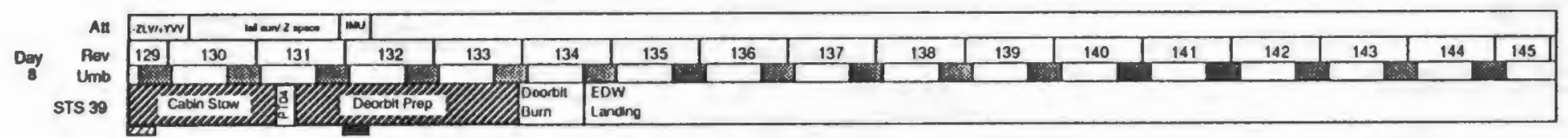


Deveropeed 27 may or

Lanch as Aprll 81

1130:14 aer

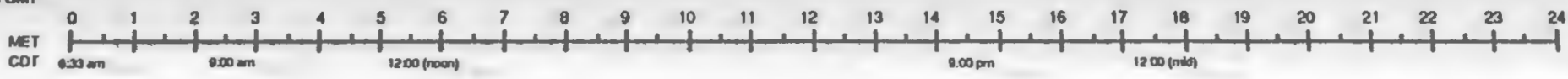

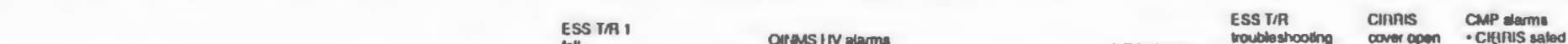

STS 39 AFP 675 Operations as flown timeline
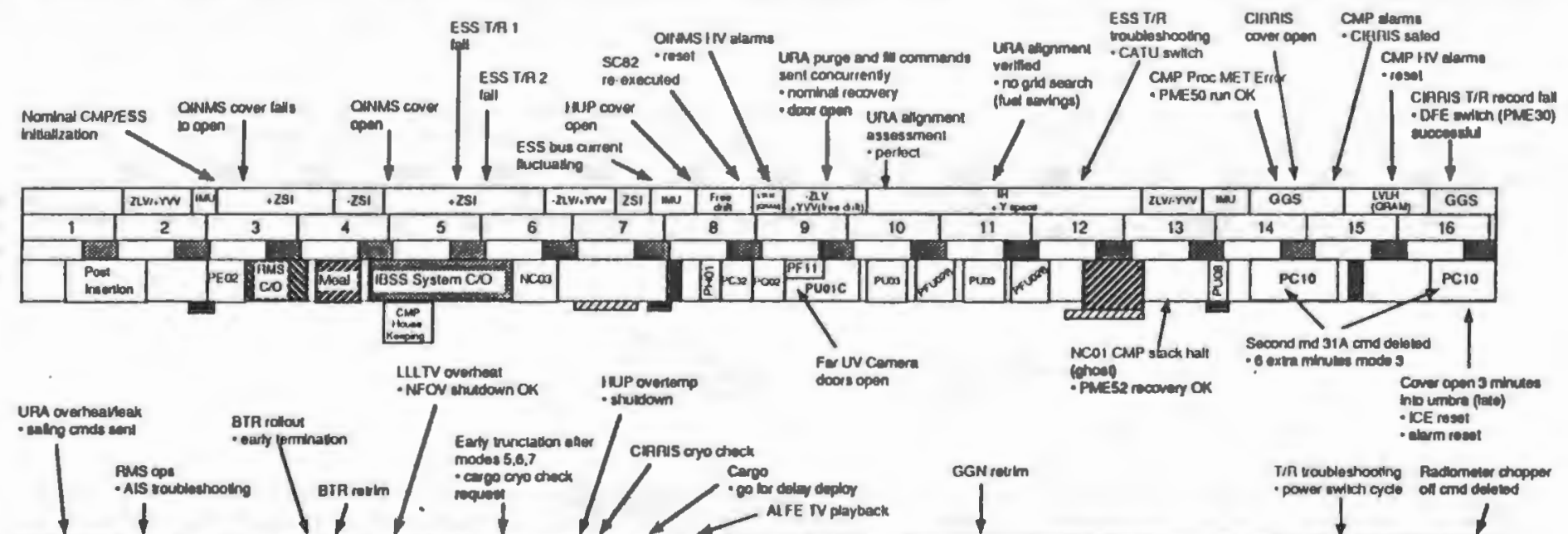
- aborm reser

Tin rouble ghooting Radiomenem chappor

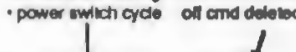

Day

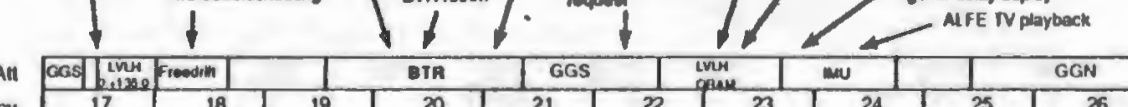

27 I

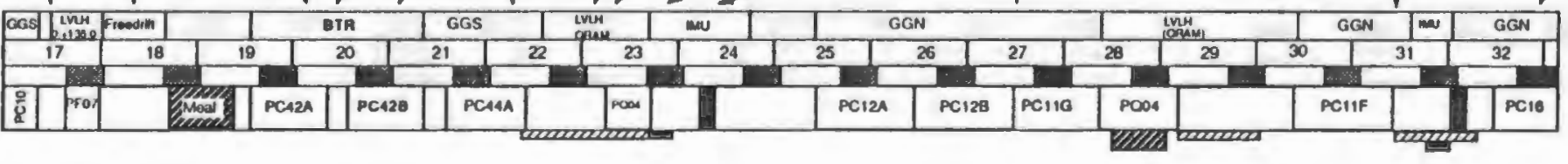

STS 39

CInvis TA leas unpowered in

beck o back blocks

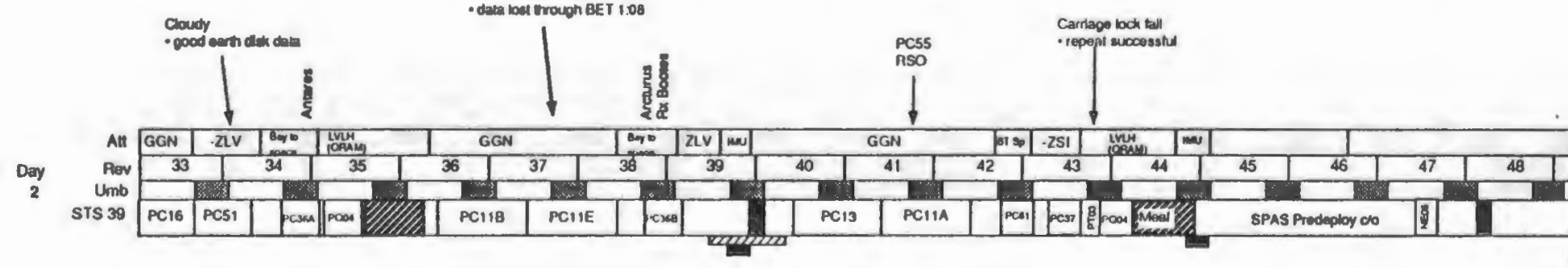




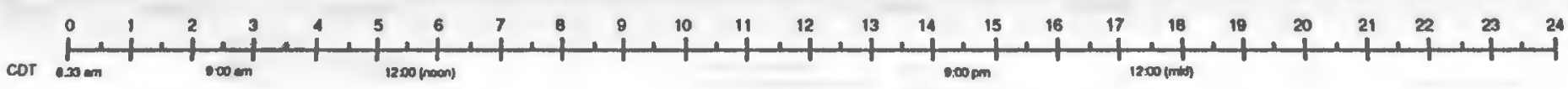
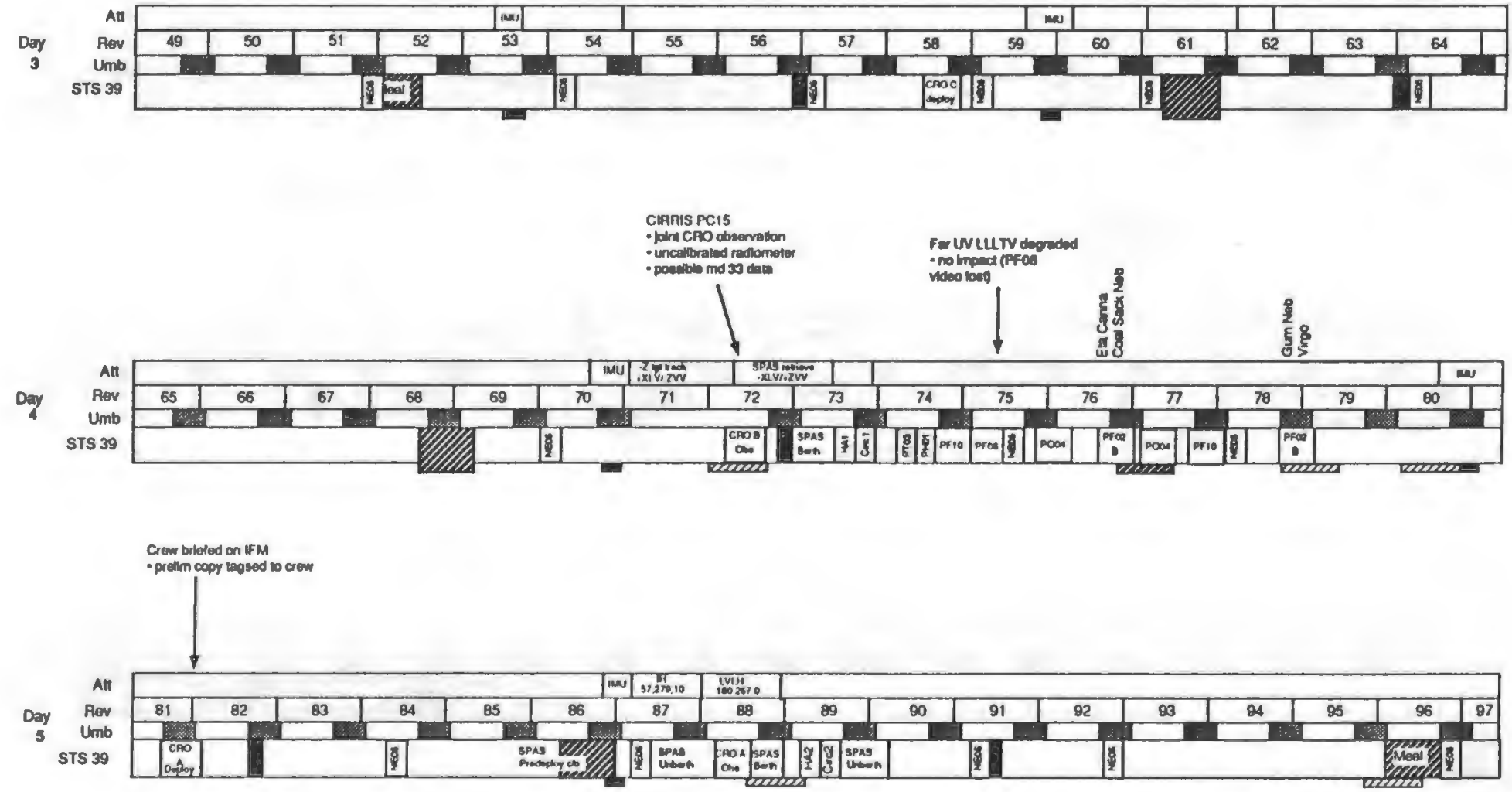
CDr $=10$

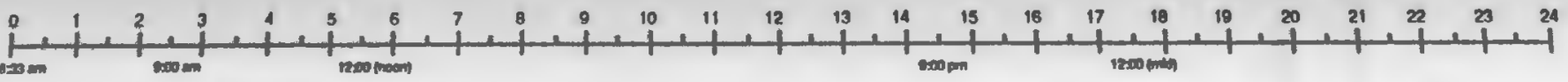

\section{IrM complete}

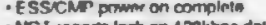

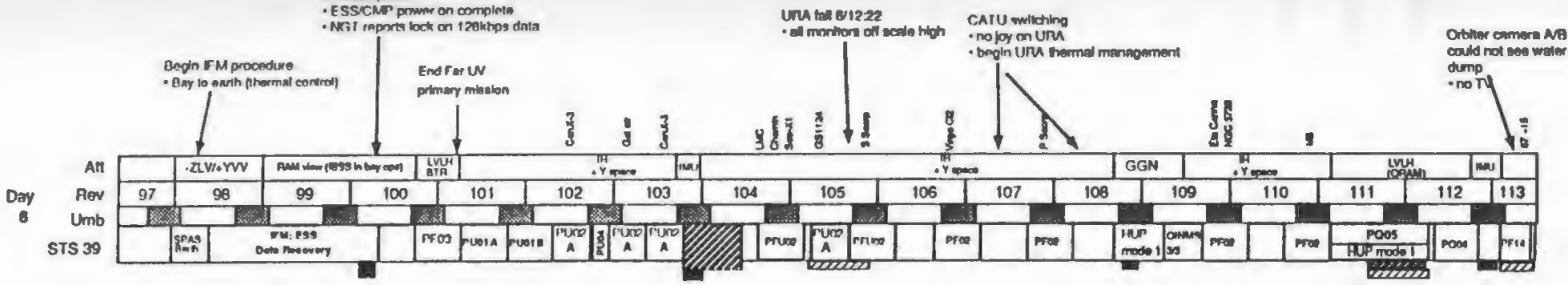
Jolnn I 5 UVI ANS

Als

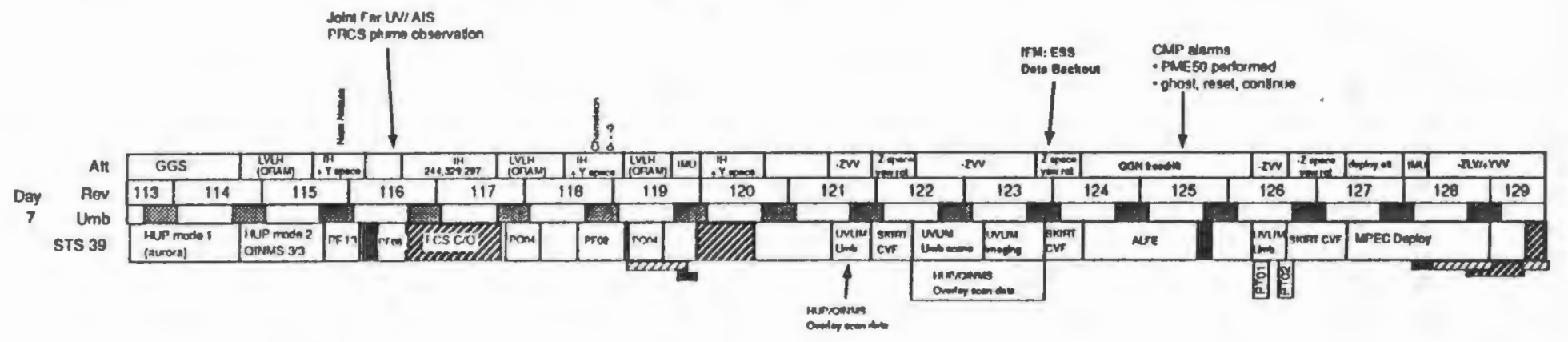

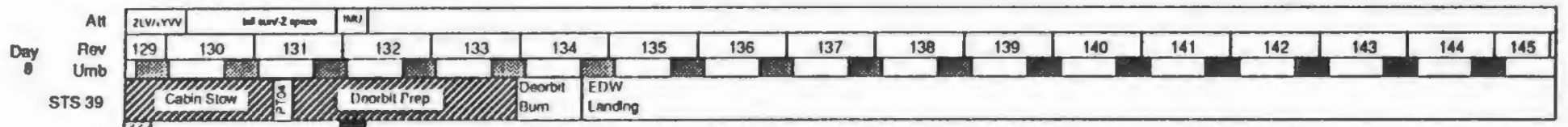




\section{Appendix II \\ SKIRT CVF Data Blocks}

This appendix is a listing of the SKIRT CVF data and is used primarily to identify data blocks recorded on Bernoulli 20 Mbyte disks. 


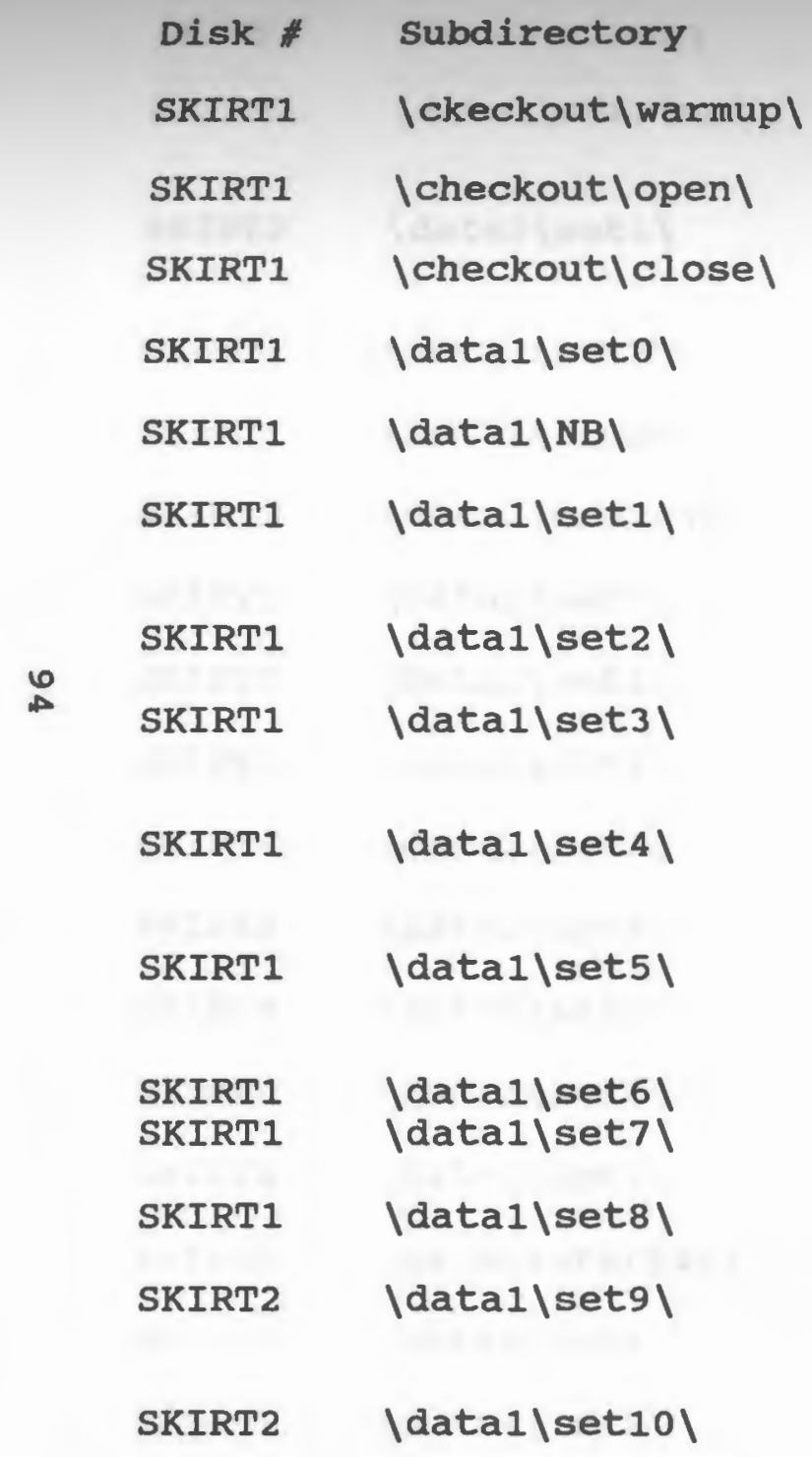

Comments

MET (Stant)

Preamp warming, first scans

$00 / 12: 14$

Cover opening first time

$00 / 12: 23$

Cover closing first time

$00 \backslash 12: 26$

Local mode just when data started

$00 \backslash 20: 18$

Narrow band data

$00 \backslash 20: 22$

A lot of data looking into GGS, glow begin 26:34.87

$00 \backslash 20 \backslash 30$

Sun starting to pass through our

constraints $73-61.9$ (sun)

sun continuing through our constraints $61.9-55$

$00 \backslash 21: 03$

$00 \backslash 21: 11$

Sun continuing through our constraints $38-30$

$00 / 21: 25$

Sun continuing through our constraints $30-29.6$

$00 / 21: 37$

Earth scans, no sun

Earth scans, sun

$00 / 22:--$

$00 / 22: 29$

Earth scans

$00 / 23: 59$

Above earthlimb, starting in darkness, moving toward the terminator

01/00:00

$01 / 00: 15$ 


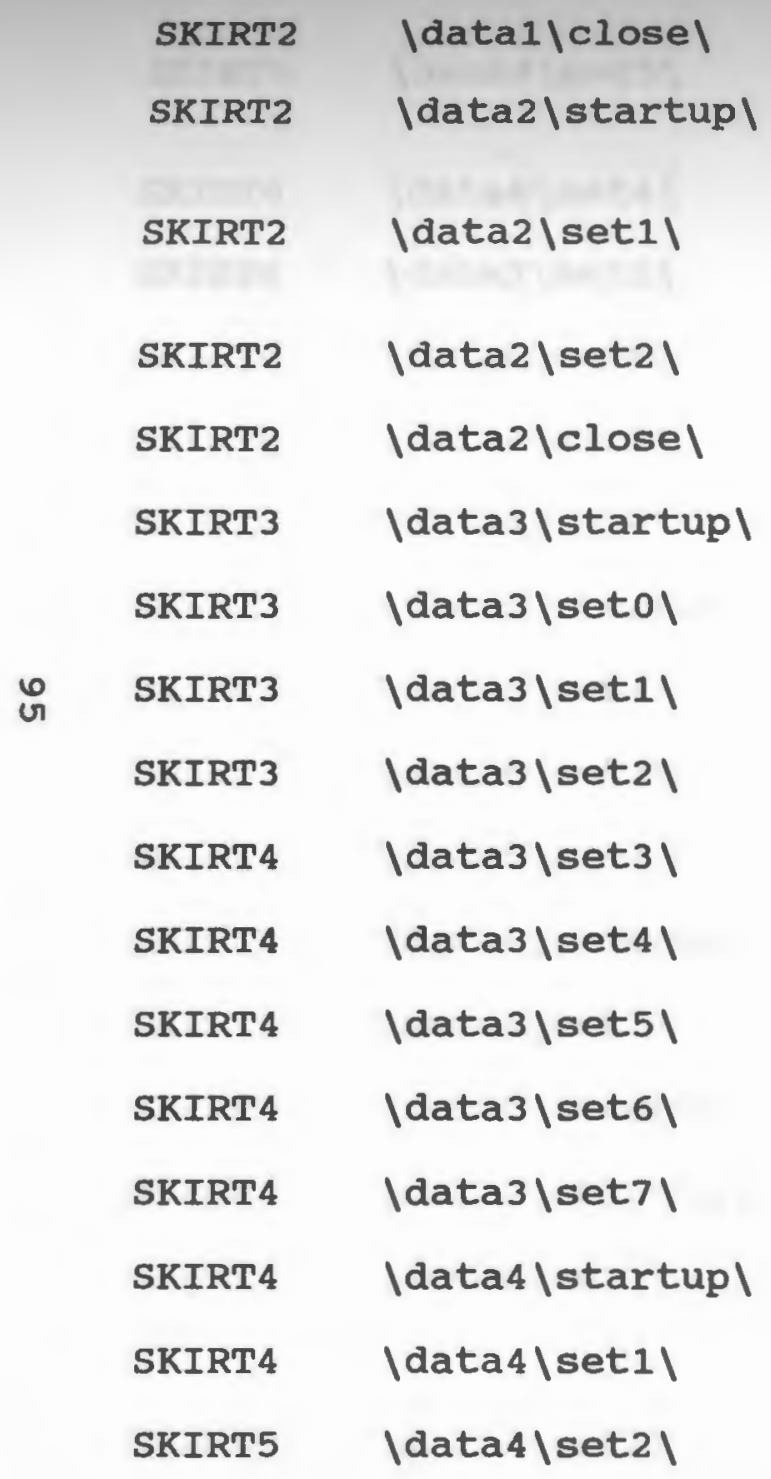

Turn off CVF, close cover

$01 / 00: 16$

Power up, preamp/detector warmup, cover open

$01 / 03: 38$

Dark earthlimb, dark to light

terminator

$01 / 03: 45$

Dark scans, long wavelength hump

$01 / 06: 52$

closing cover

$01 / 07: 45$

Turn on, open cover, preamp warmup

$01 / 12: 45$

Low background

$01 / 12: 52$

Low background, small No hump

$01 / 14: 03$

Small No hump

$01 / 15: 10$

Small No hump

$01 / 15: 15$

Low background

01/16:09

Small No and maneuvering

$01 / 16: 39$

PQ04, dark earth in background

$01 / 17: 17$

closing cover

$01 / 17: 30$

Open cover, warmup

$02 / 00: 46$

Earthlimb

$02 / 01: 05$

Hard earth

$02 / 01: 18$ 


\begin{tabular}{|c|c|c|}
\hline & SKIRT5 & |data4|set3| \\
\hline & SKIRT6 & $\mid$ data $4 \mid$ set $4 \mid$ \\
\hline & SKIRT6 & $\mid$ data3|set5| \\
\hline & SKIRT6 & $\mid$ data $4 \mid$ set $6 \mid$ \\
\hline & SKIRT6 & $\mid \operatorname{data} 4 \backslash$ set $7 \backslash$ \\
\hline & SKIRT6 & $\mid$ data $4 \mid$ set $8 \mid$ \\
\hline & SKIRT7 & $\mid$ data5\startup $\mid$ \\
\hline ă & SKIRT7 & $\mid$ data5|set $1 \mid$ \\
\hline & SKIRT7 & $\mid$ data5 $\mid$ set $2 \mid$ \\
\hline & SKIRT7 & $\mid$ data5 $\mid$ set $3 \mid$ \\
\hline & SKIRT7 & $\mid$ data6|startup $\mid$ \\
\hline & SKIRT7 & $\mid$ data6 $\mid$ set $1 \mid$ \\
\hline & SKIRT7 & |data7\startup $\mid$ \\
\hline & SKIRT7 & |data8|startup| \\
\hline & SKIRT7 & $\mid$ data8|set1| \\
\hline & SKIRT8 & $\mid$ data8\set2\} $\\
$\hline
\end{tabular}

Earth, deep space, moon within 19 deg, thruster firings?

$02 / 02: 06$

Hard earth

$02 / 03: 05$

Dark earth

$02 / 03: 47$

Empty subdirectory

$02 / 06: 14$

Small No hump

$02 / 07: 48$

Cover close, CVF off, deactivate

$02 / 08: 10$

Activation, cover open

$02 / 08: 52$

Earth scans

$02 / 08: 55$

Cover close, cover reopen

$02 / 08: 59$

Some earth, cover close

02/09:02

Cover previously opened

$02 / 14: 13$

PC61 Glow Scan

$02 / 14: 12$

Power on, CVF off, warm up

$04 / 12: 31$

CVF opening, power on, thruster

$04 / 15: 39$

Sun off axis $26.4-125$, ram=64.4

thruster burns, good glow data, good thruster 16:44

$04 / 16: 16$

Ram-37, good glow data, closing also

$04 / 16: 47$ 


\begin{tabular}{|c|c|c|}
\hline & SKIRT8 & $\mid$ data9|setup| \\
\hline & SKIRT8 & $\mid$ data9|setI| \\
\hline & SKIRT8 & $\mid$ datalo|chkcov| \\
\hline & SKIRT8 & $\mid$ data11|startup| \\
\hline & SKIRT9 & $\mid$ datal1|set $1 \mid$ \\
\hline & SKIRT9 & $\mid$ data11|set2| \\
\hline $\boldsymbol{\omega}$ & SKIRT9 & $\mid$ data11|set $3 \mid$ \\
\hline & SKIRT10 & $\mid$ data11|set $4 \mid$ \\
\hline & SKIRT10 & $\mid$ data11|set5| \\
\hline & SKIRT10 & $\mid$ data $11|\operatorname{set} 6|$ \\
\hline & SKIRT11 & $\mid$ data11|set7| \\
\hline & SKIRT11 & $\mid$ data12 |startup| \\
\hline & SKIRT11 & $\mid$ data12\set1| \\
\hline & SKIRT11 & $\mid$ data12 \set2| \\
\hline
\end{tabular}

Cover closed, NB stim, cover opening, earthlimb

$04 / 19: 02$

"Ratty " data, deep space, thrusters, close cover

$04 / 20: 00$

Check cover to see if it was cold

$04 / 21: 00$

Cover closed noise, stimulators

cycling, NB on, cover opening

$06 / 05: 28$

Dim glow, deep space background

$06 / 06: 30$

Stronger glow, sun, deep space

great limb scan

$06 / 07: 13$

Hard earth, limb, glow

06/08:07

Small glow, thruster firings, low sun

06/08:24

Good limb data

06/09:10

Hard earth, stopped CVF $\& 89.45$ and 65.79 for thrusters

06/09:50

Low sun, glow, maneuvering during

final scans, cover close

$06 / 10: 20$

Cover closed, cover opening, earthlimb

$06 / 15: 43$

Good glow, velocity vector $0+$,

sun off axis

$06 / 16: 15$

(Sun off axis $39 \mathrm{deg}$ ) deep space

$06 / 16: 33$ 


\begin{tabular}{|c|c|c|}
\hline & SKIRT11 & $\mid$ data $12 \mid$ set $3 \mid$ \\
\hline & SKIRT11 & $\mid$ data12|set4| \\
\hline & SKIRT12 & $\mid$ data12|set5| \\
\hline & SKIRT12 & $\mid$ data $12 \mid$ set $6 \mid$ \\
\hline & SKIRT12 & $\mid$ data $12|\operatorname{set} 7|$ \\
\hline & SKIRT12 & $\mid$ data13|startup| \\
\hline & SKIRT12 & $\mid$ data $13 \mid$ set 1 \\
\hline$\underset{\infty}{\bullet}$ & SKIRT13 & $\mid$ data $13 \backslash$ set2 \\
\hline & SKIRT13 & $\mid$ data $13 \mid$ set $3 \mid$ \\
\hline & SKIRT14 & $\mid$ data $13 \mid$ set $4 \mid$ \\
\hline & SKIRT14 & $\mid$ data $13 \mid$ set $5 \mid$ \\
\hline & SKIRT14 & $\mid$ data14|startup| \\
\hline & SKIRT14 & $\mid$ data $14 \mid$ set $1 \mid$ \\
\hline & SKIRT14 & $\mid$ data $14 \mid$ set $2 \mid$ \\
\hline & SKIRT14 & $\mid$ data $14 \mid$ set $3 \mid$ \\
\hline
\end{tabular}

Deep space, earthlimb, earth night

$06 / 16: 46$

Deep space

$06 / 17: 14$

Weak earth limb approx 18 deg off axis 06/17:39 Earth limb, glow, small thrusters, VCR tape

$06 / 17: 56$

Deep space, then earth day, cover close 06/18:23 Power up at $-7 / 00: 18$, cover open $-7 / 00: 40$, deep space

$07 / 00: 40$

Deep space

$07 / 01: 03$

Deep space, sun to within $35 \mathrm{deg}$, dark earth, some ratty data

$07 / 01: 10$

Lit earth

$07 / 02: 35$

Lit earth, moving off earth, eclipsed, near ram $(7.3 \mathrm{deg})$

$07 / 03: 18$

Glow, cover close

$07 / 03: 37$

Warm up, cover closed, cover opening, "intermittent Read Error"

$07 / 05: 23$

$07 / 05: 38$

$07 / 05: 43$

Moving into earthlimb, dark earth 


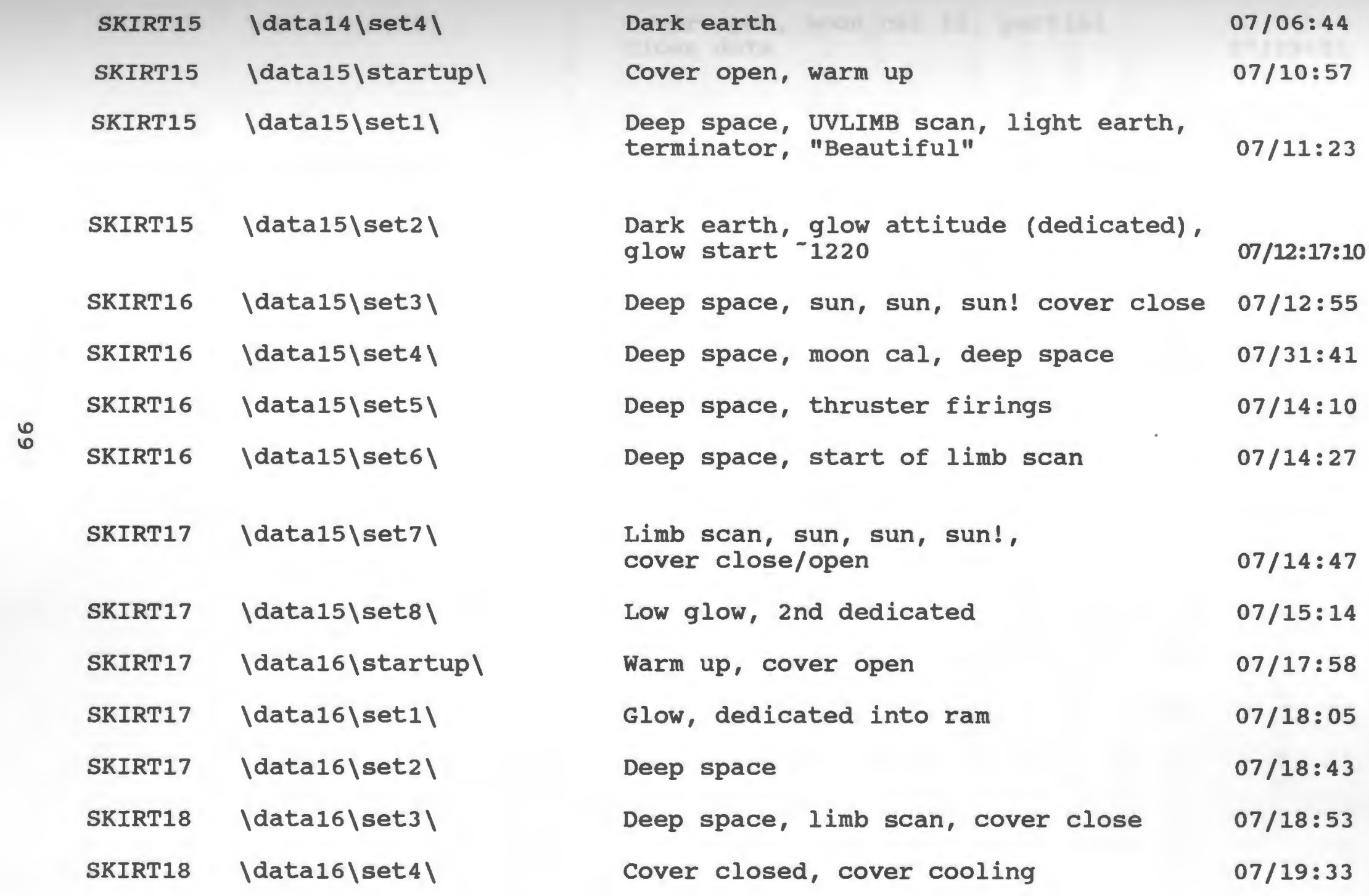


SKIRT18 |data16|set5|

$\vec{\circ}$
Cover open, moon cal II, partial close data 
STS-39 Ephemeris, Time, and Attitude Information

This appendix is a partial listing of the STS-39 ephemeris, time, and attitude information required to support the SKIRT data analysis. For example, to help analyze the spectrum of shuttle glow in Figure 26 we can use these tables for the following information based on MET.

MET:

$06 / 16: 16: 29$

Orbiter Attitude:

Pitch

$288.84 \mathrm{deg}$

Yaw

$283.56 \mathrm{deg}$

Roll

$12.69 \mathrm{deg}$

Orbiter Altitude

$266.35 \mathrm{~km}$

Local Time

$13.09 \mathrm{hrs}$

Line of sight from Ram $7.1 \mathrm{deg}$ 


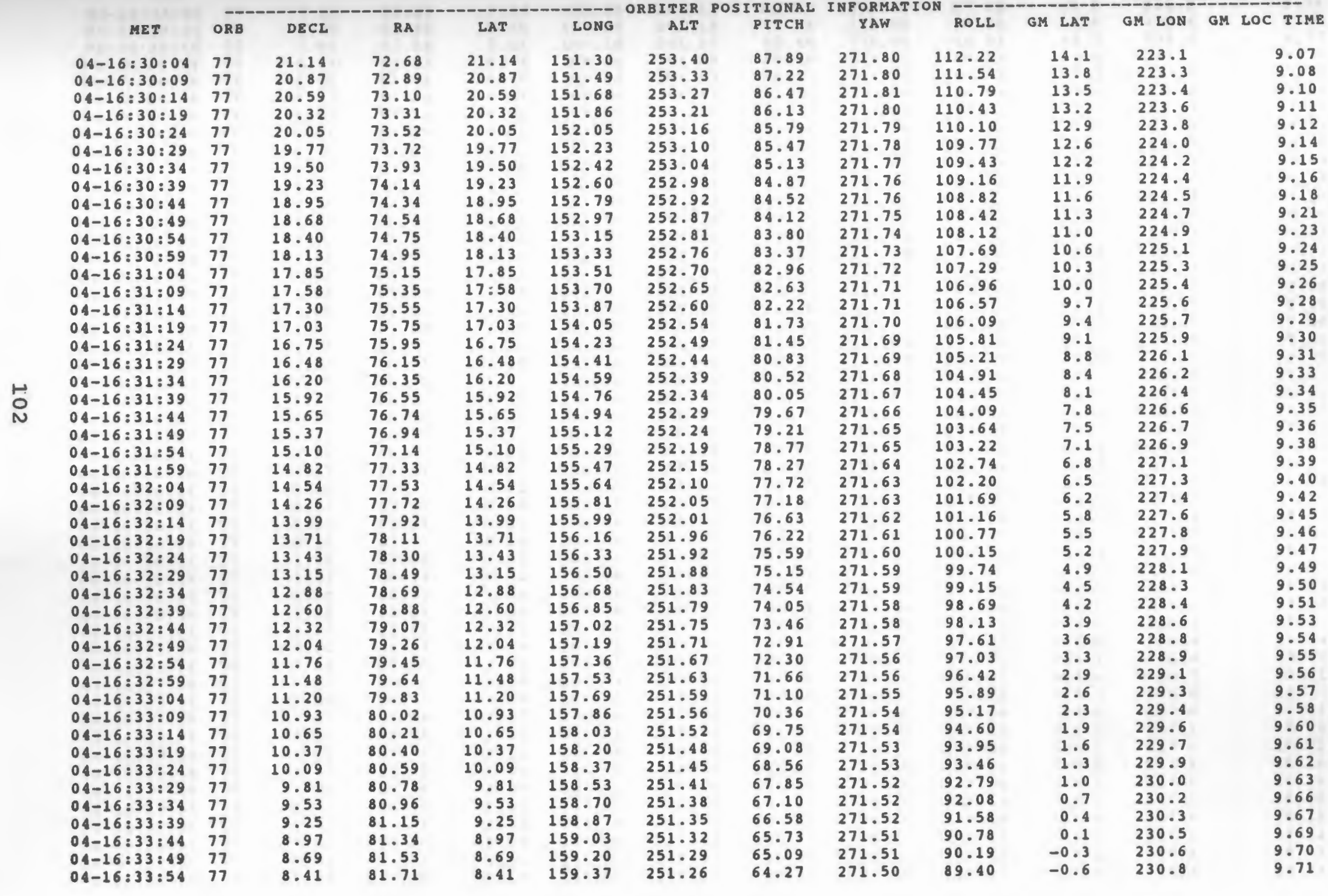




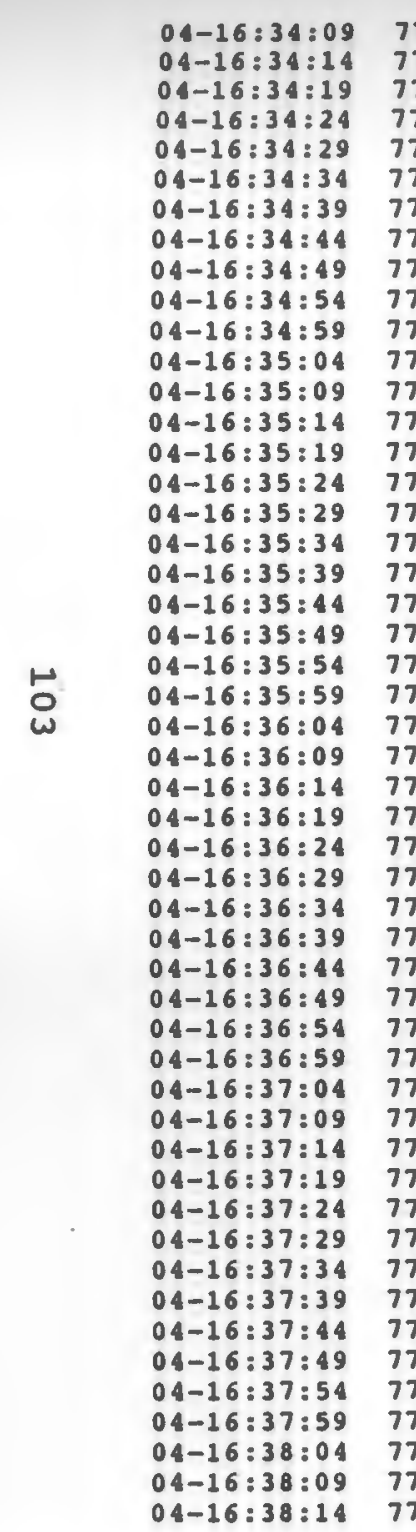

62.27 82.46

82.64

83.01
83.20

83.20
83.38

83.57

83.75

83.93

84.12

84.30

84.48

84.67

84.85

85.22

85.22
85.40

85.40
85.58

85.77

85.95

86.13

86.31

86.50

86.68

86.86

87.04

87.23

87.41

87.59

87.77

87.96

88.14

88.32

88.51

88.69

88.87

89.05

89.24

89.42

89.60

89.79

89.97

90.15

90.34

90.52

90.71

90.89

91.07

91.26

$\begin{array}{ll}7.57 & 159.86 \\ 7.29 & 160.03 \\ 7.01 & 160.19 \\ 6.73 & 160.36 \\ 6.45 & 160.52 \\ 6.17 & 160.68 \\ 5.89 & 160.85 \\ 5.61 & 161.01 \\ 5.33 & 161.17 \\ 5.05 & 161.34 \\ 4.77 & 161.50 \\ 4.49 & 161.66 \\ 4.20 & 161.83 \\ 3.92 & 161.99 \\ 3.64 & 162.15 \\ 3.36 & 162.31 \\ 3.08 & 162.47 \\ 2.80 & 162.64 \\ 2.52 & 162.80 \\ 2.24 & 162.96 \\ 1.96 & 163.12 \\ 1.67 & 163.28 \\ 1.39 & 163.45 \\ 1.11 & 163.61 \\ 0.83 & 163.77 \\ 0.55 & 163.93 \\ 0.27 & 164.09 \\ -0.01 & 164.25 \\ -0.29 & 164.42 \\ -0.57 & 164.58 \\ -0.86 & 164.74 \\ -1.14 & 164.90 \\ -1.42 & 165.06 \\ -1.70 & 165.22 \\ -1.98 & 165.39 \\ -2.26 & 165.55 \\ -2.54 & 165.71 \\ -2.82 & 165.87 \\ -3.10 & 166.03 \\ -3.39 & 166.20 \\ -3.67 & 166.36 \\ -3.95 & 166.52 \\ -4.23 & 166.68 \\ -4.51 & 166.85 \\ -4.79 & 167.01 \\ -5.07 & 167.17 \\ -5.35 & 167.34 \\ -5.63 & 167.50 \\ -5.91 & 167.66 \\ -6.19 & 167.83\end{array}$

251.17

251.14

251.12

251.09

251.07

251.04

251.02
251.00

250.98

250.96

250.94

250.92

250.90

250.88

250.87

250.85

250.84

250.82

250.81

250.80

250.79

250.78

250.77

250.76

250.75

250.75

250.74

250.74

250.73

250.73

250.73

250.73

250.72

250.73

250.73

250.73

250.73

250.73

250.74

250.75

250.75

250.76

250.77

250.78

250.79

250.80

250.81

250.82

250.83

250.85
61.38

60.66

60.86

60.97

61.34

61.45

61.36

61.60

63.16

64.63

65.98

67.36

68.60

69.87

71.54

72.93

74.28

75.89

77.10

78.44

81.29

81.29

2.79

84.33
86.02

87.55

89.00

90.37

91.87

93.43

95.28

96.94

98.50

99.98

102.58

107.01

106.21

104.08

102.89

102.12

101.67

101.40

101.22

101.15

101.15

101.12

100.21

99.28
98.49
87.42

86.68

86.01

86.24

86.38

86.79

86.93

86.82

87.03

88.56

90.00

91.32

92.68

93.91

95.15

96.79

98.17

99.49

101.08

102.28

103.62

104.94

106.45

107.93

109.45

111.12

112.64

114.08

115.46

116.94

118.49

120.33

121.97

123.52

132.17

131.77

130.05

129.29

128.94

128.92

129.08

129.34

129.70

130.56

130.05

129.50

129.07

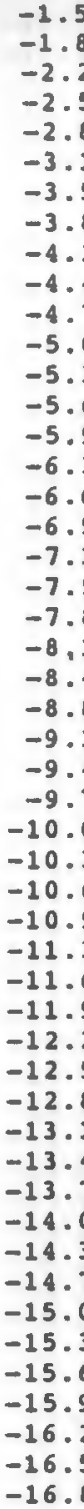

231.2

9.74

9.75

9.77

9.79

9.80

9.81

9.82

9.83

9.84

9.88

9.89

9.90

9.91

9.92

9.93

9.94

9.95

9.96

9.98

9.99

10.00

10.01

10.02

10.03

10.04

10.05

10.09

10.10

10.11

10.12

10.13

10.14

10.15

10.16

10.17

10.19

10.20

10.21

10.22

10.23

10.24

10.25

10.26

10.29

10.30

10.31

10.32

10.34 


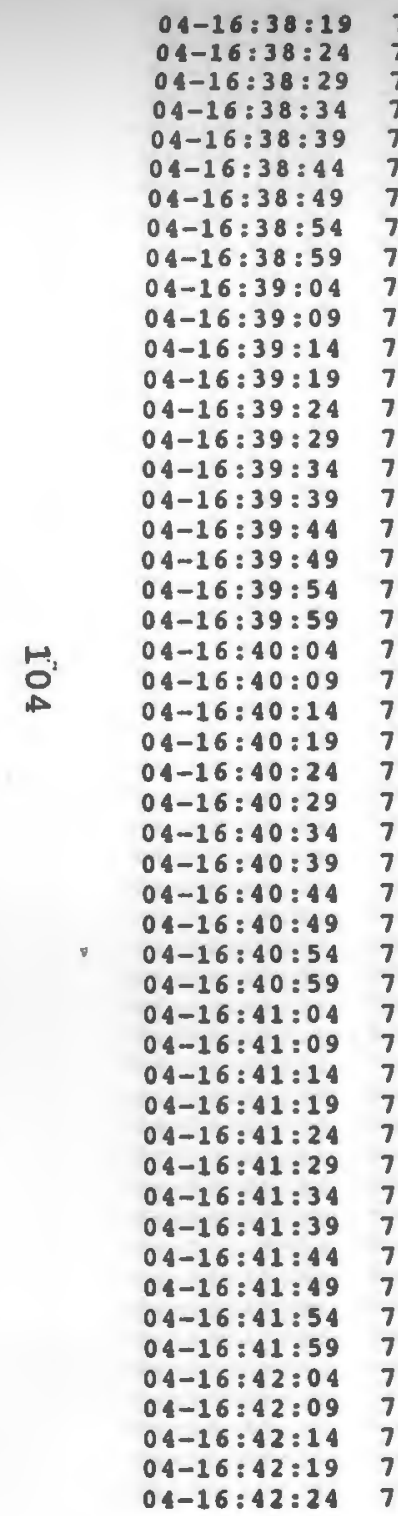

$\begin{array}{lll}77 & -6.17 & 91.14 \\ 77 & -6.75 & 91.63 \\ 77 & -7.03 & 91.81 \\ 77 & -7.32 & 92.00 \\ 77 & -7.60 & 92.18 \\ 77 & -7.88 & 92.37 \\ 77 & -8.16 & 92.56 \\ 77 & -8.44 & 92.74 \\ 77 & -8.72 & 92.93 \\ 77 & -9.00 & 93.12 \\ 77 & -9.27 & 93.30 \\ 77 & -9.55 & 93.49 \\ 77 & -9.83 & 93.68 \\ 77 & -10.11 & 93.87 \\ 77 & -10.39 & 94.06 \\ 77 & -10.67 & 94.24 \\ 77 & -10.95 & 94.43 \\ 77 & -11.23 & 94.62 \\ 77 & -11.51 & 94.81 \\ 77 & -11.79 & 95.00 \\ 77 & -12.07 & 95.19 \\ 77 & -12.34 & 95.39 \\ 77 & -12.62 & 95.58 \\ 77 & -12.90 & 95.77 \\ 77 & -13.18 & 95.96 \\ 77 & -13.46 & 96.15 \\ 77 & -13.73 & 96.35 \\ 77 & -14.01 & 96.54 \\ 77 & -14.29 & 96.73 \\ 77 & -14.57 & 96.93 \\ 77 & -14.84 & 97.12 \\ 77 & -15.12 & 97.32 \\ 77 & -15.40 & 97.52 \\ 77 & -15.67 & 97.71 \\ 77 & -15.95 & 97.91 \\ 77 & -16.23 & 98.11 \\ 77 & -16.50 & 98.31 \\ 77 & -16.78 & 98.51 \\ 77 & -17.05 & 98.70 \\ 77 & -17.33 & 98.90 \\ 77 & -17.60 & 99.11 \\ 77 & -17.88 & 99.31 \\ 77 & -18.15 & 99.51 \\ 77 & -18.43 & 99.71 \\ 77 & -18.70 & 99.91 \\ 77 & -18.98 & 100.12 \\ 77 & -19.25 & 100.32 \\ 77 & -19.53 & 100.53 \\ 77 & -19.80 & 100.73 \\ 77 & -20.07 & 100.94\end{array}$

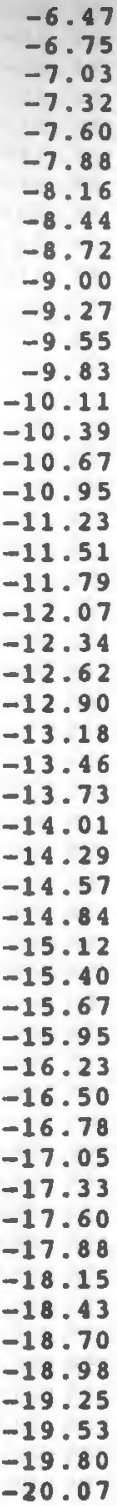

167.99 168.15 168.32 168.48 168.65 168.81 168.98 169.14 169.31 169.48 169.64 169.81 169.98 170.14 170.31 170.31 170.48 170.65
170.82 170.98 171.15

171.32 171.49 171.66 171.84 172.01 172.18 172.35 172.52 172.70 172.70
172.87 173.04 173.22 173.39 173.57 173.57
173.75 173.75
173.92 174.10

174.28

174.46 174.64 174.82 175.00 175.18 175.36 175.54 175.72 175.91 176.09 176.28 176.46
250.86 250.88 250.89 250.91 250.9 250.95 250.97 250.99 251.01 251.03 251.05 251.0 251.10 251.13 251.15 251.18 251.21 251.2 251.27 251.30 251.33 251 . 36 251.39 251.4 251.46 251.49 251.5 251.56 251.60 251.6 251.68 251.71 251.75 251.79 251.8 251.8 251.92 251.96 252.00 252.05 252.09 252.14 252.19 252.23 252.28 252.33 252.38 252.42 252.47 252.52

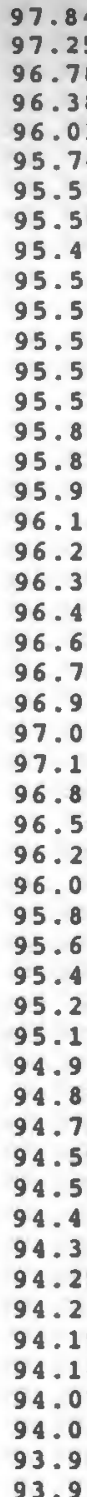
282.69 283.38 284.08 284.77
285.48 285.48 286.17 286.81 287.46 288.10 288.10 288.75
289.39 290.06 290.74

291.32

291.97 292.62 293.26 293.91 294.56 295.21 295.87 295.87 296.52
297.17 297.17
297.83 298.47 299.05 299.64 299.64 300.24 301.44 302.05 302.65 303.26 303.88 304.49 305.10 305.72 306.34 306.96 306.96 307.58
308.22 308.85 309.48

310.12 310.76

311.35

311.95

312.54

313.14
128.82 128.61 128.53 128.53 128.58 128.70 128.91 129.27 129.67 130.11 130.54 131.00 131.43 131.84 132.50 133.0 133.57 134.1 134.67 135.26 135.84 136.44 137.05 137.6 138.31 138.84 139.06 139.28 139.52 139.8 140.09 140.40 140.75 141.09 141.47 141.86 142.26 142.69

143.13 143.60 144.07 144.55 145.05 145.55 146.0 146.63 147.04 147.40 147.76
$-17.1$ $-17.4$ $-17.7$

$-18.3$

$-18.6$

$-18.9$

-19.2
-19.5

$-19.8$

$-19.8$

$-20.4$

$-20.7$ $-21.0$

$-21.4$

.

$-22.3$

$-22.6$ $-22.9$

$-23.2$

$-23.5$

$-23: 8$

$-24.1$

$-24.4$ $-24.7$

$-25.0$

$-25.3$

$-25.6$

$-25.9$

$-26.2$

$-26.5$

$-26.8$

$-27.1$

$-27.4$

$-27.7$

$-28.0$

$-28.3$

$-28.6$

$-28.9$

$-29.2$

$-29.5$

$-29.8$

$-30.1$

$-30.4$

$-30.7$

$-31.0$

$-31.3$

-31.5
-31.8

238.4

238.5

238.7

238.8

238.9
239.1

239.2

239.4

239.5

239.7

239.8

240.0

240.1

240.3

240.4

240.6

240.7

240 .

241.0

241.2

1.5

241.6

241.8

242.0

42.3

242.

242.6

242 .

242.9

243.0

43.2

43.5

243.8

244.0

244.1

244.3 
$04-16: 12: 29 \quad 77$ $04-16: 42: 347$ $04-16: 42: 39 \quad 77$ $04-16: 42: 44 \quad 77$ $0:-16: 42: 49 \quad 77$ $04-16: 42: 54 \quad 77$ $04-16: 42: 59 \quad 77$ $04-16: 43: 04 \quad 77$ $04-16: 43: 0977$ $04-16: 43: 1477$ 04-16:43:19 77 $04-16: 43: 24 \quad 77$ $04-16: 43: 2977$ 04-16:43:34 77 $04-16: 43: 3977$ $04-16: 43: 4477$ $04-16: 43: 49 \quad 77$ $04-16: 43: 54 \quad 77$ $04-16: 43: 59 \quad 77$ $04-16: 44: 0477$ $04-16: 44: 09 \quad 77$ 04-16:44:14 7 04-16:44:19 77 04-16:44:24 77 $04-16: 44: 2977$ $04-16: 44: 3477$ $04-16: 44: 39 \quad 77$ $04-16: 44: 447$ $04-16: 44: 49 \quad 77$ 04-16:44:5477 $04-16: 44: 5977$ 04-16:45:04 77 $04-16: 45: 09 \quad 77$ $04-16: 45: 14 \quad 7$ $04-16: 45: 19 \quad 77$ $04-16: 45: 24 \quad 77$ $04-16: 45: 29 \quad 77$ $04-16: 45: 3477$ $04-16: 45: 3977$ $04-16: 45: 447$ $04-16: 45: 4977$ $04-16: 45: 54 \quad 77$ $04-16: 45: 59 \quad 77$ $04-16: 46: 0477$ $04-16: 46: 0977$ $04-16: 46: 147$ 04-16:46:19 77 $04-16: 46: 24 \quad 77$

$04-16: 46: 2977$ $04-16: 46: 34 \quad 77$
$-20.35$ $-20.62$ $-20.89$ $-21.16$ $-21.44$ $-21.71$

$-21.98$

$-22.25$

$-22.52$

$-22.79$

$-23.06$

$-23.33$

$-23.60$

$-23.87$

$-24.14$

$-24.41$

$-24.95$

$-25.21$

$-25.48$

$-25.75$

$-26.02$

$-26.28$

$-26.55$

$-26.81$

$-27.08$

$-27.34$

$-27.61$

$-27.87$

$-28.14$

$-28.40$

$-28.66$

$-28.93$

$-29.19$

$-29.45$

$-29.71$

$-30.23$

$-30.49$

$-30.75$

$-31.01$

$-31.27$

$-31.53$

$-31.79$

$-32.04$

$-32.30$

$-32.56$

$-32.81$

$-33.07$

$-33.32$
101.15

101.36

101.77

101.98

102.19

102.41

102.62

102.83

103.05

103.26

103.48

103.70

103.91

104.13

104.35

104.57

104.79

105.02

105.24

105.46

105.69

105.92

106.14

106.37

106.60

106.83

107.07

107.30

107.53

107.77

108.01

108.24

108.48

108.72

108.96

109.21

109.45

109.70

109.94

110.19

110.44

110.69

111.20

111.45

111.71

111.96

112.22

112.48
$-20.62$

$-20.89$

176.84

177.02

177.21

177.59

177.78

177.98

178.17

178.36

178.56

178.95

179.14

179.34

179.54

179.74

179.94

180.14

180.35
180.55

180.55
180.75

180.96

181.17

181.37

181.58

181.79

182.00

182.22

182.43

182.64

182.86

183.08

183.29

183.51

183.96

184.18

184.40

184.63

184.86

185.08

185.31

185.55

185.78

186.01

186.25

186.48

186.96
252.57 252.63

252.68

252.73

252.78

252.84

252.89

252.95

253.00

253.06

253.11

253.17

253.23

253.28

253.34

253.40

253.46

253.52

253.58

253.64

253.70

253.76

253.82

253.88

253.94

254.01

254.07

254.13

254.20

254.26

254.32

254.39

254.45

254.52

254.58

254.65

254.72

254.78

254.85

254.92

254.98

255.05

255.12

255.18

255.25

255.32

255.39

255.46

255.52

255.59
93.88

93.85

93.81

93.79

93.78

93.78

93.58

93.04

92.80

92.55

92.31

92.08

91.90

91.71

91.61

91.53

91.46

91.44

91.60

92.32

92.69

93.06

93.43

93.80

94.16

94.9

95.27

95.63

96.00

96.36

96.73

97.09

97.82

98.18

98.54

98.90

9.25

99.62

100.33

100.68

101.03

101.39 

113.28 113.54 $\begin{array}{ll}-34.59 & 113.81\end{array}$ $\begin{array}{lll}-34.84 & 114.08\end{array}$ $\begin{array}{ll}-35.09 & 114.35\end{array}$ $\begin{array}{ll}-35.34 & 114.63\end{array}$ $\begin{array}{ll}-35.59 & 114.90\end{array}$ $-35.83 \quad 115.18$ $-36.08 \quad 115.46$ $-36.33 \quad 115.74$ $-36.58 \quad 116.02$ $-36.82 \quad 116.30$
-37.07 $\begin{array}{ll}-37.07 & 116.59\end{array}$ $\begin{array}{ll}-37.31 & 116.88\end{array}$ $-37.56 \quad 117.17$ $\begin{array}{ll}-37.80 & 117.46\end{array}$ $-38.04 \quad 117.75$
-38.08 $-38.28 \quad 118.05$ $\begin{array}{ll}-38.53 & 118.35 \\ -38.77 & 118.65\end{array}$ $-39.00$ $-39.24 \quad 119.25$ $\begin{array}{ll}-39.24 & 119.25 \\ -39.48 & 119.56\end{array}$ $-39.72 \quad 119.86$ $\begin{array}{ll}-39.95 & 120.17\end{array}$ 120.49 $\begin{array}{ll}-40.42 & 120.80\end{array}$ $-40.66 \quad 121.12$ $\begin{array}{ll}-40.89 & 121.43 \\ -41.12 & 121.75\end{array}$ $-41.35 \quad 122.08$ $\begin{array}{ll}-41.58 & 122.40\end{array}$ $\begin{array}{ll}-11.81 & 122.73\end{array}$ $-12.04 \quad 123.06$
-42.27 $\begin{array}{ll}-42.27 & 123.39\end{array}$ $\begin{array}{ll}-42.50 & 123.73\end{array}$ $-12.72 \quad 124.06$ $\begin{array}{ll}-42.95 & 124.40\end{array}$ $\begin{array}{ll}-43.17 & 124.75\end{array}$ $\begin{array}{ll}-43.39 & 125.09\end{array}$ $\begin{array}{ll}-43.61 & 125.44\end{array}$ $\begin{array}{ll}-43.83 & 125.79\end{array}$ $-44.05 \quad 126.14$ $\begin{array}{ll}-44.27 & 126.50\end{array}$ $\begin{array}{lll}-4.49 & 126.85\end{array}$ $\begin{array}{lll}-14.70 & 127.21\end{array}$ $-44.92 \quad 127.58$ $-45.13 \quad 127.94$
187.20 187.45 187.69 187.94

255.66 255.73 255.80 255.87 255.94 256.01 256.08 256.14 256.2 256.28 256.35 256.42 256.49 256.56 256.63 256.70 256.77 256.84 256.91 256.98 257.05 257.11 257.18 257.25 257.32 257.39 257.46 257.53 257.59 257.66 257.73 257.80 257.86 257.93 258.00 258.07 258.13 258.20 258.26

258.33

258.40

258.46

258.53
258.59

258.66

258.72

258.78

258.85

258.91

$-44.70$

$-44.92$ 201.38
101.75 102.11 102.46 102.81 103.16 103.50 103.84 104.18 104.52 104.86 105.20 105.53 105.85 106.17 106.50 106.82 107.13 107.45 107.76 108.07 108.39 108.69

108.99

109.28 109.56 109.85 110.14 110.42

110.69

110.97

111.24

111.53 111.81 112.08 112.36 112.72

113.26 113.82 114.36

114.68

114.98

115.34

115.70 116.05 116.41 116.76 117.10 117.45 117.80 118.14

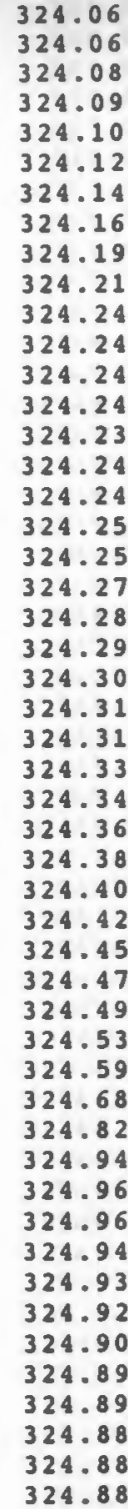

157.26 157.31 157.38 157.44 157.51 157.58 157.64 157.71 157.78 157.85 157.93 157.91 157.82 157.76 157.68 157.60 157.52 157.45 157.38 157.31 157.24 157.17 157.10 157.04 156.96

156.90 156.83 156.77

156.71

156.64 156.58

156.52 156.45 156.39

156.33

156.39

156.54

156.69 156.82

156.83

156.81

156.81

156.82

156.81

156.82

156.82

156.83

156.84

156.84 156.86
$-46.5$

$-46.7$

$-47.0$

$-47.3$

$-47.5$

$-47.8$

$-48.1$

$-48.4$

$-48.6$

$-48.9$

$-49.2$

$-49.4$

$-50.0$

-50.2
-50.5

$-50.8$

$-51.0$

$-51.3$

$-51.6$

$-51.8$

$-52.1$

$-52.3$

$-52.6$

$-52.8$

-53.1
-53.3

$-53.6$

$-53.8$

$-54.1$

$-54.3$

$-54.6$

$-54.8$

$-55.1$

$-55.6$

$-55.8$

$-56.0$

$-56.3$

$-56.5$

$-56.7$

$-57.0$

$-57.2$

$-57.4$

$-57.7$

$-57.9$

$-58.1$

$-58.3$

$-58.5$

$-58.7$

256.3

256.6

256.9

257.1

257.4

257.7

257.9

258.2

258.5

258.8

259.1

259.4

259.7

260.0

260.3

260.6

260.9

261.2

261.5

261.9

262.2

262.5

262.9

263.2

263.6

264.0

264.3

264.7

265.1

265.4 


\begin{tabular}{|c|c|c|c|c|c|c|c|c|c|c|c|c|}
\hline $04-16: 50: 49$ & 77 & -45.34 & 128.31 & -45.34 & 201.72 & 259.03 & 118.48 & 324.88 & 156.86 & -59.0 & 274.6 & 13.17 \\
\hline $04-16: 50: 54$ & 77 & -45.56 & 128.68 & -45.56 & 202.07 & 259.10 & 118.82 & 324.88 & 156.87 & -59.2 & 275.1 & 13.21 \\
\hline $04-16: 50: 59$ & 77 & -45.77 & 129.05 & -45.77 & 202.43 & 259.16 & 119.16 & 324.88 & 156.88 & -59.4 & 275.6 & 13.24 \\
\hline $04-16: 51: 04$ & 77 & -45.97 & 129.43 & -45.97 & 202.78 & 259.22 & 119.49 & 324.88 & 156.89 & -59.6 & 276.1 & 13.28 \\
\hline $04-16: 51: 09$ & 77 & -46.18 & 129.81 & -46.18 & 203.14 & 259.28 & 119.83 & 324.89 & 156.90 & -59.8 & 276.7 & 13.32 \\
\hline $04-16: 51: 14$ & 77 & -46.39 & 130.19 & -46.39 & 203.50 & 259.34 & 120.15 & 324.90 & 156.91 & -60.0 & 277.2 & 13.35 \\
\hline $04-16: 51: 19$ & 77 & -46.59 & 130.58 & -46.59 & 203.87 & 259.40 & 120.49 & 324.91 & 156.92 & -60.2 & 277.7 & 13.39 \\
\hline $04-16: 51: 24$ & 77 & -46.80 & 130.97 & -46.80 & 204.23 & 259.46 & 120.82 & 324.92 & 156.93 & -60.4 & 278.3 & 13.43 \\
\hline $04-16: 51: 29$ & 77 & -47.00 & 131.36 & -47.00 & 204.60 & 259.52 & 121.14 & 324.93 & 156.94 & -60.6 & 278.8 & 13.47 \\
\hline $04-16: 51: 34$ & 77 & -47.20 & 131.75 & -47.20 & 204.98 & 259.58 & 121.46 & 324.93 & 156.93 & -60.7 & 279.4 & 13.50 \\
\hline $04-16: 51: 39$ & 77 & -47.40 & 132.15 & -47.40 & 205.35 & 259.64 & 121.78 & 324.93 & 156.91 & -60.9 & 280.0 & 13.54 \\
\hline $04-16: 51: 44$ & 77 & -47.60 & 132.55 & -47.60 & 205.73 & 259.69 & 122.10 & 324.93 & 156.89 & -61.1 & 280.5 & 13.58 \\
\hline $04-16: 51: 49$ & 77 & -47.79 & 132.95 & -47.79 & 206.12 & 259.75 & 122.42 & 324.93 & 156.87 & -61.3 & 281.1 & 13.62 \\
\hline $04-16: 51: 54$ & 77 & -47.99 & 133.36 & -47.99 & 206.50 & 259.81 & 122.73 & 324.94 & 156.84 & -61.5 & 281.7 & 13.69 \\
\hline $04-16: 51: 59$ & 77 & -48.18 & 133.77 & -48.18 & 206.89 & 259.86 & 123.04 & 324.94 & 156.83 & -61.6 & 282.3 & 13.73 \\
\hline $04-16: 52: 04$ & 77 & $-48 \cdot 38$ & 134.18 & -48.38 & 207.28 & 259.92 & 123.36 & 324.95 & 156.82 & -61.8 & 282.9 & 13.77 \\
\hline $04-16: 52: 09$ & 77 & -48.57 & 134.60 & -48.57 & 207.68 & 259.98 & 123.73 & 324.94 & 156.83 & -62.0 & 283.5 & 13.81 \\
\hline $04-16: 52: 14$ & 77 & -48.76 & 135.02 & -48.76 & 208.07 & 260.03 & 124.08 & 324.93 & 156.84 & -62.1 & 284.2 & 13.85 \\
\hline $04-16: 52: 19$ & 77 & -48.94 & 135.44 & -48.94 & 208.47 & 260.08 & 124.43 & 324.93 & 156.86 & -62.3 & 284.8 & 13.90 \\
\hline $04-16: 52: 24$ & 77 & -49.13 & 135.86 & -49.13 & 208.88 & 260.14 & 124.79 & 324.93 & 156.87 & -62.5 & 285.4 & 13.94 \\
\hline $04-16: 52: 29$ & 77 & -49.32 & 136.29 & -49.32 & 209.29 & 260.19 & 125.13 & 324.93 & 156.88 & -62.6 & 286.1 & 13.99 \\
\hline $04-16: 52: 34$ & 77 & -49.50 & 136.72 & -49.50 & 209.70 & 260.25 & 125.48 & 324.94 & 156.89 & -62.8 & 286.7 & 14.03 \\
\hline $04-16: 52: 39$ & 77 & -49.68 & 137.16 & -49.68 & 210.11 & 260.30 & 125.82 & 324.94 & 156.90 & -62.9 & 287.4 & 14.08 \\
\hline $04-16: 52: 44$ & 77 & -49.86 & 137.59 & -49.86 & 210.53 & 260.35 & 126.16 & 324.94 & 156.91 & -63.1 & 288.1 & 14.12 \\
\hline $04-16: 52: 49$ & 77 & -50.04 & 138.04 & -50.04 & 210.95 & 260.40 & 126.49 & 324.94 & 156.92 & -63.2 & 288.7 & 14.17 \\
\hline $04-16: 52: 54$ & 77 & -50.22 & 138.48 & -50.22 & 211.37 & 260.45 & 126.83 & 324.95 & 156.93 & -63.4 & 289.4 & 14.22 \\
\hline $04-16: 52: 59$ & 77 & -50.39 & 138.93 & -50.39 & 211.80 & $260: 50$ & 127.16 & 324.94 & 156.92 & -63.5 & 290.1 & 14.27 \\
\hline $04-16: 53: 04$ & 77 & -50.56 & 139.38 & -50.56 & 212.23 & 260.55 & 127.50 & 324.94 & 156.91 & -63.7 & 290.9 & 14.32 \\
\hline $04-16: 53: 09$ & 77 & -50.73 & 139.83 & -50.73 & 212.66 & 260.60 & 127.83 & 324.93 & 156.91 & -63.8 & 291.6 & 14.36 \\
\hline $04-16: 53: 14$ & 77 & -50.90 & 140.29 & -50.90 & 213.10 & 260.65 & 128.16 & 324.94 & 156.89 & -63.9 & 292.3 & 14.41 \\
\hline $04-16: 53: 19$ & 77 & -51.07 & 140.75 & -51.07 & 213.54 & 260.69 & 128.48 & 324.93 & 156.87 & -64.1 & 293.0 & 14.48 \\
\hline $0:-16: 53: 24$ & 77 & -51.24 & 141.22 & -51.24 & 213.98 & 260.74 & 128.80 & 324.93 & 156.87 & -64.2 & 293.7 & 14.53 \\
\hline $04-16: 53: 29$ & 77 & -51.40 & 141.68 & $-51 \cdot 40$ & 214.43 & 260.79 & 129.11 & 324.94 & 156.85 & -64.3 & 294.4 & 14.58 \\
\hline $04-16: 53: 34$ & 77 & -51.56 & 142.16 & -51.56 & 214.88 & 260.83 & 129.43 & 324.94 & 156.83 & -64.4 & 295.1 & 14.63 \\
\hline $04-16: 53: 39$ & 77 & -51.72 & 142.63 & -51.72 & 215.33 & 260.88 & 129.74 & 324.95 & 156.82 & -64.5 & 295.8 & 14.68 \\
\hline $04-16: 53: 44$ & 77 & -51.88 & 143.11 & -51.88 & 215.79 & 260.92 & 130.07 & 324.95 & 156.81 & -64.6 & 296.5 & 14.73 \\
\hline $04-16: 53: 49$ & 77 & -52.04 & 143.59 & -52.04 & 216.25 & 260.97 & 130.44 & 324.94 & 156.83 & -64.7 & 297.3 & 14.78 \\
\hline $04-16: 53: 54$ & 77 & -52.19 & 144.07 & -52.19 & 216.71 & 261.01 & 130.79 & 324.93 & 156.84 & -64.8 & 298.0 & 14.83 \\
\hline $04-16: 53: 59$ & 77 & -52.35 & 144.56 & -52.35 & 217.18 & 261.05 & 131.15 & 324.93 & 156.86 & -64.9 & 298.8 & 14.88 \\
\hline $04-16: 54: 04$ & 77 & -52.50 & 145.05 & -52.50 & 217.65 & 261.20 & 131.49 & 324.92 & 156.87 & -64.9 & 299.5 & 14.93 \\
\hline $04-16: 54: 09$ & 77 & -52.65 & 145.55 & -52.65 & 218.12 & 261.14 & 131.84 & 324.92 & 156.88 & -65.0 & 300.3 & 14.99 \\
\hline $04-16: 54: 14$ & 77 & -52.79 & 146.05 & -52.79 & 218.60 & 261.18 & 132.19 & 324.92 & 156.89 & -65.1 & 301.1 & 15.04 \\
\hline $04-16: 54: 19$ & 77 & -52.94 & 146.55 & -52.94 & 219.08 & 261.22 & 132.53 & 324.92 & 156.89 & -65.2 & 301.9 & 15.09 \\
\hline $04-16: 54: 24$ & 77 & -53.08 & 147.05 & -53.08 & 219.57 & 261.26 & 132.87 & 324.92 & 156.91 & -65.3 & 302.7 & 15.15 \\
\hline $04-16: 54: 29$ & 77 & -53.22 & 147.56 & -53.22 & 220.05 & 261.29 & 133.21 & 324.92 & 156.92 & -65.3 & 303.5 & 15.20 \\
\hline $04-16: 54: 34$ & 77 & -53.36 & 148.07 & -53.36 & 220.54 & 261.33 & 133.54 & 324.92 & 156.93 & -65.4 & 304.3 & 15.26 \\
\hline $04-16: 54: 39$ & 77 & -53.49 & 148.58 & -53.49 & 221.04 & 261.37 & 133.87 & 324.92 & 156.92 & -65.5 & 305.1 & 15.31 \\
\hline $04-16: 54: 44$ & 77 & -53.63 & 149.10 & -53.63 & 221.53 & 261.41 & 134.20 & 324.92 & 156.91 & -65.5 & 305.9 & 15.39 \\
\hline $04-16: 54: 49$ & 77 & -53.76 & 149.62 & -53.76 & 222.03 & 261.44 & 134.52 & 324.93 & 156.89 & -65.6 & 306.7 & 15.44 \\
\hline $04-16: 54: 54$ & 77 & -53.89 & 150.15 & -53.89 & 222.54 & 261.48 & 134.84 & 324.94 & 156.86 & -65.6 & 307.5 & 15.50 \\
\hline
\end{tabular}


$-54.01$

$-54.14$

$-54.26$

-54.38
-54.49

$-54.61$

$-54.72$

$-54.83$

$-54.94$

$-55.04$

$-55.15$

$-55.25$

$-55.34$

$-55.44$

$-55.53$

$-55.62$

$-55.70$

$-55.79$

$-55.87$

$-55.95$

$-56.02$

$-56.10$

$-56.17$

$-56.23$

$-56.30$

$-56.36$

$-56.42$

$-56.47$

$-56.53$

$-56.58$

$-56.62$

$-56.67$

$-56.71$

$-56.75$

$-56.78$

$-56.82$

$-56.85$

$-56.87$

$-56.89$

$-56.92$

$-56.93$

$-56.95$

$-56.96$

$-56.97$

$-56.97$

$-56.98$

$-56.97$

$-56.97$

$-56.96$

$-56.95$
223.04 224.07

224.58

225.10

225.62

226.15

226.68 227.21

227.74

228.28

228.82

229.36 229.91 230.46

31.01

231.56

232.12

232.67 233.24

33.80

234.36

234.93

235.50

236.07

236.65

37.22

237.80

238.38

238.96

239.54

240.12

241.88

242.47

243.06

243.65

244.24

244.83

245.43

246.02

246.61

247.21

247.80

248.39

248.99

249.58

250.18

250.77 261.54 261.58 261.61 261.64 261.67 261.70 261.73 261.76 261.79 261.8 261.84 261.86 261.89 261.91 261.93 261.96 261.98 262.00 262.02 262.04 262.06 262.07 262.09 262.10 262.12 262.13 262.15 262.16 262.17 262.18 262.19 262.20 262.21 262.22 262.22 262.23 262.23 262.24 262.24 262.24 262.24 262.25 262.24 262.24 262.24 262.24 262.24 262.23

262.23 $\begin{array}{lll}135.46 & 324.96 & 156.84\end{array}$

$\begin{array}{lll}136.12 & 324.97 & 156.80\end{array}$

$\begin{array}{lll}136.48 & 324.97 & 156.81\end{array}$

$\begin{array}{lll}136.84 & 324.96 & 156.83\end{array}$

$\begin{array}{lll}137.20 & 324.96 & 156.83\end{array}$

$\begin{array}{lll}137.54 & 324.96 & 156.83\end{array}$

$\begin{array}{lll}137.90 & 324.96 & 156.83\end{array}$

$\begin{array}{lll}138.25 & 324.96 & 156.84\end{array}$

138.940324 .97

$\begin{array}{lll}139.28 & 324.98 & 156.84\end{array}$

$139.61 \quad 324.99 \quad 156.84$

$\begin{array}{llll}139.95 & 325.00 & 156.84\end{array}$

$\begin{array}{llll}140.29 & 325.00 & 156.83\end{array}$

$\begin{array}{llll}140.62 & 325.01 & 156.83\end{array}$

$\begin{array}{lll}140.95 & 325.02 & 156.82\end{array}$

$\begin{array}{lll}141.27 & 325.03 & 156.82 \\ 141.59 & 325.04 & 156.81\end{array}$

$\begin{array}{llll}141.90 & 325.05 & 156.79\end{array}$

$\begin{array}{lll}142.20 & 325.05 & 156.77\end{array}$

$\begin{array}{lll}142.52 & 325.05 & 156.76\end{array}$

$\begin{array}{lll}142.88 & 325.03 & 156.78\end{array}$

$\begin{array}{lll}143.23 & 325.03 & 156.78\end{array}$

$\begin{array}{lll}143.59 & 325.02 & 156.80\end{array}$

$\begin{array}{llll}143.93 & 325.01 & 156.80\end{array}$

$\begin{array}{llll}144.28 & 325.01 & 156.81\end{array}$

$\begin{array}{lll}144.62 & 325.00 & 156.81\end{array}$

$\begin{array}{lll}144.96 & 324.99 & 156.81\end{array}$

$\begin{array}{lll}145.30 & 324.99 & 156.82\end{array}$

$\begin{array}{lll}145.64 & 324.99 & 156.82\end{array}$

$145.97 \quad 324.98 \quad 156.82$

$\begin{array}{lll}146.30 & 324.97 & 156.81\end{array}$

$\begin{array}{lll}146.96 & 324.97 & 156.81\end{array}$

$\begin{array}{lll}147.28 & 324.96 & 156.80\end{array}$

$\begin{array}{llll}147.61 & 324.96 & 156.80\end{array}$

$\begin{array}{lll}147.93 & 324.95 & 156.79\end{array}$

$\begin{array}{lll}148.26 & 324.95 & 156.78\end{array}$

$\begin{array}{lll}148.58 & 324.95 & 156.76\end{array}$

$148.89 \quad 324.95 \quad 156.75$

$149.20 \quad 324.95 \quad 156.74$

$\begin{array}{lll}149.51 & 324.95 & 156.72\end{array}$

$\begin{array}{lll}149.85 & 324.94 & 156.73\end{array}$

$\begin{array}{lll}150.20 & 324.93 & 156.74\end{array}$

$150.55 \quad 324.92 \quad 156.74$

$\begin{array}{lll}150.89 & 324.91 & 156.7\end{array}$

$\begin{array}{llll}151.24 & 324.91 & 156.7\end{array}$

$\begin{array}{lll}151.57 & 324.90 & 156.74\end{array}$
$-65.7$

5.7

$-65 \cdot 7$

$-65.8$

$-65.8$

$-65.8$

-65.8
-65.8

$-65.8$

$-65.7$

$-65.7$

$-65.7$

$-65.7$

$-65.7$

$-65.6$

$-65.5$

$-65.5$

$-65.4$

$-65.4$

$-65.3$

$-65.2$

$-65.2$

-65.1
-65.0

$-65.0$

$-64.9$

$-64.8$

$-64.7$

$-64.6$

$-64.4$

$-64.3$

$-64.2$

$-64.1$

$-64.0$

$-63.8$

$-63.7$

$-63.6$

$-63.4$

$-63.3$

$-63.2$

$-63.0$

$-62.9$

$-62.7$

$-62.6$

-62.4
-62.2

308.3

309.1

309.9

311.5

312.3

313.1

313.9

314.7

315.5

16.3

317.2

318.0

318.8

319.6

320.5

321.3

322.1

322.9

323.7

324.4

325.2

26.0

326.8

327.5

328.3

329.9

330.6

331.4

332.2

332.9

333.7

334.5

335.2

336.6

337.3

338.0

338.6

339.3

340.0

340.7

341.3

342.6

343.3

344.0

344.6 


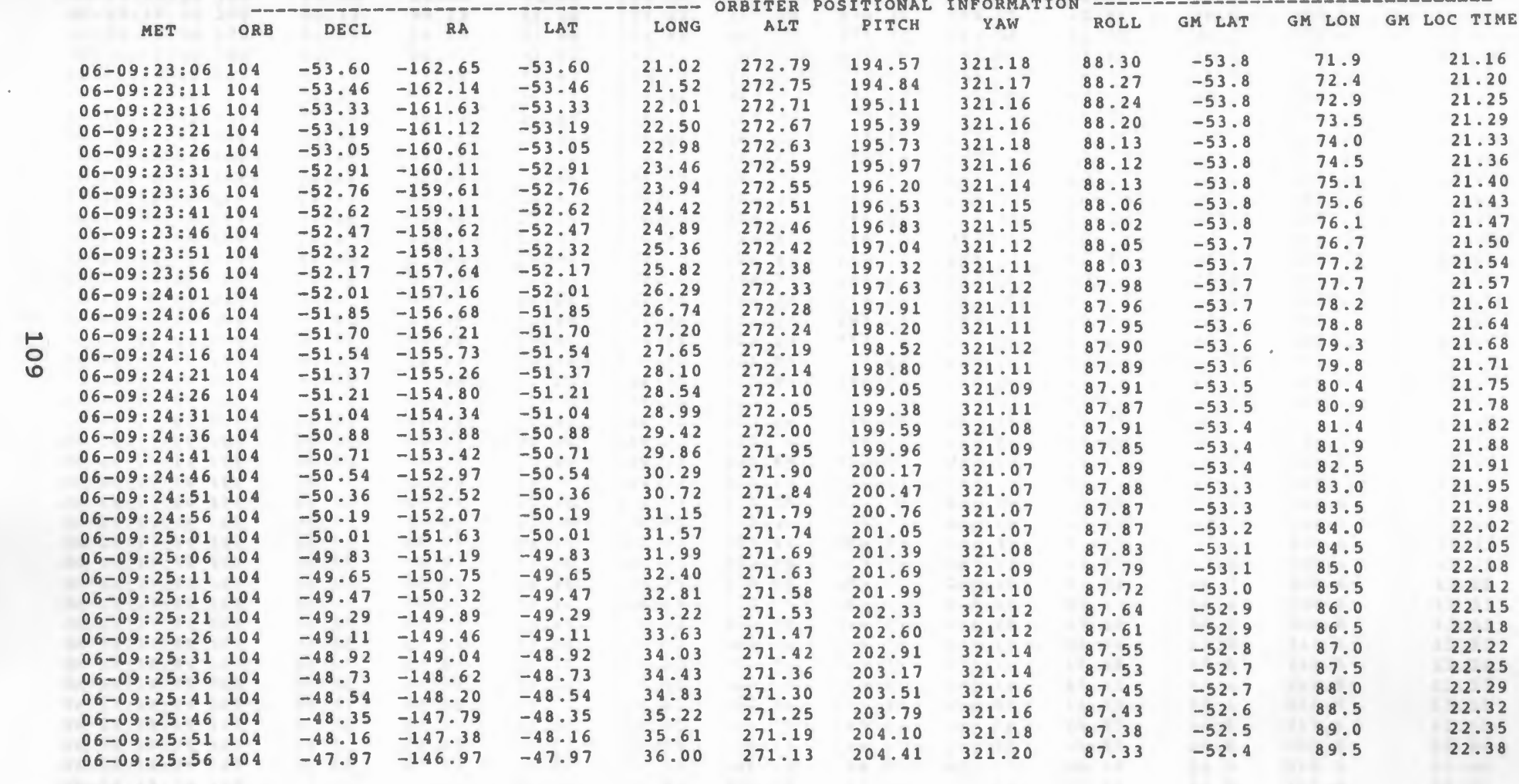




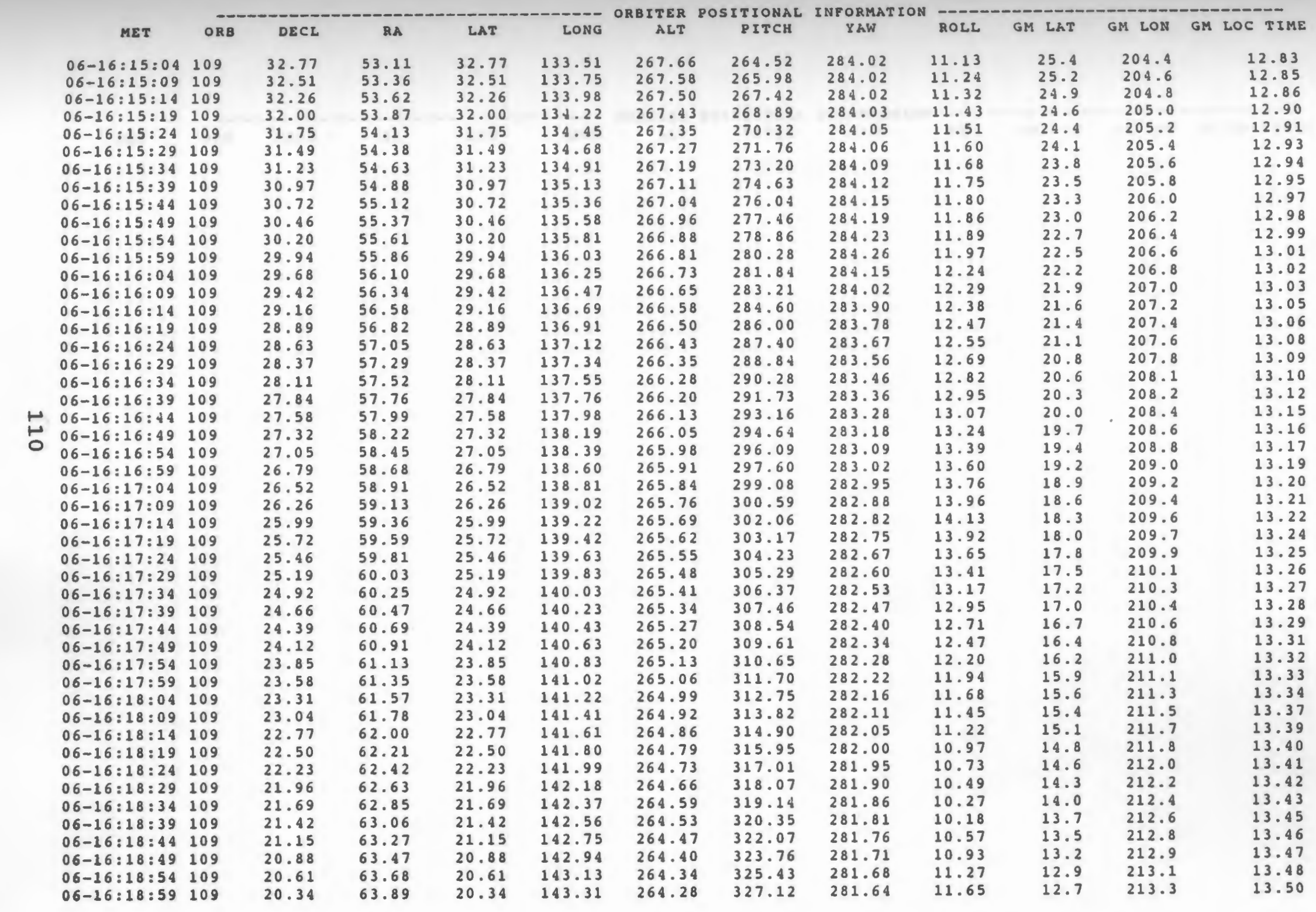




\begin{tabular}{|c|c|c|c|c|c|c|c|c|c|c|c|c|c|}
\hline MET & ORB & DECL & RA & LAT & LONG & ALT & PITCH & YAW & ROLL & GH LAT & GM LON & GM 1 & LOC TIME \\
\hline $06-16: 19: 09$ & 109 & 19.79 & 64.30 & 19.79 & 143.68 & 264.15 & 330.46 & 281.59 & 12.34 & 12.1 & 213.7 & & 13.52 \\
\hline $06-16: 19: 14$ & 109 & 19.52 & 64.51 & 19.52 & 143.87 & 264.09 & 332.12 & 281.57 & 12.69 & 11.9 & 213.8 & & 13.53 \\
\hline $06-16: 19: 19$ & 109 & 19.24 & 64.71 & 19.24 & 144.05 & 264.03 & 333.79 & 281.56 & 13.04 & 11.6 & 214.0 & & 13.54 \\
\hline $06-16: 19: 24$ & 109 & 18.97 & 64.92 & 18.97 & 144.23 & 263.97 & 335.49 & 281.56 & $13 .+3$ & 11.3 & 214.2 & & 13.55 \\
\hline $06-16: 19: 29$ & 109 & 18.70 & 65.12 & 18.70 & 144.42 & 263.91 & 337.16 & 281.56 & 13.80 & 11.0 & 214.4 & & 13.57 \\
\hline $06-16: 19: 34$ & 109 & 18.42 & 65.32 & 18.42 & 144.60 & 263.86 & 338.82 & 281.57 & 14.14 & 10.8 & 214.6 & & 13.60 \\
\hline $06-16: 19: 39$ & 109 & 18.15 & 65.52 & 18.15 & 144.78 & 263.80 & 340.18 & 281.58 & 14.50 & 10.5 & 214.7 & & 13.61 \\
\hline $06-16: 19: 44$ & 109 & 17.88 & 65.73 & 17.88 & 144.96 & 263.74 & 342.14 & 281.60 & 14.85 & 10.2 & 214.9 & & 13.62 \\
\hline $06-16: 19: 49$ & 109 & 17.60 & 65.93 & 17.60 & 145.14 & 263.69 & 343.77 & 281.62 & 15.17 & 9.9 & 215.1 & & 13.64 \\
\hline $06-16: 19: 54$ & 109 & 17.33 & 66.13 & 17.33 & 145.32 & 263.63 & 345.39 & 281.64 & 15.50 & 9.6 & 215.3 & & 13.65 \\
\hline $06-16: 19: 59$ & 109 & 17.05 & 66.33 & 17.05 & 145.50 & 263.57 & 346.99 & 281.68 & 15.79 & 9.4 & 215.5 & & 13.66 \\
\hline
\end{tabular}




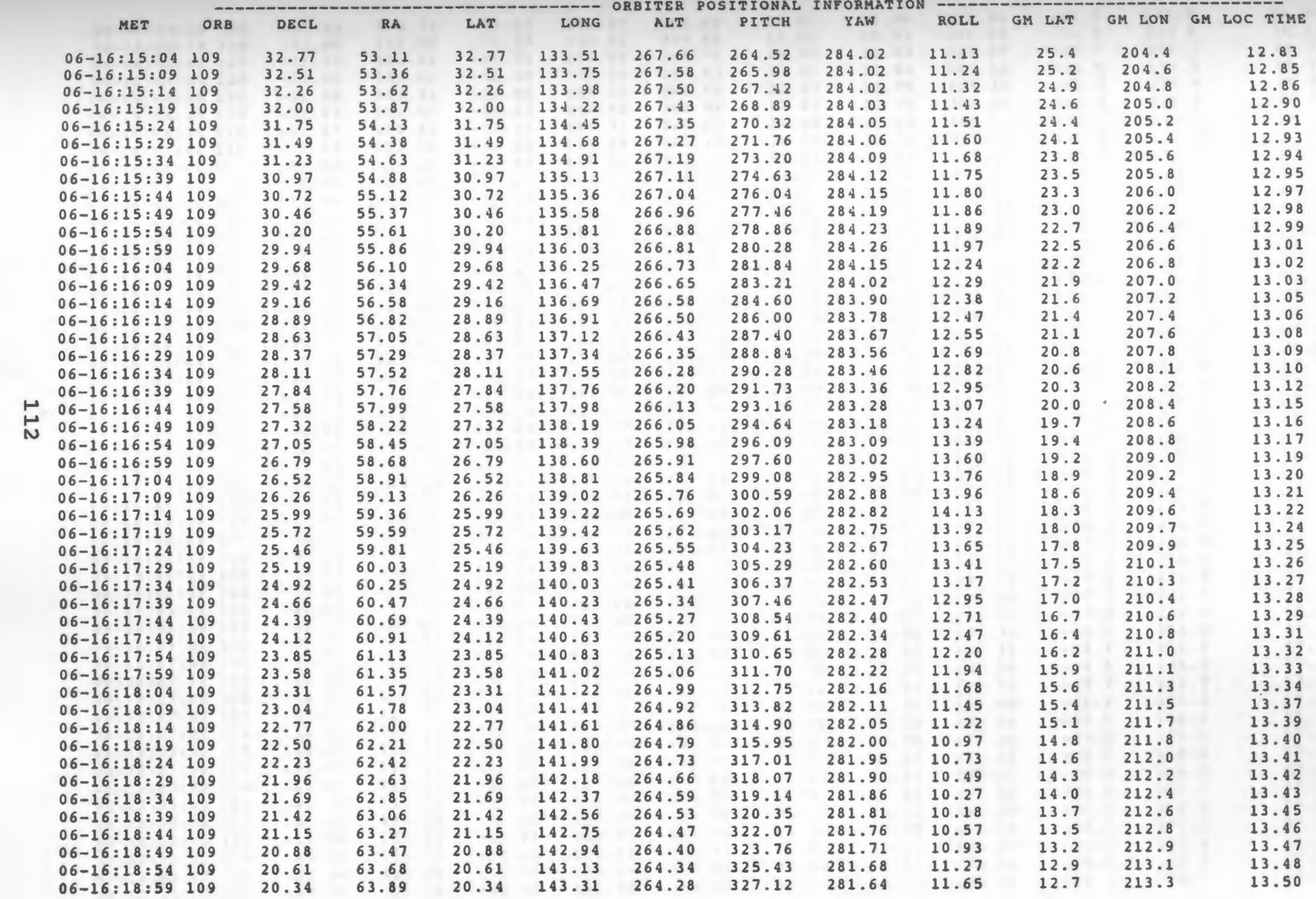


$06-18: 04: 09110$ $06-18: 04: 19110$ $06-18: 04: 24110$ $06-18: 04: 29110$ $06-18: 04: 34110$ $06-18: 04: 39110$ 06-18:04:44110 $06-18: 04: 49110$ $06-18: 04: 54110$ $06-18: 04: 59110$ $06-18: 05: 04110$ 06-18:05:09110 $06-18: 05: 14110$ $06-18: 05: 19110$ $06-18: 05: 24110$ $06-18: 05: 29110$ $06-18: 05: 34 \quad 110$ $06-18: 05: 39110$ $06-18: 05: 44110$ $06-18: 05: 49110$ $06-18: 05: 54 \quad 110$ $06-18: 05: 59110$ 06-18:06:04 110 06-18:06:09110 $06-18: 06: 14110$ 06-18:06:19 110 06-18:06:24110 $06-18: 06: 29110$ $06-18: 06: 34110$ $06-18: 06: 39110$ $06-18: 06: 44110$ $06-18: 06: 49110$ $06-18: 06: 54110$ $06-18: 06: 59110$ 06-18:07:04 110 $06-18: 07: 09110$ 06-18:07:14110 $06-18: 07: 19110$ $06-18: 07: 24110$ $06-18: 07: 29110$ 06-18:07:34110 06-18:07:39110 06-18:07:44 110 06-18:07:49 110 06-18:07:54 110 $06-18: 07: 59110$ 06-18:08:04110 06-18:08:09110 $06-18: 08: 14110$
$-30.83$ $-31.09$

$-31.35$ $-31.60$ $-31.86$ $-32.12$ $-32.37$ $-32.63$

$-32.88$

$-33.14$

$-33.39$

$-33.64$ $-33.90$

$-34.15$

$-34.40$

$-34.65$

$-34.90$

$-35.15$

$-35.40$

$-35.65$

$-35.90$

$-36.14$

$-36.64$

$-36.88$

$-37.13$

$-37.37$

$-37.61$

$-37.85$

$-38.10$

$-38.58$

$-38.82$

$-39.06$

$-39.29$

$-39.53$

$-39.77$

$-40.00$

$-40.24$

$-40.47$

$-40.70$

$-40.94$

$-41.17$

$-41.40$

$-41.63$

$-41.86$

$-42.08$

$-42.31$

$-\$ 2.76$
$-30.83$

100.81

101.06

101.31

101.57

101.82

102.08

102.34

102.59

102.86

103.12

103.38

103.65

103.91

104.18

104.15

104.72

105.00

105.27

105.55

105.83

106.11

106.39

106.67

106.96

107.25

107.54

107.83

108.12

108.42

108.71

109.01

109.31

109.62

109.92

110.23

110.54

110.85

111.16

111.48

111.80

112.12

112.44

112.77

113.09

113.42

113.75

114.09

114.43

$-31.35$

$-31.60$

$-31.86$

$-32.12$

$-32.37$

$-32.63$

$-32.88$

$-33.39$

$-33.64$

$-33.90$

$-34.15$

$-34.40$

$-34.65$

-34.90
-35.15

$-35.40$

$-35.65$

$-35.90$

$-36.14$

$-36.39$

$-36.64$

$-36.88$

-37.13
-37.37

$-37.61$

$-37.85$

$-38.10$

$-38.34$

-38.58
-38.8

$-39.06$

$-39.29$

$-39.53$

$-39.77$

$-40.00$

$-40.24$

$-40.47$

$-40.70$

$-40.94$

$-41.17$

$-41.40$

$-41.63$

-41.86
-42.08

$-42.31$

$-42.54$

$-\$ 2.76$
153.37
$-09 \quad 153.60$ 53.60

154.06

154.29

154.52

154.75
154.99

155.23

155.46

155.70

155.95

156.19

156.43

156.68

156.93

157.18

157.43

157.68

157.93

158.45

158.71

158.97

159.23

159.49

159.76

160.03

160.30

160.57

160.85

161.12

161.40

161.96

162.25

162.53

162.82

163.11

163.41

163.70

164.00

164.60

164.90

165.21

165.52

165.83

166.46 65.76

265.83

265.89

265.96

266.03

266.10

266.17

266.24

266.31

266.38

266.45

266.52

266.59

266.66

266.73

266.80

266.87

266.95

267.02

267.09

267.16

267.23

267.30

267.37

267.44

267.51

267.58

267.66

267.73

267.80

267.87

267.94

268.01

268.08

268.15

268.22

268.29

268.36

268.43

268.50

268.57

268.64

268.71

268.78

268.84

268.91

268.98

269.05

22.96 22.93

23.55 


\begin{tabular}{|c|c|c|c|c|c|c|c|c|c|c|c|c|c|c|}
\hline & MET & ORB & DECL & RA & LAT & LONG & ALT & PITCH & ZAW & ROLL & GM LAT & GM LON & GM & LOC TIME \\
\hline & $06-18: 00: 04$ & 110 & -17.72 & 89.49 & -17.72 & 143.57 & 262.75 & 311.53 & 13.87 & 236.28 & -27.1 & 216.3 & & 15.25 \\
\hline & $06-18: 00: 09$ & 110 & -17.99 & 89.69 & -17.99 & 143.75 & 262.80 & 312.88 & 14.28 & 235.88 & -27.4 & 216.5 & & 15.26 \\
\hline & $06-18: 00: 14$ & 110 & -18.27 & 89.89 & -18.27 & 143.93 & 262.85 & 314.23 & 14.68 & $235 .+7$ & -27.7 & 216.7 & & 15.28 \\
\hline & $06-18: 00: 19$ & 110 & -18.54 & 90.09 & -18.54 & 144.11 & 262.89 & 315.60 & 15.04 & 235.05 & $-28 \cdot 0$ & 216.9 & & 15.29 \\
\hline & $06-18: 00: 24$ & 110 & -18.81 & 90.29 & -18.81 & 144.29 & 262.94 & 316.97 & 15.40 & 234.62 & -28.2 & 217.2 & & 15.31 \\
\hline & $06-18: 00: 29$ & 110 & -19.09 & 90.50 & -19.09 & 144.48 & 262.99 & 318.35 & 15.75 & 234.20 & -28.5 & 217.4 & & 15.32 \\
\hline & $06-18: 00: 34$ & 110 & -19.36 & 90.70 & $-19 \cdot 36$ & 144.66 & 263.04 & 319.73 & 16.11 & 233.76 & -28.8 & 217.6 & & 15.34 \\
\hline & $06-18: 00: 39$ & 110 & -19.63 & 90.91 & -19.63 & 144.84 & 263.09 & 321.10 & 16.45 & 233.33 & -29.1 & 217.9 & & 15.36 \\
\hline & $06-18: 00: 44$ & 110 & -19.91 & 91.11 & -19.91 & 145.03 & 263.14 & 322.48 & 16.78 & 232.90 & -29.3 & 218.1 & & 15.37 \\
\hline & $06-18: 00: 49$ & 110 & -20.18 & 91.32 & -20.18 & 145.21 & 263.19 & 323.86 & 17.10 & 232.46 & -29.6 & 218.4 & & 15.41 \\
\hline & $06-18: 00: 54$ & 110 & -20.45 & 91.53 & -20.45 & 145.40 & 263.24 & 325.25 & 17.43 & 232.02 & -29.9 & 218.6 & & 15.43 \\
\hline & $06-18: 00: 59$ & 110 & -20.72 & 91.73 & -20.72 & 145.59 & 263.29 & 326.63 & 17.74 & 231.58 & -30.2 & 218.9 & & 15.44 \\
\hline & $06-18: 01: 04$ & 110 & -21.00 & 91.94 & -21.00 & 145.77 & 263.34 & 328.02 & 18.04 & 231.13 & -30.5 & 219.1 & & 15.46 \\
\hline & $06-18: 01: 09$ & 110 & -21.27 & 92.15 & -21.27 & 145.96 & 263.40 & 329.40 & 18.34 & 230.69 & -30.8 & 219.3 & & 15.48 \\
\hline & $06-18: 01: 14$ & 110 & -21.54 & 92.36 & -21.54 & 146.15 & $263 .+5$ & 330.79 & 18.63 & 230.25 & -31.0 & 219.6 & & 15.49 \\
\hline & $06-18: 01: 19$ & 110 & -21.81 & 92.57 & -21.81 & 146.34 & 263.50 & 332.19 & 18.92 & 229.80 & -31.3 & 219.8 & & 15.51 \\
\hline & $06-18: 01: 24$ & 110 & -22.08 & 92.79 & -22.08 & 146.53 & 263.56 & 333.57 & 19.19 & 229.34 & -31.6 & 220.1 & & 15.53 \\
\hline & $06-18: 01: 29$ & 110 & -22.35 & 93.00 & -22.35 & 146.72 & 263.62 & 334.97 & 19.45 & 228.90 & -31.9 & 220.4 & & 15.54 \\
\hline & $06-18: 01: 34$ & 110 & -22.62 & 93.21 & -22.62 & 146.92 & 263.67 & 336.37 & 19.72 & 228.45 & -32.2 & 220.6 & & 15.56 \\
\hline & $06-18: 01: 39$ & 110 & -22.89 & 93.43 & -22.89 & 147.11 & 263.73 & 337.77 & 19.98 & 227.99 & -32.4 & 220.9 & & 15.58 \\
\hline & $06-18: 01: 44$ & 110 & -23.16 & 93.64 & -23.16 & 147.30 & 263.79 & 339.17 & 20.22 & 227.53 & -32.7 & 221.1 & & 15.59 \\
\hline & $06-18: 01: 49$ & 110 & -23.43 & 93.86 & -23.43 & 147.50 & 263.84 & 340.58 & 20.44 & 226.91 & -33.0 & 221.4 & & 15.61 \\
\hline & $06-18: 01: 54$ & 110 & $-23 \cdot 70$ & 94.07 & -23.70 & 147.70 & 263.90 & 341.98 & 20.64 & 226.27 & -33.3 & 221.7 & & 15.63 \\
\hline & $06-18: 01: 59$ & 110 & -23.97 & 94.29 & -23.97 & 147.89 & 263.96 & 343.39 & 20.83 & 225.63 & -33.6 & 221.9 & & 15.65 \\
\hline & $06-18: 02: 04$ & 110 & -24.24 & 94.51 & -24.24 & 148.09 & 264.02 & 344.80 & 21.01 & 224.99 & -33.8 & 222.2 & & 15.67 \\
\hline & $06-18: 02: 09$ & 110 & -24.50 & 94.73 & -24.50 & 148.29 & 264.08 & 346.20 & 21.19 & 224.35 & -34.1 & 222.5 & & 15.68 \\
\hline & $06-18: 02: 14$ & 110 & -24.77 & 94.95 & -24.77 & 148.49 & 264.14 & 347.62 & 21.36 & 223.71 & -34.4 & 222.8 & & 15.72 \\
\hline & $06-18: 02: 19$ & 110 & -25.04 & 95.17 & -25.04 & 148.69 & 264.20 & 349.02 & 21.52 & 223.09 & -34.6 & 223.0 & & 15.74 \\
\hline & $06-18: 02: 24$ & 110 & -25.31 & 95.39 & -25.31 & 148.89 & 264.26 & 350.44 & 21.67 & 222.44 & -34.9 & 223.3 & & 15.76 \\
\hline & $06-18: 02: 29$ & 110 & -25.57 & 95.62 & -25.57 & 149.09 & 264.32 & 351.86 & 21.82 & 221.81 & -35.1 & 223.6 & & 15.78 \\
\hline & $06-18: 02: 34$ & 110 & -25.84 & 95.84 & -25.84 & 149.30 & 264.38 & 353.28 & 21.95 & 221.17 & -35.4 & 223.9 & & 15.80 \\
\hline & $06-18: 02: 39$ & 110 & -26.11 & 96.07 & -26.11 & 149.50 & 264.44 & 354.70 & 22.08 & 220.54 & -35.7 & 224.2 & & 15.82 \\
\hline & $06-18: 02: 44$ & 110 & -26.37 & 96.29 & -26.37 & 149.71 & 264.51 & 356.12 & 22.20 & 219.91 & -35.9 & 224.4 & & 15.84 \\
\hline & $06-18: 02: 49$ & 110 & -26.64 & 96.52 & -26.64 & 149.91 & 264.57 & 357.55 & 22.31 & 219.27 & -36.2 & 224.7 & & 15.86 \\
\hline & $06-18: 02: 54$ & 110 & -26.90 & 96.75 & -26.90 & 150.12 & 264.63 & 358.98 & 22.42 & 218.64 & -36.5 & 225.0 & & 15.87 \\
\hline & $06-18: 02: 59$ & 110 & -27.17 & 96.98 & -27.17 & 150.33 & 264.69 & 0.41 & 22.51 & 218.02 & -36.7 & 225.3 & & 15.89 \\
\hline & $06-18: 03: 04$ & 110 & -27.43 & 97.21 & -27.43 & 150.54 & 264.76 & 1.84 & 22.60 & 217.40 & -37.0 & 225.6 & & 15.91 \\
\hline & $06-18: 03: 09$ & 110 & -27.69 & 97.44 & -27.69 & 150.75 & 264.82 & 3.28 & 22.68 & 216.77 & -37.3 & 225.9 & & 15.93 \\
\hline & $06-18: 03: 14$ & 110 & -27.96 & 97.67 & -27.96 & 150.96 & 264.89 & 4.72 & 22.75 & 216.15 & -37.5 & 226.2 & & 15.95 \\
\hline & $06-18: 03: 19$ & 110 & -28.22 & 97.91 & -28.22 & 151.17 & 264.95 & 6.15 & 22.81 & 215.53 & -37.8 & 226.5 & & 15.97 \\
\hline & $06-18: 03: 24$ & 110 & -28.48 & 98.14 & -28.48 & 151.39 & 265.02 & 7.60 & 22.86 & 214.92 & $-38 \cdot 0$ & 226.8 & & 15.99 \\
\hline & $06-18: 03: 29$ & 110 & -28.75 & 98.38 & -28.75 & 151.60 & 265.08 & 9.04 & 22.91 & 214.29 & -38.2 & 227.1 & & 16.01 \\
\hline & $06-18: 03: 34$ & 110 & -29.01 & 98.62 & -29.01 & 151.82 & 265.15 & 10.48 & 22.95 & 213.70 & -38.5 & 227.4 & & 16.05 \\
\hline & $06-18: 03: 39$ & 110 & -29.27 & 98.86 & -29.27 & 152.04 & 265.22 & 11.92 & 22.98 & 213.10 & -38.7 & 227.7 & & 16.07 \\
\hline & $06-18: 03: 44$ & 110 & -29.53 & 99.10 & -29.53 & 152.26 & 265.28 & 13.38 & 22.99 & 212.50 & -39.0 & 228.0 & & 16.09 \\
\hline & $06-18: 03: 49$ & 110 & -29.79 & 99.34 & -29.79 & 152.48 & 265.35 & 14.82 & 23.00 & 211.89 & -39.2 & 228.3 & & 16.11 \\
\hline & $06-18: 03: 54$ & 110 & -30.05 & 99.58 & -30.05 & 152.70 & 265.42 & 16.27 & 23.00 & 211.31 & -39.5 & 228.6 & & 16.13 \\
\hline
\end{tabular}


06-18:04:09 110 $06-18: 04: 14110$
$06-18: 04: 19$
$06-110$ 06-18:04:24 110 06-18:04:29 110 $06-18: 04: 34110$ $06-18: 04: 39110$ $06-18: 04: 44110$ 06-18:04:49 110 $06-18: 04: 54110$ 06-18:04:59110 06-18:05:04 110 06-18:05:09110 $06-18: 05: 14110$ 06-18:05:19 110 $06-18: 05: 24110$ 06-18:05:29110 $06-18: 05: 34110$ $06-18: 05: 39110$ 06-18:05:44 110 $06-18: 05: 49110$ $06-18: 05: 54110$ $06-18: 05: 59110$ 06-18:06:04110 06-18:06:09 110 06-18:06:14 110 06-18:06:19 110 06-18:06:24110 $06-18: 06: 29110$ 06-18:06:34110 $06-18: 06: 39110$ 06-18:06:44110 $06-18: 06: 49110$ $06-18: 06: 54110$ $06-18: 06: 59110$ 06-18:07:04 110 06-18:07:09 110 $06-18: 07: 14110$ 06-18:07:19 110 $06-18: 07: 24110$ $06-18: 07: 29 \quad 110$ 06-18:07:34 110 06-18:07:39 110 $06-18: 07: 44 \quad 110$ 06-18:07:49110 06-18:07:54 110 $06-18: 07: 59110$ $06-18: 08: 04110$ 06-18:08:09110 06-18:08:14 110 100.56 100.81 100.81
101.06 101.06 101.5 101.82 102.08 102.0 102.34
102.59 102.59
102.86 103.12 103.38 103.65 103.91 104.18 104.45 104.72 105.00 105.27 105.55 105.83 106.11 106.39 106.67 106.96 107.25 107.54 107.83 108.12 108.42 108.71

109.01 109.31 109.62 109.92 110.23 110.54 110.85 111.16 111.48 111.80 112.12 112.44 112.77 113.09 113.42 $\begin{array}{ll}-42.08 & 113.42 \\ -42.31 & 113.75\end{array}$ $\begin{array}{ll}-42.31 & 113.75 \\ -42.54 & 114.09\end{array}$ $-42.76$

-30.83
-31.09
-31.35
-31.60
-31.86
-32.12
-32.37
-32.63
-32.88
-33.14
-33.39
-33.64
-33.90
-34.15
-34.40
-34.65
-34.90
-35.15
-35.40
-35.65
-35.90
-36.14
-36.39
-36.64
-36.88
-37.13
-37.37
-37.61
-37.85
-38.10
-38.34
-38.58
-38.82
-39.06
-39.29
-39.53
-39.77
-40.00
-40.24
-40.47
-40.70
-40.94
-41.17
-41.40
-41.63
-41.86
-42.08
-42.31
-42.54
-42.76

153.37 153.60 153.83 154.06 154.29 154.52 154.75 154.99 155.23 155.46 155.70 155.95 156.19 156.43 156.68 156.93 157.18 157.43 157.68 157.93 158.19 158.19 158.45 158.71 158.97 159.23 159.49 159.76 160.03 160.03 160.30 160.57 160.85 161.12

161.40 161.68 161.96 162.25 162.53 162.82 163.11 163.41 163.70 164.00 164.30 164.60 164.90 165.21 165.52

165.83
166.14 166.46
265.62 265.6 265.83 265.89 265.96 266.03 266.10 266.17 266.24 266.31 266.38 266.45 266.52 266.59 266.66 266.73 266.80 266.87 266.95 267.02 267.09 267.16 267.23 267.30 267.37 267.44 267.58 267.66 267.73 267.80 267.87 267.94 268.01 268.08 268.15 268.22 268.29 268.36 268.43 268.50 268.57 268.64 268.71 268.78

268.8 268.84 268.91 268.98
269.05
20.63 22.09 25.01 26.47 27.94 29.40 30.72 32.0 33.3 34.6 35.92 37.22

38.52

39.82 41.12 42.4 43.70 45.00 46.29 47.58 47.58 48.8 .1 51.45 52.73 54.02 55.3 56.59 57.85 59.1 60.36 61.61 62.85 64.10 65.35 66.5 67.8 69.0 70.32 71.59 72.85 74.13 75.3 76.65 77.91 79.17

80.40

81.62

82.86 84.09

22.96 22.93 22.89 22.84 22.78 22.71 22.63 22.48 22.31 22.14 21.96 21.77 21.57 21.37 21.15 20.93 20.70 20.44 20.18 19.90 19.63 19.34 19.05 18.75 18.45 18.1 혀 17.82 17.50 17.18 
$06-18: 08: 19110$ $06-18: 08: 24110$ $06-18: 08: 29110$ $06-18: 08: 34110$ $06-18: 08: 39110$ $06-18: 08: 44 \quad 110$ $06-18: 08: 49110$ $06-18: 08: 54110$ $06-18: 08: 59110$ 06-18:09:04 110 $06-18: 09: 09 \quad 110$ 06-18:09:14 110 $06-18: 09: 19110$ $06-18: 09: 24110$ 06-18:09:29 110 06-18:09:34110 06-18:09:39 110 $06-18: 09: 44110$ 06-18:09:49 110 06-18:09:54110 $06-18: 09: 59110$ $06-18: 10: 04110$ 06-18:10:09 110 $06-18: 10: 14110$ $06-18: 10: 19110$ 06-18:10:24110 $06-18: 10: 29110$ $06-18: 10: 34110$ $06-18: 10: 39110$ $06-18: 10: 44110$ $06-18: 10: 49110$ $06-18: 10: 54110$ $06-18: 10: 59110$ 06-18:11:04 110 $06-18: 11: 09110$ $06-18: 11: 14110$ $06-18: 11: 19110$ $06-18: 11: 24110$ 06-18:11:29 110 $06-18: 11: 34110$ 06-18:11:39 110 06-18:11:44 110 $06-18: 11: 49 \quad 110$ 06-18:11:54 110 06-18:11:59 110 06-18:12:04 110 06-18:12:09110 06-18:12:14 110 $06-18: 12: 19110$ $06-18: 12: 24110$ $-43.21$ $-43.43$ $-43.65$ $-43.87$ $-44.09$ $-44.30$ $-44.52$ $-44.74$ $-44.95$ $-45.16$ $-45.37$ $-45.58$ $-45.79$ $-46.00$ $-46.21$ $-46.41$ $-46.62$ $-46.82$ $-47.02$ $-47.22$ $-47.82$ $-48.01$ $-48.20$ $-48.40$

$-48.59$

$-48.78$

$-48.96$

$-49.15$

$-49.33$ $-49.52$ $-49.88$ $-50.05$ $-50.23$ $-50.40$ $-50.58$ $-50.75$ $-50.92$ $-51.08$ $-51.25$ $-51.41$ $-51.57$ $-51.73$ $-51.89$ $-52.20$ $-52.35$
114.76 115. 11 115.45 15.80 116.15 116.50 116.85 117.21 117.57 117.93 118.30 118.67 119.04 119.41 119.79 120.17 120.55 20.93 121.32 121.71 122.10 122.50 122.90 123.30 23.71 124.12 124.53 124.94 125.36 125.78 26.21 126.64 127.07 127.50 127.94 128.38 128.82 29.27 129.72 130.17 130.63 131.09 131.55 132.02 132.49 132.96

133.44

134.40 134.89
$-42.98$ $-43.21 \quad 167.10$ $-43.43$ $-43.65$ $-43.87$ $-44.09$ $-44.30$ $-44.52$ $-44.74$ $-44.95$ $-45.16$ $-45.37$ $-45.58$ $-45.79$ $-46.00$ $-46.21$ $-46.21$ $-46.41$ $-46.62$ $-46.82$ $-47.02$ $-47.22$ $-47.42$ $-47.62$ $-47.62$ $-47.82$ -48.01
-48.20 $-48.40$ $-48.59$ $-48.78$ $-48.96$ $-49.15$ $-49.33$ $-49.52$ $-49.70$ $-49.88$ $-50.05$ $-50.23$ $-50.40$ $-50.58$ $-50.75$ $-50.92$ $-51.08$ $-51.25$ $-51.41$ $-51.57$ $-51.73$ $-51.89$ $-52.05$ 5 $-52.35$
269.12 269.19 269.25 269.32 269.39 $269 .+5$ 269.52 269.58 269.65 269.72 269.78 269.85 269.91 269.97 270.04 270.10 270.16 270.22 270.29 270.35 270.41 270.47 270.53 270.59 270.65 270.71 270.77 270.82 270.88 270.9 270.99 271.05 271.1 271.16 271.21 271.27 271.32 271.37

271.4 271.48 271.53

271.58 271.63 271.68

271.73 271.77 271.82 271.87

271.91 271.96

85.33 86.55 87.78 89.01 90.23 91.45 92.67 93.89 95.11 96.32

97.53 98.73

99.95 101.15 102.35 103.55 104.75 105.95 107.15 108.32 109.43 110.54 111.65 112.75 113.86 114.96 116.07 117.16 118.25 119.38 120.60 121.85 123.08 124.30 125.31 125.95 126.30 
06-18:12:29 110 06-18:12:34110 06-18:12:39110 06-18:12:44110 06-18:12:49 110 $06-18: 12: 54 \quad 110$ 06-18:12:59 110 $06-18: 13: 04110$ $06-18: 13: 09110$ 06-18:13:14 110 $06-18: 13: 19110$ 06-18:13:24110 06-18:13:29 110 $06-18: 13: 34 \quad 110$ $06-18: 13: 39110$ $06-18: 13: 44 \quad 110$ 06-18:13:49110 $06-18: 13: 54 \quad 110$ $06-18: 13: 59 \quad 110$ $06-18: 14: 04110$ 06-18:14:09 110 06-18:14:14 110 $06-18: 14: 19110$ 06-18:14:24 110 06-18:14:29 110 $06-18: 14: 34 \quad 110$ $06-18: 14: 39110$ $06-18: 14: 44 \quad 110$ 06-18:14:49 110 06-18:14:54 110 06-18:14:59 110 $06-18: 15: 04 \quad 110$ 06-18:15:09 110 $06-18: 15: 14110$ 06-18:15:19 110 $06-18: 15: 24110$ 06-18:15:29110 $06-18: 15: 34110$ $06-18: 15: 39 \quad 110$ 06-18:15:44 110 06-18:15:49 110 $06-18: 15: 54110$ 06-18:15:59 110 $06-18: 16: 04110$ 06-18:16:09 110 $06-18: 16: 14110$ 06-18:16:19 110 06-18:16:24110 $06-18: 16: 29110$ $06-18: 16: 34110$
$-52.50$ $-52.65$ $-52.80$ $-52.94$ $-53.08$ $-53.22$ $-53.36$ $-53.50$ $-53.63$ $-53.76$ $-53.89$ $-54.01$ $-54.14$ $-51.26$ $-54.38$ $-54.49$ $-54.61$ $-54.72$ $-54.83$ $-54.94$ $-55.04$ $-55.14$ $-55.24$ $-55.34$ $-55.43$ $-55.53$ $-55.61$ $-55.70$ $-55.78$ $-55.87$ $-55.94$ $-56.02$ $-56.09$ $-56.16$ $-56.23$ $-56.29$

$-56.35$

$-56.41$

$-56.47$

$-56.52$ $-56.57$ $-56.62$

$-56.66$

$-56.70$

$-56.74$

$-56.78$ $-56.81$

$-56.84$

$-56.87$

$-56.89$
135.38 135.87 136.87 137.37 137.88 138.39 138.91 139.42 139.94 140.46 140.99

141.52 142.05 142.59 143.13 143.67 144.21

144.76 145.31 145.87 146.42 146.98 147.54

148.11 148.68 149.25 149.82 150.40 150.97 151.55 152.14 152.72 153.31 153.90 154.49 155.08 155.67 156.27 156.87 157.47 158.07

158.67 159.28 159.88 160.49 161.10 161.71

162.32

162.93
$-52.50$ $-52.65$ $-52.80$ $-52.94$ $-53.08$ $-53.22$ $-53.50$ $-53.63$ $-53.76$ $-53.89$ $-54.01$ $-54.14$ $-54.26$ -54.38
-54.49 $-54.6$ $-54.72$ $-54.83$ $-54.94$ $-55.04$ $-55.14$ $-55.24$ $-55.34$ $-55.43$ $-55.53$ $-55.61$ $-55.70$ -55.78
-55.87 $-55.94$ $-56.02$ $-56.09$ $-56.16$ $-56.23$ $-56.29$ $-56.35$ $-56.41$ $-56.47$ $-56.52$ $-56.57$ $-56.62$ $-56.66$ $-56.70$ $-56.74$ $-56.78$ $-56.81$ -56.84
-56.87 $-56.89$
186.35 186.82 187.30 188.26 188.75 189.24 189.73 190.22 90.72 191.23 191.73 192.24 192.75 193.27 193.78 194.30 194.83 195.36 195.89 196.12 196.95 197.49 198.03 198.58 199.12 199.67 200.23 200.78 201.34 201.90 202.46 203.02 203.59 204.15 204.72 205.30 205.87 206.45 07.02 207.60 208.18 208.76 209.35 209.93 210.52 211.10 211.69 212.28 212.87

272.00 272.05 27. 列 272.26 272.30 272.38 272.42 272.45 272.49 272.52 272.56 272.59 272.63 272.66 272.69 272.73 272.76 272.79 272.81 272.84 272.87 272.90 272.92 272.95 272.97 273.00 273.02 273.04 273.06 273.09 273.11 273.13 273.14 273.16 273.18 273.19 273.21 273.22 273.24 273.25 
$06-18: 16: 39 \quad 110$ 06-18:16:44 110 $06-18: 16: 49110$ 06-18:16:54110 06-18:16:59 110 $06-18: 17: 04 \quad 110$ 06-18:17:09 110 $06-18: 17: 14110$ 06-18:17:19 110 06-18:17:24 110 06-18:17:29 110 $06-18: 17: 34110$ 06-18:17:39 110 $06-18: 17: 44 \quad 110$ 06-18:17:49 110 $06-18: 17: 54 \quad 110$ $06-18: 17: 59 \quad 110$ 06-18:18:04110 06-18:18:09110 $06-18: 18: 14110$ $06-18: 18: 19110$ $06-18: 18: 24110$ $06-18: 18: 29110$ 06-18:18:34110 06-18:18:39110 $06-18: 18: 44110$ $06-18: 18: 49110$ $06-18: 18: 54110$ 06-18:18:59 110 06-18:19:04 110 06-18:19:09110 $06-18: 19: 14110$ 06-18:19:19 110 06-18:19:24 110 06-18:19:29 110 06-18:19:34110 06-18:19:39110 06-18:19:44 110 06-18:19:49 110 06-18:19:54 110 $06-18: 19: 59110$
$-56.91$ $-56.93$ $-56.94$ $-56.96$ $-56.96$ $-56.97$ $-56.97$ $-56.97$ $-56.97$ 56.97 $-56.95$ $-56.95$ $-56.94$ $-56.92$ $-56.91$ $-56.89$ $-56.86$ $-56.83$ $-56.80$ $-56.77$ $-56.73$ $-56.69$ $-56.65$ $-56.61$ $-56.56$ $-56.51$ $-56.46$ $-56.40$ $-56.34 \quad 179.96$ $-56.28-179.45$ $-56.21-178.86$ $-56.14-178.27$ $\begin{array}{ll}-56.07 & -177.69\end{array}$ $-56.00 \quad-177.10$ $\begin{array}{ll}-55.92 & -176.52\end{array}$ $\begin{array}{ll}-55.85 & -175.94\end{array}$ $-55.76-175.36$ $\begin{array}{ll}-55.68 & -174.79\end{array}$ $\begin{array}{ll}-55.59 & -174.22\end{array}$ $\begin{array}{ll}-55.50 & -173.65\end{array}$ $-55.41-173.0$ $-55.32-172.52$ $-56.93$ $-56,96$ $-56.96$ $-56.96$ $-56.97$ $-56.97$ $-56.97$ $-56.97$ $-56.96$ $-56.95$ $-56.94$ $-56.92$ $-56.91$ $-56.89$ $-56.86$ $-56.83$ $-56.80$ $-56.77$ $-56.73$ $-56.69$ $-56.65$ $-56.61$ $-56.56$ $-56.51$ $-56.46$ $-56.40$ $-56.34$ $-56.28$ $-56.21$ $-56.14$ $-56.07$ $-56.00$ $-55.92$ $-55.85$ $-55.76$ $-55.68$ $-55.59$ $-55.50$
$213.46 \quad 273.31$ 214.05 214.64 215.24 215.83 216.42 217.01 217.61 218.20 218.79 18.78 219.97 220.57 221.16 221.75 222.34 222.93 223.51 224.10 224.68 225.27 225.85 226.43 227.01 227.59 228.17 228.74 229.32 229.89 230.46 231.03 231.59 232.15 232.72 233.27 233.83 234.38 234.93 235.48 236.03 236.57 148.16 273.33 273.3 273.33 273.34 273.34 273.34 273.34 273.34 273.34 273.3 273.33 273.33 273.32 273.32 273.31 273.30 273.30 273.29 273.28 273.27 273.26 273.24 273.23 273.22 273.20 273.19 273.17 273.15 273.14 273.12 273.10 273.08 273.06 273.04 273.01 272.99 272.97 272.94 272.92
147.83

351.99 352.00 352.00 352.00 352.01 352.01 50 149.82 150.15 150.17 150.79 151.14 151.49 151.84 152.19 152.53 152.88 153.21 153.54 153.87 154.20 154.52 154.84 155.17 155.48 155.80 156.16 156.52 156.87 157.22 157.57 157.91 158.25 158.60 158.94 159.28 159.62 159.95 160.29 160.62 160.95 161.28

178.09

178.07

178.06

178.06

178.05

178.05

178.04

178.03

178.02

178.01

178.0

178.00

177.99

177.99

177.97

177.96

177.95

177.96

177.97

177.98

177.99

178.00

178.01

178.02

178.03

178.02

178.02

178.02

178.02

178.02

178.01

178.01

178.01

177.99

177.99 
06-18:19:04110 $06-18: 19: 09110$ $06-18: 19: 14110$ $06-18: 19: 19110$ $06-18: 19: 24110$ $06-18: 19: 29110$ $06-18: 19: 34110$ $06-18: 19: 39110$ 06-18:19:14110 $06-18: 19: 49 \quad 110$ 06-18:19:54 110 06-18:19:59 110 06-18:20:04 110 06-18:20:09110 06-18:20:14 110 $06-18: 20: 19 \quad 110$ 06-18:20:24 110 06-18:20:29 110 $06-18: 20: 34110$ $06-18: 20: 39110$ 06-18:20:44 110

106-18:20:49 110

अ 06-18:20:54 110

$006-18: 20: 59110$ 06-18:21:04110 06-18:21:09110 06-18:21:14110 06-18:21:19 110 06-18:21:24110 06-18:21:29 110 06-18:21:34 110 $06-18: 21: 39110$ 06-18:21:44 110 06-18:21:49 110 06-18:21:54 110 06-18:21:59 110 $06-18: 22: 04110$ 06-18:22:09 110 06-1::22:14 110 06-18:22:19 110 06-18:22:24110 $06-18: 22: 29110$ 06-18:22:34 110 06-18:22:39 110 06-18:22:44110 06-18:22:49 110 06-18:22:54110 $06-18: 22: 59110$ $06-18: 23: 04110$

$\begin{array}{ll}-56.21 & -178.86 \\ -56.14 & -178.27 \\ -56.07 & -177.69 \\ -56.00 & -177.10 \\ -55.92 & -176.52 \\ -55.85 & -175.94 \\ -55.76 & -175.36 \\ -55.68 & -174.79 \\ -55.59 & -174.22 \\ -55.50 & -173.65 \\ -55.41 & -173.08 \\ -55.32 & -172.52 \\ -55.22 & -171.96 \\ -55.12 & -171.40 \\ -55.02 & -170.84 \\ -54.91 & -170.29 \\ -54.80 & -169.74 \\ -54.69 & -169.19 \\ -54.58 & -168.65 \\ -54.47 & -168.11 \\ -54.35 & -167.57 \\ -54.23 & -167.03 \\ -54.11 & -166.50 \\ -53.98 & -165.97 \\ -53.85 & -165.15 \\ -53.73 & -164.92 \\ -53.59 & -164.41 \\ -53.16 & -163.89 \\ -53.33 & -163.38 \\ -53.19 & -162.87 \\ -53.05 & -162.36 \\ -52.91 & -161.86 \\ -52.76 & -161.36 \\ -52.61 & -160.86 \\ -52.17 & -160.37 \\ -52.32 & -159.88 \\ -52.16 & -159.10 \\ -52.01 & -158.91 \\ -51.85 & -158.43 \\ -51.69 & -157.96 \\ -51.53 & -157.49 \\ -51.37 & -157.02 \\ -51.21 & -156.55 \\ -51.04 & -156.09 \\ -50.87 & -155.63 \\ -50.70 & -155.17 \\ -50.53 & -154.72 \\ -50.36 & -154.27 \\ -50.18 & -153.82\end{array}$

$-56.21$ $-56.14$ $-56.07$ $-56.00$ $-55.92$ $-55.85$ $-55.76$ $-55.68$ $-55.59$ $-55.50$ $-55.41$ $-55.32$ $-55.22$ $-55.12$ $-55.02$ $-54.91$ $-54.80$ $-54.69$ $-54.58$ $-54.47$ $-54.35$ $-54.23$ $-54.11$ $-53.98$ $-53.85$ $-53.73$ $-53.59$ $-53.16$ $-53.33$ $-53.19$ $-53.05$ $-52.91$ $-52.76$ $-52.61$ $-52.47$ $-52.32$ $-52.16$ $-52.01$ $-51.85$ $-51.69$ $-51.53$ $-51.37$ $-51.21$ $-51.04$ $-50.87$ $-50.70$ $-50.53$ $-50.36$ $-50.18$
$230.46 \quad 273.15$ 231.03 231.59 232.15 232.72 233.27 233.83 234.38 234.93 235.48 236.03 236.57 237.11 237.65 238.19 238.72 239.25 239.77 240.30 240.82 241.33 241.85 242.36 242.87 243.37 243.37 243.87 244.37 245.36 245.85 246.33 246.81 247.29 247.29
247.77 248.24 246.71 249.17 249.63 249.63 250.09
250.55 251.00 251.45 251.89 252.33 252.77 253.21 253.64 254.07 254.49 273.10 273.08 273.06 273.0 273.0 272.99 272.97 272.94 272.92 272.89 272.86 272.84 272.81 272.78 272.75 272.72 272.68 272.65 272.62 272.59 272.55 272.5 272.48 272.4 272.41 272.37 272.33 272.29 272.2 272.2 272.17 272.13 272.08 272.04 272.00 271.95 271.91 271.86 271.81 271.72 271.6 271.62 271.57

271.47
157.57 158.25 158.60

158.94 159.28 159.62

159.95 160.29 160.62

160.95

161.28 161.61

161.93 162.26 162.58 162.90 163.22 163.54 163.86 164.18 164.50 164.85

165.20 165.54 165.89

166.23 166.58 166.91

167.25

167.59

167.92

168.26

168.60 168.94 169.27 169.60 169.94 170.27

170.61

170.94

171.27

171.60

171.93

172.26

172.59

172.91

173.56

352.00 352.00 352.00 352.00 352.00 351.99 351.99 351.99 351.99 351.99 351.99 351.99 351.98 351.98 351.98 351.98 351.98 351.98 351.99 351.98 351.98 351.97 351.98 351.97 351.97 351.97 351.96 351.96 351.96 351.96 351.96 351.96 351.96 351.96 351.96 351.96 351.96 351.96 351.96 351.96 351.96 351.96 351.95 
06-18:23:09 110 $06-18: 23: 14110$ 06-18:23:19 110 $06-18: 23: 24110$ 06-18:23:29 110 $06-18: 23: 34110$ $06-18: 23: 39110$ 06-18:23:44 110 06-18:23:49 110 06-18:23:54 110 06-18:23:59 110 06-18:24:04 110 $06-18: 24: 09110$ 06-18:24:14 110 $06-18: 24: 19110$ 06-18:24:24110 06-18:24:29 110 $06-18: 24: 34110$ $06-18: 24: 39110$ 06-18:24:44 110 $06-18: 24: 49110$ $06-18: 24: 54110$

$06-18: 24: 59 \quad 110$ 06-18:25:04 110 06-18:25:09 110 06-18:25:14110 06-18:25:19 110 $06-18: 25: 24110$ 06-18:25:29 110 $06-18: 25: 34110$ 06-18:25:39 110 $06-18: 25: 44110$ 06-18:25:49 110 06-18:25:54 110 $06-18: 25: 59110$ 06-18:26:04110 06-18:26:09 110 $06-18: 26: 14110$ 06-18:26:19 110 06-18:26:24 110 $06-18: 26: 29110$ $06-18: 26: 34110$ $06-18: 26: 39110$ 06-18:26:44110 06-18:26:49 110 06-18:26:54 110 06-18:26:59 110 06-18:27:04 110 06-18:27:09 110 $06-18: 27: 14 \quad 110$

\begin{tabular}{|c|c|c|c|}
\hline $\begin{array}{l}-50.01 \\
-49.83\end{array}$ & $\begin{array}{l}-153.38 \\
-152.94\end{array}$ & $\begin{array}{l}-50.01 \\
-49.83\end{array}$ & $\begin{array}{l}254.91 \\
255.33\end{array}$ \\
\hline-49.65 & -152.50 & -49.65 & 255.75 \\
\hline-49.47 & -152.07 & -49.47 & 256.16 \\
\hline-19.29 & -151.64 & -49.29 & 256.57 \\
\hline-49.10 & -151.22 & -49.10 & 256.98 \\
\hline-48.92 & -150.79 & -48.92 & 257.38 \\
\hline-48.73 & -150.37 & -48.73 & 257.78 \\
\hline-48.54 & -149.95 & -48.54 & 258.17 \\
\hline$-48 \cdot 35$ & -149.54 & -48.35 & 258.57 \\
\hline-48.16 & -149.13 & $-48 \cdot 16$ & 258.96 \\
\hline-47.96 & -148.72 & -47.96 & 259.34 \\
\hline-47.77 & -148.32 & -47.77 & 259.73 \\
\hline-47.57 & -147.91 & -47.57 & 260.11 \\
\hline-47.37 & -147.52 & -47.37 & 260.49 \\
\hline-47.17 & -147.12 & -47.17 & 260.86 \\
\hline-46.97 & -146.73 & -46.97 & 261.23 \\
\hline-46.77 & $-146,34$ & -46.77 & 261.60 \\
\hline-46.57 & -145.95 & -46.57 & 261.97 \\
\hline-46.36 & -145.57 & -46.36 & 262.33 \\
\hline-46.16 & -145.18 & -46.16 & 262.69 \\
\hline-45.95 & -144.81 & -45.95 & 263.05 \\
\hline-45.74 & -144.43 & -45.74 & 263.41 \\
\hline-45.53 & -144.06 & -45.53 & 263.76 \\
\hline-45.32 & -143.69 & -45.32 & 264.11 \\
\hline-45.11 & -143.32 & -45.11 & 264.45 \\
\hline-44.90 & -142.96 & -14.90 & 264.80 \\
\hline-44.68 & -142.59 & -44.68 & 265.14 \\
\hline .47 & -142.24 & .47 & 265.48 \\
\hline 25 & -141.88 & -44.25 & 265.81 \\
\hline-44.03 & -141.52 & -14.03 & 266.14 \\
\hline-43.81 & -141.17 & -43.81 & 266.47 \\
\hline-43.59 & -140.83 & -43.59 & 266.80 \\
\hline-43. & -140.48 & -43.37 & 7.13 \\
\hline .15 & 0.14 & -43.15 & 267.45 \\
\hline-42.93 & -139.79 & -42.93 & 267.77 \\
\hline-42.70 & -139.46 & -42.70 & 268.09 \\
\hline-42.48 & -139.12 & -42.48 & 268.40 \\
\hline-42 & -138.79 & -42.25 & 268.72 \\
\hline-42.03 & -138.45 & .03 & .03 \\
\hline-41 & -138.13 & -41.80 & 269.33 \\
\hline 57 & -137.80 & -41.57 & 269.64 \\
\hline-11.34 & -137.47 & -41.34 & 269.94 \\
\hline-41.11 & -137.15 & -41.11 & 270.24 \\
\hline 40.88 & -136.83 & -40.88 & 270.54 \\
\hline 10.65 & 136.51 & -40.65 & 270.84 \\
\hline 41 & 36.20 & -40.41 & 271.14 \\
\hline & -135.89 & -40.18 & 271.43 \\
\hline & -135.58 & -39.94 & 271.72 \\
\hline & -135. & -39.71 & 272.01 \\
\hline
\end{tabular}

271.37 271.32 271.26 271.21 271.16 271.10 271.05 270.99 270.88 270.8 270.82 270.77
270.71 270.65 270.59 270.53 270.47 270.41 270.35 270.29 270.23 270.17 270.11 270.05
269.98 269.92 269.86 269.79 269.73
269.67 269.60 269.54 269.47 269.41 269.34 269.28 269.21 269.14 269.08 269.01 268.94 268.88 268.81 268.74 268.67 268.60 268.54 268.47 268.40

$\begin{array}{ll}173.89 & 351.95 \\ 174.22 & 351.95 \\ 174.54 & 351.95 \\ 174.87 & 351.94 \\ 175.20 & 351.94 \\ 175.53 & 351.94 \\ 175.87 & 351.94 \\ 176.21 & 351.94 \\ 176.55 & 351.94 \\ 176.88 & 351.94 \\ 177.22 & 351.94 \\ 177.56 & 351.94 \\ 177.89 & 351.94 \\ 178.23 & 351.94 \\ 178.56 & 351.95 \\ 178.89 & 351.95 \\ 179.22 & 351.96 \\ 179.55 & 351.97 \\ 179.89 & 351.98 \\ 180.22 & 351.98 \\ 180.56 & 351.98 \\ 180.90 & 351.99 \\ 181.23 & 352.00 \\ 181.57 & 352.01 \\ 181.91 & 352.01 \\ 182.25 & 352.02 \\ 182.59 & 352.02 \\ 182.93 & 352.03 \\ 183.26 & 352.05 \\ 183.60 & 352.06 \\ 183.95 & 352.06 \\ 184.28 & 352.07 \\ 184.63 & 352.07 \\ 184.96 & 352.07 \\ 185.31 & 352.07 \\ 185.65 & 352.08 \\ 185.99 & 352.08 \\ 186.34 & 352.09 \\ 186.68 & 352.09 \\ 187.02 & 352.10 \\ 187.36 & 352.10 \\ 187.72 & 352.11 \\ 188.07 & 352.11 \\ 188.12 & 352.12 \\ 188.76 & 352.12 \\ 189.11 & 352.11 \\ 189.45 & 352.11 \\ 189.77 & 352.10 \\ 190.09 & 352.10 \\ 190.41 & 352.09\end{array}$

178.04
178.03 178.03 178.03 178.04 178.04 178.04 178.05 178.04 178.04 178.05 178.05 178.05 178.05 178.05 178.05 178.05 178.05 178.05 178.06 178.06 178.07 178.07 178.07 178.07 178.07 178.07

178.07

178.07 178.08 178.08 178.08 178.08 178.08 178.09 178.08 178.09 178.09 178.10 178.10 178.11 178.10 178.10 178.10 178.10 178.09 178.09 178.08 178.08
$-39.5$

$-39.3$

$-39.0$

$-38.8$

$-38.6$

$-38$.

$-38$.

-37.8
-37.6

$-37.3$

$-37.1$

$-36.8$

$-36.6$

-36.3
-36.1

$-35.8$

$-35.6$

$-35.3$

$-35$.

-34.8
-34.6

$-34.3$

$-34.1$

$-33.8$

$-33.6$

-33.3
-33.1

$-32.8$

$-32.6$

$-32.3$

$-32$.

-31.8
-31.5

$-31.3$

$-31.0$

$-30.8$

$-30.5$

$-30.2$

$-30.0$

$-29$.

$-29.5$

$-29.2$

$-28.9$

$-28.7$

$-28$.

$-28.1$

$-27.9$

$-27.6$

-27.4
-27.1
337.9

338.2

338.5

339.0

339.3

339.5

339.8

340.1

340.3

340.6

340.8

341.1

341.3

341.6

341.8

342.0

42.5

342.7

342.9

343.1

343.3

343.6

343.8

344.0

344.2

344.4

344.6

344.8

345.0

345.3

345.5

345.7

345.9

346.1

346.3

346.5

346.7

346.9

347.1

347.3

347.5

347.7

347.8

348.0

348.2

348.3

348.5

348.7

23.71

.73

23.77

23.79

23.82

23.84

23.86

23.88

23.89

23.91

23.93

23.94

23.96

23.98

23. 99

0.02

0.04

0.07

0.09

0.10

0.12

0.13

0.15

0.16

0.17

0.19

0.20

0.22

0.23

0.24

0.26

0.27

0.2

0.32

0.34

0.35

0.36

0.38

0.39

0.40

0.42

0.43

0.44 
06-18:27:19 110 06-18:27:24110 06-18:27:29 110 06-18:27:34 110 $06-18: 27: 39110$ 06-18:27:44 110 06-18:27:49 110 06-18:27:54 110 06-18:27:59 110 $06-18: 28: 04110$ 06-18:28:09 110 06-18:28:14110 $06-18: 28: 19110$ 06-18:28:24110 06-18:28:29 110 06-18:28:34 110 06-18:28:39110 06-18:28:44 110 $06-18: 28: 49 \quad 110$ $06-18: 28: 54110$ 06-18:28:59 110

06-18:29:14 110 $06-18: 29: 19110$ 06-18:29:24 110 $06-18: 29: 29110$ $06-18: 29: 34110$ 06-18:29:39 110 06-18:29:44 110 $06-18: 29: 49110$ $06-18: 29: 54110$ 06-18:29:59 110 $06-18: 30: 04110$ $06-18: 30: 09110$ 06-1: $30: 14110$ $06-18: 30: 19110$ 06-18:30:24 110 $06-18: 30: 29110$ $06-18: 30: 34110$ $06-18: 30: 39110$ 06-18:30:44 110 06-18:30:49 110 $06-18: 30: 54110$ 06-18:30:59 110 06-18:31:04 110 06-18:31:09 110 06-18:31:14110 $06-18: 31: 19110$ $06-18: 31: 24 \quad 110$

$-39.47-134.96$ $\begin{array}{ll}-39.23 & -134.65\end{array}$ $\begin{array}{lll}-39.00 & -134.35\end{array}$ $-38.76-134.05$ $\begin{array}{ll}-38.52 & -133.75\end{array}$ $\begin{array}{lll}-38.28 & -133.46\end{array}$ $\begin{array}{lll}-38.04 & -133.16\end{array}$ $\begin{array}{lll}-37.79 & -132.87\end{array}$ $-37.55-132.58$ $\begin{array}{ll}-37.31 & -132.29\end{array}$ $\begin{array}{ll}-37.06 & -132.00\end{array}$ $\begin{array}{lll}-36.82 & -131.72\end{array}$ $\begin{array}{ll}-36.57 & -131.43\end{array}$ $-36.33-131.15$ $-36.08-130.87$ $\begin{array}{ll}-35.83 & -130.59\end{array}$ $\begin{array}{ll}-35.59 & -130.32\end{array}$

$\begin{array}{ll}-35.34 & -130.04\end{array}$ $\begin{array}{ll}-35.09 & -129.77\end{array}$

$\begin{array}{ll}-34.84 & -129.50\end{array}$

$\begin{array}{ll}-34.59 & -129.23\end{array}$

$\begin{array}{ll}-34.34 & -128.96\end{array}$ $\begin{array}{ll}-34.09 & -128.69\end{array}$ $\begin{array}{ll}-33.83 & -128.43\end{array}$

$\begin{array}{ll}-33.58 & -128.17\end{array}$

$\begin{array}{ll}-33.33 & -127.91\end{array}$

$\begin{array}{ll}-33.07 & -127.64\end{array}$

$-32.82-127.39$

$-32.56-127.13$ $-32.31-126.87$

$\begin{array}{ll}-32.05 & -126.62\end{array}$

$\begin{array}{lll}-31.80 & -126.37\end{array}$

$\begin{array}{lll}-31.54 & -126.11\end{array}$

$-31.28-125.86$

$\begin{array}{ll}-31.02 & -125.62\end{array}$

$\begin{array}{ll}-30.77 & -125.37\end{array}$

$-30.51-125.12$

$\begin{array}{ll}-29.99 & -124.63\end{array}$

$\begin{array}{ll}-29.73 & -124.39\end{array}$

$-29.47-124.15$

$\begin{array}{lll}-29.21 & -123.91\end{array}$

$\begin{array}{lll}-28.94 & -123.67\end{array}$

$-28.68-123.44$

$\begin{array}{ll}-28.42 & -123.20\end{array}$

$-28.16-122.96$

$\begin{array}{ll}-27.89 & -122.73\end{array}$

$\begin{array}{ll}-27.63 & -122.50\end{array}$

$\begin{array}{ll}-27.37 & -122.27\end{array}$
$-39.47$ $-39.23$ $-39.0$ $-38.76$ $-38.52$ $-38.28$ $-38.08$ $-37.79$ $-37.55$ $-37.31$ $-37.06$ $-36.82$ $-36.57$ $-36.33$ $-35.83$ $-35.59$ $-35.34$ $-35.09$ $-34.84$ $-34.59$ $-34.34$ $-34.09$ $-33.83$ $-33.58$ $-33.33$ $-33.07$ $-32.82$ $-32.56$ $-32.31$ $-32.05$ $-31.80$ $-31.54$ $-31.28$ $-31.02$ $-30.77$ $-30.51$ $-30.25$ $-29.99$ $-29.73$ $-29.47$ $-29.21$ $-28.94$ $-28.68$

$-28.42$ $-28.16$ $-27.89$ $-27.63$ $-27.37$
272.29 272.58 272.86 273.14 273.41 273.96 274.24 274.51 274.77 275.04 275.30 275.57 275.83 276.09 276.34 276.60 276.85 277.10 277.36 277.60 277.85 278.10 278.34
278.58 278.58 279.06 279.30 279.54 279.77 280.01 280.24 280.47 280.70 280.92 281.15 281.38 281.60 281.82 282.04 282.26 282.48 282.70 282.92 283.13 283.35 283.56 283.77 283.98 284.19

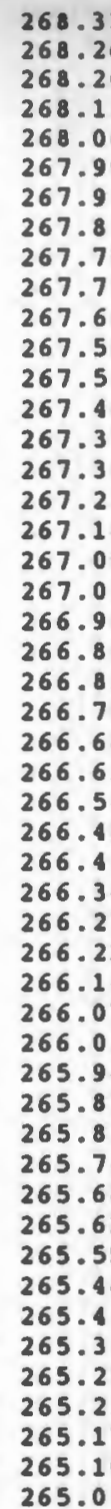

268.33 191.06 191.39 191.72 192.04 192.37 192.70 193.03 193.03
193.37 193.37 193.70 194.05 194.38 194.72 195.06 195.06 195.41 195.76 196.11 196.47 196.80 197.11 197.11 197.43 197.75 198.08 198.41 198.74 199.07 199.40 199.73 200.06 200.40 200.74 201.08 201.43 201.77 202.12 202.47 202.82 203.15 203.47 203.4 203.7 204.10
204.42 204.42
204.74 205.06 205.38 205.71 205.7 206.04 206.37 206.70 265.04

352.09
352.08
352.08
352.07
352.07
352.07
352.07
352.07
352.06
352.06
352.05
352.05
352.04
352.04
352.04
352.03
352.04
352.03
352.02
352.01
352.01
352.01
352.01
352.01
352.01
352.02
352.02
352.02
352.02
352.02
352.01
352.01
352.02
352.02
352.02
352.02
352.03
352.03
352.03
352.03
352.02
352.03
352.03
352.03
352.03
352.04
352.04
352.04
352.04
352.04

(1)
178.06 178.06 178.06 178.05 178.05 178.04 178.03
178.03 178.03 178.03

178.02

178.02 178.00 177.99 177.99 177.98 177.97

177.96 177.97 177.97 177.98 177.98 177.98 177.99 178.00 178.00 178.01 


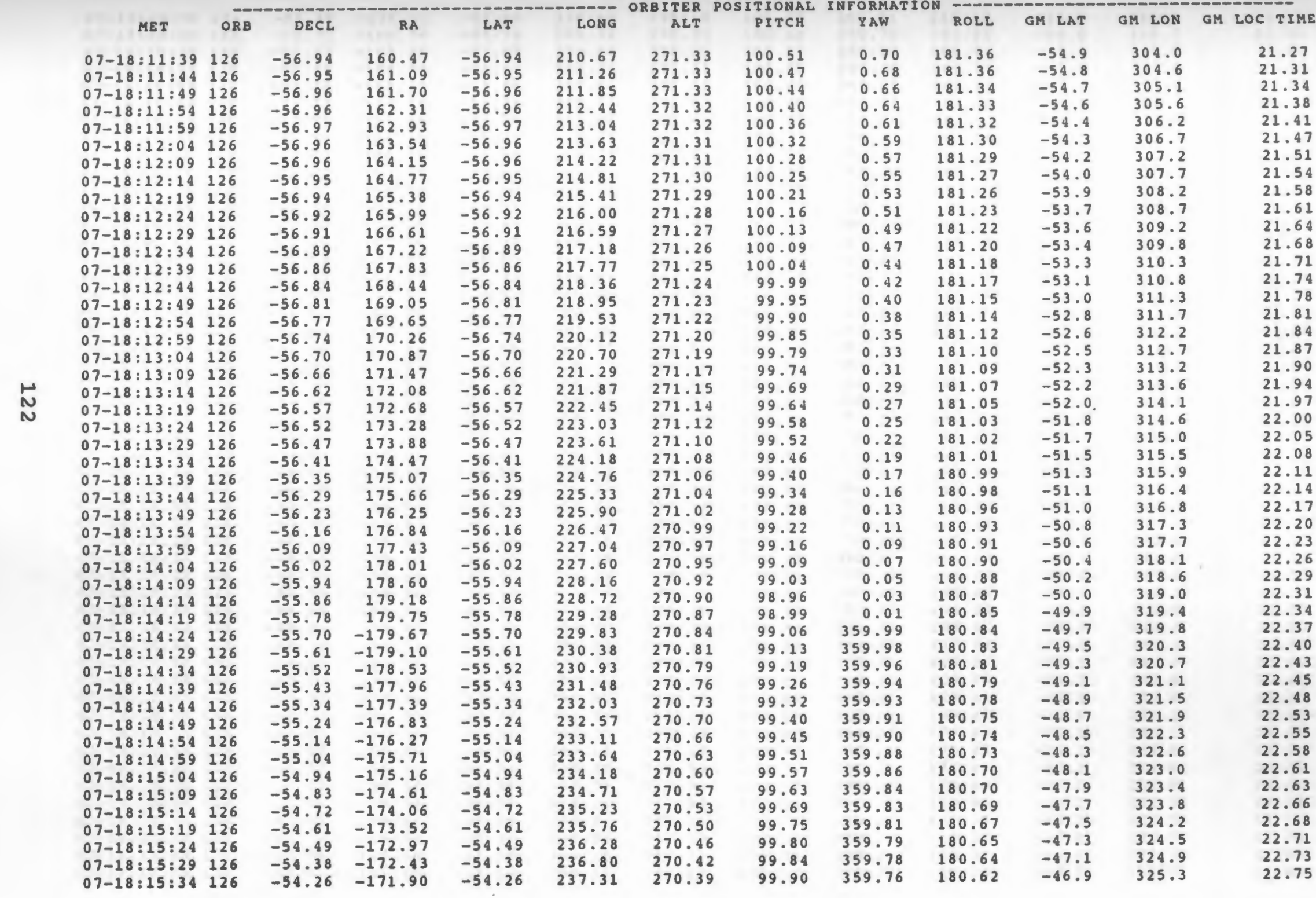


$07-18: 15: 49 \quad 126$
$07-18: 15: 54$
0726 $07-18: 15: 59126$ $07-18: 16: 04 \quad 126$ $07-18: 16: 09126$ $07-18: 16: 14126$ 07-18:16:19 126 $07-18: 16: 24 \quad 126$ 07-18:16:29126 $07-18: 16: 34 \quad 126$ $07-18: 16: 39126$ 07-18:16:44 126 07-18:16:49 126 $07-18: 16: 54126$ 07-18:16:59 126 $07-18: 17: 04126$ $07-18: 17: 09126$ 07-18:17:14 126 07-18:17:19 126 $07-18: 17: 24 \quad 126$ $07-18: 17: 29 \quad 126$ $07-18: 17: 34126$ 07-18:17:39 126 $07-18: 17: 44126$ 07-18:17:49 126 $07-18: 17: 54 \quad 126$ $07-18: 17: 59126$ 07-18:18:04 126 07-18:18:09 126 07-18:18:14 126 07-18:18:19 126 07-18:18:24 126 $07-18: 18: 29126$ 07-18:18:34 126 $07-18: 18: 39126$ $07-18: 18: 44 \quad 126$ 07-18:18:49 126 $07-18: 18: 54126$ 07-18:18:59 126 07-18:19:04 126 07-18:19:09 126 07-18:19:14 126 07-18:19:19 126 07-18:19:24 126 07-18:19:29 126 07-18:19:34 126 07-18:19:39 126 07-18:19:44 126 07-18:19:49 126 $07-18: 19: 54126$ $\begin{array}{ll}-53.89 & -170.31\end{array}$ $\begin{array}{ll}-53.76 & -169.78\end{array}$ $\begin{array}{ll}-53.63 & -169.26\end{array}$ $\begin{array}{ll}-53.49 & -168.75\end{array}$ $-53.36-168.23$ $-53.22-167.72$ $\begin{array}{ll}-53.08 & -167.22\end{array}$ $-52.94-166.71$ $-52.80-166.21$ $\begin{array}{ll}-52.65 & -165.71\end{array}$ $\begin{array}{ll}-52.50 & -165.22\end{array}$ $\begin{array}{ll}-52.35 & -164.73\end{array}$ $\begin{array}{lll}-52.20 & -164.24\end{array}$ $\begin{array}{ll}-52.05 & -163.76\end{array}$ $\begin{array}{ll}-51.89 & -163.28\end{array}$ $-51.73-162.80$ $-51.57-162.33$ $\begin{array}{ll}-51.41 & -161.86\end{array}$ $-51.25-161.39$ $\begin{array}{ll}-51.08 & -160.93\end{array}$ $-50.92-160.47$ $-50.75-160.01$ $-50.58-159.55$ $-50.40-159.10$ $-50.23-158.66$

$-50.05-158.21$

$\begin{array}{ll}-49.88 & -157.77\end{array}$

$-49.70-157.33$

$-49.51-156.90$

$\begin{array}{ll}-49.33 & -156.47\end{array}$

$-49.15-156.04$

$-48.96-155.62$
-48.77

$-48.77-155.19$

$-48.59-154.78$

$-48.40-154.36$

$-48.20-153.95$

$-48.01-153.54$

$\begin{array}{ll}-47.82 & -153.13\end{array}$

$\begin{array}{ll}-47.62 & -152.73\end{array}$

$\begin{array}{ll}-47.42 & -152.33\end{array}$

$\begin{array}{ll}-47.22 & -151.93\end{array}$

$\begin{array}{ll}-47.02 & -151.54\end{array}$

$-46.82-151.15$

$-46.62-150.76$

$-46.41-150.38$

$-46.21-149.99$

$-46.00 \quad-149.61$

$\begin{array}{ll}-45.79 & -149.24\end{array}$

$\begin{array}{ll}-45.58 & -148.86\end{array}$

$-45.37-148.49$
$-53.76$

$-53.63$

$-53.49$

$-53.36$

$-53.22$

$-53.08$

$-52.94$

$-52.65$

$-52.50$

$-52.35$

$-52.20$

$-52.05$

$-51.89$

$-51.73$

$-51.57$

$-51.41$

$-51.25$

$-51.08$

$-50.92$

$-50.75$

$-50.58$

$-50.23$

$-50.05$

$-49.88$

$-49.70$

$-49.51$

$-49.33$

$-49.15$

$-48.96$

$-48.77$

$-48.59$

$-48.40$

$-48.01$

$-47.82$

$-47.62$

$-47.42$

$-47.22$

$-47.02$

$-46.82$

$-46.62$

$-46.41$

$-46.21$

$-45.79$

$-45.58$

$-45.37$ 239.34 239.84 240.34 240.83 41.32 241.81 242.29 242.77 243.25 243.72 244.19 244.65 245.12 45.58 246.03 246.49 246.94 247.38 247.83 248.27 48.70 249.13 249.56 249.99 250.41 250.83 251.25 251.66 252.07 252.48 252.88 253.29 253.68 254.08 254.47 255.24 255.62 256.00 256.38 256.75 257.12 257.49 257.85 258.21 258.57

258.93 259.28 259.63
270.27 270.23 270.19 270.15 270.11 270.07 270.02 269.98 269.93 269.89 269.84 269.80 269.75 269.70 269.66 269.61 269.56 269.51 269.46 $269 .+1$

269.36 269.31 269.25 269.20 269.15 269.09 269.04 268.98 268.93 268.87 268.81 268.76 268.70 268.64 268.59 268.53 268.47

268.41

268.35 268.29 268.23

268.17

268.10

268.04

267.98 267.92

267.86

267.79

267.73

267.67

$100.05 \quad 359.71$ $100.10 \quad 359.70$ $100.15 \quad 359.68$ $100.19 \quad 359.66$ $100.24 \quad 359.65$ $100.29 \quad 359.64$

$100.33 \quad 359.63$ $100.37 \quad 359.62$ $100.11 \quad 359.61$ $100.46 \quad 359.59$

$100.49 \quad 359.58$

$100.53 \quad 359.56$

$100.57 \quad 359.55$ $100.60 \quad 359.54$

$100.64 \quad 359.52$

$100.67 \quad 359.50$

100.69359 .48

$100.72 \quad 359.47$

$100.75 \quad 359.45$

$100.78 \quad 359.44$

$100.81 \quad 359.43$

$100.84 \quad 359.42$

$100.86 \quad 359.40$

$100.89 \quad 359.38$

100.91359 .37

$100.93 \quad 359.35$

$100.95 \quad 359.34$

$100.97 \quad 359.32$

100.97359 .31

$100.96 \quad 359.30$

$100.96 \quad 359.28$

$100.95 \quad 359.27$

$100.95 \quad 359.25$

$100.94 \quad 359.24$

$100.93 \quad 359.23$

$100.92 \quad 359.21$

$100.91 \quad 359.20$

$100.91 \quad 359.18$

$100.90 \quad 359.18$

$100.88 \quad 359.16$

$100.86 \quad 359.16$

$100.82 \quad 359.17$

$100.79 \quad 359.18$

$100.76 \quad 359.19$ 
07-18:19:59 126 07-18:20:04 126 07-18:20:09 126 07-18:20:14 126 07-18:20:19 126 07-18:20:24 126 $07-18: 20: 29 \quad 126$ $07-18: 20: 34126$ $07-18: 20: 39126$ 07-18:20:44 126 07-18:20:49 126 $07-18: 20: 54 \quad 126$ 07-18:20:59 126 07-18:21:04 126 $07-18: 21: 09126$ $07-18: 21: 14126$ 07-18:21:19 126 07-18:21:24 126 07-18:21:29 126 07-18:21:34126 $07-18: 21: 39126$ $07-18: 21: 44 \quad 126$ 07-18:21:49 126 07-18:21:54 126 07-18:21:59 126 07-18:22:04 126 07-18:22:09 126 $07-18: 22: 14 \quad 126$ $07-18: 22: 19126$ $07-18: 22: 24126$ $07-18: 22: 29 \quad 126$ 07-18:22:34 126 07-18:22:39 126 07-18:22:44 126 07-18:22:49 126 $07-18: 22: 54 \quad 126$ $07-18: 22: 59126$ $07-18: 23: 04 \quad 126$ 07-18:23:09 126 07-18:23:14 126 $07-18: 23: 19126$ $07-18: 23: 24 \quad 126$ $07-18: 23: 29126$ 07-18:23:34 126 07-18:23:39 126 07-18:23:44 126 07-18:23:49 126 07-18:23:54 126 07-18:23:59 126 07-18:24:04 126
$-45.16$ $-44.95$ $-44.73$ -44.52
-44.30 $-44.09$ $-43.87$ $-43.65$ $-43.43$ $-43.20$ $-42.98$ $-42.76$ $-42.53$ $-42.31$ $-42.08$ $-41.85$ $-41.62$ $-41.16$ $-40.93$

$-40.70$

$-40.47$

$-40.23$ $-40.00$

$-39.76$

$-39.53$

$-39.29$

$-39.05$

$-38.81$

-38.57
-38.33

$-38.09$

$-37.85$

$-37.61$

$-37.36$

$-37.12$

-36.88
-36.63

$-36.38$

$-36.14$

$-35.89$

$-35.64$

$-35.39$

$-35.14$

$-34.64$

$-34.39$

$-34.14$

$-33.89$

$-33.64$
$-148.12$

$-147.76$ $-147.40$ $-147.04$

$-146.68$

$-145.97$

$-145.62$

$-145.28$

$-144.93$

$-144.59$

$-144.25$

$-143.91$

$-143.58$

$-143.25$

$-142.92$

$-142.59$

$-142.26$

$-141.62$

$-141.30$

$-140.98$

$-140.67$

$-140.36$

$-140.05$

$-139.44$

$-139.13$

$-138.83$

$-138.53$

$-138.23$

$-137.94$

$-137.35$

$-137.07$

$-136.78$

$-136.49$

$-136.21$

$-135.93$

$-135.37$

$-135.09$

$-134.81$

$-134.54$

$-134.27$

$-133.73$

-133. 46

$-133.20$

$-132.93$
$-45.16$ $-44.95$ $-44.73$ $-44.52$

$-44.30$

$-44.09$

$-43.87$

$-43.65$

$-43.43$

$-43.20$

$-42.98$

$-42.76$

$-42.53$

$-42.31$

$-42.08$

$-41.85$

$-41.62$

$-41.40$

$-41.16$

$-40.93$

$-40.70$

$-40.47$

$-40.23$

$-40.00$

$-39.76$

$-39.53$

$-39.29$

$-39.05$

$-38.81$

$-38.57$

$-38.33$

$-38.09$

$-37.85$

$-37.61$

$-37.36$

$-37.12$

$-36.88$

$-36.63$

$-36.38$

$-36.14$

$-35.89$

$-35.64$

$-35.39$

$-35.14$

$-34.89$

-34.64
-34.39

$-34.14$

$-34.14$

-33.89
-33.64
59.98 260.32 260.67 261.00 261.34 261.67 262.01 262.66
262.98 262.98
263.31 263.62 263.94 264.2 264.25
264.5 264.87 265.18 265.49 265.79 266.09 266.38 266.68 266.97 267.26 267.55 267.84 268.12 268.41 268.6 268.9 269.24 269.52 269.79 270.06 270.33 270.60 270.86 271.12 271.38

271.64

271.90 272.41

272.66

272.92 273.17

273.41

273.66

273.90

274.15

267.60 267.54 267.47 267.41 267.34 267.28 267.21 267.14 267.08 267.01 266.94 266.88 266.81 266.74 266.68 266.61 266.54 266.47 266.40

266.34

266.27 266.20 266.13 266.06 265.99 265.92

265.86

265.79 265.72 265.65

265.58 265.51 265.44 265.37 265.30 265.24 265.17 265.10 265.03

264.96

264.89

264.82 264.75 264.69 264.62 264.55 264.48

264.41

264.35 
MET

$04-16: 30: 04$ $04-16: 30: 09$ $04-16: 30: 14$ $04-16: 30: 19$ $04-16: 30: 24$ $04-16: 30: 29$ $04-16: 30: 34$ $04-16: 30: 39$ $04-16: 30: 44$ $04-16: 30: 49$ $04-16: 30: 54$ $04-16: 30: 59$ $04-16: 31: 04$ 04-16:31:09 $04-16: 31: 14$ $04-16: 31: 19$ $04-16: 31: 24$ $04-16: 31: 29$ $04-16: 31: 34$ $04-16: 31: 39$ $04-16: 31: 44$ $04-16: 31: 49$ $04-16: 31: 54$ $04-16: 31: 59$ $04-16: 32: 04$ 04-16:32:09 $04-16: 32: 14$ $04-16: 32: 19$ $04-16: 32: 24$ $04-16: 32: 29$

$04-16: 32: 34$ $04-16: 32: 39$ $04-16: 32: 44$ $04-16: 32: 49$ $04-16: 32: 54$ $04-16: 32: 59$ $04-16: 33: 04$ $04-16: 33: 09$ $04-16: 33: 14$ $04-16: 33: 19$ $04-16: 33: 24$ $04-16: 33: 29$ $04-16: 33: 34$ $04-16: 33: 39$ $04-16: 33: 44$ $04-16: 33: 49$ $04-16: 33: 54$

\section{LAT}

ALT

53.40

21.14

151.40

20.59

20.32

20.05

19.77

19.50

19.23

18.95

18.68

18.40

18.13

17.85

17.58

17.30

17.03

16.75

16.48

16.20

15.92

15.65

15.37

15.10

14.82

14.54

14.26

13.99

13.71

13.43

13.15

12.88

12.60

12.32

12.0

11.76

11.48

11.20

10.93

10.65

10.37

10.09

9.81

9.53

9.25

8.97

8.69

8.41 $\begin{array}{ll}51.68 & 253.27\end{array}$

$151.86 \quad 253.21$

$152.05 \quad 253.16$

$152.23 \quad 253.10$

$152.42 \quad 253.04$

$152.60 \quad 252.98$

$152.79 \quad 252.92$

\begin{tabular}{l}
$52.97 \quad 252.87$ \\
\hline
\end{tabular}

$153.15 \quad 252.81$

$\begin{array}{ll}153.33 & 252.76\end{array}$

$153.51 \quad 252.70$

$153.70 \quad 252.65$

$\begin{array}{ll}53.87 & 252.60\end{array}$

$154.05 \quad 252.54$

$154.23 \quad 252.49$

$154.41 \quad 252.44$

$154.59 \quad 252.39$

$\begin{array}{ll}54.76 & 252.34\end{array}$

$154.94 \quad 252.29$

$155.12 \quad 252.24$
155.29

$\begin{array}{ll}155.29 & 252.19 \\ 155.47 & 252.15\end{array}$

155.64252 .10

$\begin{array}{ll}155.81 & 252.05\end{array}$

$155.99 \quad 252.01$

$156.16 \quad 251.96$

$156.33 \quad 251.92$

$156.50 \quad 251.88$

$156.68 \quad 251.83$

$\begin{array}{ll}156.85 & 251.79\end{array}$

$157.02 \quad 251.75$

$157.19 \quad 251.71$

$\begin{array}{ll}157.36 & 251.67\end{array}$

$\begin{array}{ll}157.53 & 251.63\end{array}$

251.56

$158.03 \quad 251.52$

$158.20 \quad 251.48$

$158.37 \quad 251.45$

$158.53 \quad 251.41$

$158.70 \quad 251.38$

$\begin{array}{ll}158.87 & 251.35\end{array}$

$159.03 \quad 251.32$

$159.20 \quad 251.29$

159.37

251.26

DEC RA RAM ANG SUN ANG LAT LON TAN HT

0.03

$-0.24$

$-0.52$

$-0.80$

$-1.08$

$-1.35$

$-1.63$

$-1.90$

$-2.19$

$-2.47$

3.76

$-3.32$

$-3.60$

$-3.90$

$-4.18$

$-4.47$

$-4.76$

$-5.05$

$-5.34$

$-5.62$

$-5.92$

$-6.21$

$-6.50$

$-6.80$

$-7.09$

$-7.39$

$-7.69$

$-7.98$

$-8.28$

$-8.58$

$-8.88$

$-9.18$

$-9.48$

$-9.78$

$-10.09$

$-10.39$

$-10.69$

$-10.99$

$-11.30$

$-11.59$

$-11.90$

$-12.21$

$-12.51$

$-12.83$

$-13.14$

$-13.45$

\subsection{1}

85.38

85.55

85.73

85.91

86.10

86.28

86.47

86.66

86.85

87.04

87.22

87.41

87.61

87.80

87.99

88.18

88.37

88.57

88.76

88.96

89.15

89.35

89.54

89.74

89.94

90.14

90.34

90.54

90.74

90.94

91.15

91.35

91.55

91.76

91.97

92.17

92.38

92.59

92.80

93.00

93.21

93.42

93.63

93.85

94.07

94.29

65.
66.1
66.6
67.
67.
67.
68.
68.
69.
69.
70.
70.
71.
71.
72.
72.
73.
73.
74.
74.
75.
75.
76.
76.
77.
77.
78.
78.
78.
79.
79.
80.
80.9
81.
81.
82.
82.
83.
83.
84.
84.
85.
85.
86.
86.
87.
87.

$\begin{array}{lllll}28.6 & -9999.00 & -9999.00 & -9999.00\end{array}$

$28.7-9999.00-9999.00-9999.00$

$28.7-9999.00-9999.00-9999.00$

$28.8-9999.00-9999.00-9999.00$

$28.9-9999.00-9999.00-9999.00$

$29.0-9999.00-9999.00-9999.00$

$29.0-9999.00-9999.00-9999.00$

$29.1-9999.00-9999.00-9999.00$

$29.2-9999.00-9999.00-9999.00$

$29.3-9999.00-9999.00-9999.00$

$29.4 \quad-9999.00-9999.00-9999.00$

$29.5-9999.00-9999.00-9999.00$

$29.6-9999.00-9999.00-9999.00$

$29.7-9999.00-9999.00-9999.00$

$29.8-9999.00-9999.00-9999.00$

$29.9-9999.00-9999.00-9999.00$

$30.0-9999.00-9999.00-9999.00$

$30.2-9999.00-9999.00-9999.00$

$30.3-9999.00-9999.00-9999.00$

$30.4-9999.00-9.999 .00-9999.00$

$30.5-9999.00-9999.00-9999.00$

$30.7-9999.00-9999.00-9999.00$

$30.8-9999.00-9999.00-9999.00$

$31.0-9999.00-9999.00-9999.00$

$31.1-9999.00-9999.00-9999.00$

$31.2-9999.00-9999.00-9999.00$

$31.4-9999.00-9999.00-9999.00$

$31.6-9999.00-9999.00-9999.00$

$31.7-9999.00-9999.00-9999.00$

$31.9-9999.00-9999.00-9999.00$

$32.0-9999.00-9999.00-9999.00$

$32.2-9999.00-9999.00-9999.00$

$32.4-9999.00-9999.00-9999.00$

$32.6-9999.00-9999.00-9999.00$

$32.7-9999.00-9999.00-9999.00$

$32.9-9999.00-9999.00-9999.90$

$33.1-9999.00-9999.00-9999.00$

$33.3-9999.00-9999.00-9999.00$

$33.5-9999.00-9999.00-9999.00$

$33.7-9999.00-9999.00-9999.00$

$33.8-9999.00-9999.00-9999.00$

$34.0-9999.00-9999.00-9999.00$

$34.2-9999.00-9999.00-9999.00$

$34.5-9999.00-9999.00-9999.00$

$34.7-9999.00-9999.00-9999.00$

$34.9-9999.00-9999.00-9999.00$ 


\begin{tabular}{|c|c|c|c|c|c|c|}
\hline $04-16: 34: 09$ & 7.57 & 159.86 & 251.17 & -14.39 & 94.94 & 89.1 \\
\hline $04-16: 34: 14$ & 7.29 & 160.03 & 251.14 & -14.70 & 95.16 & 89.6 \\
\hline $04-16: 34: 19$ & 7.01 & 160.19 & 251.12 & -15.02 & 95.38 & 90.1 \\
\hline $04-16: 34: 24$ & 6.73 & 160.36 & 251.09 & -15.33 & 95.57 & 90.6 \\
\hline $04-16: 34: 29$ & 6.45 & 160.52 & 251.07 & -15.66 & 95.76 & 91.1 \\
\hline $04-16: 34: 34$ & 6.17 & 160.68 & 251.04 & -15.98 & 95.95 & 91.6 \\
\hline $04-16: 34: 39$ & 5.89 & 160.85 & 251.02 & -16.29 & 96.14 & 92.1 \\
\hline $04-16: 34: 44$ & 5.61 & 161.01 & 251.00 & -16.55 & 96.33 & 92.6 \\
\hline $04-16: 34: 49$ & 5.33 & 161.17 & 250.98 & -16.80 & 96.52 & 93.0 \\
\hline $04-16: 34: 54$ & 5.05 & 161.34 & 250.96 & -17.06 & 96.69 & 93.5 \\
\hline $04-16: 34: 59$ & 4.77 & 161.50 & 250.94 & -17.31 & 96.87 & 93.9 \\
\hline $04-16: 35: 04$ & 4.49 & 161.66 & 250.92 & -17.56 & 97.05 & 94.4 \\
\hline $04-16: 35: 09$ & 4.20 & 161.83 & 250.90 & -17.82 & 97.24 & 94.8 \\
\hline $04-16: 35: 14$ & 3.92 & 161.99 & 250.88 & -18.09 & 97.43 & 95.3 \\
\hline $04-16: 35: 19$ & 3.64 & 162.15 & 250.87 & -18.33 & 97.62 & 95.7 \\
\hline $04-16: 35: 24$ & 3.36 & 162.31 & 250.85 & -18.58 & 97.82 & 96.1 \\
\hline $04-16: 35: 29$ & 3.08 & 162.47 & 250.84 & -18.84 & 98.02 & 96.6 \\
\hline $04-16: 35: 34$ & 2.80 & 162.64 & 250.82 & -19.09 & 98.22 & 97.0 \\
\hline $04-16: 35: 39$ & 2.52 & 162.80 & 250.81 & -19.34 & 98.43 & 97.4 \\
\hline $04-16: 35: 44$ & 2.24 & 162.96 & 250.80 & -19.60 & 98.63 & 97.9 \\
\hline $04-16: 35: 49$ & 1.96 & 163.12 & 250.79 & -19.86 & 98.84 & 98.3 \\
\hline $04-16: 35: 54$ & 1.67 & 163.28 & 250.78 & -20.12 & 99.05 & 98.7 \\
\hline $04-16: 35: 59$ & 1.39 & 163.45 & 250.77 & -20.38 & 99.26 & 99.2 \\
\hline $04-16: 36: 04$ & 1.11 & 163.61 & 250.76 & -20.64 & 99.46 & 99.6 \\
\hline $04-16: 36: 09$ & 0.83 & 163.77 & 250.75 & -20.89 & 99.67 & 100.0 \\
\hline $04-16: 36: 14$ & 0.55 & 163.93 & 250.75 & -21.14 & 99.89 & 100.4 \\
\hline $04-16: 36: 19$ & 0.27 & 164.09 & 250.74 & -21.39 & 100.11 & 100.8 \\
\hline $04-16: 36: 24$ & -0.01 & 164.25 & 250.74 & -21.65 & 100.32 & 101.2 \\
\hline $04-16: 36: 29$ & -0.29 & 164.42 & 250.73 & -21.91 & 100.55 & 101.7 \\
\hline $04-16: 36: 34$ & -0.57 & 164.58 & 250.73 & -22.17 & 100.77 & 102.1 \\
\hline $04-16: 36: 39$ & -0.86 & 164.74 & 250.73 & -22.41 & 100.99 & 102.5 \\
\hline $04-16: 36: 44$ & -1.14 & 164.90 & 250.73 & -22.66 & 101.22 & 102.9 \\
\hline $04-16: 36: 49$ & -1.42 & 165.06 & 250.72 & -22.91 & 101.44 & 103.3 \\
\hline $04-16: 36: 54$ & -1.70 & 165.22 & 250.73 & -23.16 & 101.67 & 103.7 \\
\hline $04-16: 36: 59$ & -1.98 & 165.39 & 250.73 & -23.41 & 101.90 & 104.1 \\
\hline $04-16: 37: 04$ & -2.26 & 165.55 & 250.73 & -23.71 & 102.12 & 104.5 \\
\hline $04-16: 37: 09$ & -2.54 & 165.71 & 250.73 & -24.21 & 102.23 & 105.2 \\
\hline $04-16: 37: 14$ & -2.82 & 165.87 & 250.73 & -25.09 & 102.29 & 106.2 \\
\hline $04-16: 37: 19$ & -3.10 & 166.03 & 250.74 & -26.07 & 102.23 & 107.3 \\
\hline $04-16: 37: 24$ & -3.39 & 166.20 & 250.75 & -27.05 & 102.20 & 108.4 \\
\hline $04-16: 37: 29$ & -3.67 & 166.36 & 250.75 & -28.04 & 102.18 & 109.5 \\
\hline $04-16: 37: 34$ & -3.95 & 166.52 & 250.76 & -29.02 & 102.17 & 110.6 \\
\hline $04-16: 37: 39$ & -4.23 & 166.68 & 250.77 & -30.00 & 102.18 & 111.7 \\
\hline $04-16: 37: 44$ & -4.51 & 166.85 & 250.78 & -30.98 & 102.20 & 112.8 \\
\hline $04-16: 37: 49$ & -4.79 & 167.01 & 250.79 & -31.96 & 102.24 & 113.9 \\
\hline $04-16: 37: 54$ & -5.07 & 167.17 & 250.80 & -32.93 & 102.30 & 114.9 \\
\hline $04-16: 37: 59$ & -5.35 & 167.34 & 250.81 & -33.92 & 102.37 & 115.9 \\
\hline $04-16: 38: 04$ & -5.63 & 167.50 & 250.82 & -34.89 & 102.35 & 117.0 \\
\hline $04-16: 38: 09$ & -5.91 & 167.66 & 250.83 & -35.85 & 102.29 & 118.0 \\
\hline $04-16: 38: 14$ & -6.19 & 167.83 & 250.85 & -36.81 & 102.25 & 119.1 \\
\hline
\end{tabular}

$35.7-9999.00-9999.00-9999.00$ $36.0-9999.00-9999.00-9999.00$ $36.2-9999.00-9999.00-9999.00$ $36.4-9999.00-9999.00-9999.00$ $36.6-9999.00-9999.00-9999.00$ $36.8-9999.00-9999.00-9999.00$ $37.0-9999.00-9999.00-9999.00$ $37.2-9999.00-9999.00-9999.00$ $37.4 \quad-9999.00-9999.00-9999.00$ $37.6-9999.00-9999.00-9999.00$ $37.8-9999.00-9999.00-9999.00$ $38.0-9999.00-9999.00-9999.00$ $38.2-9999.00-9999.00-9999.00$ $38.4-9999.00-9999.00-9999.00$ $\begin{array}{lllll}38.6 & -9999.00 & -9999.00 & -9999.00\end{array}$ $38.8-9999.00-9999.00-9999.00$ $39.0-9999.00-9999.00-9999.00$ $39.2-9999.00-9999.00-9999.00$ $39.5-9999.00-9999.00-9999.00$ $39.7-9999.00-9999.00-9999.00$ $39.9-9999.00-9999.00-9999.00$ $40.2-9999.00-9999.00-9999.00$ $40.4-9999.00-9999.00-9999.00$ $40.6-9999.00-9999.00-9999.00$ $40.8-9999.00-9999.00-9999.00$ $41.1-9999.00-9999.00-9999.00$ $41.3-9999.00-9999.00-9999.00$ $41.6-9999.00-9999.00-9999.00$ $41.8-9999.00-9999.00-9999.00$ $42.0-9999.00-9999.00-9999.00$ $42.3-9999.00-9999.00-9999.00$ $42.5-9999.00-9999.00-9999.00$ $42.8-9999.00-9999.00-9999.00$ $43.0-9999.00-9999.00-9999.00$ $43.3-9999.00-9999.00-9999.00$ $43.5-9999.00-9999.00-9999.00$ $43.7-9999.00-9999.00-9999.00$ $43.9-9999.00-9999.00-9999.00$ $44.1-9999.00-9999.00-9999.00$ $44.3-9999.00-9999.00-9999.00$ $\begin{array}{llll}44.3 & -9999.00 & -9999.00 & -9999.00 \\ 44.5 & -9999.00 & -9999.00 & -9999.00\end{array}$ $44.7-9999.00-9999.00-9999.00$ $45.0 \quad-9999.00-9999.00-9999.00$ $45.3-9999.00-9999.00-9999.00$ $45.6-9999.00-9999.00-9999.00$ $45.9-9999.00-9999.00-9999.00$ $46.3-9999.00-9999.00-9999.00$ $46.6-9999.00-9999.00-9999.00$ $46.9-9999.00-9999.00-9999.00$ $47.2-9999.00-9999.00-9999.00$ 
$04-16: 38: 19$ $04-16: 38: 24$ $04-16: 38: 29$ $04-16: 38: 34$ $04-16: 38: 39$ $04-16: 38: 44$ $04-16: 38: 49$ $04-16: 38: 54$ $04-16: 38: 59$ 04-16:39:04 04-16:39:09 $04-16: 39: 14$ $04-16: 39: 19$ $04-16: 39: 24$ $04-16: 39: 29$ $04-16: 39: 34$ $04-16: 39: 39$ $04-16: 39: 44$ $04-16: 39: 49$ $04-16: 39: 54$ $04-16: 39: 59$ 04-16:40:04 04-16:40:09 $04-16: 40: 14$ $04-16: 40: 19$ $04-16: 40: 24$ $04-16: 40: 29$ $04-16: 40: 34$ $04-16: 40: 39$ $04-16: 40: 44$ $04-16: 40: 49$ $04-16: 40: 54$ $04-16: 40: 59$ 04-16:41:04 $04-16: 41: 09$ $04-16: 41: 14$ $04-16: 41: 19$ $04-16: 41: 24$ $04-16: 41: 29$ $04-16: 41: 34$ 04-16:41:39 $04-16: 41: 44$ $04-16: 41: 49$ 04-16:41:54 $04-16: 41: 59$ $04-16: 42: 04$ $04-16: 42: 09$ $04-16: 42: 14$ $04-16: 42: 19$ $04-16: 42: 24$
170.98

$-12.07$

$-12.34$

$-12.62$

$-12.90$

$-13.18$

$-13.46$

$-13.73$

$-14.01$

$-14.29$

$-14.57$

$-14.84$

$-15.12$

$-15.40$

$-15.67$

$-15.95$

$-16.23$

$-16.50$

$-16.78$

$-17.05$

$-17.33$

$-17.60$

$-17.88$

$-18.15$

$-18.43$

$-18.70$

$-18.98$

$-19.25$

$-19.53$

$-19.80$

$-20.07$ 171.84 172.01 172.18 172.35 172.52 172.70 172.87 173.04 173.22 173.39 173.57 173.75 173.92 174.10 174.28 174.46 174.64 174.82 175.00 175.18 175.36 175.54 175.72 175.91 176.09 176.28 176.46
250.86 250.88 250.89 250.91 250.93 250.95 250.97 250.99 251.01 251.03 251.05 251.08 251.10 251.13 251.15 251.18 251.21 251.24 251.27 251.30 251.33 251.36 251.39
$-37.77$

$-38.75$ $-39.71$ $-40.68$ $-41.64$ $-42.62$ $-43.58$ $-44.48$ $-45.39$ -46.30
-47.22 $-48.12$ -49.07
-50.03 $-50.83$ $-51.73$ $-52.63$ $-53.51$ $-54.40$ $-55.29$ $-56.17$ $-57.05$ $-57.93$ $-58.79$ $-59.64$ $-60.50$ $-61.41$ $-62.34$ $-63.25$ $-64.16$ $-65.05$ $-65.95$ $-66.82$ $-67.70$ $-68.55$ $-69.38$ $-70.21$ $-71.01$ $-71.78$ $-72.52$ $-73.24$ $-73.92$ $-74.56$ $-75.15$ $-75.69$ $-76.17$ $-76.60$ $-76.99$ $-77.33$ $-77.60$
102.23 102.20 102.20 102.22 102.24 102.28 102.34 102.49 102.65 102.83 103.04 103.27 103.51 103.76 104.12 104.45 104.83 105.23 105.66 106.15 106.68 107.25 107.87 108.55 109.29 110.0 110.70 111.42 112.17 113.02 113.93 114.94 116.03 117.24 118.55 120.01 121.59 123.36 125.28 127.39 129.72 132.28 135.06 138.06 141.43 145.02 148.36 151.64 155.16 158.86

120.1

21.

122.1

124.1

125.

125.9

126.8

127.6

128.4

129.1

129.8

130.6

131.3

131.9

132.5

133.1

133.6

134.1

134.6

135.1

135.5 
$04-16: 42: 29$ $04-16: 42: 34$ $04-16: 42: 39$ $04-16: 42: 44$ $04-16: 42: 49$ $04-16: 4$ $04-16: 42: 59$ $04-16: 43: 04$ 04-16:43:09 $04-16: 43: 14$ $04-16: 43: 19$ $04-16: 43: 24$ $04-16: 43: 29$ $04-16: 43: 34$ $04-16: 43: 39$ $04-16: 43: 44$ 04-16:43:49 $04-16: 43: 54$ $04-16: 43: 59$ $04-16: 44: 04$ $04-16: 44: 09$ 04-16:44:14 $04-16: 44: 19$ $04-16: 44: 24$ $04-16: 44: 29$ $04-16: 44: 34$ $04-16: 44: 39$ $04-16: 44: 44$ $04-16: 44: 49$ $04-16: 44: 54$ $04-16: 44: 59$ $04-16: 45: 04$ $04-16: 45: 09$ $04-16: 45: 14$ $04-16: 45: 19$ $04-16: 45: 24$ $04-16: 45: 29$ $04-16: 45: 34$ $04-16: 45: 39$ $04-16: 45: 44$ $04-16: 45: 49$ $04-16: 45: 54$ $04-16: 45: 59$ $04-16: 46: 04$ 04-16:46:09 $04-16: 46: 14$ 04-16:46:19 $04-16: 46: 24$ $04-16: 46: 29$ $04-16: 46: 34$
$-20.35$ $-20.62$ $-20.89$

$-21.16$

$-21.44$

$-21.71$

$-21.98$

$-22.25$

$-22.52$

$-22.79$

$-23.06$

$-23.33$

$-23.60$

$-23.87$

$-24.14$

$-24.41$

24.95

$-25.21$

$-25.48$

$-25.75$

$-26.02$

$-26.28$

$-26.55$

$-26.81$

$-27.08$

$-27.34$

$-27.61$

28.14

$-28.1$

-28.40
-28.66

$-28.93$

$-29.19$

$-29.45$

$-29.71$

$-29.97$

$-30.23$

$-30.49$

$-30.75$

$-31.01$

$-31.27$

$-31.53$

$-31.79$

$-32.04$

$-32.30$

$-32.5$

$-32.81$

$-33.07$

$-33.32$
176.6

176.84

177.02

77.21

77.59

177.78

177.98

178.17

178.36

178.56

178.75

178.95

179.14

179.34

179.54

179.74

179.94

180.14

180.35

180.55

180.75

180.96

181.17

181.37

181.58

181.79

182.00

182.22

182.43

182.64

182.86

183.08

183.29

183.51

183.73

183.96

184.18

184.40

184.63

184.86

185.08

185.31

185.55

185.78

186.01

186.25

186.48

186.72

186.96
252.57

252.63

252.68

252.73

252.78

252.89

252.95

253.00

253.06

253.11

253.17

253.23

253.28

253.34

253.40

253.46

253.52

253.58

253.64

253.70

253.76

253.82

253.88

253.94

254.01

254.07

254.13

254.20

254.26

254.32

254.39

254.45

254.52

254.58

254.65

254.72

254.78

254.85

254.92

254.98

255.05

255.12

255.18

255.25

255.32

255.39

255.46

255.52

255.59

$-78.03$

$-78.04$

$-77.97$

$-77.84$

$-77.62$

$-77.35$

$-77.09$

$-76.77$

$-76.41$

-75.98
-75.50

$-74.96$

$-74.39$

$-73.74$

$-73.03$

$-72.29$

$-71.51$

$-70.80$

$-70.45$

$-70.44$

$-70.42$

$-70.42$

$-70.41$

$-70.40$

-70.39
-70.37

$-70.35$

$-70.34$

$-70.32$

$-70.30$

$-70.28$

$-70.25$

$-70.24$

$-70.18$

$-70.15$

$-70.11$

$-70.09$

$-70.05$

$-70.02$

$-69.98$

$-69.93$

$-69.90$

$-69.85$

$-69.76$

$\begin{array}{ll}-69.72 & -135.22 \\ -69.67 & -135.27\end{array}$

$\begin{array}{ll}-69.72 & -135.22 \\ -69.67 & -135.27\end{array}$

162.76

166.79

170.83

179.13

$-176.81$

$-172.81$

$-169.01$

$-161.22$

$-157.52$

$-154.09$

$-150.84$

$-147.82$

$-145.02$

$-140.53$

$-138.64$

$-136.86$

$-135.28$

$-134.05$

$-133.12$

$-132.70$

$-132.79$

$-132.93$

$-133.22$

$-133.35$

$-133.48$

$-133.73$

$-133.86$

$-133.96$

$-134.06$

$-134.28$

$-134.39$

$-134.48$

$-134.58$

$-134.66$

$-134.74$

$-134.81$

$-134.89$

$-135.03$

$-135.08$

$-135.13$

$-135.18$

$-135.27$ 
$04-16: 46: 39$ $04-16: 46: 44$ $04-16:$ $04-16: 46: 54$ $04-16: 46: 54$ $04-16: 47: 04$ $04-16: 47: 09$ $04-16: 47: 14$ $04-16: 47: 19$ 04-16:47:24 $04-16: 47: 29$ $04-16: 47: 34$ $04-16: 47: 39$ 04-16:47:44 $04-16: 47: 49$ $04-16: 47: 54$ $04-16: 47: 59$ $04-16: 48: 04$ 04-16:48:09 04-16:48:14 $04-16: 48: 19$ $04-16: 48: 24$
$-33.58$ $-34.08$ $-34.08$ $-34.33$ $-34.59$ $-34.84$ $-35.09$ $-35.34$

$-35.59$

$-35.83$

$-36.08$

$-36.33$

$-36.58$

$-36.82$

$-37.07$

$-37.31$

$-37.56$

$-37.80$

$-38.04$

$-38.28$

$-38.53$

$-38.77$

$-39.00$

$-39.24$

$-39.48$

$-39.72$

$-39.95$

$-40.19$

$-40.42$

$-40.66$

$-40.89$

$-41.12$

$-41.35$

$-41.58$

$-41.81$

$-42.04$

$-42.27$

$-42.50$

$-42.72$

$-42.95$

$-43.17$

$-43.39$

$-43.61$

$-43.83$

$-44.05$

$-44.27$

$-44.49$

$-44.70$

$-44.92$

$-45.13$
187.20

87.45

87.69

187.94

188.19

88.43

188.69

188.94

189.19

189.45

189.71

189.97

190.23

190.49

190.76

191.02

191.29

191.56

191.83

192.11

192.39

192.66

192.94

193.23

193.51

193.80

194.09

194.38

194.67

194.97

195.26

195.56

195.87

196.17

196.48

196.79

197.10

197.41

197.73

198.05

198.37

198.69

199.02

199.35

199.68

200.01

200.35

200.69

201.03

201.38
256.01

256.08 256.14 256.21

256.28

256.35

256.42

256.49

256.56

256.63

256.70

256.77

256.84

256.91

256.98

257.05

257.11

257.18

257.25

257.32

257.39

257.46

257.53

57.59

257.66

257.73

257.80

257.86

257.93

258.00

258.07

258.13

258.20

258.26

258.33

258.40

258.46

258.59

258.66

258.66

258.72

258.78

258.85

258.91

258.97
$.61-135.33$ $\begin{array}{ll}-69.51 & -135.40\end{array}$ $-69.45-135.43$ $40-135.4$ $-69.33-135.44$ $.33-135.44$ . $.20-135.44$ $9.14-135.44$ $\begin{array}{ll}-69.07 & -135.43\end{array}$ $-68.99-135.41$ $\begin{array}{ll}-69.01 & -135.40\end{array}$ $\begin{array}{lll}-69.08 & -135.36\end{array}$ $-69.14-135.33$ $-69.22-135.31$ $\begin{array}{lll}-69.28 & -135.26\end{array}$ $\begin{array}{ll}-69.35 & -135.21\end{array}$ $-69.41-135.15$ $-69.47-135.09$
$-69.52-135.002$ $-69.52-135.02$ $-69.58-134.95$ $-69.62-134.85$ $\begin{array}{lll}-69.67 & -134.76\end{array}$ $\begin{array}{ll}-69.70 & -134.65\end{array}$ $-69.74-134.51$ $-69.78-134.40$ $-69.81-134.27$ $-69.84-134.13$ $-69.87-133.98$ $\begin{array}{lll}-69.89 & -133.82\end{array}$ $-69.92-133.66$ $\begin{array}{ll}-69.95 & -133.51\end{array}$ $-69.98-133.37$ $-70.00-133.19$ $-70.02-133.02$ $\begin{array}{lll}-69.98 & -133.02\end{array}$ $\begin{array}{ll}-69.95 & -133.37\end{array}$ $\begin{array}{lll}-69.94 & -133.69\end{array}$ $-69.93-134.00$ $-69.92-133.96$ $-69.92-133.89$ $-69.93-133.94$ $-69.93-134.01$ $-69.95-134.07$ $-69.96-134.14$ $\begin{array}{lll}-69.96 & -134.17\end{array}$ $-69.96-134.19$ $-69.96-134.2$ $-69.96-134.25$ $-69.95-134.27$
107.6

107.3

107.0

106.7

106.4

106.1

105.9

105.8

105.6

105.4

105.1

104.9

104.7

104.6

104.4

104.0

103.8

103.6

103.4

103.2

102.9

102.7

102.5

101.8

101.6

101.4

100.9

100.7

100.4

100.2

100.0

99.7

99.3

99.1

98.8

98.6

98.4

98.1

97.9

$99.1-9999.00-9999.00-9999.00$ $99.1-9999.00-9999.00-9999.00$ $99.2-9999.00-9999.00-9999.00$ $99.2-9999.00-9999.00-9999.00$ $99.3-9999.00-9999.00-9999.00$ 9 40

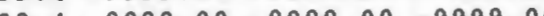
$99.5-9999.00-9999.00-9999.00$ $99.6-9999.00-9999.00-9999.00$ $99.6-9999.00-9999.00-9999.00$ $99.7-9999.00-9999.00-9999.00$ $99.7-9999.00-9999.00-9999.00$

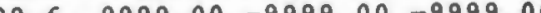
96 - $6999.00-9999.00-9999.00$ 99.5 - $9999.00-9999.00-9999.00$ $99.4-9999.00-9999.00-9999.00$ 
$04-16: 50: 49$ $04-16: 50: 54$ $04-16: 50: 59$ 04-16:51:04 $04-16: 51: 09$ $04-16: 51: 14$ $04-16: 51: 19$ $04-16: 51: 24$ 04-16:51:29 $04-16: 51: 34$ $04-16: 51: 39$ $04-16: 51: 44$ $04-16: 51: 49$ $04-16: 51: 54$ $04-16: 51: 59$ $04-16: 52: 04$ $04-16: 52: 09$ $04-16: 52: 14$ $04-16: 52: 19$ $04-16: 52: 24$ $04-16: 52: 29$ $04-16: 52: 34$ $04-16: 52: 39$ $04-16: 52: 44$ 04-16:52:49 $04-16: 52: 54$ $04-16: 52: 59$ $04-16: 53: 04$ $04-16: 53: 09$ $04-16: 53: 14$ $04-16: 53: 19$ $04-16: 53: 24$ $04-16: 53: 29$ $04-16: 53: 34$ $04-16: 53: 39$ $04-16: 53: 44$ $04-16: 53: 49$ $04-16: 53: 54$ $04-16: 53: 59$ $04-16: 54: 04$ 04-16:54:09 $04-16: 54: 14$ $04-16: 54: 19$ $04-16: 54: 24$ $04-16: 54: 29$ $04-16: 54: 34$ $04-16: 54: 39$ $04-16: 54: 44$ $04-16: 54: 49$ $04-16: 54: 54$ $98.9-9999.00-9999.00-9999.00$ $98.9-9999.00-9999.00-9999.00$ $\begin{array}{lllll}98.9 & -9999.00 & -9999.00 & -9999.00\end{array}$ $98.9-9999.00-9999.00-9999.00$ $99.0-9999.00-9999.00-9999.00$ $99.0-9999.00-9999.00-9999.00$ $99.0-9999.00-9999.00-9999.00$ $99.0-9999.00-9999.00-9999.00$ $99.0-9999.00-9999.00-9999.00$ $99.0-9999.00-9999.00-9999.00$ $99.0-9999.00-9999.00-9999.00$ $99.0-9999.00-9999.00-9999.00$ $99.0-9999.00-9999.00-9999.00$ $99.0-9999.00-9999.00-9999.00$ $99.0-9999.00-9999.00-9999.00$ $99.0-9999.00-9999.00-9999.00$ $99.0-9999.00-9999.00-9999.00$ $99.0-9999.00-9999.00-9999.00$ $99.0-9999.00-9999.00-9999.00$ $99.0-9999.00-9999.00-9999.00$ 
$04-16: 54: 59$ 04-16:55:04 04-16:55:09 $04-16: 55: 14$ $04-16: 55: 19$ $04-16: 55: 24$ $04-16: 55: 29$ $04-16: 55: 34$ $04-16: 55: 39$ $04-16: 55: 44$ $04-16: 55: 49$ $04-16: 55: 54$ $04-16: 55: 59$ $04-16: 56: 04$ $04-16: 56: 09$ $04-16: 56: 14$ $04-16: 56: 19$ $04-16: 56: 24$ $04-16: 56: 29$ $04-16: 56: 34$ $04-16: 56: 39$ $04-16: 56: 44$ $04-16: 56: 49$ $04-16: 56: 54$ $04-16: 56: 59$ $04-16: 57: 04$ $04-16: 57: 09$ $04-16: 57: 14$ $04-16: 57: 19$ $04-16: 57: 24$ $04-16: 57: 29$ $04-16: 57: 34$ $04-16: 57: 39$ $04-16: 57: 44$ $04-16: 57: 49$ $04-16: 57: 54$ $04-16: 57: 59$ $04-16: 58: 04$ $04-16: 58: 09$ $04-16: 58: 14$ $04-16: 58: 19$ $04-16: 58: 24$ $04-16: 58: 29$ $04-16: 58: 34$ $04-16: 58: 39$ $04-16: 58: 44$ $04-16: 58: 49$ $04-16: 58: 54$ $04-16: 58: 59$ $04-16: 59: 04$ $-69.90-133.96$ $-69.91-133.89$ $-69.91-133.92$ $\begin{array}{ll}-69.92 & -133.98\end{array}$ $-69.92-134.05$ $-69.93-134.09$ $\begin{array}{ll}-69.94 & -134.11\end{array}$ $-69.95-134.15$ $-69.95-134.18$ $-69.95-134.20$ $\begin{array}{ll}-69.95 & -134.22\end{array}$ $-69.96-134.21$ $-69.96-134.20$ $-69.96-134.21$ $-69.97-134.20$ $-69.97-134.18$ $-69.97-134.15$ $\begin{array}{lll}-69.97 & -134.12\end{array}$ $-69.97-134.06$ $\begin{array}{ll}-69.97 & -134.00\end{array}$ $-69.97-133.92$ $-69.97-133.89$ $-69.97-133.95$ $\begin{array}{ll}-69.97 & -134.00\end{array}$ $-69.97-134.06$ $-69.97-134.09$ $-69.97-134.12$ $\begin{array}{ll}-69.98 & -134.14\end{array}$ $\begin{array}{lll}-69.98 & -134.16\end{array}$ $-69.98-134.18$ $\begin{array}{lll}-69.98 & -134.19\end{array}$ $\begin{array}{lll}-69.98 & -134.19\end{array}$ $-69.97-134.18$ $-69.97-134.17$ $\begin{array}{ll}-69.97 & -134.16\end{array}$ $-69.97-134.14$ $-69.97-134.12$ $-69.97-134.10$ $-69.97-134.09$ $\begin{array}{ll}-69.98 & -134.05\end{array}$ $-69.97-134.00$ $-69.97-133.94$ $-69.97-133.89$ $-69.97-133.92$ $\begin{array}{ll}-69.97 & -133.95\end{array}$ $\begin{array}{ll}-69.98 & -133.99\end{array}$ $\begin{array}{ll}-69.98 & -134.02 \\ -69.99 & -134.05\end{array}$ $\begin{array}{ll}-69.99 & -134.05 \\ -69.99 & -134.06\end{array}$

$99.0-9999.00-9999.00-9999.00$ $99.0-9999.00-9999.00-9999.00$ $99.0-9999.00-9999.00-9999.00$ $99.0-9999.00-9999.00-9999.00$ $99.0-9999.00-9999.00-9999.00$ $99.0-9999.00-9999.00-9999.00$ $99.0-9999.00-9999.00-9999.00$ $99.0-9999.00-9999.00-9999.00$ $99.0-9999.00-9999.00-9999.00$ $99.0-9999.00-9999.00-9999.00$ $99.0-9999.00-9999.00-9999.00$ $99.0-9999.00-9999.00-9999.00$ $99.0-9999.00-9999.00-9999.00$ $99.0-9999.00-9999.00-9999.00$ $99.0-9999.00-9999.00-9999.00$ $99.0-9999.00-9999.00-9999.00$ $99.0-9999.00-9999.00-9999.00$ 
04-16:59:09 04-16:59:14 $04-16: 59: 19$ $04-16: 59: 24$ $04-16: 59: 29$ $04-16: 59: 34$ $04-16: 59: 39$

$04-16: 59: 44$ $04-16: 59: 49$ $04-16: 59: 54$ $04-16: 59: 59$ 04-17:00:04 $04-17: 00: 09$ 04-17:00:14 $04-17: 00: 19$ $04-17: 00: 24$ $04-17: 00: 29$ $04-17: 00: 34$ $04-17: 00: 39$ $04-17: 00: 44$ $04-17: 00: 49$ $04-17: 00: 54$ $04-17: 00: 59$

04-17:01:19 04-17:01:24 $04-17: 01: 29$ 04-17:01:34 $04-17: 01: 39$ 04-17:01:44 04-17:01:49 04-17:01:54 04-17:01:59 04-17:02:04 $04-17: 02: 09$ $04-17: 02: 14$ 04-17:02:19 $04-17: 02: 24$ $04-17: 02: 29$ 04-17:02:34 $04-17: 02: 39$ $04-17: 02: 44$ 04-17:02:49 04-17:02:54 04-17:02:59 04-17:03:04 $04-17: 03: 09$ $04-17: 03: 14$

251.36 251.96 252.55 253.14 253.73 254.32 254.91 255.50 256.09 256.67 257.26 257.84 258.42 259.00 259.58 260.15 260.73 261.30 261.87 262.44 263.01 263.57 264.13 264.69 265.25 265.81 266.36 266.91 267.45 268.00 268.54 269.08 269.61 270.15 270.68 271.2 272.25 272.77 273.28 273.79 274.30 274.81 275.31 275.81 276.30 276.80 277.29 277.77 278.25
62.11 262.10 262.08 262.07 262.05 262.03 262.01 261.99 261.97 261.95 261.93 61.90 261.88 261.85

261.83

261.80 261.77 261.75 261.72 261.69 261.66 261.63 261.59 261.56 261.53

261.49 261.46 261.42 261.39 261.35 261.31

261.27 261.23 261.19 261.15 261.11

261.07 261.03 260.98 260.94 $\begin{array}{lll}-70.00 & -134.12\end{array}$ $-70.00-134.12$ $\begin{array}{lll}-70.00 & -134.10\end{array}$ $-70.00-134.10$ $-70.01-134.09$ $-70.01-134.06$ $-70.01 \quad-134.02$ $\begin{array}{ll}-70.01 & -133.98\end{array}$ $-70.01-133.92$ $-70.01-133.88$ $-70.00-133.90$ $\begin{array}{ll}-70.01 & -133.93\end{array}$ $\begin{array}{ll}-70.01 & -133.94\end{array}$ $\begin{array}{lll}-70.02 & -133.97\end{array}$ $-70.03-133.99$ $-70.03-134.02$ $-70.04-134.06$ $-70.05-134.10$ $\begin{array}{ll}-70.05 & -134.09\end{array}$ $-70.02-134.05$ $-69.99-134.04$ $-69.97-134.02$ $\begin{array}{ll}-69.95 & -133.99\end{array}$ $-69.93-133.96$ $-69.91-133.91$ $-69.89-133.89$ $\begin{array}{ll}-69.89 & -133.93\end{array}$ $\begin{array}{ll}-69.90 & -133.96\end{array}$ $\begin{array}{ll}-69.92 & -133.99\end{array}$ $-69.93-134.00$ $-69.95-134.02$ $-69.95-134.03$ $-69.96-134.05$ $\begin{array}{ll}-69.97 & -134.04\end{array}$ $\begin{array}{lll}-69.98 & -134.04\end{array}$ $-69.99-134.04$ $-70.01-134.03$ $-70.03-134.03$ $-70.05 \quad-134.01$ $-70.04 \quad-134.04$ $-70.03 \quad-134.04$ $-70.03-134.05$ $\begin{array}{ll}-70.02 & -134.04\end{array}$ $-70.02-134.04$ $\begin{array}{ll}-70.02 & -134.04\end{array}$ $\begin{array}{ll}-70.01 & -134.04\end{array}$ $\begin{array}{ll}-70.02 & -134.03\end{array}$ $-70.02-134.01$ 


\begin{tabular}{|c|c|c|c|c|c|c|c|c|c|c|c|}
\hline & --- & BITEE & $-\cdots-$ & & & & & & & & \\
\hline MET & LAT & LON & $A L T$ & $\mathrm{DEC}$ & RA & $A M$ ANG & SELONG & LAT & LON & TAN HT & $G M$ \\
\hline $06-09: 23: 06$ & -53.60 & 21.02 & 272.79 & -24.53 & 32.77 & 126.8 & 23.4 & -63.89 & 15.04 & 160.00 & \\
\hline $06-09: 23: 11$ & -53.46 & 21.52 & 272.75 & -24.54 & 32.77 & 126.7 & 23.4 & -63.97 & 15.60 & 155.71 & \\
\hline $06-09: 23: 16$ & -53.33 & 22.01 & 272.71 & -24.54 & 32.79 & 126.7 & 23.4 & -64.05 & 16.17 & $151.4 \%$ & \\
\hline $06-09: 23: 21$ & -53.19 & 22.50 & 272.67 & -24.54 & 32.80 & 126.6 & 23.3 & -64.13 & 16.73 & 146.81 & \\
\hline $06-09: 23: 26$ & -53.05 & 22.98 & 272.63 & $-2+.+7$ & 32.75 & 126.5 & 23.4 & -64.29 & 17.27 & $1+0.52$ & \\
\hline $06-09: 23: 31$ & -52.91 & 23.46 & 272.59 & -24.51 & 32.79 & 126.4 & 23.3 & -64.32 & 17.86 & 136.84 & \\
\hline $06-09: 23: 36$ & -52.76 & 23.94 & 272.55 & -24.57 & 32.84 & 126.4 & 23.3 & -64.34 & 18.46 & 133.45 & \\
\hline $06-09: 23: 41$ & -52.62 & 24.42 & 272.51 & -24.51 & 32.80 & 126.3 & 23.3 & -64.47 & 19.03 & 127.22 & \\
\hline $06-09: 23: 46$ & -52.47 & 24.89 & 272.46 & -24.50 & 32.79 & 126.2 & 23.3 & -04.50 & 19.61 & 121.83 & \\
\hline $06-09: 23: 51$ & -52.32 & 25.36 & 272.42 & -24.59 & 32.87 & 126.2 & 23.3 & -64.53 & 20.23 & 119.32 & \\
\hline $06-09: 23: 56$ & -52.17 & 25.82 & 272.38 & -24.60 & 32.88 & 126.1 & 23.3 & -64.58 & 20.83 & 114.54 & \\
\hline $06-09: 24: 01$ & -52.01 & 26.29 & 272.33 & -24.57 & 32.86 & 126.0 & 23.3 & -04.68 & 21.42 & 108.61 & \\
\hline $06-09: 24: 06$ & -51.85 & 26.74 & 272.28 & $-2+.58$ & 32.88 & 125.9 & 23.3 & -64.73 & 22.02 & 103.60 & \\
\hline $06-09: 24: 11$ & -51.70 & 27.20 & 272.24 & -24.59 & 32.88 & 125.8 & 23.3 & -64.78 & 22.63 & 98.63 & \\
\hline $06-09: 24: 16$ & -51.54 & 27.65 & 272.19 & -24.56 & 32.87 & 125.7 & 23.3 & -64.87 & 23.23 & 92.43 & \\
\hline $06-09: 24: 21$ & -51.37 & 28.10 & 272.14 & -24.57 & 32.87 & 125.6 & 23.3 & -64.91 & 23.85 & 87.40 & \\
\hline $06-09: 24: 26$ & -51.21 & 28.54 & 272.10 & -24.63 & 32.92 & 125.5 & 23.3 & -64.90 & 24.47 & 83.63 & \\
\hline $06-09: 24: 31$ & -51.04 & 28.99 & 272.05 & -24.60 & 32.90 & 125.4 & 23.3 & -64.98 & 25.09 & 77.14 & \\
\hline $06-09: 24: 36$ & -50.88 & 29.42 & 272.00 & -24.71 & 32.98 & 125.4 & 23.2 & -64.92 & 25.72 & 74.56 & \\
\hline $06-09: 24: 41$ & -50.71 & 29.86 & 271.95 & -24.63 & 32.93 & 125.3 & 23.3 & -65.04 & 26.34 & 66.75 & \\
\hline $06-09: 24: 46$ & -50.54 & 30.29 & 271.90 & -24.73 & 33.00 & 125.2 & 23.2 & -64.98 & 26.97 & 63.90 & \\
\hline $06-09: 24: 51$ & -50.36 & 30.72 & 271.84 & -24.75 & 33.01 & 125.1 & 23.2 & -65.00 & 27.60 & 58.62 & \\
\hline $06-09: 24: 56$ & -50.19 & 31.15 & 271.79 & -2.1 .77 & 33.02 & 125.0 & 23.2 & -65.02 & 28.24 & 53.31 & \\
\hline $06-09: 25: 01$ & -50.01 & 31.57 & 271.74 & -24.79 & 33.03 & 124.9 & 23.2 & -05.03 & 28.87 & 48.06 & \\
\hline $06-09: 25: 06$ & -49.83 & 31.99 & 271.69 & -24.75 & 33.00 & $12+.8$ & 23.3 & -65.10 & 29.51 & 40.94 & \\
\hline $06-09: 25: 11$ & -49.65 & 32.40 & 271.63 & -24.73 & 32.98 & 124.7 & 23.3 & -65.15 & 30.16 & 34.24 & \\
\hline $06-09: 25: 16$ & -49.47 & 32.81 & 271.58 & -24.69 & 32.95 & 124.5 & 23.3 & -65.21 & 30.81 & 26.82 & \\
\hline $06-09: 25: 21$ & -49.29 & 33.22 & 271.53 & -24.62 & 32.90 & 124.4 & 23.3 & -05.31 & 31.48 & 18.26 & \\
\hline $06-09: 25: 26$ & -49.11 & 33.63 & 271.17 & -24.63 & 32.90 & 124.3 & 23.3 & -65.32 & 32.13 & 12.24 & \\
\hline $06-09: 25: 31$ & -48.92 & 34.03 & $271 .+2$ & -24.60 & 32.87 & 124.1 & 23.3 & -65.37 & 32.80 & 4.78 & \\
\hline $06-09: 25: 36$ & -48.73 & 37.43 & 271.36 & -24.62 & 32.88 & 124.0 & 23.3 & -65.36 & 33.45 & -1.00 & \\
\hline $06-09: 25: 41$ & -48.54 & 34.83 & 271.30 & -24.55 & 32.82 & 123.8 & 23.3 & -65.41 & 34.15 & -9.85 & \\
\hline $06-09: 25: 46$ & -48.35 & 35.22 & 271.25 & -24.56 & 32.83 & 123.7 & 23.3 & -65.43 & 34.81 & -15.81 & \\
\hline $06 \rightarrow 09: 25: 51$ & -48.16 & 35.61 & 271.19 & -24.54 & 32.81 & 123.6 & 23.3 & -65.46 & 35.49 & -23.33 & \\
\hline $06-09: 25: 56$ & -47.97 & 36.00 & 271.13 & -2.1 .51 & 32.77 & 123.4 & 23.4 & -65.49 & 36.18 & -30.93 & \\
\hline
\end{tabular}


134.22 267.58

$-52.31$

126.36

16.5115.

$\begin{array}{ll}15.2 & 112.5 \\ 13.9 & 109.8\end{array}$

$134.91 \quad 267.27$

31.23

30.97

$06-16: 15: 34$

$06-16: 15: 39$

$06-16: 15: 44$

$06-16: 15: 49$

$06-16: 15: 54$

$06-16: 15: 59$

$06-16: 16: 04$

$06-16: 16: 09$

$06-16: 16: 09$
$06-16: 16: 14$

$06-16: 16: 14$
$06-16: 16: 19$

$06-16: 16: 19$

$06-16: 16: 29$

$06-16: 16: 34$

$06-16: 16: 39$

$06-16: 16: 44$

$06-16: 16: 49$

$06-16: 16: 54$

$06-16: 16: 59$

$06-16: 17: 04$

$06-16: 17: 09$

$06-16: 17: 14$

$06-16: 17: 19$

$06-16: 17: 24$

$06-16: 17: 29$

$06-16: 17: 34$

$06-16: 17: 39$

$06-16: 17: 44$

06-16:17:49

$06-16: 17: 49$
$06-16: 17: 54$

$06-16: 17: 54$
$06-16: 17: 59$

$06-16: 17: 59$
$06-16: 18: 04$

$06-16: 18: 04$
$06-16: 18: 09$

$06-16: 18: 14$

$06-16: 18: 19$

$06-16: 18: 24$

$06-16: 18: 24$

$06-16: 18: 29$
$06-16: 18: 34$

$06-16: 18: 34$
$06-16: 18: 39$

$06-16: 18: 44$

$06-16: 18: 49$

$06-16: 18: 54$ $\begin{array}{lll}30.46 & 135.58 & 266.96\end{array}$

$30.20 \quad 135.81 \quad 266.88$

$\begin{array}{lll}29.68 & 136.25 & 266.73\end{array}$

$29.42 \quad 136.47 \quad 266.65$

$29.16 \quad 136.69 \quad 266.58$

$28.89 \quad 136.91 \quad 266.50$

$28.63 \quad 137.12 \quad 266.43$

$28.37 \quad 137.34 \quad 266.35$

$\begin{array}{lll}28.11 & 137.55 & 266.28\end{array}$

$\begin{array}{lll}27.84 & 137.76 & 266.20\end{array}$

$\begin{array}{lll}27.58 & 137.98 & 266.13\end{array}$

$\begin{array}{lll}27.32 & 138.19 & 266.05\end{array}$

$\begin{array}{lll}27.05 & 138.39 & 265.98\end{array}$

$26.79 \quad 138.60 \quad 265.91$

$26.52 \quad 138.81 \quad 265.84$

$\begin{array}{lll}26.26 & 139.02 & 265.76\end{array}$

$\begin{array}{lll}25.99 & 139.22 & 265.69\end{array}$

$\begin{array}{lll}25.72 & 139.42 & 265.62\end{array}$

$\begin{array}{lll}25.46 & 139.63 & 265.55\end{array}$

25.190139 .83

$24.92 \quad 140.03$

$24.66 \quad 140.23$

$24.39 \quad 140.43$

$24.12 \quad 140.63$

$23.85 \quad 140.83$

$23.58 \quad 141.02$

$23.31 \quad 141.22$

$23.04 \quad 141.41$

$22.77 \quad 141.61$

$22.50 \quad 141.80$

$22.23 \quad 141.99$

$21.96 \quad 142.18$

$21.69 \quad 142.37$

$\begin{array}{ll}21.42 & 142.56 \\ 21.15 & 142.75\end{array}$

$20.88 \quad 142.94$

$20.61 \quad 143.13$

265.48

265.41

265.34

265.27

265.20

265.13

265.06

264.99

264.92

264.86

264.79

264.73

264.66

264.59

264.53

264.47

264.40

264.34
$29.94 \quad 136.03 \quad 266.8$ $\begin{array}{lll}123.61 & 13.9 & 109.8 \\ 122.26 & 12.5 & 107.2 \\ 120.98 & 11.2 & 104.5\end{array}$

$-51.18$

$-50.59$

$-50.00$

$-49.38$

$-48 \cdot 75$

$-48.11$

$\begin{array}{rrr}120.98 & 11.2 & 104.5 \\ 119.72 & 9.9 & 101.9\end{array}$

$118.47 \quad 8.6 \quad 99.3$

$\begin{array}{lll}117.27 & 7.4 \quad 96.7\end{array}$

$\begin{array}{llll}-46.78 & 114.94 & 5.0 & 91.7\end{array}$

$-46.10$

$-45.42$

$-44.79$

$-44.10$

$-43.41$

113.82

112.73
111.72

110.75

109.82

108.89

$-42.01 \quad 107.98$

$-41.31 \quad 107.09$

$-40.60 \quad 106.21$

$-39.88 \quad 105.34$

$-38.16104 .49$

$-37.71 \quad 102.84$

$-36.71$

$-36.25$

$-35.52$

$-34.78$

-34.78
-33.98

$-33.16$

$-32.36$

$-31.55$

$-30.75$

$-29.93$

$-29.12$

$-27.48$

$-26.66$

$-25.85$

$-25.04$

$-24.22$

$-23.40$

$-22.59$

$-21.78$

$-20.97$

$-20.19$

102.03
101.23

100.44

99.67

99.00

98.34

97.69

97.05

96.42

95.80

95.19

94.01

93.43

92.85

92.28

91.72

91.17

90.62

90.08

89.51
88.84

$-18.62$

88.19

87.54

$4.0 \quad 89.3$

3.286 .9

$3.0 \quad 84.8$

30.1

32.7

34.0

36.6

37.8

47.4

39.1

40.4

43.1

44.4

42.7 $\begin{array}{llll}-47.45 & 116.09 & 6.1 & 94.2\end{array}$

$\begin{array}{lllll}3.2 & 82.7 & -999.00 & -999.00 & -999.00 \\ 3.9 & 80.7 & -999.00 & -999.00 & -999.00\end{array}$

$\begin{array}{lll}19.44 & 143.95 & -2.10\end{array}$

$20.31 \quad 143.35 \quad 10,28$

$\begin{array}{lll}21.17 & 142.74 & 79.15\end{array}$

$\begin{array}{lll}22.04 & 142.12 & 114.68\end{array}$

$\begin{array}{lll}22.89 & 141.51 & 146.00\end{array}$

$\begin{array}{lll}23.75 & 140.88 & 174.06 \\ 24.61 & 140.24 & 198.53\end{array}$

$\begin{array}{lll}25.46 & 139.59 & 219.15\end{array}$

$\begin{array}{lll}26.32 & 138.93 & 236.20\end{array}$

$27.17 \quad 138.27 \quad 249.44$

$28.02 \quad 137.60 \quad 258.94$

$28.86 \quad 136.92 \quad 264.69$

$29.65 \quad 136.28 \quad 266.72$

$\begin{array}{lllll}4.9 & 78.7 & -999.00 & -999.00 & -999.00\end{array}$

$6.0 \quad 76.8 \quad-999.00-999.00-999.00$

$\begin{array}{lllll}7.1 & 74.9 & -999.00 & -999.00 & -999.00\end{array}$

$\begin{array}{lllll}8.3 & 73.1 & -999.00 & -999.00 & -999.00\end{array}$

$\begin{array}{lllll}9.6 & 71.4 & -999.00 & -999.00 & -999.00\end{array}$

$\begin{array}{lllll}10.8 & 69.7 & -999.00 & -999.00 & -999.00\end{array}$

$13.4 \quad 66.5 \quad-999.00 \quad-999.00 \quad-999.00$

$14.466 .5 \quad 65.0 \quad-999.00 \quad-999.00-999.00$

$15.9 \quad 63.6 \quad-999.00 \quad-999.00 \quad-999.00$

$17.2 \quad 62.1 \quad-999.00 \quad-999.00 \quad-999.00$

$\begin{array}{lllll}18.5 & 60.8 & -999.00 & -999.00 & -999.00\end{array}$

$\begin{array}{lllll}19.8 & 59.6 & -999.00 & -999.00 & -999.00\end{array}$

$\begin{array}{lllll}21.1 & 58.4 & -999.00 & -999.00 & -999.00\end{array}$

$\begin{array}{lllll}22.4 & 57.3 & -999.00 & -999.00 & -999.00\end{array}$

$23.756 .3-999.00-999.00-999.00$

$\begin{array}{lllll}24.9 & 55.2 & -999.00 & -999.00 & -999.00\end{array}$

$26.2 \quad 54.2 \quad-999.00 \quad-999.00 \quad-999.00$

$\begin{array}{lllll}27.5 & 53.3 & -999.00 & -999.00 & -999.00\end{array}$

$\begin{array}{lllll}28.8 & 52.3 & -999.00 & -999.00 & -999.00\end{array}$

$51.4-999.00$

$51.4 \quad-999.00 \quad-999.00$

$-999.00$

$48.9-999.00$

$-999.00$

$-999.00$

$-999.00$

$\begin{array}{ll}47.4 & -999.00 \\ 46.6 & -999.00\end{array}$

$\begin{array}{ll}46.6 & -999.00 \\ 45.9 & -999.00\end{array}$

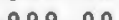

$-999.00$

$-999.00$

$44.3-999.00$

$\begin{array}{ll}-999.00 & -999.00 \\ -999.00 & -999.00\end{array}$

$-99.00$

$-999.00$

$-999.00$

-999.00
-999.00

$-999.00$

$-999.00$

$-999.00$ 
ME I

$06-16: 19: 09$ $06-16: 19: 14$ $06-16: 19: 19$ $06-16: 19: 24$ $06-16: 19: 29$ $06-16: 19: 34$ $06-16: 19: 39$ $06-16: 19: 44$ $06-16: 19: 49$ $06-16: 19: 54$ $06-16: 19: 59$

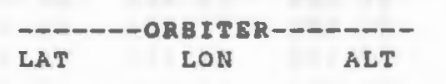

$$
\text { LON }
$$

$\begin{array}{lll}19.79 & 143.68 & 264.15\end{array}$

$\begin{array}{lll}19.52 & 143.87 & 264.09\end{array}$

$19.24 \quad 144.05 \quad 264.03$

$\begin{array}{lll}18.97 & 144.23 & 263.97\end{array}$

$18.70 \quad 144.42 \quad 263.91$

$\begin{array}{lll}18.42 & 144.60 & 263.86\end{array}$

$\begin{array}{lll}18.15 & 144.78 & 263.80\end{array}$

$\begin{array}{lll}17.88 & 144.96 & 263.74\end{array}$

$17.60 \quad 145.14 \quad 263.69$

$17.33 \quad 145.32 \quad 263.63$

$17.05 \quad 145.50$

\section{DEC}

$-16.26$

$-15.47$

$-14.69$

$-13.91$

$-13.13$

$-12.35$

$-11.57$

$-10.79$

$-10.01$

$-9.23$

$-8.45$

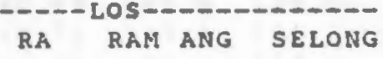

RAM ANG SELONG

85.63

85.01

48.

$\begin{array}{lllll}40.4 & -999.00 & -999.00 & -999.00\end{array}$

LAT

LON

DANGERT

84.39

3.76

51.0

52.4

$38.9-999$

$38.9-999.00$

83.14

82.53

81.92

1.32

80.72

80.72

80.13

79.53
53.

56.

57.6

58.9

60.2

61.6
$37.5 \quad-999.00$

$-999.00 \quad-999.00$

$-999.00 \quad-999.00$

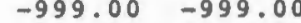

$\begin{array}{llll}36.2 & -999.00 & -999.00 & -999.00\end{array}$

$\begin{array}{llll}35.5 & -999.00 & -999.00 & -999.00\end{array}$

$34.9-999.00-999.00-999.00$

$\begin{array}{llll}34.3 & -999.00 & -999.00 & -999.00\end{array}$

$\begin{array}{llll}33.6 & -999.00 & -999.00 & -999.00\end{array}$ 


\section{LAT}

$-17.72$

$06-18: 00: 04$

06-18:00:09

06-18:00:14

$06-18: 00: 19$

$06-18: 00: 24$

06-18:00:29

$06-18: 00: 34$

$06-18: 00: 39$

$06-18: 00: 44$

$06-18: 00: 49$

$06-18: 00: 54$

$06-18: 00: 59$

$06-18: 01: 04$

06-18:01:09

$06-18: 01: 14$

06-18:01:19

06-18:01:24

06-18:01:29

$06-18: 01: 34$

06-18:01:39

$06-18: 01: 44$

06-18:01:49

06-18:01:54

06-18:01:59

06-18:02:04

06-18:02:09

06-18:02:14

06-18:02:19

06-18:02:24

06-18:02:29

06-18:02:34

06-18:02:39

06-18:02:44

$06-18: 02: 49$

$06-18: 02: 54$

$06-18: 02: 59$

06-18:03:04

06-18:03:09

$06-18: 03: 14$

$06-18: 03: 19$

06-18:03:24

$06-18: 03: 29$

06-18:03:34

$06-18: 03: 39$

$06-18: 03: 44$

$06-18: 03: 49$

$06-18: 03: 54$

$06-18: 03: 59$

06-18:04:04

$-18.27$

$-18.54$

$-18.81$

$-19.09$

$-19.36$

$-19.63$

$-19.91$

$-20.18$

$-20.45$

$-20.72$

$-21.00$

$-21.27$

$-21.54$

$-21.81$

$-22.08$

$-22.35$

$-22.62$

$-22.89$

$-23.16$

$-23.43$

$-23.70$

$-23.97$

$-24.24$

$-24.50$

$-24.77$

$-25.04$

$-25.31$

$-25.57$

$-25.84$

$-26.11$

$-26.37$

$-26.64$

$-26.90$

$-27.1$

$-27.43$

$-27.69$

$-27.96$

$-28.22$

$-28.48$

$-28.75$

$-29.01$

$-29.27$

$-29.53$

$-29.79$

$-30.05$

$-30.31$

$-30.57$
ROITE
LON

ALT
143.57

262.75

262.8

$144.29 \quad 262.94$

$144.66 \quad 263.04$

144.84263 .09

$145.03 \quad 263.14$

$145.21 \quad 263.19$

$145.40 \quad 263.24$

$145.59 \quad 263.29$

145.77263 .34

$145.96 \quad 263.40$

146.15263 .45

$146.34 \quad 263.50$

$146.53 \quad 263.56$

$146.72 \quad 263.62$

$146.92 \quad 263.67$

$147.11 \quad 263.73$

$147.50 \quad 263.84$

$147.70 \quad 263.90$

$147.89 \quad 263.96$

$148.09 \quad 264.02$

$148.29 \quad 264.08$

$148.49 \quad 261.14$

$148.69 \quad 264.20$

$148.89 \quad 264.26$

$149.09 \quad 264.32$

$149.30 \quad 264.38$

$149.50 \quad 264.44$

149.71264 .51

$149.91 \quad 264.57$

$150.12 \quad 264.63$

150.33264 .69

$150.54 \quad 264.76$

$150.75 \quad 264.82$

$150.96 \quad 264.89$

$151.17 \quad 264.95$

$\begin{array}{ll}151.39 & 265.02\end{array}$

$151.60 \quad 265.08$

$151.82 \quad 265.15$

$152.04 \quad 265.22$

$152.26 \quad 265.28$

$152.48 \quad 265.35$

$152.70 \quad 265.42$

$152.92 \quad 265.48$

$153.15 \quad 265.55$
$144.48 \quad 262.99$

$147.30 \quad 263.79$
DEC RA RAM ANG SELONG

54.95

$\begin{array}{llll}-151.17 & 106.4 & 127.6\end{array}$

$\begin{array}{lllll}54.41 & -149.92 & 105.8 & 129.4\end{array}$

$\begin{array}{llll}53.86 & -148.71 & 105.1 & 131.2\end{array}$

$\begin{array}{llll}53.29 & -147.56 & 104.4 & 132.9\end{array}$

$52.70-146.16 \quad 103.7 \quad 134.7$

$51.47-144.39 \quad 102.2138 .2$

$\begin{array}{llll}51.47 & -144.39 & 102.2 & 138.2 \\ 50.84 & -1+3.41 & 101.4 & 139.9\end{array}$

$\begin{array}{llll}50.19 & -142.50 & 100.6 & 141.6\end{array}$

$\begin{array}{llll}49.52 & -141.62 & 99.8 & 143.3\end{array}$

$\begin{array}{llll}48.84 & -140.77 & 99.0 & 144.9\end{array}$

$\begin{array}{llll}18.14 & -139.97 & 98.2 & 146.5\end{array}$

$\begin{array}{llll}47.44 & -139.20 & 97.3 & 148.1\end{array}$

$\begin{array}{llll}46.72 & -138.49 & 96.5 & 149.7\end{array}$

$\begin{array}{llll}46.00 & -137.80 & 95.6 & 151.2\end{array}$

$\begin{array}{llll}45.26 & -137.15 & 94.7 & 152.6\end{array}$

$\begin{array}{llll}44.52 & -136.52 & 93.8 & 154.0\end{array}$

$\begin{array}{llll}13.77 & -135.93 & 92.9 & 155.4\end{array}$

$\begin{array}{llll}43.00 & -135.37 & 92.0 & 156.8\end{array}$

$\begin{array}{llll}42.23 & -134.83 & 91.0 & 158.1\end{array}$

$\begin{array}{lllll}11.46 & -134.33 & 90.1 & 159.3\end{array}$

$\begin{array}{llll}40.75 & -133.65 & 89.2 & 160.7\end{array}$

$\begin{array}{llll}40.04 & -132.99 & 88.4 & 162.0\end{array}$

$\begin{array}{llll}39.31 & -132.35 & 87.5 & 163.3\end{array}$

$\begin{array}{llll}38.58 & -131.74 & 86.6 & 164.6\end{array}$

$\begin{array}{llll}37.84 & -131.15 & 85.7 & 165.9\end{array}$

$\begin{array}{llll}37.08 & -130.59 & 84.8 & 167.1\end{array}$

$\begin{array}{llll}36.32 & -130.07 & 83.8 & 168.2\end{array}$

$\begin{array}{llll}35.55 & -129.55 & 82.9 & 169.3\end{array}$

$\begin{array}{llll}34.77 & -129.07 & 81.9 & 170.4\end{array}$

$\begin{array}{llll}33.98 & -128.61 & 81.0 & 171.5\end{array}$

$\begin{array}{lllll}33.18 & -128.17 & 80.0 & 172.5\end{array}$

$\begin{array}{llll}32.38 & -127.75 & 79.0 & 173.4\end{array}$

$\begin{array}{llll}31.57 & -127.36 & 78.0 & 174.4\end{array}$

$30.75-126.98 \quad 77.0 \quad 175.3$

$\begin{array}{llll}29.93 & -126.63 & 76.0 & 176.1\end{array}$

$29.10 \quad-126.30 \quad 75.0 \quad 176.9$

$\begin{array}{llll}28.27 & -125.98 & 73.9 & 177.7\end{array}$

$\begin{array}{llll}27.42 & -125.68 & 72.9 & 178.5\end{array}$

$\begin{array}{llll}26.58 & -125.41 & 71.8 & 179.2\end{array}$

$\begin{array}{llll}25.72 & -125.15 & 70.8 & 179.9\end{array}$

$\begin{array}{llll}24.86 & -124.89 & 69.7 & 179.5\end{array}$

$\begin{array}{lllll}24.01 & -124.68 & 68.6 & 178.8\end{array}$

$\begin{array}{llll}23.14 & -124.48 & 67.5 & 178.3\end{array}$

$\begin{array}{llll}22.27 & -124.29 & 66.4 & 177.7\end{array}$

$\begin{array}{llll}21.40 & -124.10 & 65.3 & 177.1\end{array}$

$\begin{array}{llll}20.52 & -123.95 & 64.2 & 176.6\end{array}$

$\begin{array}{llll}19.64 & -123.80 & 63.1 & 176.1\end{array}$

$18.76-123.67$

$62.0 \quad 175.7$
LAT LON TAN HT

$8.00 \quad 161.36 \quad-695.94$

$\begin{array}{lll}8.36 & 162.30 & -753.13\end{array}$

$8.69 \quad 163.26 \quad-811.22$

$8.98 \quad 164.23 \quad-869.15$

$9.23 \quad 165.22 \quad-927.51$

$9.45 \quad 166.22 \quad-985.98$

$9.64 \quad 167.26-1045.09$

$9.78 \quad 168.30-1103.79$

$9.88 \quad 169.36-1161.85$

$9.93 \quad 170.14-1219.53$

$9.93 \quad 171.54-1277.45$

$9.89 \quad 172.66-1334.17$

$9.80 \quad 173.78-1390.15$

$9.64 \quad 174.92-1444.17$

$9.44 \quad 176.07-1497.78$

$9.18 \quad 177.24-1549.83$

$8.87 \quad 178.40-1600.43$

$8.50 \quad 179.57-1648.98$

$8.06 \quad 180.75-1695.55$

$\begin{array}{ll}7.57 \quad 181.92 & -1740.34\end{array}$

$7.02 \quad 183.09-1782.82$
6.56

$6.56 \quad 184.30-1834.11$

$6.07 \quad 185.50-1884.55$

$5.52 \quad 186.72-1933.19$

$+90 \quad 187.92-1979.09$

$421 \quad 189.13-2022.57$
$3.46 \quad 190.33-2063.40$

$3.46 \quad 190.33-2063.40$

$2.64 \quad 191.50-2100.17$

$1.77 \quad 192.68-2135.34$

$0.82 \quad 193.83-2166.37$

$\begin{array}{lll}-0.18 & 194.97-2193.94\end{array}$

$-1.23 \quad 196.07-2217.96$

$-2.34 \quad 197.15-2238.29$

$\begin{array}{lll}-3.51 \quad 198.20 & -2254.73\end{array}$

$\begin{array}{lll}-4.72 & 199.21 & -2266.80\end{array}$

$\begin{array}{lll}-5.98 & 200.17-2274.32\end{array}$

$-7.27 \quad 201.10-2278.41$
$-8.59 \quad 201.99-2278.43$

$-8.59201 .99-2278.23$

$\begin{array}{lll}-9.95 & 202.83 & -2273.33\end{array}$

$\begin{array}{lll}-11.33 & 203.61-2264.36\end{array}$

$-12.72 \quad 204.34-2251.08$

$\begin{array}{lll}-14.13 & 205.03-2234.62\end{array}$

$-15.54 \quad 205.64-2212.09$

$-16.96 \quad 206.19-2185.90$

$\begin{array}{lll}-18.37 & 206.69 & -2156.57\end{array}$

$\begin{array}{lll}-19.77 & 207.14 & -2123.89\end{array}$

$207.50-2086.82$

$\begin{array}{lll}-22.53 & 207.81-2046.97\end{array}$

$\begin{array}{lll}-23.88 & 208.06 & -2003.34\end{array}$ 
06-18:04:09 $06-18: 04: 14$ $06-18: 04: 19$ 06-18:04:24 $06-18: 04: 29$ $06-18: 04: 34$ $06-18: 04: 39$ 06-18:04:44 06-18:04:49 06-18:04:54 06-18:04:59 06-18:05:04 $06-18: 05: 09$ 06-18:05:1 $06-13: 05: 19$ 06-18:05: 24 $06-18: 05: 29$ $06-18: 05: 34$ $06-18: 05: 39$ $06-18: 05: 44$ 06-18:05:49 $06-18: 05: 54$ 06-18:05:59 06-18:06:04 $06-18: 06: 09$ $06-18: 06: 14$ 06-18:06:19 $06-18: 06: 24$ $06-18: 06: 29$ 06-18:06:34 $06-18: 06: 39$ $06-18: 06: 44$ $06-18: 06: 49$ $06-18: 06: 54$ 06-18:06:59 $06-18: 07: 04$ 06-18:07:09 $06-18: 07: 14$ 06-18:07:19 $06-18: 07: 24$ 06-18:07:29 06-18:07:34 $06-18: 07: 39$ 06-18:07:44 $06-18: 07: 49$ 06-18:07:54 06-18:07:59 $06-18: 08: 04$ 06-18:08:09 06-18:08:14
$-31.09$

$-31.35$

$-31.60$

$-31.86$

$-32.12$

$-32.37$

$-32.63$

$-32.88$

$-33.14$

$-33.39$

$-33.90$

$-34.15$

$-34.40$

$-34.65$

$-34.90$

$-35.15$

$-35.40$

$-35.65$

$-35.90$

$-36.14$

$-36.39$

$-36.64$

$-36.88$

$-37.13$

$-37.37$

$-37.61$

$-37.85$

$-38.10$

$-38.34$

$-38.58$

$-38.82$

$-39.06$

$-39.29$

$-39.53$

$-39.7$

$-40.00$

$-40.24$

$-40.70$

$-40.94$

$-41.17$

$-41.40$

$-41.63$

$-41.86$

$-42.08$

$-42.31$

$-42.54$

$-42.76$
.37

53.60

153.8

154.29

154.52

154.75

154.99

155.23

155.46

155.70

155.95

156.19

$156 .+3$

156.68

156.93

157.18

157.43

157.68

157.93

158.19

158.71

158.97

159.23

159.49

159.76

160.03

160.30

160.57

160.85

161.12

161.40

161.68

161.96

162.25

162.53

162.82

163.11

163.41

164.00

164.30

164.60

164.90

165.21

165.52

165.83

166.14
166.46

16.98

16.08

15.18

$-123.44$

$-123.35$

265.76

265.83

265.89

265.96

266.03

266.10

266.17

266.24

266.31

266.38

266.45

266.52

266.59

266.66

266.73

266.87

266.95

267.02

267.09

267.16

267.23

267.30

267.37

267.44

267.51

267.58

267.66

267.73

267.80

267.87

267.94

268.01

268.08

268.15

268.22

268.29

268.36

268.43

268.50

268.57

268.64

268.71

268.78

268.84

268.91

268.98

269.05

14.27
13.37

$-123.22$

$12.46-123.14$

$11.70 \quad-123.07$

$10.95-123.00$

$10.20-122.95$

$9.45-122.91$

$-122.88$

$93-122.86$
.828

$7.18-122.85$

$6.42-122.87$

$5.65-122.89$

$4.87-122.81$

$3.29-122.56$

$2.49-122.46$

$1.69-122.36$

$0.87-122.27$

$0.06 \quad-122.21$

$-0.76-122.14$

$\begin{array}{ll}-1.57 & -122.10\end{array}$

$\begin{array}{ll}-2.40 & -122.07\end{array}$

$-3.23-122.04$

$\begin{array}{lll}-4.06 & -122.04\end{array}$

$\begin{array}{ll}-4.87 & -122.04\end{array}$

$-122.05$

$-6.50-122.08$

$-7.33-122.12$

$\begin{array}{ll}-8.14 & -122.17\end{array}$

$\begin{array}{ll}-8.96 & -122.23\end{array}$

$\begin{array}{lll}-10.61 & -122.39\end{array}$

$\begin{array}{ll}-11.43 & -122.49\end{array}$

$-12.25-122.60$

$-13.08-122.72$

$-13.93-122.88$

$\begin{array}{ll}-15.62 & -123.23\end{array}$

$\begin{array}{ll}-16.47 & -123.42\end{array}$

$-17.31-123.63$

$-18.15-123.85$

$-19.00 \quad-124.08$

$\begin{array}{ll}-19.82 & -124.31\end{array}$

$\begin{array}{ll}-20.64 & -124.54\end{array}$

$\begin{array}{ll}-21.48 & -124.78\end{array}$

$\begin{array}{ll}-22.31 & -125.04\end{array}$

60.9175 .2

$58.6 \quad 174.4$

$57.4 \quad 174.0$

56.3173 .7

$55.1 \quad 173.4$

53.9173 .0

$\begin{array}{ll}52.9 & 172.7\end{array}$

$51.9 \quad 172.5$

$50.9 \quad 172.2$

$49.9 \quad 171.9$

$47.8 \quad 171.4$

$46.8 \quad 171.2$

$45.7 \quad 171.1$

$44.7 \quad 170.9$

$43.7 \quad 170.6$

$42.6 \quad 170.2$

$41.6 \quad 169.9$

$40.5 \quad 169.6$

$39.5 \quad 169.3$

38.4169 .0

$36.3 \quad 168.8$

$35.1 \quad 168.3$

$34.0 \quad 168.0$

$32.9 \quad 167.8$

$31.8 \quad 167.6$

30.7 167.4

$28.5 \quad 167.1$

27.4167 .0

26.3166 .8

25.2166 .7

$24.1 \quad 166.6$

$21.8 \quad 166.4$

$21.8 \quad 166.4$

$19.6 \quad 166.3$

18.4166 .3

16.1166 .2

$15.0 \quad 166.2$

$13.8 \quad 166.2$

$12.7 \quad 166.2$

10.4166 .3 
$06-18: 08: 19$

$06-18: 08: 24$

$06-18: 08: 29$

$06-18: 08: 34$

$06-18: 08: 39$

$06-18: 08: 44$

$06-18: 08: 49$

$06-18: 08: 5$

06-18:08:59

06-18:09:04

$06-18: 09: 09$

$06-18: 09: 14$

$06-18: 09: 19$

06-18:09:24

$06-18: 09: 29$

$06-18: 09: 34$

$06-18: 09: 39$

$06-18: 09: 44$

$06-18: 09: 49$

06-18:09:54

06-18:09:59

06-18:10:04

$06-18: 10: 09$

$06-18: 10: 14$

$06-18: 10: 19$

$06-18: 10: 24$

$06-18: 10: 29$

$06-18: 10: 34$

$06-18: 10: 39$

$06-18: 10: 44$

$06-18: 10: 49$

$06-18: 10: 54$

$06-18: 10: 59$

06-18:11:04

06-18:11:09

$06-18: 11: 14$

$06-18: 11: 19$

06-18:11:24

$06-18: 11: 29$

$06-18: 11: 34$

06-18:11:39

$06-18: 11: 44$

06-18:11:49

$06-18: 11: 54$

06-18:11:59

06-18:12:04

06-18:12:09

$06-18: 12: 14$

$06-18: 12: 19$

$06-18: 12: 24$ $\begin{array}{rr}-42.98 & 166.78\end{array}$

$-43.21$

$-43.43$

3.65

43.87

44.30

$-44.52$

$-44.95$

$-45.16$

$-45.37$

$-45.58$

$-45.79$

$-46.00$

$-46.21$

$-46.41$

$-46.62$

$-46.82$

$-47.02$

$-47.22$

$-47.42$

$-47.62$

$-47.82$

8.01

$-48.20$

$-48.40$

$-48.59$

$-48.78$

8.96

$-49.15$

$-49.33$

$-49.52$

$-49.70$

50.05

$-50.23$

$-50.40$

$-50.58$

$-50.75$

$-50.92$

$-51.08$

$-51.25$

$-51.41$

$-51.57$

$-51.73$

$-51.89$

$-52.05$

$-52.20$

$-52.35$
167.42

167.75

168.08

168.41

169.08

169.42

169.76

170.10

170.45

170.80

171.15

171.51

172.23

172.59

172.96

173.33

173.70

174.08

174.45

174.84

175.22

175.61

176.00

176.39

176.79

177.59

178.00

178.41

178.82

179.24

180.51

180.94

181.37

181.81

182.25

182.69

183.13

183.58

184.04

184.49

184.95

185.41

185.88
269.12

69.19

269.25

269.32

69.39

269.5

269.58

269.65

269.72

69.78

269.85

269.91

269.97

270.04

270.10

270.16

270.22

270.29

70.35

270.41

270.47

270.53

270.59

.65

70.77

270.82

270.88

770.99

271.11

271.16

271.21

271.27

271.32

271.37

271.43

271.53

271.58

271.63

271.68

271.73

271.77

271.82

271.87

271.96
$98-125.59$

$\begin{array}{ll}-24.81 & -125.89\end{array}$

$-25.62-126.21$

$-26.44-126.54$

$-27.25-126.88$

$\begin{array}{lll}-28.07 & -127.24\end{array}$

$\begin{array}{lll}-28.88 & -127.62\end{array}$

$\begin{array}{ll}-29.68 & -128.01\end{array}$

$\begin{array}{ll}-30.47 & -128.43\end{array}$

$-31.26-128.86$

$\begin{array}{lll}-32.05 & -129.30\end{array}$

$\begin{array}{lll}-32.83 & -129.77\end{array}$

$-33.60-130.25$

$\begin{array}{ll}-34.37 & -130.74\end{array}$

$\begin{array}{ll}-35.12 & -131.26\end{array}$

$\begin{array}{lll}-35.87 & -131.81\end{array}$

$\begin{array}{ll}-36.62 & -132.37\end{array}$

$\begin{array}{ll}-37.35 & -132.96\end{array}$

$-38.07-133.53$

$-38.77-134.03$

$\begin{array}{lll}-39.44 & -134.57\end{array}$

$-40.12-135.12$

$-40.77-135.70$
-41.43

$\begin{array}{lll}-41.43 & -136.30\end{array}$

$-12.08 \quad-136.92$
-42.71

$\begin{array}{ll}-42.71 & -137.57\end{array}$

$\begin{array}{ll}-43.33 & -138.24\end{array}$

$-43.93-138.92$

$\begin{array}{ll}-44.55 & -139.67\end{array}$

$-45.28-140.49$

$-46.01-141.36$

$-46.72$

$\begin{array}{ll}-47.40 & -143.17\end{array}$

$\begin{array}{lll}-47.87 & -143.90\end{array}$

$\begin{array}{ll}-48.07 & -144.26\end{array}$

$\begin{array}{lll}-48.12 & -144.24\end{array}$

$-48.18-144.28$

$-48.23-144.35$

$-48.25-144.43$

$\begin{array}{lll}-48.23 & -144.36\end{array}$

$-48.22-144.34$

$-48.24-144.36$

$\begin{array}{ll}-48.25 & -144.38\end{array}$

$\begin{array}{lll}-48.27 & -144.39\end{array}$

$\begin{array}{lll}-48.27 & -144.40\end{array}$

$\begin{array}{lll}-48.28 & -144.41\end{array}$

$\begin{array}{ll}-48.28 & -144.42\end{array}$

$\begin{array}{ll}-48.28 & -144.41\end{array}$

$-48.29-144.40$

$\begin{array}{ll}5.3 & 166.5 \\ 3.5 & 166.6\end{array}$

3.9166 .7

$\begin{array}{ll}3.7 & 166.8 \\ 3.8 & 166.9\end{array}$

4.3167 .0

5.0 167.

$5.9 \quad 167.2$

6.9167 .4

8.0167 .5

$9.1 \quad 167.7$

$\begin{array}{ll}10.2 & 167.9 \\ 11.3 & 168.1\end{array}$

$11.3 \quad 168.1 \quad-999.00$

$\begin{array}{lll}12.5 & 168.3 & -999.00\end{array}$

$\begin{array}{lll}13.6 & 168.5 & -999.00\end{array}$

$\begin{array}{llll}14.8 & 168.7 & -999.00\end{array}$

$\begin{array}{lll}16.0 & 169.0 & -999.00\end{array}$

$\begin{array}{lll}17.2 & 169.2 & -999.00\end{array}$

$18.3 \quad 169.5 \quad-999.00$

$19.5 \quad 169.6 \quad-999.00$

$20.6 \quad 169.8 \quad-999.00$

$21.7 \quad 170.1 \quad-999.00$

$22.8 \quad 170.3 \quad-999.00$

$23.9 \quad 170.5 \quad-999.00$

$\begin{array}{lll}25.0 & 170.8 & -999.00\end{array}$

$26.1 \quad 171.1 \quad-999.00$

$27.3 \quad 171.4 \quad-999.00$

$28.4 \quad 171.7 \quad-999.00$

$\begin{array}{lll}29.5 & 172.0 & -999.00\end{array}$

$30.8 \quad 172.3 \quad-999.00$

$\begin{array}{lll}32.1 & 172.7 & -999.00\end{array}$

$\begin{array}{lll}33.3 & 173.1 & -999.00 \\ 34.6 & 173.4 & -999.00\end{array}$

$\begin{array}{lll}35.6 & 173.8 & -999.00\end{array}$

$36.2 \quad 173.9 \quad-999.00$

$\begin{array}{lll}36.6 & 173.9 & -999.0\end{array}$

$\begin{array}{lll}37.0 & 173.9 & -999.00 \\ 37.4 & 173.9 & -999.00\end{array}$

$\begin{array}{lll}37.8 & 174.0 & -999.00\end{array}$

$\begin{array}{llll}38.1 & 173.9 & -999.00\end{array}$

$\begin{array}{lll}38.4 & 173.9 & -999.00\end{array}$

$\begin{array}{lll}38.7 & 173.9 & -999.00\end{array}$

$\begin{array}{lll}39.1 & 173.9 & -999.00\end{array}$

$\begin{array}{lll}39.4 & 173.9 & -999.00\end{array}$

$39.8 \quad 173.9 \quad-999.00$

$40.1 \quad 174.0 \quad-999.00$

$40.8 \quad 174.0 \quad-999.00$

$41.1 \quad 173.9 \quad-999.00$ 
06-18:12:29 $06-18: 12: 34$ $06-18: 12: 39$ $06-18: 12: 44$ $06-18: 1$ $06-18: 12: 54$ $06-18: 12: 59$ 06-18:13:04 06-18:13:09 06-18:13:14 $06-18: 13: 19$ $06-18: 13: 24$ 06-18:13:29 $06-18: 13: 34$ $06-18: 13: 39$ $06-18: 13: 44$ $06-18: 13: 49$ $06-18: 13: 54$ $06-18: 13: 59$ $06-18: 14: 04$ $06-18: 14: 09$ 06-18:14:14 $06-18: 14: 19$ 06-18:14:24 $06-18: 14: 29$ $06-18: 14: 34$ $06 \rightarrow 18: 14: 39$ 06-18:14:44 $06-18: 14: 49$ 06-18:14:54 $06-18: 14: 59$ 06-18:15:04 06-18:15:09 $06-18: 15: 14$ $06-18: 15: 19$ 06-18:15:24 $06-18: 15: 29$ $06-18: 15: 34$ 06-18:15:39 $06-18: 15: 44$ $06-18: 15: 49$ 06-18:15:54 06-18:15:59 06-18:16:04 06-18:16:09 $06-18: 16: 14$ $06-18: 16: 19$ 06-18:16:24 $06-18: 16: 29$ $06-18: 16: 34$
186.35

$-53.08$

$-53.22$

$-53.36$

$-53.50$

53.63

$-54.01$

$-54.14$

$-54.26$

$-54.38$

$-54.49$

$-54.61$

$-54.72$

$-54.83$

$-54.94$

$-55.04$

$-55.14$

$-55.24$

$-55.34$

$-55.43$

$-55.53$

$-55.61$

$-55.70$

$-55.78$

$-55.87$

$-55.94$

$-56.02$

$-56.09$

$-56.16$

$-56.23$

$-56.29$

$-56.35$

$-56.41$

$-56.47$

$-56.52$

$-56.57$

$-56.62$

$-56.66$

$-56.70$

$-56.74$

$-56.78$

$-56.81$

$-56.84$

$-56.87$

$-56.89$
272.00

272.05

272.09

272.13

272.18

272.22

272.26

272.30

272.34

272.38

272.42

272.45

272.49

272.52

272.56

272.59

272.63

272.66

272.69

272.73

272.76

272.79

272.81

272.84

272.87

272.90

272.92

272.95

272.97

273.00

273.02

273.04

273.06

273.09

273.11

273.13

273.14

273.18

273.18

273.19
273.21

273.22

273.24

273.25

273.26

273.27

273.28

273.29

273.30

273.31
$-48.28-144.40$

$-48.28-144.39$

$\begin{array}{lll}-48.27 & -144.37\end{array}$

$\begin{array}{ll}48.27 & -144.35\end{array}$

$-48.26-144.33$

$-48.25-144.32$

$-48.25-1+4.32$

$-48.26-144.34$

$-48.25-144.35$

$\begin{array}{ll}-48.27 & -144.35\end{array}$

$-48.26-144.35$

$-48.26-144.34$

$-48.27-144.33$

$\begin{array}{lll}-48.26 & -144.32\end{array}$

$-48.26-144.32$

$\begin{array}{ll}-48.26 & -144.35\end{array}$

$\begin{array}{ll}-48.27 & -144.39\end{array}$

$-48.28-144.41$

$-48.28-144.44$

$\begin{array}{lll}-48.29 & -144.46\end{array}$

$-48.29-144.46$

$\begin{array}{ll}-48.29 & -144.48\end{array}$

$\begin{array}{ll}-48.29 & -144.49\end{array}$

$-48.28-144.50$

$-48.27-144.50$

$-48.26-144.49$

$-48.26-144.49$

$-48.25-144.19$

$-48.23-144.48$

$-48.22-144.46$

$-48.20-144.44$

$\begin{array}{ll}-48.19 & -144.42\end{array}$

$-48.17-144.40$

$-48.16-144.40$

$-48.16-144.43$

$-48.16-144.46$

$-48.16-144.49$

$-48.15-144.51$

$-48.15-144.52$

$-48.16-144.50$

$-48.17-144.50$

$-48.17-144.50$

$-48.16-144.47$

$-48.15-144.46$

$-48.15-144.45$

$-48.14-144.41$

$-48.15-144.42$

$-48.16-144.43$

$\begin{array}{ll}-48.18 & -144.44\end{array}$
$1.5 \quad 173.9$

$41.8 \quad 173.9$

$42.1 \quad 173.9$

42.4
+2.7
+373.9

$43.1 \quad 173.9$

$43 .+173.9$

$43.8 \quad 173.9$

$44.1 \quad 173.9$

$4.4 \quad 173.9$

49.8173 .9

$45.4 \quad 173.9$

$45.7 \quad 173.9$

$46.1 \quad 173.9$

$46.4 \quad 173.9$

$46.8 \quad 173.9$

$47.1 \quad 174.0$

77.5174 .0

$47.8 \quad 174.0$

$48.2 \quad 174.0$

48.5174 .0

$48.9 \quad 174.0$

$49.2 \quad 174.0$

49.5174 .0

$49.8 \quad 174.0$

$50.2 \quad 174.0$

(50.5 174.0

51.1174 .0

$51.4 \quad 174.0$

$51.8 \quad 174.0$

$52.1 \quad 174.0$

$52.4 \quad 174.0$

$52.7 \quad 174.0$

53.1174 .0

$53.4 \quad 174.1$

$53.8 \quad 174.1$

$54.1 \quad 174.1$

$54.5 \quad 174.1$

$54.8 \quad 174.1$

$55.1 \quad 174.1$

$55.4 \quad 174.1$

$55.8 \quad 174.1$

$56.4 \quad 174.0$

$57.1 \quad 174.0$

57.4174 .0

$57.8 \quad 174.0$

99.00

$-999.00$

$-999.00$

$-999.00$

$-999.00$

$-999.00$

$-999.00$

$-999.00$

-999.00
-999.00

$-999.00$

$-999.00$

-999.00
-999.00

$-999.00$

$-999.00$

$-999.00$

$-999.00$

$-999.00$

-999.00
-999.00

$-999.00$

$-999.00$

$-999.00$

$-999.00$

$-999.00$

$-999.00$

$-999.00$

$-999.00$

$-999.00$

-999.00
-999.00

$-999.00$

$-999.00$

$-999.00$

$-999.00$

$-999.00$

$-999.00$

$-999.00$

$-999.00$

$-999.00$

-999.00
-999.00

$-999.00$

$-999.00$ 


\begin{tabular}{|c|c|c|c|c|c|c|c|c|c|c|}
\hline $06-18: 16: 39$ & -56.91 & 213.46 & 273.31 & $-48 \cdot 19$ & -144.44 & 58.1 & 174.0 & -999.00 & -999.00 & -999.00 \\
\hline $06-18: 16: 44$ & -56.93 & 214.05 & 273.32 & $-48 \cdot 20$ & $-1+4 .+3$ & 58.4 & 174.0 & -999.00 & -999.00 & -999.00 \\
\hline $06-18: 16: 49$ & -56.94 & 214.64 & 273.33 & -48.21 & $-1+4.3$ & 58.8 & 174.0 & -999.00 & -999.00 & -999.00 \\
\hline $06-18: 16: 54$ & -56.96 & 215.24 & 273.33 & -48.21 & -144.43 & 59.1 & 174.0 & -999.00 & -999.00 & -999.00 \\
\hline $06-18: 16: 59$ & -56.96 & 215.83 & 273.33 & -48.22 & $-1+4 .+2$ & 59.5 & 174.0 & -999.00 & -999.00 & -999.00 \\
\hline $06-18: 17: 04$ & -56.97 & 216.42 & 273.34 & -48.22 & $-1+4.41$ & 59.8 & 174.0 & -999.00 & -999.00 & -999.00 \\
\hline $06-18: 17: 09$ & -56.97 & 217.01 & 273.34 & -48.22 & -144.39 & 60.1 & 174.0 & -999.00 & -999.00 & -999.00 \\
\hline $06-18: 17: 14$ & -56.97 & 217.61 & 273.34 & -48.22 & -144.38 & 60.4 & 174.0 & -999.00 & -999.00 & -999.00 \\
\hline $06-18: 17: 19$ & -56.97 & 218.20 & 273.34 & -48.22 & $-1+4.36$ & 60.8 & 173.9 & -999.00 & -999.00 & -999.00 \\
\hline $06-18: 17: 24$ & -56.96 & 218.79 & 273.34 & -48.22 & -144.33 & 61.1 & 173.9 & -999.00 & -999.00 & -999.00 \\
\hline $06-18: 17: 29$ & -56.95 & 219.38 & 273.34 & -48.24 & -144.35 & 61.4 & 173.9 & -999.00 & -999.00 & -999.00 \\
\hline $06-18: 17: 34$ & -56.94 & 219.97 & 273.34 & -48.25 & $-1+4.36$ & 61.8 & 173.9 & -999.00 & -999.00 & -999.00 \\
\hline $06-18: 1$ & -56.92 & 220.57 & 273.33 & -48.28 & $-1+1.37$ & 62.1 & 173.9 & -999.00 & -999.00 & -999.00 \\
\hline $06-18: 17: 44$ & -56.91 & 221.16 & 273.33 & -+8.28 & -141.39 & 62.5 & 173.9 & -999.00 & -999.00 & -999.00 \\
\hline $06-18: 17: 49$ & -56.89 & 221.75 & 273.32 & -48.30 & -144.39 & 62.8 & 173.9 & -999.00 & -999.00 & -999.00 \\
\hline $06-18: 17: 54$ & -56.86 & 222.34 & 273.32 & $-48 \cdot 31$ & -144.39 & 63.2 & 173.9 & -999.00 & -999.00 & -999.00 \\
\hline $06-18: 17: 59$ & -56.83 & 222.93 & 273.32 & $-48,32$ & $-1+4.38$ & 63.5 & 173.9 & -999.00 & -999.00 & -999.00 \\
\hline $06-18: 18: 04$ & -56.80 & 223.51 & 273.30 & -48.32 & -144.38 & 03.8 & 173.9 & -999.00 & -999.00 & -999.00 \\
\hline $06-18: 18: 09$ & -56.77 & 224.10 & 273.30 & -48.30 & -144.39 & $6+.2$ & 173.9 & -999.00 & -999.00 & -999.00 \\
\hline $06-18: 18: 14$ & -56.73 & 1.68 & 273.29 & -48.29 & $-1+4.39$ & 64.5 & 173.9 & -999.00 & -999.00 & -999.00 \\
\hline $06-18: 18: 19$ & -56.69 & 225.27 & 273.28 & -48.27 & -144.38 & 64.8 & 173.9 & -999.00 & -999.00 & -999.00 \\
\hline $06-18: 18: 24$ & -56.65 & 225.85 & 273.27 & -48.26 & $-1+4.37$ & 65.1 & 173.9 & -999.00 & -999.00 & -999.00 \\
\hline $06-18: 18: 29$ & -56.61 & $226 .+3$ & 273.26 & -48.24 & -144.37 & 65.5 & 173.9 & -999.00 & -999.00 & -999.00 \\
\hline $06-18: 18: 34$ & -56.56 & 227.01 & 273.24 & -48.22 & -144.35 & 05.8 & 173.9 & -999.00 & -999.00 & -999.00 \\
\hline $06-18: 18: 39$ & -56.51 & .59 & 273.23 & -48.21 & $-1+4.34$ & 66.1 & 173.9 & -999.00 & -999.00 & -999.00 \\
\hline $06-18: 18: 42$ & -56.46 & 228.17 & 273.22 & -48.23 & $-1+4.37$ & 66.4 & 173.9 & -999.00 & -999.00 & -999.00 \\
\hline $06-18: 18: 49$ & -56.40 & 228.74 & 273.20 & -48.24 & -144.39 & 66.8 & 174.0 & -999.00 & -999.00 & -999.00 \\
\hline $06-18: 18: 54$ & -56.34 & 229.32 & 273.19 & -48.25 & $-1+4.1$ & 67.2 & 17.4 .0 & -999.00 & -999.00 & -999.00 \\
\hline $06-18: 18: 59$ & -56.28 & .89 & 273.17 & -48.26 & $-1+4.42$ & 67.5 & $17 t .0$ & -999.00 & -999.00 & -999.00 \\
\hline $06-18: 19: 04$ & -56.21 & 230.16 & 273.15 & -48.27 & $-1+4.45$ & 67.8 & 174.0 & -999.00 & -999.00 & -999.00 \\
\hline $06-18: 19: 09$ & -56.14 & 231.03 & 273.14 & -48.28 & -144.45 & 68.2 & 174.0 & -999.00 & -999.00 & -999.00 \\
\hline $06-18: 19: 14$ & -56.07 & 231.59 & 273.12 & -48.29 & -144.46 & 68.5 & 174.0 & -999.00 & -999.00 & -999.00 \\
\hline $06-18: 19: 19$ & -56.00 & 232.15 & 273.10 & -48.30 & -144.47 & 68.9 & 174.0 & -999.00 & -999.00 & -999.00 \\
\hline $06-18: 19: 24$ & -55.92 & 232.72 & 273.08 & -48.31 & $-1+4.47$ & 69.2 & 174.0 & -999.00 & -999.00 & -999.00 \\
\hline $06-18: 19: 29$ & -55.85 & 233.27 & 273.06 & $-48 \cdot 32$ & $-144 \cdot+7$ & 69.6 & 174.0 & -999.00 & -999.00 & -999.00 \\
\hline $06-18: 19: 34$ & -55.76 & 233.83 & 273.04 & -48.31 & $-1+4.48$ & 69.9 & 174.0 & -999.00 & -999.00 & -999.00 \\
\hline $06-18: 19: 39$ & -55.68 & 234.38 & 273.01 & -48.32 & $-144 \cdot+8$ & 70.2 & 174.0 & -999.00 & -999.00 & -999.00 \\
\hline $06-18: 19: 44$ & -55.59 & 234.93 & 272.99 & -48.32 & -144.48 & 70.6 & 174.0 & -999.00 & -999.00 & -999.00 \\
\hline $06-18: 19: 49$ & -55.50 & 235.48 & 272.97 & $-48 \cdot 33$ & -144.47 & 70.9 & 174.0 & -999.00 & -999.00 & -999.00 \\
\hline $06-18: 19: 54$ & -55.41 & 236.03 & 272.94 & -48.33 & -144.46 & 71.2 & 174.0 & -999.00 & -999.00 & -999.00 \\
\hline $06-18: 19: 59$ & -55.32 & 236.57 & 272.92 & -48.33 & -144.45 & 71.6 & 174.0 & -999.00 & -999.00 & -999.00 \\
\hline
\end{tabular}


$06-18: 19: 04$ 06-18:19:09 $06-18: 19: 14$ $06-18: 19: 19$ 06-18:19:24 $06-18: 19: 29$ $06-18: 19: 34$ $06-18: 19: 39$ $06-18: 19: 44$ $06-18: 19: 49$ $06-18: 19: 54$ $06-18: 19: 59$ 06-18:20:04 $06-18: 20: 09$ $06-18: 20: 14$ $06-18: 20: 19$ 06-18:20:24 $06-18: 20: 29$ $06-18: 20: 34$ $06-18: 20: 39$ 06-18:20:44 06-18:20:49 $06-18: 20: 54$ $06-18: 20: 59$ $06-18: 21: 04$ 06-18:21:09 06-18:21:14 06-18:21:19 $06-18: 21: 24$ $06-18: 21: 29$ $06-18: 21: 34$ $06-18: 21: 39$ $06-18: 21: 44$ 06-18:21:49 $06-18: 21: 54$ $06-18: 21: 59$ 06-18:22:04 $06-18: 22: 09$ 06-18:22:14 $06-18: 22: 19$ $06-18: 22: 24$ $06-18: 22: 29$ 06-18:22:34 06-18:22:39 06-18:22:44 06-18:22:49 $06-18: 22: 54$ 06-18:22:59 06-18:23:04
$-56.21$ $-56.14$ $-56.07$ $-56.00$ $-55.92$

$-55.85$ $-55.76$

$-55.68$

$-55.59$

$-55.50$

$-55.41$

$-55.32$

$-55.22$

$-55.12$

$-55.02$

$-54.91$

54.80

$-54.69$

$-54.58$

-54.47
-54.35

$-54.23$

$-54.11$

$-53.98$

$-53.85$

$-53.73$

$-53.59$

$-53.46$

-53.33
-53.19

$-53.05$

$-52.91$

$-52.76$

$-52.61$

$-52.47$

$-52.32$

$-52.16$

$-52.01$

$-51.85$

$-51.69$

$-51.53$

$-51.37$

$-51.21$

$-51.04$

$-50.87$

$-50.70$

$-50.53$

$-50.36$

$-50.18$
230.46 231.03 231.59 232.15 232.72 233.27

233.83 234.38 234.93 235.48 236.03 236.57 237.11 237.65 238.19 238.72 239.25 239.77 240.30 240.82 241.33 241.85 242.36 242.87 243.37 243.87 244.37 244.87 245.36 245.85 246.33 246.81 247.29 247.77 248.24 248.71 249.17 249.63 250.09 250.55 251.00 251.45 251.89 252.33 252.77 253.21 253.64
254.07 254.49
273.15 273.14 273.12 273.10 273.08 273.06 273.04 273.01 272.99 272.97 272.94 272.92 272.89 272.86 272.84 272.81 272.78 272.75 272.72 272.68 272.65 272.62 272.59 272.55 272.52 272.48 272.44 272.41 272.37 272.33 272.29 272.25 272.21 272.17 272.13 272.08 272.04 272.00 271.95 271.91 271.86 271.81 271.77 271.72 271.67 271.62 271.57 271.52 271.47
$-48.27-144.45$ $-48.28-144.45$ $\begin{array}{ll}-48.29 & -144.46\end{array}$ $-48.30-144.47$ $-48.31-144.47$ $-48.32-144.47$

$-48.31-144.48$ $-48.32-144.48$ $-48.32-144.48$ $-48.33-144.47$ $\begin{array}{ll}-48.33 & -144.46\end{array}$ $-48.33-144.45$ $-48.33-144.44$ $-48.33-144.42$ $-48.33-144.41$ $-48.32-144.39$ $-48.31-144.38$

$\begin{array}{ll}-48.30 & -144.36\end{array}$

$\begin{array}{ll}-48.29 & -144.35\end{array}$

$-48.28-144.33$

$-48.27-144.31$

$-48.26-144.30$

$\begin{array}{lll}-48.27 & -144.31\end{array}$

$-48.28-144.33$

$-48.28-144.35$

$-48.28-144.37$ $\begin{array}{ll}-48.28 & -144.38\end{array}$

$-48.28-144.40$

$-48.28-144.41$

$-48.28-144.41$

$-48.27-144.42$

$-48.27-144.42$

$-48.27-144.43$

$-48.27-144.43$

$-48.27-144.44$
-48.27

$-48.27-144.45$

$-48.27-144.44$

$-48.27-144.45$

$-48.27-144.44$

$-48.27-144.45$

$-48.26-144.44$

$-48.26-144.44$

$-48.26-144.43$

$-48.25-144.43$

$-144.43$

$-48.24$

$-48.23-144.41$

$-48.22-144.39$

$67.8 \quad 174.0 \quad-999.00$ $68.2 \quad 174.0 \quad-999.00$ $\begin{array}{lll}68.5 & 174.0 & -999.00\end{array}$ $\begin{array}{lll}68.9 & 174.0 & -999.00\end{array}$ $69.2 \quad 174.0 \quad-999.00$ $69.6 \quad 174.0 \quad-999.00$ $69.9 \quad 174.0 \quad-999.00$

$70.2 \quad 174.0 \quad-999.00$

$70.6 \quad 174.0 \quad-999.00$

$70.9 \quad 174.0 \quad-999.00$

$71.2 \quad 174.0 \quad-999.00$

$71.6 \quad 174.0 \quad-999.00$

$71.9 \quad 174.0 \quad-999.00$

$72.2 \quad 173.9 \quad-999.00$

$\begin{array}{lll}72.5 & 173.9 & -999.00\end{array}$

$72.9 \quad 173.9 \quad-999.00$

$73.2 \quad 173.9 \quad-999.00$

$\begin{array}{lll}73.5 & 173.9 & -999.00\end{array}$

$\begin{array}{lll}73.8 & 173.9 & -999.00\end{array}$

$\begin{array}{lll}74.1 & 173.9 & -999.00\end{array}$

$74.5 \quad 173.9 \quad-999.00$

$74.8 \quad 173.9 \quad-999.00$

$75.1 \quad 173.9 \quad-999.00$

$\begin{array}{lll}75.5 & 173.9 & -999.00\end{array}$

$\begin{array}{lll}75.8 & 173.9 & -999.00\end{array}$

$76.2 \quad 173.9 \quad-999.00$

$\begin{array}{lll}76.5 & 173.9 & -999.00\end{array}$

$76.8 \quad 174.0 \quad-999.00$

$77.2 \quad 174.0 \quad-999.00$

$77.5 \quad 174.0-999.00$

$77.9 \quad 174.0 \quad-999.00$

$78.2 \quad 174.0 \quad-999.00$

$78.5 \quad 174.0 \quad-999.00$

$78.9 \quad 174.0 \quad-999.00$

$79.2 \quad 174.0-999.00$

$79.5 \quad 174.0 \quad-999.00$

$79.9 \quad 174.0 \quad-999.00$

$80.2 \quad 174.0 \quad-999.00$

$80.5 \quad 174.0 \quad-999.00$

$80.9 \quad 174.0 \quad-999.00$

$81.2 \quad 174.0 \quad-999.00$

$81.5 \quad 174.0 \quad-999.00$

$81.9 \quad 174.0 \quad-999.00$

$82.2 \quad 174.0 \quad-999.00$

$82.5 \quad 174.0 \quad-999.00$

$82.8 \quad 174.0-999.00$

$83.2 \quad 174.0 \quad-999.00$ 
271.42

271.37 271.32 271.26

271.21

271.16

271.10

271.05
270.99

270.94

270.88

270.82

270.77

270.71

270.65

270.59

270.47

270.41

270.35

270.29

270.23

270.17

270.11

269.98

269.92

269.86

269.79

269.73

269.67

269.60

269.54

269.47

269.41

269.34

269.28

269.21

269.14
269.08

269.01

268.94

268.88

268.81

268.74 268.67

268.60
$-48.21-144.39$

$-48.21-144.38$ $-48.20-144.37$ $-48.20-144.36$ $48.19-144.36$ $-48.19-144.36$ $-48.19-144.36$ $-48.19-144.37$ $-48.19-144.38$ $\begin{array}{ll}-48.19 & -144.37\end{array}$ $-48.19-144.37$ $-48.19-144.38$ $-48.19-144.39$ $-48.19-144.39$ $-48.19-144.38$ $-48.19-144.38$ $-48.18-144.37$ $48.18-144.37$ $-48.18-144.37$ $-48.18-144.38$ $-48.18-144.39$ $-48.18-144.40$ $-48.18-144.40$ $-48.18-144.40$ $-48.18-144.41$ $-48.18-144.41$ $-48.18-144.42$ $-48.19-144.42$ $-48.19-144.43$ $-48.19-144.44$ $-48.19-144.45$ $\begin{array}{lll}-48.19 & -144.46\end{array}$ $-48.19-144.46$ $-48.20-144.48$ $-48.20-144.49$
-48.21 $-48.21-144.50$ $-48.21-144.52$ $-48.21-144.53$ $-48.21-144.54$ $-48.22-144.54$ $-48.22-144.58$ $-48.24-144.59$
-48.24 $-48.24-144.60$ $-48.26-144.61$ $-48.26-144.63$ $-48.27-144.63$ $-48.26-144.61$ $-48.26-144.59$

$\begin{array}{lllll}84.1 & 174.0 & -999.00 & -999.00 & -999.00 \\ 84.5 & 174.0 & -999.00 & -999.00 & -999.00 \\ 84.8 & 174.0 & -999.00 & -999.00 & -999.00 \\ 85.1 & 174.0 & -999.00 & -999.00 & -999.00 \\ 85.5 & 174.0 & -999.00 & -999.00 & -999.00 \\ 85.8 & 174.0 & -999.00 & -999.00 & -999.00 \\ 86.1 & 174.0 & -999.00 & -999.00 & -999.00 \\ 86.5 & 174.0 & -999.00 & -999.00 & -999.00 \\ 86.8 & 174.0 & -999.00 & -999.00 & -999.00 \\ 87.1 & 174.0 & -999.00 & -999.00 & -999.00 \\ 87.5 & 174.0 & -999.00 & -999.00 & -999.00 \\ 87.8 & 174.0 & -999.00 & -999.00 & -999.00 \\ 88.1 & 174.0 & -999.00 & -999.00 & -999.00 \\ 88.5 & 174.0 & -999.00 & -999.00 & -999.00 \\ 88.8 & 174.0 & -999.00 & -999.00 & -999.00 \\ 89.1 & 174.0 & -999.00 & -999.00 & -999.00 \\ 89.5 & 174.0 & -999.00 & -999.00 & -999.00 \\ 89.8 & 174.0 & -999.00 & -999.00 & -999.00 \\ 90.1 & 174.0 & -999.00 & -999.00 & -999.00 \\ 90.5 & 174.0 & -999.00 & -999.00 & -999.00 \\ 90.8 & 174.0 & -999.00 & -999.00 & -999.00 \\ 91.1 & 174.0 & -999.00 & -999.00 & -999.00 \\ 91.5 & 174.0 & -999.00 & -999.00 & -999.00 \\ 91.8 & 174.0 & -999.00 & -999.00 & -999.00 \\ 92.2 & 174.0 & -999.00 & -999.00 & -999.00 \\ 92.5 & 174.0 & -999.00 & -999.00 & -999.00 \\ 92.8 & 174.0 & -999.00 & -999.00 & -999.00 \\ 93.2 & 174.0 & -999.00 & -999.00 & -999.00 \\ 93.5 & 174.0 & -999.00 & -999.00 & -999.00 \\ 93.8 & 174.0 & -999.00 & -999.00 & -999.00 \\ 94.2 & 174.0 & -999.00 & -999.00 & -999.00 \\ 94.5 & 174.0 & -999.00 & -999.00 & -999.00 \\ 94.9 & 174.0 & -999.00 & -999.00 & -999.00 \\ 95.2 & 174.0 & -999.00 & -999.00 & -999.00 \\ 95.5 & 174.0 & -999.00 & -999.00 & -999.00 \\ 95.9 & 174.1 & -999.00 & -999.00 & -999.00 \\ 96.2 & 174.1 & -999.00 & -999.00 & -999.00 \\ 96.6 & 174.1 & -999.00 & -999.00 & -999.00 \\ 96.9 & 174.1 & -999.00 & -999.00 & -999.00 \\ 97.3 & 174.1 & -999.00 & -999.00 & -999.00 \\ 97.6 & 174.1 & -999.00 & -999.00 & -999.00 \\ 97.9 & 174.1 & -999.00 & -999.00 & -999.00 \\ 98.3 & 174.1 & -999.00 & -999.00 & -999.00 \\ 98.6 & 174.1 & -999.00 & -999.00 & -999.00 \\ 99.0 & 174.1 & -999.00 & -999.00 & -999.00 \\ 99.3 & 174.1 & -999.00 & -999.00 & -999.00 \\ 99.7 & 174.1 & -999.00 & -999.00 & -999.00 \\ 100.0 & 174.1 & -999.00 & -999.00 & -999.00 \\ 100.3 & 174.1 & -999.00 & -999.00 & -999.00 \\ 100.6 & 174.1 & -999.00 & -999.00 & -999.00\end{array}$

268.54

268.47

$\begin{array}{lll}-40.18 & 271.43 & 268.54 \\ -39.94 & 271.72 & 268.47\end{array}$

272.01 
$06-18: 27: 19$ 06-18:27:24

$06-18: 27: 29$

$06-18: 27: 34$

$06-18: 27: 39$

$06-18: 27: 44$

$06-18: 27: 49$

$06-18: 27: 54$

$06-18: 27: 59$

$06-18: 28: 04$

$06-18: 28: 09$

$06-18: 28: 14$

$06-18: 28: 19$

$06-18: 28: 24$

$06-18: 28: 29$

$06-18: 28: 34$

$06-18: 28: 39$

$06-18: 28: 44$

$06-18: 28: 49$

$06-18: 28: 54$

$06-18: 28: 59$

06-18:29:04

$06-18: 29: 09$
$-39.47$ $-39.23$

$-39.00$

$-38.76$

$-38.52$

$-38.28$

$-38.04$

$-37.79$

$-37.55$

$-37.31$

$-36.82$

$-36.57$

$-36.33$

$-36.08$

$-35.59$

$-35.34$

$-35.09$

-34.84
-34.59

$-34.34$

$-34.09$

$-33.83$

$-33.58$

$-33.33$

$-32.82$

$-32.82$

$-32.31$

$-32.05$

$-31.80$

-31.54
-31.28

-31.28
-31.02

$-30.77$

$-30.51$

$-30.25$

$-29.99$

$-29.21$

$-28.94$

$-28.68$

$-28.42$

$-28.16$

$-27.89$

$-27.63$

$-27.37$

$-27.10$
272.29 272.58

72.86

273.4

273.69

273.96

274.24

274.51

74.77

275.04

275.30

275.57

275.83

76.09

276.34

276.60

276.85

277.10

277.36

277.60

77.85

278.10

278.34

278.58

278.82

279.06

79.30

279.77

280.01

280.24

280.47

280.70

280.92

281.15

281.38

281.60

281.82

282.04

282.26

282.48

282.70

282.92

283.13

283.35

283.56

283.77

283.98
284.19
268.33 268.20

268.13

268.06

267.99

267.92

267.85

267.78

267.71

267.64

267.58

267.51

267.44

267.37

267.30

267.23

267.16

267.09

267.02

266.96

266.89

266.82

266.75

266.68

266.61

266.54

266.48

266.41

266.34

266.27

266.21

266.14

266.0

266.01

265 .87

265.81

265.74

265.68

265.61

265.55

265.48

265.42

265.35

265.29

265.23

265.17

265.10

265.04

$-48.26-144.56$

-48.26
-48.26

$-48.26$

$-48.26$

$-48.25$

$-48.26$

-48.26
-48.26

$-48.26$

$-48.27$

$-48.28$

$-48.28$

$-48.29$

$-48.32$

$-48.34$

$-48.36$

$-48.36$

-48.36
-48.36

$-48.34$

$-48.34$

$-48.33$

$-48.32$

$-48.32$

$-48.31$

$-48.31$

$-48.30$

$-48.31$

$-48.30$

$-48.31$

$-48.31$

$-48.31$

$-48.33$

$-48.32$

$-48 \cdot 31$

$-48.28$

$-48.28$

$-48.26$

$-48.25$

$-48.25$

$-48.23$

$-48.23$

$-48.23$

$-48.22$

$\begin{array}{rrr}144.56 & 101.0 & 174.1\end{array}$

$-144.53$

$101.3 \quad 174.1$

-999.00
-999.00

$-999.00$

$-999.00$

$102.0 \quad 174.1$

$-144.49-102.6 \quad 174.0$

144.48

$102.6 \quad 174.0$

$-999.00$

$\begin{array}{llll}-144.48 & 103.3 & 174.0 & -999.00\end{array}$

$\begin{array}{lllll}-144.47 & 103.6 & 174.0 & -999.00\end{array}$

$\begin{array}{llll}-144.47 & 103.9 & 174.0 & -999.00\end{array}$

$\begin{array}{rrrr}144.49 & 104.3 & 174.0 & -999.00 \\ -144.48 & 104.6 & 174.0 & -999.00\end{array}$

$\begin{array}{llll}-144.49 & 105.0 & 174.0 & -999.00\end{array}$

$\begin{array}{rrrr}-144.49 & 105.3 & 174.0 & -999.00 \\ -144.51 & 105.6 & 174.0 & -999.00\end{array}$

$\begin{array}{llll}-144.51 & 106.0 & 174.0 & -999.00\end{array}$

$\begin{array}{llll}-144.52 & 106.4 & 174.0 & -999.00\end{array}$

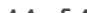

$-999.00$

$\begin{array}{rrrr}-144.51 & 107.4 & 174.0 & -999.00\end{array}$

$\begin{array}{llll}-144.48 & 107.7 & 174.0 & -999.00\end{array}$

$\begin{array}{llll}-144.48 & 108.0 & 174.0 & -999.00\end{array}$

$\begin{array}{llll}-144.47 & 108.3 & 174.0 & -999.00\end{array}$

$-144.45$

$109.0 \quad 174.0$

$-999.00$

-999.00
-999.00

-999.00
-999.00

$\begin{array}{rrrr}-144.45 & 109.6 & 174.0 & -999.00 \\ -144.45 & 110.0 & 174.0 & -999.00\end{array}$

144.46

$-144.47$

$-144.48$

$-144.49$

$-144.51$

$-144.53$

$-144.56$

$-144.57$

$-144.57$

$-144.56$

$-144.51$

$-144.49$

$-144.48$

$-144.46$

$-144.44$

$-144.44$

$-144.4$

$110.3 \quad 174.0 \quad-999.00$

$110.6 \quad 174.0 \quad-999.00$

$111.0 \quad 174.0 \quad-999.00$

$111.3 \quad 174.0 \quad-999.00$

$112.0 \quad 174.0 \quad-999.00$

$\begin{array}{lll}112.3 & 174.0 & -999.00\end{array}$

$112.7 \quad 174.1 \quad-999.00$

$113.0 \quad 174.1 \quad-999.00$

$\begin{array}{lll}113.4 & 174.1 & -999.00 \\ 113.7 & 174.1 & -999.00\end{array}$

$114.0 \quad 174.0 \quad-999.00$

$114.3 \quad 174.0 \quad-999.00$

$114.6 \quad 174.0 \quad-999.00$

$115.0 \quad 174.0 \quad-999.00$

$115.3 \quad 174.0$

$115.6 \quad 174.0$

$-999.00$

$-999.00$

$-999.00$

116.3174 .0

116.6174 .0

$\begin{array}{llll}-144.43 & 116.9 & 174.0 & -999.00\end{array}$

$\begin{array}{llll}-144.44 & 117.3 & 174.0 & -999.00\end{array}$ 
MET

$07-18: 11: 39$ $07-18: 11: 44$ $07-18: 11: 49$ $07-18: 11: 54$ $07-18: 11: 59$ $07-18: 12: 04$ $07-18: 12: 09$ $07-18: 12: 14$ $07-18: 12: 19$ $07-18: 12: 24$ $07-18: 12: 29$ $07-18: 12: 34$ $07-18: 12: 39$ $07-18: 12: 44$ $07-18: 12: 49$ $07-18: 12: 54$ $07-18: 12: 59$ $07-18: 13: 04$ 07-18:13:09 $07-18: 13: 14$ $07-18: 13: 19$ $07-18: 13: 24$ 07-18:13:29 $07-18: 13: 34$ $07-18: 13: 39$ $07-18: 13: 44$ $07-18: 13: 49$ $07-18: 13: 54$ 07-18:13:59 07-18:14:04 $07-18: 14: 09$ $07-18: 14: 14$ $07-18: 14: 19$ $07-18: 14: 24$ $07-18: 14: 29$ $07-18: 14: 34$ $07-18: 14: 39$ $07-18: 14: 44$ $07-18: 14: 49$ $07-18: 14: 54$ $07-18: 14: 59$ $07-18: 15: 04$ $07-18: 15: 09$ $07-18: 15: 14$ $07-18: 15: 19$ $07-18: 15: 24$

$07-18: 15: 29$

$07-18: 15: 34$

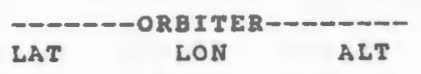

$-56.94$ $-56.95$ $-56.96$ $-56.96$ $-56.97$ $-56.96$

$-56.96$

$-56.95$

$-56.94$

$-56.92$

$-56.91$

$-56.89$

$-56.86$

$-56.84$

$-56.81$

$-56.77$

$-56.74$

$-56.70$

$-56.66$

$-56.62$

$-56.57$

$-56.52$

$-56.47$

$-56.41$

$-56.35$

$-56.29$

$-56.23$

$-56.16$

$-56.09$

$-56.02$

$-55.94$

$-55.86$

$-55.78$

$-55.70$

$-55.61$

$-55.52$

$-55.43$

$-55.34$

$-55.24$

$-55.14$

$-55.04$

$-54.94$

$-54.83$

$-54.72$

$-54.61$

$-54.49$

$-54.38$

$-54.26$
71.33

210.67 $211.85 \quad 271.33$ $212.44 \quad 271.32$ $213.04 \quad 271.32$ $213.63 \quad 271.31$ $214.22 \quad 271.31$ $214.81 \quad 271.30$ $215.41 \quad 271.29$ $216.00 \quad 271.28$ $216.59 \quad 271.27$ $217.18 \quad 271.26$ 217.77271 .25 $\begin{array}{ll}218.36 & 271.24\end{array}$ $218.95 \quad 271.23$ $219.53 \quad 271.22$ $220.70 \quad 271.19$ $221.29 \quad 271.17$ $221.87 \quad 271.15$ $222.45 \quad 271.14$ $223.03 \quad 271.12$ $223.61 \quad 271.10$ $224.18 \quad 271.08$ $224.76 \quad 271.06$ $225.33 \quad 271.04$ $225.90 \quad 271.02$ $226.47 \quad 270.99$ $227.04 \quad 270.97$ $227.60 \quad 270.95$ $228.16 \quad 270.92$ $228.72 \quad 270.90$ $229.28 \quad 270.87$ $229.83 \quad 270.84$ $230.38 \quad 270.81$ $230.93 \quad 270.79$ $\begin{array}{ll}231.48 & 270.76\end{array}$ $232.03 \quad 270.73$ $232.57 \quad 270.70$ $233.11 \quad 270.66$ $233.64 \quad 270.63$ $234.18 \quad 270.60$ $234.71 \quad 270.57$ $235.23 \quad 270.53$ $235.76 \quad 270.50$ $236.28 \quad 270.46$ $236.80 \quad 270.42$ $237.31 \quad 270.39$ $211.26 \quad 271.33$ $220.12 \quad 271.20$

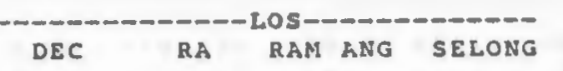

RA RAM ANG SELONG

$\begin{array}{ll}-9.08 & -114.88\end{array}$

$\begin{array}{lll}-8.78 & -114.67\end{array}$

$-8.48-114.45$

$\begin{array}{lll}-8.18 & -114.23\end{array}$

$\begin{array}{rr}-7.87 & -114.01 \\ -7.57 & -113.79\end{array}$

$\begin{array}{ll}-7.26 & -113.57\end{array}$

$-6.96-113.35$

$-6.66-113.13$

$-6.36-112.90$

$-6.05-112.68$

$\begin{array}{ll}-5.75 & -112.46\end{array}$

$-5 .+4 \quad-112.23$

$-5.12-112.01$

$\begin{array}{ll}-4.82 & -111.79\end{array}$

$\begin{array}{ll}-+.51 & -111.57\end{array}$

$-4.19-111.34$

$-3.88 \quad-111.11$

$-3.56-110.89$

$-3.25-110.66$

$-2.93-110.13$

$\begin{array}{lll}-2.61 & -110.20\end{array}$

$\begin{array}{ll}-2.29 & -109.98\end{array}$

$\begin{array}{ll}-1.96 & -109.75\end{array}$

$\begin{array}{ll}-1.64 & -109.53\end{array}$

$\begin{array}{ll}-1.32 & -109.29\end{array}$

$-1.00-109.06$

$\begin{array}{lll}-0.68 & -108.83\end{array}$

$-0.36-108.59$

$\begin{array}{lll}-0.03 & -108.36\end{array}$

$0.29-108.14$

$0.62-107.90$

$0.87-107.72$

$1.09-107.57$

$1.31-107.41$

$1.53-107.25$

$1.74-107.09$

$1.96-106.93$

$2.17-106.77$

$2.39-106.61$

$2.61-106.44$

$2.83-106.28$

$3.06-106.12$

$3.29-105.96$

$3.51-105.80$

$3.74-105.63$

$3.98-105.46$

$4.20-105.29$

LAT LON TAN HT

$\begin{array}{lllll}0.5 & 160.1 & -999.00 & -999.00 & -999.00\end{array}$

$\begin{array}{lllll}0.5 & 159.9 & -999.00 & -999.00 & -999.00\end{array}$

$\begin{array}{lllll}0.5 & 159.7 & -999.00 & -999.00 & -999.00\end{array}$

$\begin{array}{lllll}1 & 159.6 & -999.00 & -999.00 & -999.00\end{array}$

$\begin{array}{lllll}10.3 & 159.2 & -999.00 & -999.00 & -999.00\end{array}$

$\begin{array}{lllll}0.3 & 159.0 & -999.00 & -999.00 & -999.00\end{array}$

$\begin{array}{lllll}0.3 & 158.9 & -999.00 & -999.00 & -999.00\end{array}$

$10.2 \quad 158.7 \quad-999.00 \quad-999.00 \quad-999.00$

$\begin{array}{lllll}10.1 & 158.3 & -999.00 & -999.00 & -999.00\end{array}$

$\begin{array}{lllll}10.1 & 158.2 & -999.00 & -999.00 & -999.00\end{array}$

$\begin{array}{lllll}0.0 & 158.0 & -999.00 & -999.00 & -999.00\end{array}$

$\begin{array}{lllll}0.0 & 157.8 & -999.00 & -999.00 & -999.00\end{array}$

$\begin{array}{lllll}9.9 & 157.6 & -999.00 & -999.00 & -999.00\end{array}$

$\begin{array}{lllll}.9 & 157.4 & -999.00 & -999.00 & -999.00\end{array}$

\begin{tabular}{llllll}
\hline .8 & 157.3 & -999.00 & -999.00 & -999.00
\end{tabular}

$8 \quad 157.1 \quad-999.00-999.00-999.00$

$\begin{array}{lllll}.7 & 156.9 & -999.00 & -999.00 & -999.00\end{array}$

$\begin{array}{lllll}9.6 & 156.7 & -999.00 & -999.00 & -999.00\end{array}$

$\begin{array}{lllll}9.6 & 156.5 & -999.00 & -999.00 & -999.00\end{array}$

$\begin{array}{lllll}9 & 156.1 & -999.00 & -999.00 & -999.00\end{array}$

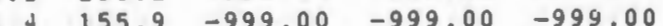

$\begin{array}{lllll}.3 & 155.7 & -999.00 & -999.00 & -999.00\end{array}$

$\begin{array}{lllll}.3 & 155.5 & -999.00 & -999.00 & -999.00\end{array}$

$\begin{array}{lllll}9.2 & 155.3 & -999.00 & -999.00 & -999.00\end{array}$

$\begin{array}{lllll}.1 & 155.1 & -999.00 & -999.00 & -999.00\end{array}$

$\begin{array}{lllll}9.1 & 154.9 & -999.00 & -999.00 & -999.00\end{array}$

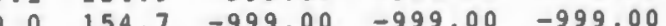

$\begin{array}{lllll}.0 & 154.6 & -999.00 & -999.00 & -999.00\end{array}$

$\begin{array}{lllll}9.1 & 154.4 & -999.00 & -999.00 & -999.00\end{array}$

$\begin{array}{lllll}9.2 & 154.3 & -999.00 & -999.00 & -999.00\end{array}$

$\begin{array}{llll}154.2 & -999.00 & -999.00 & -999.00\end{array}$

\begin{tabular}{lllll}
\hline & 154.0 & -999.00 & -999.00 & -999.00
\end{tabular}

$\begin{array}{lllll}3 & 153.9 & -999.00 & -999.00 & -999.00\end{array}$

$\begin{array}{lllll}.4 & 153.7 & -999.00 & -999.00 & -999.00\end{array}$

$\begin{array}{lllll}9.5 & 153.6 & -999.00 & -999.00 & -999.00\end{array}$

$\begin{array}{lllll}9.5 & 153.4 & -999.00 & -999.00 & -999.00\end{array}$

$\begin{array}{llllll}9.6 & 153.1 & -999.00 & -999.00 & -999.00\end{array}$

$\begin{array}{lllll}9.7 & 153.0 & -999.00 & -999.00 & -999.00\end{array}$

$\begin{array}{lllll}9.8 & 152.8 & -999.00 & -999.00 & -999.00\end{array}$

$\begin{array}{llllll}9.8 & 152.7 & -999.00 & -999.00 & -999.00\end{array}$

$9.9 \quad 152.4 \quad-999.00 \quad-999.00 \quad-999.00$ 
$07-18: 15: 49$ $07-18: 15: 54$ 07-18:15:59

$07-18: 16: 04$

07-18:16:09

07-18:16:14

07-18:16:19

$07-18: 16: 24$

07-18:16:29

$07-18: 16: 34$

$07-18: 16: 39$

$07-18: 16: 44$

07-18:16:49

$07-18: 16: 54$

$07-18: 16: 59$

07-18:17:04

$07-18: 17: 09$

$07-18: 17: 14$

07-18:17:19

$07-18: 17: 24$

07-18:17:29

07-18:17:34

$07-18: 17: 39$

07-18:17:44

$07-18: 17: 49$

07-18:17:54

$07-18: 17: 59$

$07-18: 18: 04$

$07-18: 18: 09$

$07-18: 18: 14$

$07-18: 18: 19$

07-18:18:24

$07-18: 18: 29$

$07-18: 18: 34$

$07-18: 18: 39$

$07-18: 18: 44$

07-18:18:49

07-18:18:54

$07-18: 18: 59$

07-18:19:04

07-18:19:09

$07-18: 19: 14$

07-18:19:19

07-18:19:24

07-18:19:29

07-18:19:34

07-18:19:39

07-18:19:44

07-18:19:49

$07-18: 19: 54$
$-53.89$

$-53.76$

$-53.63$

$-53.49$

$-53.22$

$-53.08$

$-52.94$

$-52.80$

$-52.50$

$-52.35$

$-52.20$

$-52.05$

$-51.89$

$-51.57$

$-51.41$

$-51.25$

$-50.92$

$-50.75$

$-50.58$

$-50.40$

$-50.23$

$-50.05$

$-49.88$

$-49.51$

$-49.33$

$-49.15$

$-48.96$

$-48.77$

$-48.59$

$-48.40$

$-48,20$

$-48.01$

$-47.82$

$-47.42$

$-47.22$

$-47.02$

$-46.82$

$-46.62$

$-46.41$

$-46.21$

$-46.00$

$-45.79$

$-45.37$
38.84

239.34

239.84

40.34

41.32

242.29

242.77

243.25

243.72

244.19

244.65

245.12

245.58

246.03

246.49

246.94

247.38

247.83

248.27

248.70

249.13

249.56

249.99

50.41

.83

1.25

51.66

252.07

52.48

52.88

253.68

254.08

254.47

254.86

255.24

255.62

256.00

256.38

256.75

257.12

257.49

257.85

258.21

258.57

258.93

259.28

259.63
270.27

270.23

270.19

270.15

270.11

270.07

270.02

269.98

269.93

269.89

269.84

269.80

269.75

269.70

269.66

269.61

269.56

269.51

269.46

269.41

269.36

269.31

269.25

269.20

269.15

269.09

269.04

268.98

268.93

268.87

268.81

268.76

268.70

268.64

268.59

268.53

268.47

268.41

268.35

268.29

268.23

268.17

268.10

268.04

267.98

267.92

267.86

267.79

267.73

267.67
$4.89-104.79$

$5.12-104.62$

$5.35-104.15$

$5.59-104.27$

$5.82-104.10$

$6.05-103.93$

$\begin{array}{ll}6.28 & -103.75\end{array}$

$6.51-103.58$

$6.75-103.40$

$6.99-103.22$

$7.23-103.05$

$7 .+7-102.87$

$7.71-102.69$

$7.95-102.51$

$8.19-102.33$

$8.44-102.15$

$8.69-101.97$

8.

$9.18-101.60$

$9.43-101.42$

$9.67-101.23$

$9.91-101.04$

$10.16-100.85$

$10.41-100.66$

$10.66-100.47$

$10.91-100.28$

$11.16-100.09$

11.42

$11.69 \quad-99.69$

$11.96-99.48$

$12.23-99.27$

12.50

12.77

13.05

13.32

13.59

13.86

14.12

14.41

14.69

14.97

15.27

15.56

15.86

16.15

16.47

16.77

17.06

17.36

17.66

$-98.63$

$-98.42$

$-98.20$

$-97.99$

$-97.56$

$-97.34$

$-97.11$

$-96.89$

$-96.66$

$-96.43$

$-96.20$

$-95.97$

$-95.74$

$-999.00$

$10.2 \quad 151.2 \quad-999.00$

$10.3 \quad 151.1 \quad-999.00$

$10.3 \quad 150.9 \quad-999.00$

$10.4 \quad 150.7 \quad-999.00$

$10.4 \quad 150.6 \quad-999.00$

$10.5 \quad 150.4 \quad-999.00$

$10.5 \quad 150.2 \quad-999.00$

$\begin{array}{lll}10.5 & 150.1 & -999.00\end{array}$

$10.6 \quad 149.9 \quad-999.00$

$\begin{array}{lll}10.6 & 149.7 & -999.00\end{array}$

$\begin{array}{lll}10.6 & 149.5 & -999.00\end{array}$

$10.7 \quad 149.3 \quad-999.00$

$10.7 \quad 149.2 \quad-999.00$

$\begin{array}{lll}10.7 & 149.0 & -999.00\end{array}$

$10.7 \quad 148.8 \quad-999.00$

$10.8 \quad 148.6 \quad-999.00$

$10.8 \quad 148.4 \quad-999.00$

$\begin{array}{lll}10.8 & 148.2 \quad-999.00\end{array}$

$\begin{array}{lll}10.8 & 148.0 & -999.00\end{array}$

$10.9 \quad 147.8 \quad-999.00$

$\begin{array}{lll}10.9 & 147.6 & -999.00\end{array}$

$10.9 \quad 147.4 \quad-999.00$

$10.9 \quad 147.2 \quad-999.00$

$10.9 \quad 147.0 \quad-999.00$

$11.0 \quad 146.8 \quad-999.00$

$10.9 \quad 146.6 \quad-999.00$

$10.9 \quad 146.4 \quad-999.00$

$10.9 \quad 146.1 \quad-999.00$

$10.9 \quad 145.9 \quad-999.00$

$10.9 \quad 145.7-999.00$ 


\section{Appendix IV \\ CIRRIS-1A RMS Glow Flight Data File}

This appendix shows the Flight Data File instructions used by the shuttle crew to perform the attempted glow measurement with the CIRRIS-1A. Each experiment operation executed by a crew member was conducted by these types of checklists. 


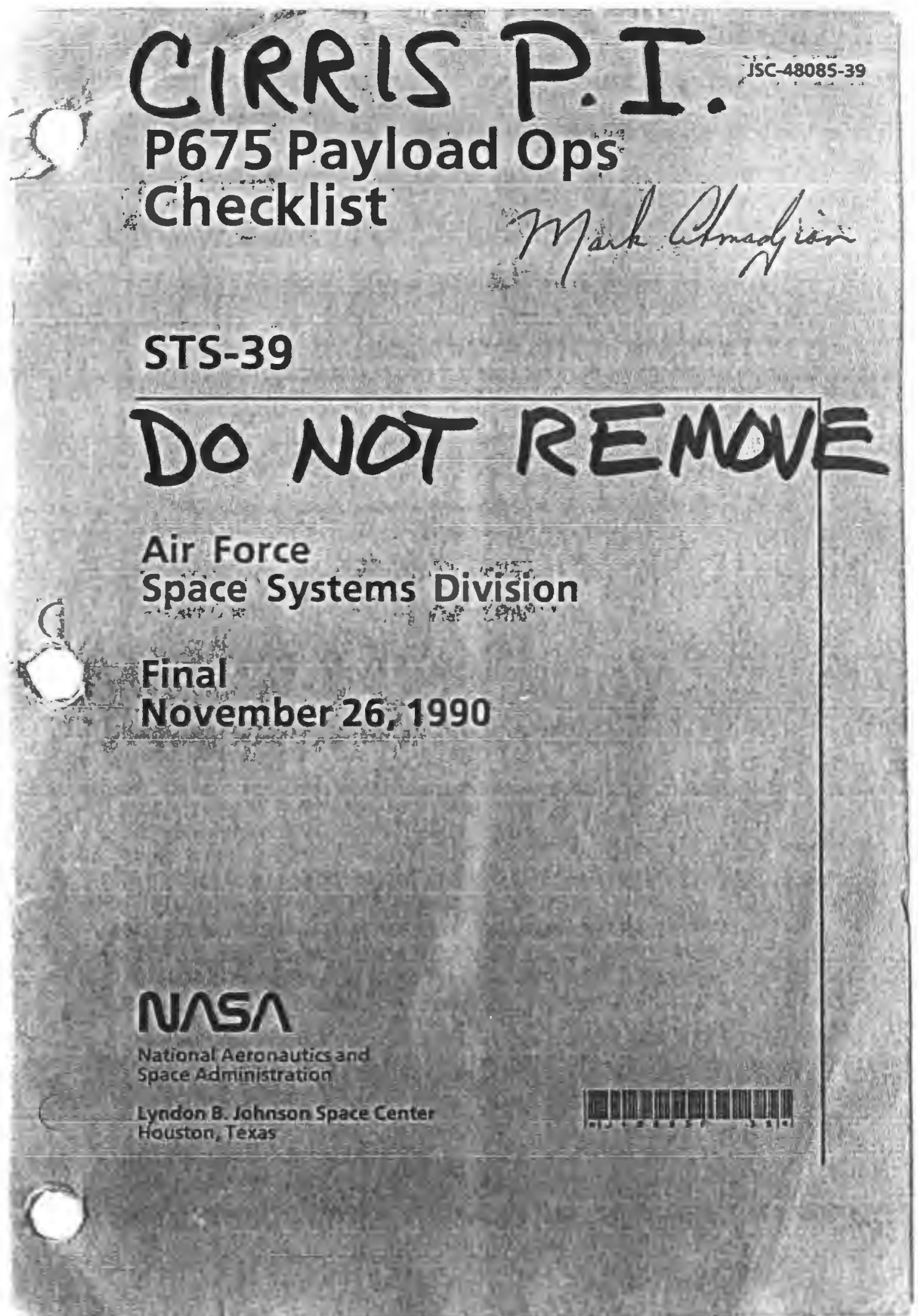


PC61 RMS GLOW

\section{PC61 RMS GLOW}

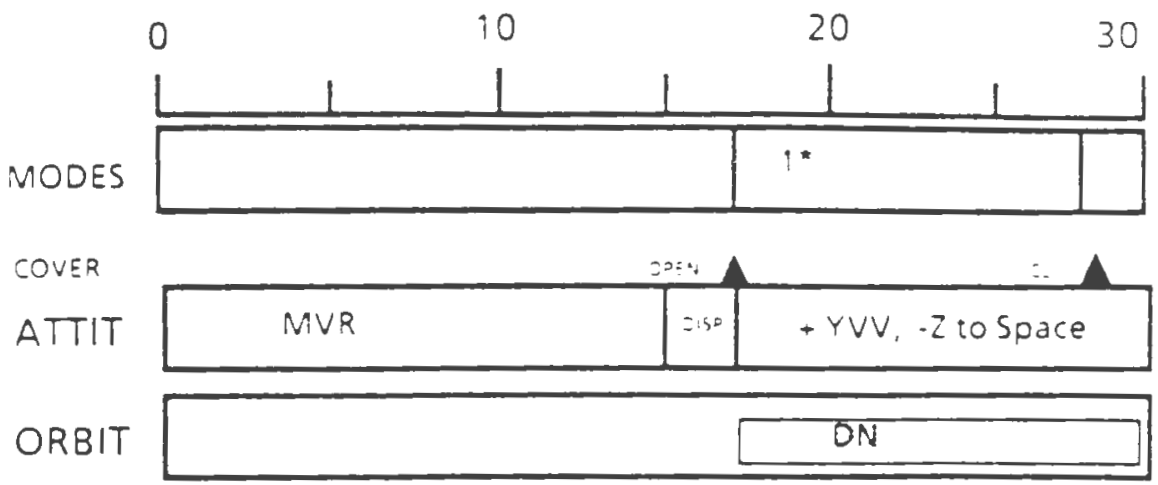

\section{CONSTRAINTS:}

\begin{tabular}{lr} 
MINUTES PRIOR TO COVER OPEN: \\
\hline - NO water dumps & 60 \\
- NO Fuel Cell purges & 60 \\
- NO Flash Evaporator Ops & 60 \\
- NO PRCS & 30 \\
- NO VRCS & 2
\end{tabular}

- No RCS operations when CIRRIS-iA cover opens

- Vibration limited

- Sun $>85^{\circ}$ from telescope LOS

- Velocity Vector $>90^{\circ}$ ielescope LOS

- Run Heaters On for at least 180 minutes

- Dewar Heaters On for at least 30 minutes

- This procedure is an integrated procedure and is accomplished in conjunction with an RMS operation.

- This procedure requires the RMS be positioned so that a section of the arm is parallel to the Orbiter X-axis, iwo (2) $m$ above the CIRRIS Aperture and one (1) $\mathrm{m}$ port from the CIRRIS LOS relative to the CIRRIS 0.0 pitcturoll position.

\section{GENERAL REQUIREMENTS:}

- PAD: PCGIPAD

- Logis: TCO3

- Cue Cards: CIRRIS POWER UPICLOSEOUT

- NONBLOCK Procedures: None

- Video Cassette Usage: 1

- PGSCUsage: No

DURATION: $30 \mathrm{~min}$ 


PC61 RMS GLOW $\partial_{-} 230$ mir

- BEGIN MANEUVEQ

$P-\frac{1}{(P A D)}-1$ Start Event imer $\quad 00: 00: 00$

2 EXEC SD26 QINMS - $3 / 1530 \mathrm{~min}$

3 TD01

VO912 CMD EXECUTING $=1$

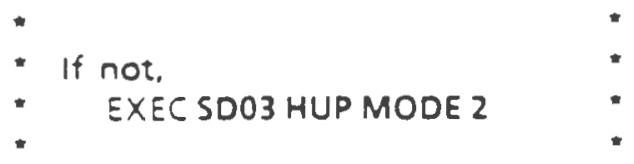

4 Edit SC5O BUILD YOUR OWN SEQ

$\begin{array}{llll}\text { Add: } & \text { O6 } & \text { C200 MODE O } & i .4 \\ & 07 & \text { C102 TAN HEIGHT TABLE 2 } & 2.4 \\ \text { 08 } & \text { C193 PITCH POS 29 } & 2.6 \\ \text { 09 } & \text { C270 IFR FW POS 0 } & 20.2\end{array}$

5 Save SCSO.X (_ ) BUILD YOUR OWN SEQ

6 Load Cmo StK - PCGI PAD, (CIRRISPADS) 
PC61 RMS GLOW

7 CONFIGURE CCTV

IF VTR ?.

VTR 1, CAMRC, Pan/Tilt to RMS

DNLK, CMP

MON, CIRRISIF/RAD

Else.

VTR 2, CAMRC

MON, CAMRC, Pan Tilt to RMS

MON, CIRRIS IF/RAD

8 VTR I(2) PWR - ON

- Load new cassette

TAPE POS PD - RESET

$\checkmark$ TAPE POSITION $=000$

POWER UP

9 Perform CIRRIS POWER UP (CUE CAROS)

10

$$
\text { TC02:2 }
$$

$\checkmark C 804$ LASEROSC SELECTED $=$ LASR 1

* If not.

- execczgrLAser 1 on

11 TCO2

VC815-C814 LASER ENV VOLTS (two) - within limits

$2.4-39$

$675 / 39 / F I N$ 


\section{PC61 RMS GLOW}

12

EXEC C042 IFR DET2 IFG SELECT

"END MANEUVERBEGIN 2 MIN DISPERSAL" "

13 VTR 1(2) pb-PLAYIRCD (simo)

ICOM - Say VTR\#, Block ID, MET for videotape

END DISPERSALENTER UMBRA*

-14 EXEC SC50.X(
YPAD)

$00: 17: 00$

15

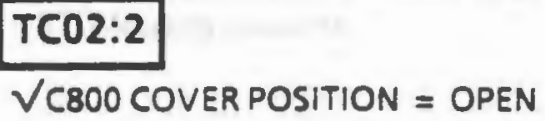

TC02:2

VC800 COVER POSITION = OPEN

NOTE

Interferogram signal for det 12 on CCTV.

(This is the background radiance).

is i $i$ " w

$16 \quad$ MPC js-gimbal

\section{TC06}

C620 GMBL ROLL POS DEG $-17.6^{\circ}$

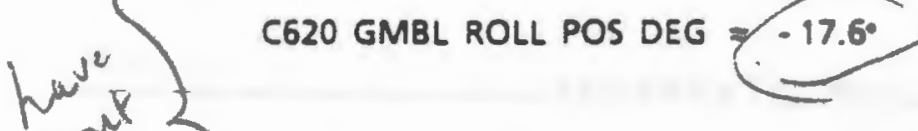

GMBL ROLL POS - until Interferogram saturates, then back off until out of saturation.

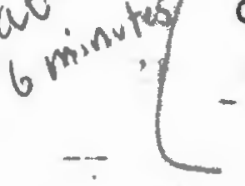

17 EXEC SC40 B/U MODE 1
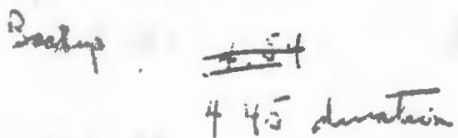
PC61 RMS GLOW

18

TC03

TCO3 LOG (LOGS), RCD:

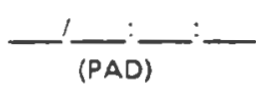

19 ICOM - Say VTR\#, Block ID, MET for videotape VTR i(2) pb-STOP

Wait $10 \mathrm{sec}$

$$
\text { PWR - OFF }
$$

- EJECT, remove used cassette

MARK used cassette with VTR\#, Block\#, MET

STOW used cassette

\section{TC02:2}

$\checkmark$ CBOO COVER POSITION $=$ CLSD

\section{TCO1:1(2)}

$\checkmark$ C502 (C522) TV HS PHT QCM PWR 1(2) = OFF

22 Perform CIRRIS CLOSEOUT (CUE CARDS) 


\section{Bibliography}

Ahmadjian, M., E.R. Huppi, T. Conley, and K. Baker, "Cryogenic IR Measurements on Board the space shuttle," SPIE Technical Symposium East 1981, SPIE Conference Proceedings, Washington, D.C., April 20-24, 1981.

Ahmadjian, M., J.O. Wise, R.M. Nadile, B. Bartshci, "CIRRIS1A Space Shuttle Experiment," Journal of Spacecraft and Rockets, Volume 27, Number 6, pages 669-674, 1990.

Ahmadjian, M., Jennings, D.E., Mumma, M.J., Espanak, F., Rice, C.J., Russell, R.W., Green, B.D., and Brown, C.W., "Infrared Spectral Identification of space Shuttle Glow," 1991 Fall Meeting of The American Geophysical Union, San Fransisco, CA, December 9-13, 1991.

Ahmadjian, M., Jennings, D., Mumma, M., Rice, C., Green, D., Oakes, D., Malonson, M., Fraser, M., Gauthier, M., and Gelb, A., "Infrared Space shuttle Glow Measurements from STS-39; Laboratory Measurements of Vehicle Glow Arising from Gas Doped Surface", 1992 Meeting of the IRSIS Specialty Group on Targets, Backgrounds, and Discrimination, Naval Training Center, orlando, FL, January 28-30, 1992. 
Banks, P.M., P.R. Williamson, and W.J. Raitt, "Space Shuttle Glow Observations", Geophysical Research Letters, Volume 10, Number 2, pages $118-121,1983$.

Caledonia, G.E., Holtzclaw, K.W., Green, B.D., Krech, R.H., Leone, A., and Swenson, G.R, "Laboratory Investigation of Shuttle Glow Mechanisms," Geophysical Research Letters, In Press.

Cochran, C.D., D.M. Gorman, and J.D. Dumoulin,"Space Handbook", Air University Press, Air University, Maxwell Air Force Base, Alabama, 1985.

Colthup, N.B., L.H. Daly, and S.E. Wiberley, "Introduction to Infrared and Raman Spectroscopy", Academic Press, Inc, 1990.

Fontijn, A., Meyer, C.B., and Schiff, H.I., "Absolute Quantum Yield Measurement of the NO-O Reaction and its Use as a standard for Chemiliminescent Reactions," Journal of Chemical Physics, Volume 40, pp. 64-70, 1964 .

Garrett, H.B. , Chutjian, A., and Gabriel, s., "Space Vehicle Glow and its Impact on spacecraft systems," Journal of Spacecraft and Rockets, Volume 25, Number 5, pages 321-340, 1988 . 
Green, B.D., "Review of the Vehicle Glow", American Institute of Aeronautics and Astronautics, AIAA-85-6095CP,

Shuttle Environment and operations II Conference, AIAA, Washington, D.C., 1985 .

Herzberg, G. " "Molecular Spectra and Molecular structure II. Infrared and Raman spectra of Polyatomic Molecules", D. Van Nostrand Company, Inc., 1945.

Jensen, G.L. "Engineering Calibration Summary for the NS-9D Shuttle Kinetic Infrared Test (SKIRT), Space Systems Engineering, Inc., Technical Report 013-CA-0100, Space systems Engineering, Logan, UT, December 7, 1989.

Jursa, A.S., "Handbook of Geophysics and the Space Environment", Air Force Geophysics Laboratory, Air Force systems Command, United states Air Force, Hanscom AFB, MA 1985.

Mende, S.B. and G.R. Swenson, "Vehicle Glow Measurements on the Space Shuttle", Second Workshop on Spacecraft Glow, NASA Conference Publication-2391, pages1-45, 1985.

Mumma, M.J. and Jennings, D.E., "Planned Investigation of Infrared Emissions Associated with the Induced spacecraft Glow: A Shuttle Infrared Glow Experiment (SIRGE)," $\underline{\text { Second }}$ Workshop on spacecraft Glow, NASA Conference Publication- 
2391, pages 250-259, 1985.

NASA Goddard Spaceflight Center, "Space Test Program (STP) -1 Phase '0/1' '02' '03' 'Flight Safety' 'Ground Safety' Data Review Package", NASA Goddard Space Flight center, Hitchhiker and Small Payloads Program office, Greenbelt, MD, 1989, 1990, and 1990.

NASA Johnson Space Center, "Shuttle orbiter/Cargo standard Interfaces", NASA Johnson Space Center, ICD-2-19001, Houston, TX, 1990.

National Oceanic and Atmospheric Administration, National Aeronautics and Space Administration, and United States Air Force, "U.S. Standard Atmosphere, 1976", U.S. Government Printing office, NOAA-S/T 76-1562, 1976.

Park, J.H., L.S. Rothman, C.P. Rinsland, M.A.H. Smith, D.J. Richardson, and J.C. Larsen, "Atlas of Absorption lines from 0 to $17900 \mathrm{~cm}^{-1 ",}$ NASA Reference Publication 1084, 1981.

Paulsen, D.E., Sheridan, W.F., and Huffman, R.E., "Thermal and Recombination Emsission of $\mathrm{NO}_{2}, "$ Journal of Chemical Physics, Volume 53, Number 2, pages 647-658, 1970. 
Sharma, R.D., A.J. Ratkowski, R.L. Sundberg, J.W. Duff, L.S. Bernstein, P.K. Acharya, J.H. Gruninger, D.C. Robertson, R.J. Healey, "Description of SHARC, The Strategic HighAltitude Radiance Code", Geophysics Laboratory (AFSC), GLTR-89-0229, Hanscom AFB, MA, 1989.

Slanger, T.G., "Report on Vehicle Environment Interaction Workshop," American Geophysical Union, EOS Transactions, Volume 70, Noumber 39, pages 859-864, september 26, 1989.

Swenson, G.R., Mende, S.B., and Clifton, K.S., "Ram Vehicle Glow Spectrum; Implications of $\mathrm{NO}_{2}$ Recombination Continuum," Geophysical Research Letters, Volume 12, Number 97, pages $97-100,1985$.

Swenson, G.R., A. Leone, K.w. Holtzclaw, and G.E. Caledonia, "Spatial and Spectral Characterization of Laboratory Shuttle Glow Simulations, Journal of Geophysical Research, In Press, 1991.

Torr, M.R., Hays, P.B., and Kennedy, B.C., "Intercalibration of Airglow Observatories with the Atmosphere Explorer Satellite," Planetary and Space Science, Volume 25, pp. 173184,1977 . 
Torr, M.R. and Torr, D., "Preliminary Results of the Imaging spectrometric Observatory on spacelab 1," AIAA 22nd Aerospace Sciences Meeting, AIAA-84-0044, AIAA, Washington, D.C., 1984 .

Upschulte, B.L., Caledonia, G.E., Green, B.D., Ahmadjian, M., and Blumberg, W.A.M., "Mechanisms Responsible for Interaction Radiances surrounding STS-39 Based on SKIRT/GLOS Data," 1991 Fall Meeting of The American Geophysical Union, San Fransisco, CA, December 9-13, 1991.

Upschulte, B.L., Oakes, D.B., Caledonia, G.E., and Blumberg, W.A.M., "Infrared Emissions Arising from the Reactions of Fast $0 / 0^{+}$with $\mathrm{N}_{2}, "$ Geophysical Research Letters, In Press 1992 .

Vanpee, M., Hill, K.D., and Kineyko, W.R., "Absolute Rate Constant Measurement for the Radiative Combination of Atomic oxygen with Nitric Oxide," Journal of Chemical Physics, Volume 72 , Number 20, 1980.

Viereck, R.A., Murad, E., Green, B.D., Joshi, P., Pike, C.P., Hieb, R., and Harbaugh, G., "Origin of the shuttle Glow," Nature, Volume 354, November 7, 1991. 
Winick, J.R., R.H. Picard, R.A. Joseph, R.D. Sharma, P.P. Wintersteiner, "An Infrared Radiance Code for the Auroral Thermosphere (AARC)", Air Force Geophysics Laboratory (AFSC), AFGL-TR-87-0334, Hanscom AFB, MA, 1987.

Wolf, W.L. and G.J. Zeiss, "The Infrared Handbook", Environmental Research Institute of Michigan, Office of Naval Research, Department of the Navy, 1985.

Yee, J.H. and Abreu, V.J., "Optical Contamination on the Atmosphere Explorer-E Satellite," Spacecraft Contamination Environment, Proceedings of SPIE-The International Society for Optical Engineers, Volume 338, pages 120-128, 1982. 